\title{
Carnivorous mammals from the middle Eocene Washakie Formation, Wyoming, USA, and their diversity trajectory in a post-warming world
}

\author{
Susumu Tomiya, $, 2,2$ @ Shawn P. Zack, ${ }^{4}$ @ Michelle Spaulding, ${ }^{5}$ and John J. Flynn ${ }^{2,6}$ ๑ \\ ${ }^{1}$ Center for International Collaboration and Advanced Studies in Primatology, Kyoto University Primate Research Institute, 41-2 Kanrin, \\ Inuyama, Aichi 484-8506, Japan <tomiya.susumu.8r@ kyoto-u.ac.jp> \\ ${ }^{2}$ Negaunee Integrative Research and Gantz Family Collections Centers, Field Museum of Natural History, 1400 South Lake Shore Drive, \\ Chicago, Illinois 60605, USA \\ ${ }^{3}$ University of California Museum of Paleontology, Berkeley, California 94720, USA \\ ${ }^{4}$ Department of Basic Medical Sciences, University of Arizona College of Medicine, 425 N Fifth Street, Phoenix, Arizona 85004, USA \\ <zack@email.arizona.edu> \\ ${ }^{5}$ Department of Biological Sciences, Purdue University Northwest, 1401 S US Highway 421, Westville, Indiana 46391, USA <mspauldi@ \\ pnw.edu> \\ ${ }^{6}$ Richard Gilder Graduate School and Division of Paleontology, American Museum of Natural History, 200 Central Park West, New York, \\ New York 10024, USA <jflynn@amnh.org>
}

\begin{abstract}
The middle Eocene Washakie Formation of Wyoming, USA, provides a rare window, within a single depositional basin, into the faunal transition that followed the early Eocene warming events. Based on extensive examination, we report a minimum of 27 species of carnivorous mammals from this formation, more than doubling the previous taxic count. Included in this revised list are a new species of carnivoraform, Neovulpavus mccarrolli $\mathrm{n}$. sp., and up to ten other possibly new taxa. Our cladistic analysis of early Carnivoraformes incorporating new data clarified the array of middle Eocene taxa that are closely related to crown-group Carnivora. These anatomically relatively derived carnivoraforms collectively had an intercontinental distribution in North America and east Asia, exhibiting notable variations in body size and dental adaptation. This time period also saw parallel trends of increase in body size and dental sectoriality in distantly related lineages of carnivores spanning a wide range of body sizes. A new, model-based Bayesian analysis of diversity dynamics accounting for imperfect detection revealed a high probability of substantial loss of carnivore species between the late Bridgerian and early Uintan North American Land Mammal 'Ages', coinciding with the disappearance of formerly common mammals such as hyopsodontids and adapiform primates. Concomitant with this decline in carnivore diversity, the Washakie vertebrate fauna underwent significant disintegration, as measured by patterns of coordinated detection of taxa at the locality level. These observations are consistent with a major biomic transition in the region in response to climatically induced opening-up of forested habitats.
\end{abstract}

UUID: http://zoobank.org/9162f1a6-a12c-4d55-ba1d-dc66e8cda261

\section{Introduction}

Early discoveries of middle Eocene mammalian carnivores in North America stimulated development of ideas about the processes of carnivore evolution, and were essential components of the new evolutionary synthesis in the middle of the twentieth century (Simpson, 1944). Matthew's (1909) systematic work on middle Eocene-aged (Bridgerian and Uintan North American Land Mammals 'Ages' [NALMAs]) mammals from Wyoming envisioned opportunities for differential dietary adaptations as a major driver of diversification in various groups of primarily carnivorous mammals, and conceptualized the advantage of ecological incumbency in their evolutionary histories. More than a century later, these hypotheses continue to be explored and refined in various systems at different scales (Van Valkenburgh, 1999; Van Valkenburgh et al., 2004; Wesley-Hunt, 2005; Friscia and Van Valkenburgh, 2010; Sandom et al.,
2013; Silvestro et al., 2015; Slater, 2015; Balisi et al., 2018). Given the general rarity of mammalian carnivore fossils, sustained efforts to uncover, document, and reconstruct the diversity of fossil carnivore taxa are fundamental to research in this area.

The middle Eocene Washakie Formation of south central Wyoming and northwestern Colorado have produced a wealth of vertebrate fossils since the late nineteenth century (Black and Dawson, 1966; Roehler, 1973; Turnbull, 1978, 2002). A classic collection of Washakie fossil vertebrates curated at the American Museum of Natural History (AMNH) paved the way for the early works of Granger (1909) and Matthew (1909), which established the basic biostratigraphic framework for the formation. In the early 1950s, a major research program centered on the Washakie fauna was initiated under the direction of William D. Turnbull of the Field Museum of Natural History (FMNH), building on earlier work by Rainer Zangerl, and 
extended by John Flynn (who filled the FMNH fossil mammal curator position after Turnbull retired). Over five decades, Turnbull, Flynn, and colleagues collected extensively in the Washakie Basin, building one of the largest collections of vertebrate fossils from the Washakie Formation. This collection has served as the basis for a number of publications (Turnbull, 1978, 1991, 2002; Turnbull and Martill, 1988; McCarroll et al., 1996a, b), but the vast majority of the fossils remain undescribed.

A recent three-year project at FMNH reorganized and expanded knowledge of this collection through the cataloging of 3,000 additional specimens (see Acknowledgments), making the time ripe for a renewed examination of the vertebrate diversity in the Washakie Formation. This paper aims to advance our knowledge of the Bridgerian-Uintan faunal transition in the central Rocky Mountain region during an early phase of carnivoran evolution and dynamic turnover in other carnivore clades (Eizirik et al., 2010; Tomiya, 2011; Tomiya and Tseng, 2016). Our objectives are as follows: (1) we thoroughly reevaluate previously reported occurrences of carnivorous mammals from the Washakie Formation, and describe taxonomically significant specimens that have yet to be reported in the literature; (2) we present a revised phylogenetic hypothesis for early carnivoraforms to provide the evolutionary context for interpreting the morphological diversity of middle Eocene taxa from the Washakie Basin; (3) we investigate whether the sharp drop in diversity of carnivorous taxa from ca. 49 to ca. $45 \mathrm{Ma}$ in western North America (from 13 to 5 genera, or a $62 \%$ loss; Wesley-Hunt, 2005 ) is detected within a single depositional basin after accounting for sampling incompleteness. Such an assessmentmade possible by the substantial temporal span of the Washakie Basin sequence and the availability of specimen-level taxon-occurrence data-is essential for elucidating the mechanisms of diversity dynamics at larger geographic scales.

This study is concerned with taxa from the lower and middle units of the Adobe Town Member of the Washakie Formation (abbreviated as Twka1 and Twka2, respectively, in which "wk" and "a" denote Washakie Formation and Adobe Town Member [Turnbull, 1978]), because no ordinally identifiable carnivore specimen has been recovered from the underlying Kinney Rim Member, and only two are known from the upper unit of the Adobe Town Member (Twka3). We intend to describe the latter two specimens-FMNH PM 56222, an M1 fragment reported as "Miacis sp." in the faunal list of McCarroll et al. (1996b), and FMNH PM 55362, an astragalus that may be referable to the enigmatic carnivore Simidectes - in a future report on the small vertebrate assemblage from Twka3. With one exception, we have not examined carnivore material from the southernmost exposures of the Washakie Formation in the Sand Wash Basin of Colorado (West and Dawson, 1975; Stucky et al., 1996), and think that those specimens-many of which remain undescribed or uncited-warrant a separate treatment, pending completion of ongoing biostratigraphic work in the area (Stucky et al., 1996; Dunn, 2016). Likewise, carnivore material more recently collected from the Washakie Formation by joint teams from AMNH and University at Buffalo (under the direction of JJF) are still under study and will be described elsewhere.

Taxonomically, we focus on primarily carnivorous groups of mammals including mesonychians, oxyaenodontans, hyaenodontans, and carnivoramorphans. For convenience, we informally refer to them collectively as 'carnivores' while recognizing that some of their middle Eocene members may have been omnivorous or frequently consumed invertebrates, and are thus more accurately described as a broad set of animalivores (Friscia et al., 2007; Friscia and Van Valkenburgh, 2010). We also note that non-mammalian carnivores such as crocodiles, snakes, and large birds, all of which are known from the Washakie Formation, may have played important ecological roles as predators of mammals.

\section{Geological and paleoenvironmental setting}

Geology and NALMA biochronology.-Exposures of the Washakie Formation cover an area of $\sim 1,600 \mathrm{~km}^{2}$ in the Washakie Basin of south-central Wyoming, and are present in the Sand Wash Basin of northwestern Colorado (Roehler, 1973; Turnbull, 1978; Stucky et al., 1996; Fig. 1). Within the Washakie Basin, the Washakie Formation unconformably overlies the Green River Formation and is divided into the late Bridgerian Kinney Rim Member (Twkk) and the late Bridgerian to Uintan Adobe Town Member; the latter is further divided, informally, into lower (Twka1), middle (Twka2), and upper (Twka3) units based on stratigraphy (Turnbull, 1978; Flynn, 1986), with auxiliary information on characteristic mammalian assemblages (Roehler, 1973, 1992; McCarroll et al., 1996b; Robinson et al., 2004; Murphey et al., 2018; Fig. 2). We generally follow Roehler's (1973) designation of lower (Twkal of later authors) and middle

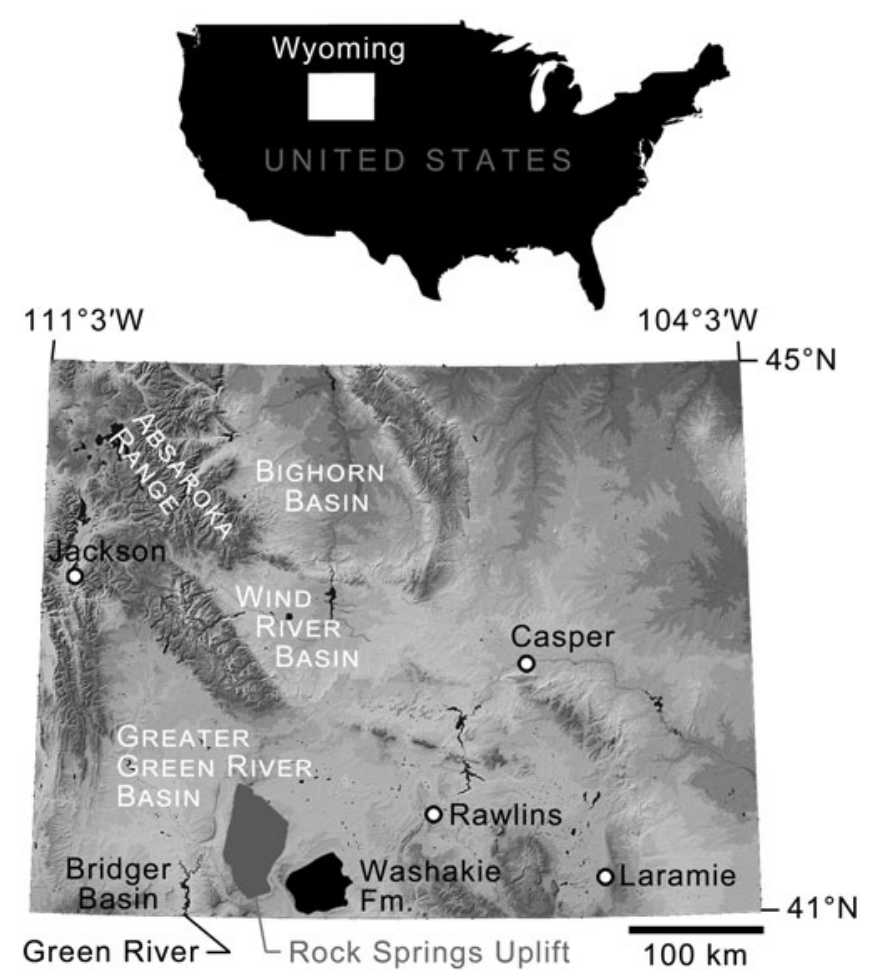

Figure 1. Geographic extent of Washakie Formation and locations of other important areas discussed in text. Base map modified from National Elevation Dataset Shaded Relief of Wyoming, courtesy of the United States Geological Survey. 


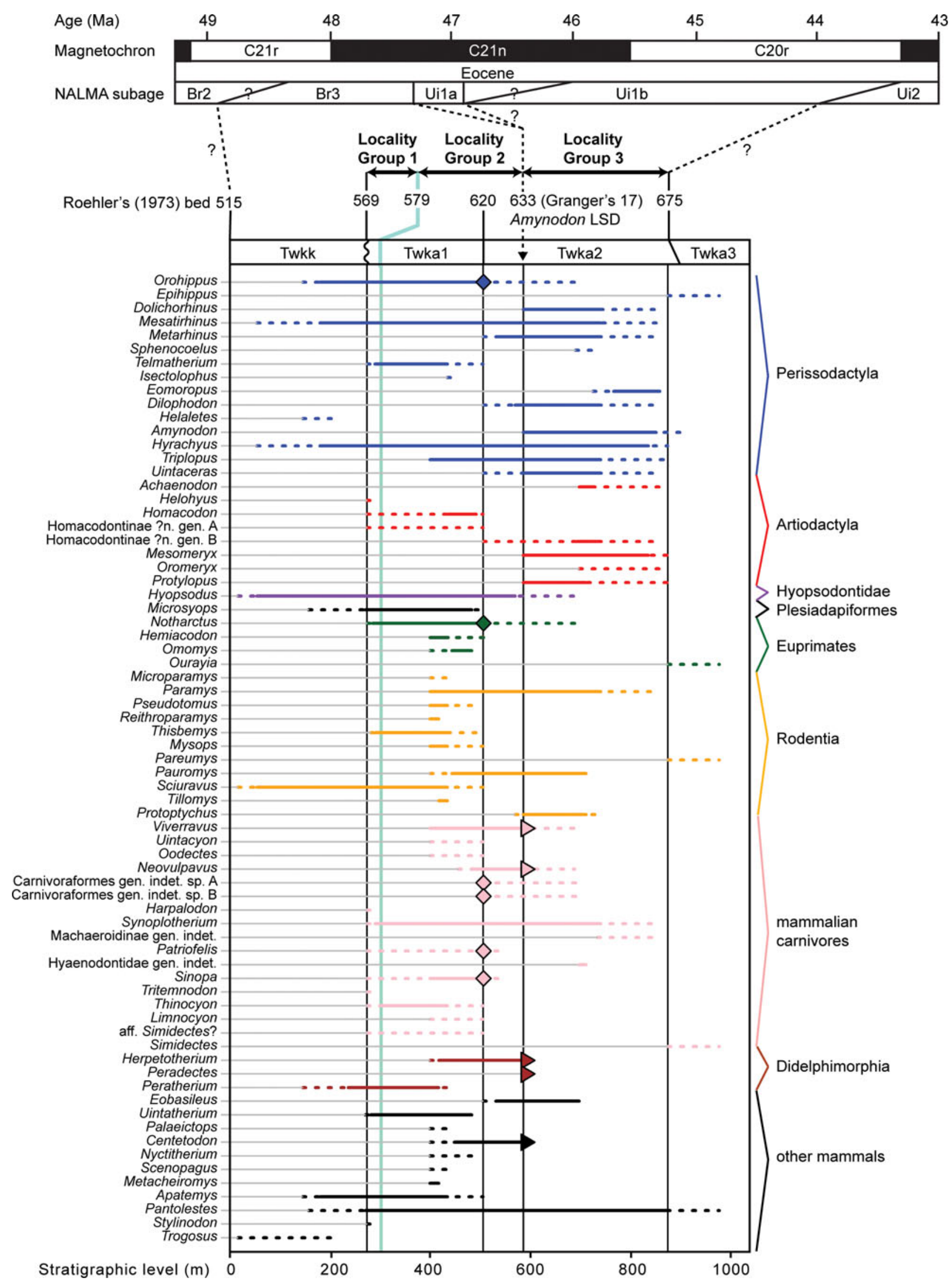


Figure 2. Stratigraphic context of this study. Successive stratigraphic units consist of Kinney Rim Member (Twkk) and lower (Twka1), middle (Twka2), and upper (Twka3) units of Adobe Town Member, Washakie Formation. Unconformity present at base of Roehler's (1973) bed 569 (base of Twka1). Light-green line corresponds to key marker bed within Twka1: Robin's-egg-blue layer (Roehler's [1973] bed 579). Stratigraphic distributions of mammalian taxa (primarily genera) within Washakie Formation projected onto a composite scale for type (for Twkk and Twka) and principal reference (for Twka) sections measured by Roehler (1973). Dotted lines indicate uncertainties attributable to limited stratigraphic resolutions of localities. Diamonds emphasize confirmed occurrences above, if not far from, Roehler's (1973) bed 620 (= Granger's [1909] stratum no. 11) - the approximate position of the traditionally accepted Bridgerian-Uintan NALMA age boundary within the formation. Triangles show occurrences within bed 633 (= Granger's [1909] stratum no. 17). Three sets of localities (locality groups) were designated and stratigraphically demarcated for our analysis of diversity dynamics. Note Uila subage is currently not recognized in Washakie Formation based on available mammalian faunal data; we consider Locality Group 3, whose lowermost horizon (Roehler's [1973] bed 633) likely contains the lowest stratigraphic datum (LSD) of the rhinocerotoid Amynodon, to be entirely early Uintan (Ui1b) in age, and Locality Groups 1 and 2 to be late Bridgerian (see text for discussion). Time scale for magnetochrons and correlations follows Tsukui and Clyde (2012), and that for NALMA subages broadly follows Kelly et al. (2012) and Murphey et al. (2018), but note that there are considerable uncertainties with positions of subage boundaries.

(Twka2 of later authors and the type section for the member) parts of the Adobe Town Member, which in turn was based on Granger's (1909) Washakie A and Washakie B units, as beds 569-619 and 621-675, respectively, but include bed 620 (= Granger's "stratum No. 11" [p. 20]) in Twka2 as its lowermost horizon (Roehler [1973] and Turnbull [1978] considered bed 620 as the dividing horizon between the lower and middle [Twka1 and Twka2] sections, and did not include it in either unit).

The Adobe Town Member is primarily composed of interbedded tuffaceous mudstones and tuffaceous or arkosic sandstones that frequently are cross-bedded and lenticular (Roehler, 1973). Much of the volcaniclastic and arkosic sediments are thought to have originated in the Absaroka or Challis volcanic fields and the Sierra Madre Range, respectively. These sediments were deposited primarily in fluvial environments, although the Adobe Town Member also contains a limited number of conglomerate layers and apparently lacustrine beds of sandstone, shale, and limestone (Roehler, 1973, 1992; Smith et al., 2008; Chetel et al., 2011). No major unconformity has been identified within this member, and the ranges of lithology and inferred sedimentary environments are broadly comparable between its subunits Twka1 and Twka2 (Granger, 1909; Roehler, 1973; Flynn, 1986). As such, no sharp or systemic difference in the range of depositional environments is apparent between the two stratigraphic units.

In this paper, we regard Roehler's (1973) beds 633-675 to be early Uintan (Uilb) in age based on the occurrence of the amynodontid rhinocerotoid Amynodon (cf., Flynn, 1986; McCarroll et al., 1996b; Gunnell et al., 2009; Murphey et al., 2018; Fig. 2; see Appendix for detailed discussion). The remaining, lower part of Twka2 (beds 620-632), in addition to Twka1, is tentatively regarded as late Bridgerian $(\mathrm{Br} 3)$ in age. Although it is possible that the actual Bridgerian-Uintan NALMA boundary is located somewhere below bed 633, it cannot be ascertained without identification of an earliest Uintan (Uila) mammalian assemblage (such as recognized in the Turtle Bluff Member of Bridger Formation; Murphey et al., 2018) within the Adobe Town Member, for which there is currently no evidence (Flynn, 1986; McCarroll et al., 1996b). It is also possible that deposits of the Ui1a subage are largely or completely absent from the Washakie Formation, in which case there must be an as-yet unrecognized unconformity, perhaps between bed 620 and bed 633. A formal biostratigraphic revision of the Washakie Formation should be informed heuristically by occurrence data for small mammals, such as rodents, lipotyphlans, and 'homacodont' artiodactyls (cf., Murphey et al., 2018).
Compared to some of the better-studied Eocene faunas from elsewhere in the central Rocky Mountain region (e.g., Bighorn Basin, Bridger Basin), the numerical geochronological ages of Washakie vertebrate assemblages are poorly constrained. Only two radioisotopic dates have been published for the Washakie Formation, based on ${ }^{40} \mathrm{~K} /{ }^{40} \mathrm{Ar}$ dating of hornblende and sanidine fractions of a tuff sample from above Roehler's (1973) bed 644 in Twka2 (Turnbull, 2002). The two dates are inconsistent, and the sanidine-based date of $45.1 \pm 1.7 \mathrm{Ma}$ preferred by Turnbull (2002) has such a large uncertainty that it adds little to the existing bio- and magnetostratigraphic data, which suggest correlation of a lower portion of Twkal with Chron C21r, an upper portion of Twka1 and a lower portion of Twka2 with Chron C21n, and an upper portion of Twka2 with Chron C20r (correlation D of McCarroll et al., 1996b, fig. 4; see also Flynn, 1986; Walsh, 1996a; Tsukui et al., 2011, 2013; Kelly et al., 2012; Murphey et al., 2018). ${ }^{40} \mathrm{Ar} /{ }^{39} \mathrm{Ar}$ dates for sanidine samples from the late Bridgerian (Br3) portion of the Bridger Formation fall within ca. 49-47 Ma (Smith et al., 2008, 2010; see also Murphey et al., 2017), and fossils from Twkal are thought to be of comparable ages. A large majority of the early Uintan (Uilb) fossils from Twka2 in the FMNH collection come from the lower portion of the unit corresponding to Chron $\mathrm{C} 21 \mathrm{n}$, and are thus likely ca. 47-45.57 Ma in age (Flynn, 1986; McCarroll et al., 1996b; Tsukui et al., 2011, 2013; Tsukui and Clyde, 2012; Murphey et al., 2018).

Paleoenvironment.-Our current knowledge of the paleoenvironment of the late Bridgerian to early Uintan of the central Rocky Mountain region is primarily derived from sedimentological and vertebrate faunal data (Matthew, 1909), somewhat confounding analysis of faunal response to environmental changes. Available paleobotanical data for the middle Eocene of North America are highly localized, widely scattered across regions, and tend to have low temporal resolution, making it difficult to distinguish their spatial and temporal trends (Wing, 1998; Woodburne, 2004). In particular, plant macrofossils are poorly known from the Washakie Formation (although petrified wood is not uncommon in certain parts of the basin; Roehler, 1973), and we are not aware of any published work on fossil pollen or phytoliths. Plant macrofossil assemblages that are in spatiotemporal proximity to the Washakie Formation are known from lacustrine deposits of the locally recognized 'upper member' of the Green River Formation in the northeastern Uinta Basin, Utah (MacGinitie, 1969; Wilf et al., 2001; Wilf, 2008) and the Parachute Creek 
Member of the same formation in northwestern Colorado (MacGinitie, 1969; Smith et al., 2008). These two assemblages, which may be separated by as much as a few million years and may predate (Colorado) or postdate (Utah) the Washakie faunas discussed in the present study (Remy, 1992; Smith et al., 2008), have been interpreted to represent mixed deciduous and evergreen forests/woodlands under a seasonally dry, warmtemperate to tropical climate (MacGinitie, 1969; Wilf et al., 2001; Smith et al., 2008; Wilf, 2008).

The global climate during the middle Eocene was marked by a trend of gradual cooling interrupted by the middle Eocene Climatic Optimum at ca. 41-40 Ma (Bohaty and Zachos, 2003; Bohaty et al., 2009). While climatic patterns within the central Rocky Mountain region during the time of deposition of the Washakie Formation are not highly resolved, it is important to note that geochemical and sedimentological studies suggest a period of major uplift (perhaps by a few kilometers) of intermontane basins, reorganization of the drainage system, and contraction of lakes in the region beginning in the middle Eocene (Carroll et al., 2008; Davis et al., 2008; Smith et al., 2008; Cather et al., 2012; Fan et al., 2014a, b). These geologic events likely had strong impacts on the regional climate, biome, and fauna (cf., Gunnell and Bartels, 1994; Townsend et al., 2010; Eronen et al., 2015). Indeed, the mammalian faunal transition through the Bridgerian NALMA in North America has been described as the Bridgerian Crash, an episode of sustained erosion of taxic diversity, which had previously been elevated during the late early Eocene Climatic Optimum (Woodburne et al., 2009). However, it has remained unclear, based on available faunal data, whether that trend continued into the early Uintan NALMA. We address this question in the present paper with regard to mammalian carnivores.

\section{Materials and methods}

Anatomical terminology follows: Szalay and Gould (1966), Van Valen (1966), Flynn and Galiano (1982), and Tomiya (2013) for dentition; O'Leary and Rose (1995) and Heinrich and Rose (1997) for postcranial elements. Upper and lower teeth are denoted by upper-case and lower-case letters, respectively. Specimens were measured (in $\mathrm{mm}$ ) either directly using digital calipers (with instrumental accuracies of $0.03-0.04 \mathrm{~mm}$ and repeatability of $0.01 \mathrm{~mm}$ ) to the nearest $0.01 \mathrm{~mm}$ or, in some cases, from digital photographs using the program tpsDig2 (Rohlf, 2017). Dental measurements generally follow illustrations in Gingerich (1983, fig. 1) for carnivoramorphans and Gingerich and Deutsch (1989, fig. 1) for hyaenodontans (except that we report maximum labiolingual widths, which are not necessarily anterior labiolingual widths; M3W was measured parallel to anterior border of tooth, and M3L perpendicular to M3W). Dental measurements of mesonychian and oxyaenodontan specimens are simply maximum dimensions. All linear measurements reported below are in units of millimeters.

Unless otherwise stated, age assignments of stratigraphic units and fossil assemblages follow Robinson et al. (2004), Gunnell et al. (2009), Tsukui et al. (2011, 2013), and Murphey et al. (2018) (see also Flynn, 1986; McCarroll et al., 1996b). We follow the revised biochronological definitions of the earliest Uintan and the early Uintan, now recognized respectively as
Uila and Uilb subages, of Gunnell et al. (2009), Kelly and Murphey (2016), Murphey and Kelly (2017), and Murphey et al. (2018). We referred to Murphey and Evanoff (2011) to determine the approximate stratigraphic positions of some localities in the Bridger Formation. We consider reports of taxonomic occurrences in published faunal lists to be unsubstantiated unless they are accompanied by lists of voucher specimens. Additional locality data and relevant accession records are on file at FMNH and are available to qualified researchers upon written request submitted to the Collection Manager of Fossil Vertebrates. Stratigraphic bed numbers refer to those of Roehler (1973; see also Turnbull, 2002, fig. 4).

Cladistic analysis of early carnivoraforms.-To facilitate taxonomic decisions and evolutionary interpretations of middle Eocene carnivoraforms, we conducted a cladistic analysis of Paleogene carnivoraforms using a modified version of Solé et al.'s (2016) morphological character matrix (Supplemental Data 2), which built on earlier works by Wyss and Flynn (1993), Wesley-Hunt and Flynn (2005), Wesley-Hunt and Werdelin (2005), Polly et al. (2006), Spaulding and Flynn (2009, 2012), Spaulding et al. (2010), and Solé et al. (2014). Our character matrix incorporates additional data from Tomiya (2011), Wang and Zhang (2015), and Tomiya and Tseng (2016), as well as new observations reported in the present paper. Modifications to character-state scores of Solé et al. (2016) are summarized in Appendix Table A1, and information sources are provided in Appendix Table A2. Unless stated otherwise, numbering and definitions of characters and character states follow those of Wesley-Hunt and Flynn (2005), Spaulding and Flynn (2012), and Solé et al. (2016). Characters 217-245 for Palaeogale sp. were scored based on published figures and descriptions of $P$. sectoria Gervais, 1848, in Wang and Zhang (2015). Following Wesley-Hunt and Flynn (2005), Character 40 was treated as ordered, and all other characters as unordered.

The following are corrections and clarifications of the character-state definitions in Solé et al. (2014; F. Solé, personal communication with ST, 30 October 2017): (1) state 2 of Character 226 (undescribed in Solé et al., 2014) is defined as p3 and p4 having equal heights but differing in lengths; and (2) the descriptions of states 0 and 1 for Character 241 in Solé et al. (2014) are reversed to be consistent with their published scores, and the character is here renamed as $241 \mathrm{R}$ to avoid future confusion. We interpret state 1 of Character 217 as an anteriorly deep dentary (lacking marked tapering toward the level of $\mathrm{p} 1$ ) regardless of the presence of a flange (Solé et al., 2014). In addition, the description of state 1 for Character 128 in Spaulding and Flynn (2012) should be corrected as the $m$. brachialis insertion site located on the medial (not lateral) margin of the ulnar shaft.

Several characters were excluded from the present analysis: Character 30 because it could not be scored consistently (Tomiya and Tseng, 2016); Character 43, following WesleyHunt and Flynn (2005); Characters 222 and 240 because they were parsimony non-informative in the present analysis; Character 223 because the distinction between the two states as originally defined (narrow vs. broad $\mathrm{p} 4$ postfossoid) was unclear, and we found it difficult to identify the extent of postfossoid precisely and consistently across taxa; Characters 234 and 235 
because, for many taxa, we could not confidently distinguish their states (presence/absence of $\mathrm{m} 1$ ecto- and postcingulid, respectively); Characters 236 and 237 because they were deemed largely redundant with other characters that reflected reduction of posterior molars (e.g., Characters 46, 52, 53, 85, 86, and 88); Characters 238 and 246, following Solé et al. (2016); and Character 239 (P4 protocone size; Solé et al., 2014) because it largely overlapped with Character 56 of Wesley-Hunt and Flynn (2005).

We performed analyses with two alternative outgroup taxa, the viverravid Didymictis spp. (a composite of D. protenus Cope, 1874 and D. vancleveae Robinson, 1966; see Zack, 2019a) and the limnocyonine hyaenodontid Thinocyon sp., because they are phylogenetically not too far removed from the carnivoraform origin (Zack, 2019a), and their skeletal anatomical traits are relatively well documented. Thus, we did not assume the monophyly of Carnivoramorpha in our cladistic analysis. However, testing of carnivoramorphan monophyly is beyond the scope of the present study, and would require a much broader sample of taxa including early hyaenodontans, oxyaenodontans, and other laurasiatherians (Zack, 2019a). Excluded from the present analysis are especially poorly documented taxa (e.g., those that are only known from a small portion of the dentition), Palaearctonyx meadi Matthew, 1909 (which could not be examined directly because the toothbearing portion of the holotype AMNH FM 12158 is currently missing from the collection), and Uintacyon vorax Leidy, 1873 (the hypodigm may consist of multiple taxa [Matthew, 1909] and requires further study). We added newly scored character states for three middle Eocene carnivoraforms: Uintacyon sp., represented by AMNH FM 128623 (cast of the cranium of USGS 1983 described by Bown, 1982); 'Miacis' lushiensis Chow, 1975, based only on UCMP 124706 (cast of the holotype dentary IVPP V4811) because we had reservations about previous referrals of other specimens to this taxon (Tong and Lei, 1986; Qi, 1991); and 'Miacis' hargeri (Wortman, 1901a). Our scoring of ' $M$.' hargeri was based solely on the holotype YPM VP 010071; the paratype YPM VP 011839 and several other specimens also were examined, but not included in our analysis because we had some doubts about their taxonomic identifications. Thus, our character matrix and cladistic analysis consisted of 47 operational taxonomic units and 238 characters. We identified the node-based crown group Carnivora based on several undisputed fossil representatives of the Caniformia and Feliformia, such as Hesperocyon gregarius Cope, 1873 and Proailurus lemanensis Filhol, 1879, respectively (Bryant, 1996; Wesley-Hunt and Flynn, 2005; Spaulding and Flynn, 2012; Tomiya and Tseng, 2016).

We performed parsimony analyses, identified synapomorphies that were common to the most-parsimonious trees (MPTs), and evaluated post-hoc hypotheses of alternative topologies using the program TNT v. 1.5 (Goloboff and Catalano, 2016) and as specified in Tomiya and Tseng (2016). The ensemble consistency index and ensemble retention index for the MPTs were obtained using the program Mesquite v. 3.51 (Maddison and Maddison, 2018).

Analysis of carnivore diversity dynamics using occupancydetection modeling.-We investigated the trajectory of mammalian carnivore diversity from the late Bridgerian to early Uintan NALMAs within the Washakie Basin. In essence, we estimated and compared species richnesses of mammalian carnivores in the original vertebrate paleocommunities (i.e., 'live' assemblages) across three stratigraphically successive portions of the formation. To this end, we built and statistically compared models of taxon occurrence and detection within the Bayesian framework, taking into account the temporal variations in sampling that may have distorted the true diversity trajectory. This model-based approach was more powerful and appropriate for our data set than the traditional use of rarefaction, which only controls for sample-size disparities and requires a number of often unrealistic ecological and taphonomic assumptions (Tipper, 1979; Behrensmeyer et al., 2000). Also importantly, our analysis leveraged the wealth of locality-level taxon detection data that have been accumulated by nearly half a century of intensive collecting in the basin.

To maximize consistency in data quality, we restricted the scope of our statistical analysis to FMNH localities because: (1) they were systematically collected with similar methods (primarily surface collecting) and goals (establishing mammalian biostratigraphy) under the direction of two researchers (W. Turnbull from the 1940s until the 1990s and JJF during the 1990s; cf., Turnbull, 1972, 1978), (2) taxonomic identifications of almost all of the mammalian specimens were recently (2013-2016) checked for obvious errors and updated by one of us (ST), and (3) more precise locations and extents of individual localities are known compared to the classic Washakie collections housed at AMNH and YPM. The specimens analyzed here were discovered predominantly as surface float, and judging from the prevalence of poorly preserved fossils that were brought back to FMNH (often indeterminate at the ordinal level), surface-collecting efforts in general appear to have been intensive and comparable across the major stratigraphic units.

Localities with unique identifying numbers were treated as a single locality in cases where they were recorded as equivalent in the FMNH collections database or original field notes. Localities with particularly poor stratigraphic resolutions were excluded. Consequently, our analysis was based on vertebrate occurrence data for 138 individual localities in Twkal and Twka2, which had collectively yielded 5,206 cataloged vertebrate specimens (including 56 securely identified as carnivore specimens) as of December 31, 2016 (Supplemental Data 3-5). For the purpose of this analysis, we treated Synoplotherium sp. indet. as a taxon distinct from S. lanius Cope, 1872c, and Viverravus sp. indet. as distinct from both $V$. gracilis Marsh, 1872a and V. minutus Wortman, 1901b (see Systematic Paleontology).

Stratigraphic data.-Although Roehler (1973) designated close to 200 lithologically distinct beds constituting the Washakie Formation within the Washakie Basin, most of the individual beds remain unidentified across much of the basin either because they are restricted to small areas or because sufficient stratigraphic work has not been conducted yet (Turnbull, 2002). As such, fossil localities in the formation are typically tied to ranges of Roehler's (1973) beds instead of specific individual beds, except when they occur in or near readily identifiable marker beds. Given the limited temporal resolution and the scarcity of carnivore fossils, we established for the purpose of our analysis 
three stratigraphically delineated groups of localities within Twka1 and Twka2, and treated them as separate 'sites' in the context of occupancy-detection modeling:

Locality Group 1: Localities in Roehler's (1973) bed 569 (Lower brown sandstone) to bed 579 (Robin's-egg-blue marker bed);

Locality Group 2: Localities in Roehler's (1973) bed 580 to bed 632;

Locality Group 3: Localities in Roehler's (1973) bed 633 (likely horizon of lowest stratigraphic datum of Amynodon = beginning of Uilb; see Appendix) to bed 675 .

Of these, Locality Group 2 crosses the traditionally recognized Twka1-Twka2 boundary at bed 620 , but we think that the division at the base of bed 633 better coincides with a major ecological turnover of the mammalian fauna regardless of where the Bridgerian-Uintan NALMA boundary should be drawn (see Fig. 2 and Discussion). Attributes of the locality groups are summarized in Table 14.

Spatial data.-As discussed below, areal sizes of individual FMNH localities and those of locality groups (minimum convex polygons encompassing locality centroids) were included in our analysis as potential covariates of taxon-detection probabilities and site-occupancy probabilities. These spatial data were obtained as follows: In the early 2000s, W. Turnbull compiled a map of Washakie Formation localities using the 1980 USGS Kinney Rim 30' x 60' Quadrangle topographic map (1:100,000 scale). We digitized this unpublished map (currently on file in the FMNH vertebrate paleontology collection) using a large-format document scanner, and then georeferenced the scanned image in QGIS v. 2.6.1 (QGIS Development Team, 2014). Originally hand-drawn extents of individual localities were manually digitized into vector-format polygonal features. To this data set, we added six localities whose extents were determined from available township and range data. The geographic coordinates of locality centroids and the areal sizes of localities under the U.S. National Atlas Equal Area (a Lambert Azimuthal Equal Area) projection were then computed in QGIS. Areal sizes of two localities lacking sufficient geographic data (FM-5-80-WDT and JJF 7-24-95-1) were assigned by mean imputation.

Statistical analysis.- Species richnesses in the three stratigraphically successive locality groups were estimated by Bayesian hierarchical multispecies occupancy-detection modeling with data augmentation to account for incomplete detection of species (Kéry and Royle, 2008, 2016; Iknayan et al., 2014). In short, this method reconstructs the original species richness in the study area by evaluating probabilistic models of speciesspecific site occupancy and detection (for both detected and never-detected species) against the observed pattern of species detection. A major strength of this approach is that potentially confounding effects of taphonomic variations can be modeled explicitly in the assessment of diversity patterns; hence, comparison of assemblages is not necessarily confined to isotaphonomic samples or subsamples, as has traditionally been the case in paleontology (Behrensmeyer et al., 2000). We compared models with different covariates of the occupancy or detection probability, and selected the most probable models in a Bayesian framework using an extension of the reversible-jump Markov chain Monte Carlo (RJMCMC) method of Barker and Link (2013; see also Green, 1995; Hooten and Hobbs, 2015), which we newly developed for multispecies models.

Following the paleontological application of occupancydetection modeling by Liow (2013), we treated the stratigraphically circumscribed locality groups as 'sites' and individual localities as 'replicates' in the neontological terminology of occupancy-detection modeling. In our discussion of temporal diversity dynamics, we prefer the term 'locality groups' to 'sites' to emphasize their subjective binning and substantial time scope, and to avoid confusion with individual paleontological localities. Different locality groups need not contain the same number of localities. Fossil assemblages from individual localities were assumed to be independent samples of the fauna. Although treated as 'replicates' from the modeling perspective, localities within a locality group are not required to be identical in their characteristics, and their differences can be accounted for by incorporating covariates into the models.

The modeling and model-comparison procedures are described in detail in Appendix. Four alternative models were constructed to account for potential sampling disparities among localities ('replicates') or locality groups ('sites'):

Model $1\left(M_{1}\right)$ included no site- or replicate-level covariate; Model $2\left(M_{2}\right)$ incorporated the square-root-transformed number of individual vertebrate specimens (NISP) as a replicate-level covariate of the detection probability $p$;

Model $3\left(M_{3}\right)$ incorporated the log-transformed locality area as a replicate-level covariate of the detection probability $p$; Model $4 \quad\left(M_{4}\right)$ incorporated the locality-group area (minimum convex polygon area encompassing all locality centroids) as a site-level covariate of the occupancy probability $\psi$.

The modeling method used here assumes that the original species 'community' was closed at each 'site' (i.e., all taxa that occurred in a locality group are assumed to have been present throughout the duration of observations represented by individual localities, and there was no immigration, emigration, origination, or extirpation during that time span). Under this assumption, the species diversity for each locality group is not affected by its temporal span because there is no species turnover within the locality group; hence, we did not consider a model with the temporal span or its proxy (e.g., stratigraphic thickness) as a site-level covariate of the occupancy probability. Violation of this assumption is common, even in biological surveys of modern communities, and is expected to inflate estimates of occupancy probabilities (Rota et al., 2009). Our discussion of the results therefore focuses on patterns of relative, not absolute, species richnesses among the locality groups, and we consider the possibility of variation in the degree of 'community' closure across the locality groups.

Analyses were performed using the program JAGS (v. 4.3.0, Plummer, 2003) and the R packages 'coda' (v. 0.19-1, Plummer et al., 2006), 'geosphere' (v. 1.5-7, Hijmans, 2017), 'HDInterval' (v. 0.2.0, Meredith and Kruschke, 2018), 'jagsUI' (v. 1.4.9, Kellner, 2017), 'rgeos' (v. 0.3.27, Bivand and Rundel, 2018), 'runjags' (v. 2.0.4-2, Denwood, 2016), and 'sp' (v. 1.2.7, 
Pebesma and Bivand, 2005), all in the R programming environment (v. 3.5.0, R Development Core Team, 2018). For the Bayesian hierarchical occupancy-detection modeling, we ran three parallel chains with MCMC specifications, as reported in Table 15. Convergence of the chains to their stationary distributions was assessed by checking that the values of the Brooks-Gelman-Rubin statistic $\hat{R}$ (= potential scale reduction factor; Gelman and Rubin, 1992; Brooks and Gelman, 1998) were less than 1.1. R scripts for these analyses are provided in Supplemental Data 1 .

Temporal dynamics of vertebrate co-detection patterns.-To help interpret the temporal dynamics of carnivore diversity in its faunal context, we examined broad patterns of co-detection (i.e., observed co-occurrence) of vertebrate taxa across the same span of time. The locality-level taxic detection data set that formed the basis for the carnivore occupancy-detection modeling was converted into three stratigraphically successive detection-non-detection matrices (corresponding to Locality Groups 1-3, with initially the same locality contents as for the analysis of carnivore diversity trajectory). Taxa were consolidated into major mammalian orders and a group combining aquatic to semiaquatic non-mammalian vertebrates (consisting of freshwater fishes, trionychid turtles, and crocodiles). Observed positive associations and negative dissociations of these taxonomic groups at the locality level were quantified by the Pearson product-moment correlation coefficient $r$ and visualized as correlation networks using the R package 'qgraph' (v. 1.6.1, Epskamp et al., 2012).

We adopted the relative standard deviation of eigenvalues of the correlation matrix for taxic detections as a measure of 'integration' of the taxonomic groups within each locality group, analogous to the integration of morphometric traits (Pavlicev et al., 2009; Goswami and Polly, 2010, equation 8). To calculate the values of this metric, 1,000 bootstrap pseudoreplicates were first generated from each of the three observed taxic-detection matrices. In doing so, and to maintain sample size equivalency, the same number of localities (29, which was the minimum number of localities per locality group) were randomly selected for all pseudoreplicates and for all locality groups. From these, the median and bias-corrected 95\% confidence interval (Efron, 1981) of the integration metric were calculated and statistically compared. In this analysis, we did not attempt to estimate occurrences of undetected taxa; instead, we considered both habitat and taphonomic effects as potentially driving the observed co-detection patterns. As a measure of taxon abundance, we calculated the proportion of localities at which each taxonomic group was detected (= "locality coverage" of Jernvall and Fortelius, 2004). R script for this analysis is provided in Supplemental Data 1.

Abbreviations. - dp/DP, lower/upper deciduous premolar; HPDI, Bayesian highest posterior density interval; L, anteroposterior length; MPT, most-parsimonious tree; MCMC, Markov chain Monte Carlo; NALMA, North American Land Mammal 'Age'; NISP, number of identified specimens; OTU, operational taxonomic unit; Twka1/Twka2/Twka3, lower/ middle/upper unit of Adobe Town Member, Washakie Formation; Twkk, Kinney Rim Member, Washakie Formation;
W, mediolateral or labiolingual width. Additional abbreviations are explained in figure/table captions.

Repositories and institutional abbreviations.-AMNH FM, Fossil Mammal Collection, American Museum of Natural History, New York, USA; ANSP, Academy of Natural Sciences of Philadelphia, Philadelphia, USA; CM, Carnegie Museum of Natural History, Pittsburgh, USA; DMNH, Denver Museum of Natural History, Denver, USA; FMNH, Field Museum of Natural History, Chicago, USA; IVPP, Institute of Vertebrate Paleontology and Paleoanthropology, Beijing, China; MCZ, Museum of Comparative Zoology, Harvard University, Cambridge, USA; MPM, Milwaukee Public Museum, Milwaukee, USA; SDSNH, San Diego Natural History Museum, San Diego, USA; UCMP, University of California Museum of Paleontology, Berkeley, USA; YPM, Yale Peabody Museum of Natural History, New Haven, USA; UCM, University of Colorado Museum of Natural History, Boulder, USA; USNM, United States National Museum of Natural History, Washington, D.C. USA; UW, University of Wyoming Geological Museum and Collections, Laramie, USA; UWBM, University of Washington Burke Museum of Natural History, Seattle, USA.

\section{Systematic paleontology}

Class Mammalia sensu Rowe, 1988

Order Mesonychia Van Valen, 1969a

Family Mesonychidae Cope, 1875

Genus Synoplotherium Cope, 1872c

Type species.-Synoplotherium lanius Cope, 1872 c, by original designation.

Synoplotherium lanius Cope, $1872 \mathrm{c}$

Figures 3.1, 3.2, 3.9-3.16, 4.2-4.16, 5.1-5.8, 5.13, 5.14, $6.2-6.15,6.22-6.26$

1872c Synoplotherium lanius Cope, p. 1.

1872d Synoplotherium canius Cope, p. 483. [reproduction of original description, with incorrect spelling of species name]

1876 Dromocyon vorax Marsh, p. 403.

1884 Mesonyx lanius Cope, p. 348, pl. 27, figs.25-28, pl. 28, figs. 1-6, pl. 29, figs. 1-6.

1901b Dromocyon vorax; Wortman, p. 291, pl. 1-4, 8-9, figs. 45, 47-51, 54-60.

1909 Synoplotherium lanius; Matthew, p. 492.

1998 Synoplotherium canius; Archibald, p. 312.

Holotype.-AMNH FM 5022, partial right and left dentaries, premaxillary and maxillary fragments bearing right I2-I3 and right and left $\mathrm{C} 1$, partial right and left manus, and additional, mostly fragmentary postcranial elements including right and left humeri, left ulna, right radius, and right and left calcanea.

Locality.-According to Cope (1884, p. 362), "on a terrace of the Mammoth Buttes [= Haystack Mountain in current usage; 


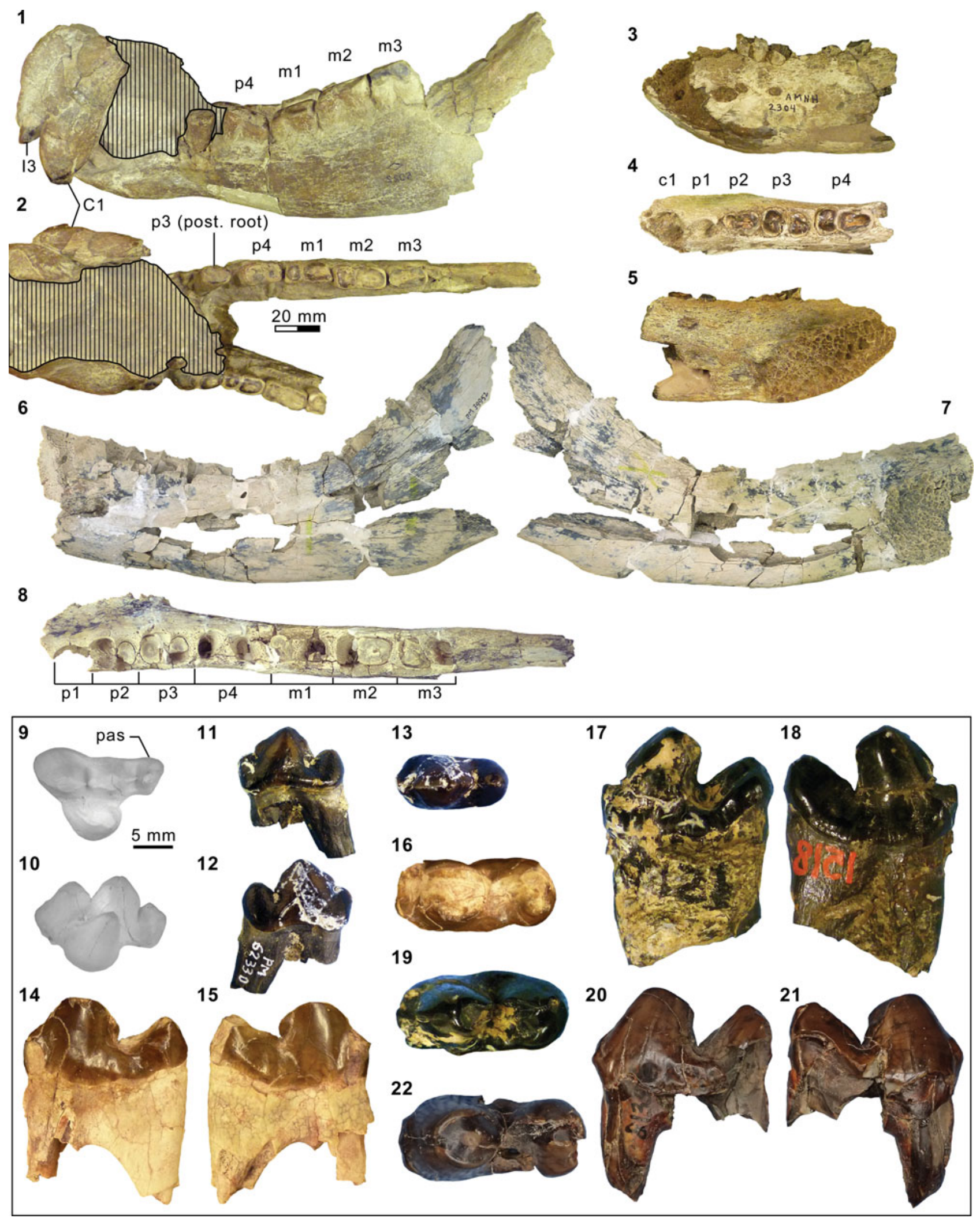

Figure 3. Mandibular and dental elements of mesonychid Synoplotherium Cope, 1872c. Synoplotherium lanius Cope, 1872c, from the Washakie Formation: (1, 2) mandible of AMNH FM 5022 (holotype) in lateral $(\mathbf{1}$; inverted) and superior (2) views (vertical stripes indicate block of matrix); (9, 10) right DP4 of FMNH PM 22423 (cf. S. lanius; cast of AMNH FM 13144) in occlusal (9) and oblique lingual (10) views; (11-13) left m3 of FMNH PM 62330 in labial (11), lingual (12), and occlusal (13) views; (14-16) left ?m1 of FMNH PM 55316 in lingual (14; inverted), labial (15; inverted), and occlusal (16; inverted) views. Synoplotherium sp. indet. from the Twin Buttes Member, Bridger Formation: (17-19) left ?p4 of AMNH FM 1518 A in lingual (17; inverted), labial (18; inverted), and occlusal (19; inverted) views. Synoplotherium sp. indet. from the Washakie Formation: (3-5) left anterior dentary fragment of AMNH FM 2304 in lateral (3), superior (4), and medial (5) views; (6-8) left dentary of FMNH PM 39952 in lateral (6), medial (7), and superior (8) views; (20-22) right ?p4 of UCMP 81352 in lingual (20), labial (21), and occlusal (22) views. Figure 3.1-3.8 and 3.9-3.22 at two different scales. Abbreviation: pas, parastyle. 


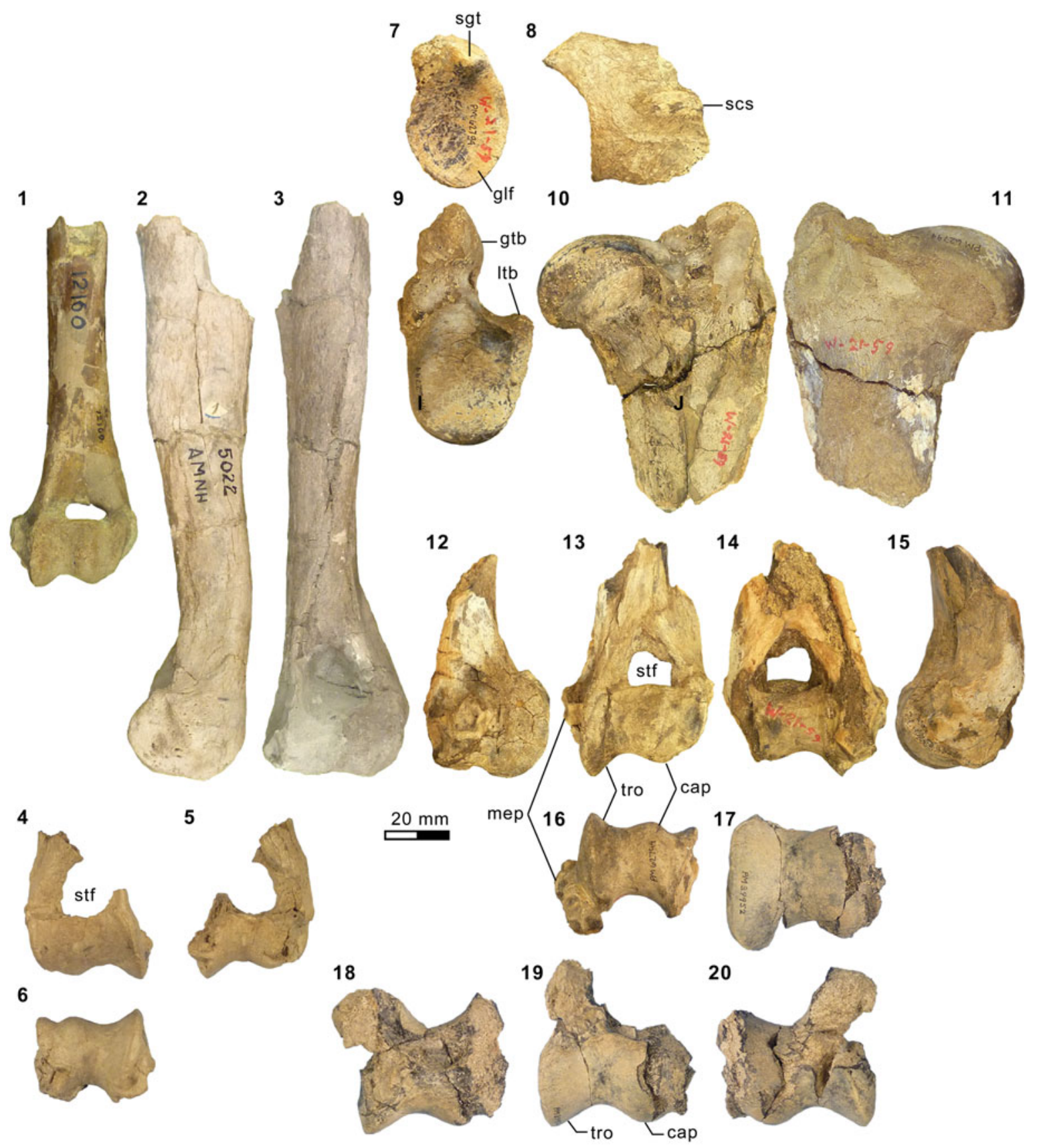

Figure 4. Appendicular elements of mesonychids Mesonyx Cope, 1872a (Bridgerian NALMA; Br3 subage) and Synoplotherium. (1) AMNH FM 12160 (Mesonyx cf. M. obtusidens), left humerus in anterior view; (2-6) AMNH FM 5022 (holotype of Synoplotherium lanius), left humerus in lateral (2) and anterior (3) views, and right distal humerus in anterior (4), posterior (5), and distal (6; anterior to top) views; (7-16) FMNH PM 62794 (S. lanius), glenoid region of left scapula in anterior (7) and lateral (8) views, left proximal humerus in proximal (9), medial (10), and lateral (11) views, and left distal humerus in medial (12), anterior (13), posterior (14), lateral (15), and distal (16; anterior to top) views; (17-20) FMNH PM 39952 (Synoplotherium sp. indet.), left distal humerus in distal (17; anterior to top), proximal (18), anterior (19), and posterior (20) views. Same $20 \mathrm{~mm}$ scale applies to all images. Abbreviations: cap, capitulum; glf, glenoid fossa; gtb, greater tuberosity; ltb, lesser tuberosity; mep, medial epicondyle; scs, scapular spine; sgt, supraglenoid tubercle; stf, supratrochlear foramen; tro, trochlea.

see Turnbull, 2002], near South Bitter Creek" Washakie Basin, Sweetwater County, Wyoming.

Horizon.-Twka1 ("Lower Washakie" according to Matthew, 1909, p. 492), Adobe Town Member, Washakie Formation.

Diagnosis (after Matthew, 1909, p. 493, 495-496).-Differs from Mesonyx obtusidens Cope, 1872a in: (1) M3 present; (2) more robust and relatively shorter mandible; (3) premolars longer and with smaller diastemata; (4) relatively shorter and more robust appendicular skeletal elements.

Occurrence.- "Volcanic-ash bed of Henry's Fork" (Wortman, 1901b, p. 432), Twin Buttes Member ("Upper Bridger" of Matthew, 1909, p. 492), Bridger Basin, Wyoming; Twka1, Adobe Town Member, Washakie Formation, Washakie Basin, 

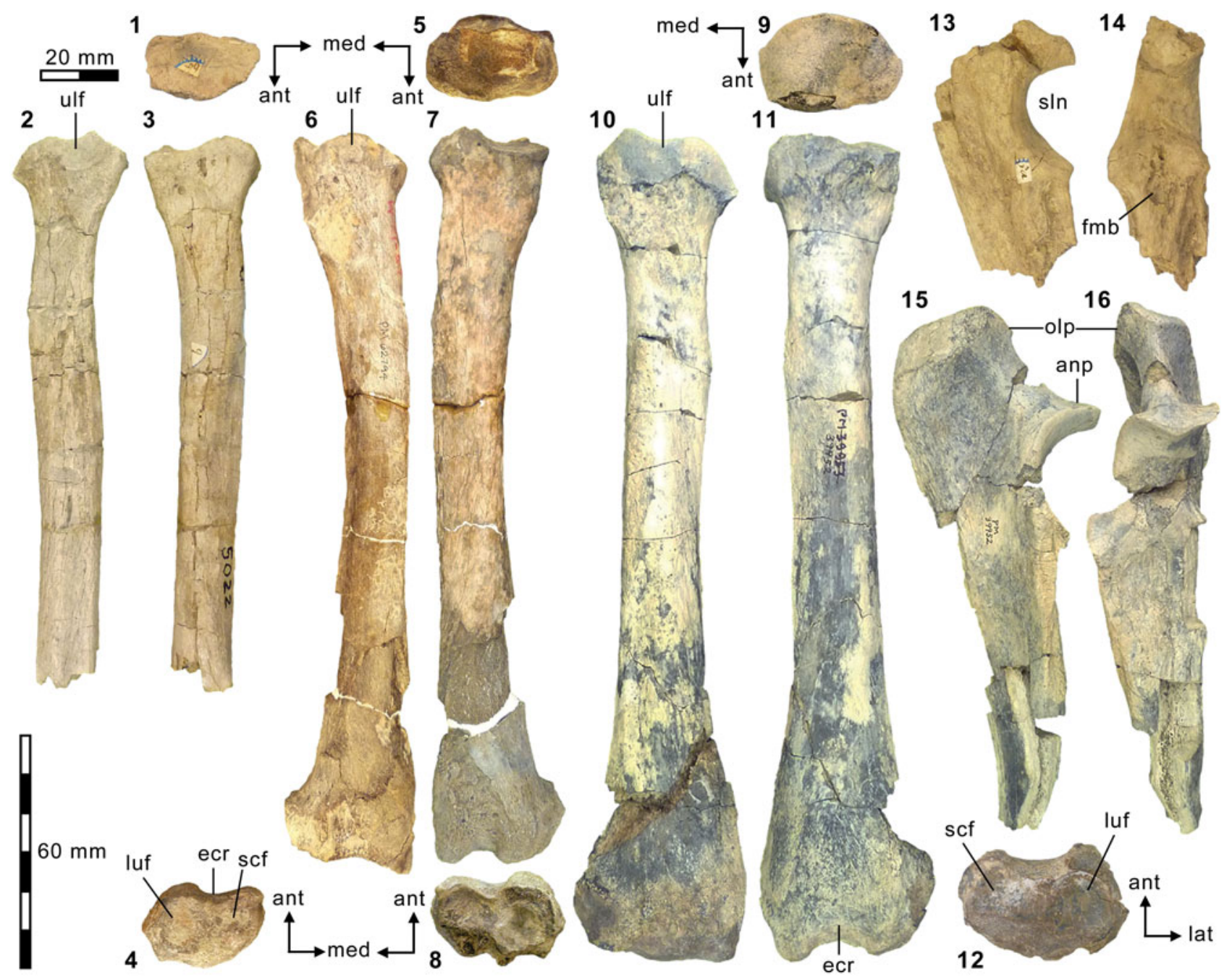

Figure 5. Additional appendicular elements of Synoplotherium. $(\mathbf{1 - 3}, \mathbf{1 3}, \mathbf{1 4})$ AMNH FM 5022 (holotype of Synoplotherium lanius), right radius in proximal $(\mathbf{1}$; anterior to bottom), posterior (2), and anterior (3) views, and left proximal ulna in medial (13) and anterior (14) views; (4-8) FMNH PM 62794 (S. lanius), right distal radius in distal view $(\mathbf{4}$; anterior to top) and left radius in proximal $(\mathbf{5}$; anterior to bottom), posterior $(\mathbf{6})$, anterior $(\mathbf{7})$, and distal $(\mathbf{8}$; anterior to top) views; $(\mathbf{9 - 1 2 , 1 5 , 1 6 )}$ FMNH PM 39952 (Synoplotherium sp. indet.), left radius in proximal (9; anterior to bottom), posterior (10), anterior (11), and distal (12; anterior to top) views; left proximal ulna in medial (15) and anterior (16) views. All images at the same scale. Abbreviations: anp, anconeal process; ecr, groove for extensor carpi radialis tendon; fmb, fossa for m. brachialis; luf, lunar facet; olp, olecranon process; scf, scaphoid facet; sln, semilunar notch; ulf, ulnar facet of proximal radius.

Sweetwater County, Wyoming (Cope, 1872c; this study). Late Bridgerian (Br3) NALMA.

Description.-The referred postcranial elements in the FMNH collection (Figs. 4.7-4.16, 5.4-5.8, 6.3-6.15, 6.22-6.26; Table 1) closely resemble the corresponding elements of the holotype AMNH FM 5022 (Figs. 4.2-4.6, 5.1-5.3, 5.13, 5.14, 6.2) from the same stratigraphic unit (Twka1), as well as those of YPM VP 010935 (holotype of 'Dromocyon vorax' from the upper Bridger Formation), whose nearly complete skeleton was thoroughly described by Wortman (1901b). As observed by previous workers (e.g., Cope, 1884), the appendicular skeletal elements are generally more robust than those of Mesonyx. For example, the astragalus of FMNH PM 61369 from Twka1 is roughly $20 \%$ larger in linear dimensions (Table 1) than that of AMNH FM 12643, Mesonyx obtusidens from Bridger B (cf., Matthew, 1909, fig. 96). The differences in skeletal robusticity persist when comparisons are restricted to specimens of $\mathrm{Br} 3$ ages (Figs. 4.1, 6.1).

It should be noted that the medial portion of the left distal humerus of AMNH FM 5022 (Fig. 4.2, 4.3) is crudely reconstructed with plaster, obliterating the supratrochlear foramen whose presence is evident in the right distal humerus of the same specimen (Fig. 4.4, 4.5), as well as in FMNH PM 62794 (Fig. 4.13, 4.14; see also Wortman, 1901b). In addition, the proximal humerus of FMNH PM 62794 preserves an anteroposteriorly elongate head (longer than is mediolaterally wide; Fig. 4.9-4.11) and a large greater tuberosity that is positioned far anterior to the head, as in Mesonyx (O'Leary and Rose, 1995, fig. 4). The distal radii of FMNH PM 61291 and FMNH PM 62794 each bear a small styloid process and, as Wortman (1901b) noted for YPM VP 010935, weakly divided concave facets for articulation with the scaphoid and lunar (Figs. 5.4, 5.8, 6.22). 
1

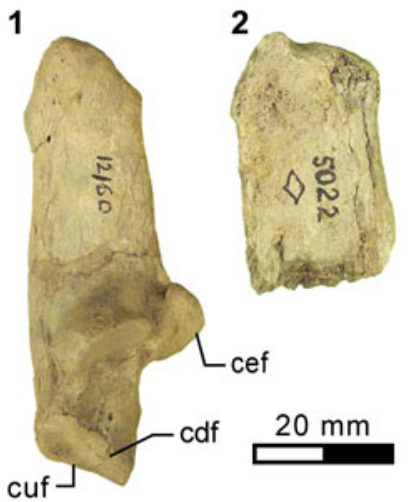

3

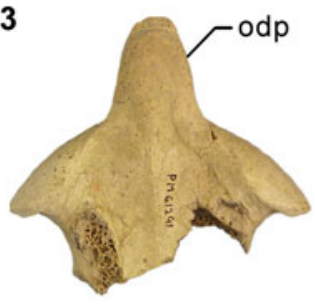

4

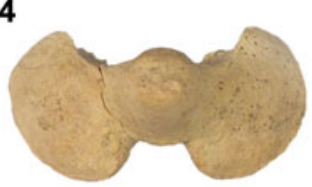

11
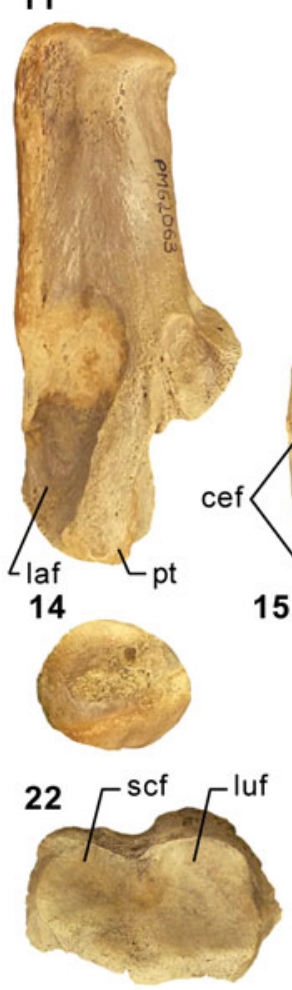

25

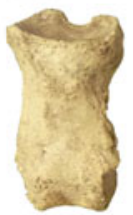

12

\section{6}

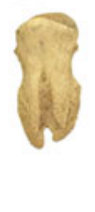

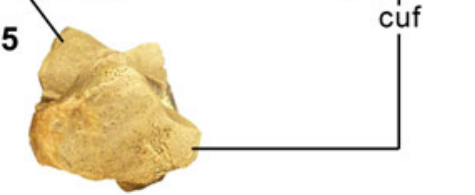

23

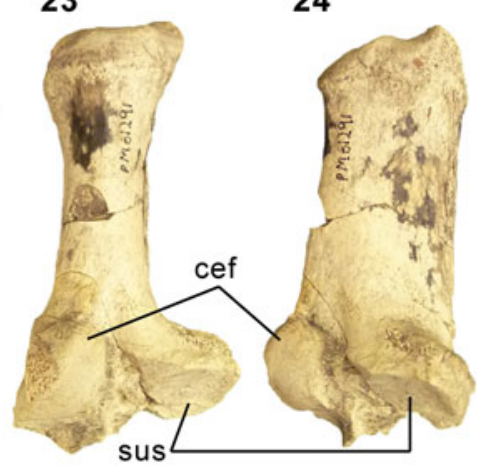

5

13

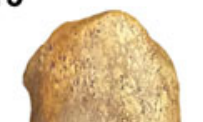

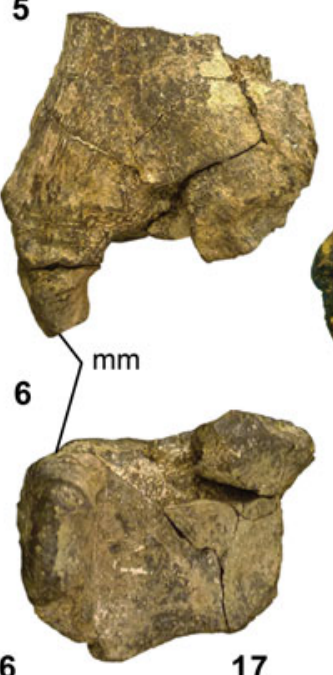

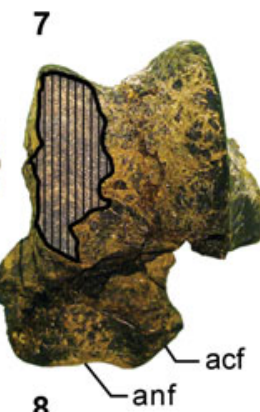

8
9

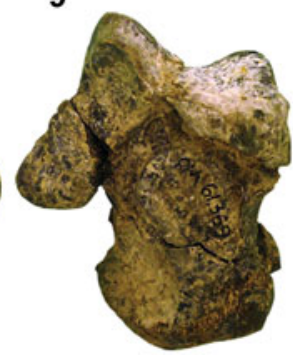

10

18
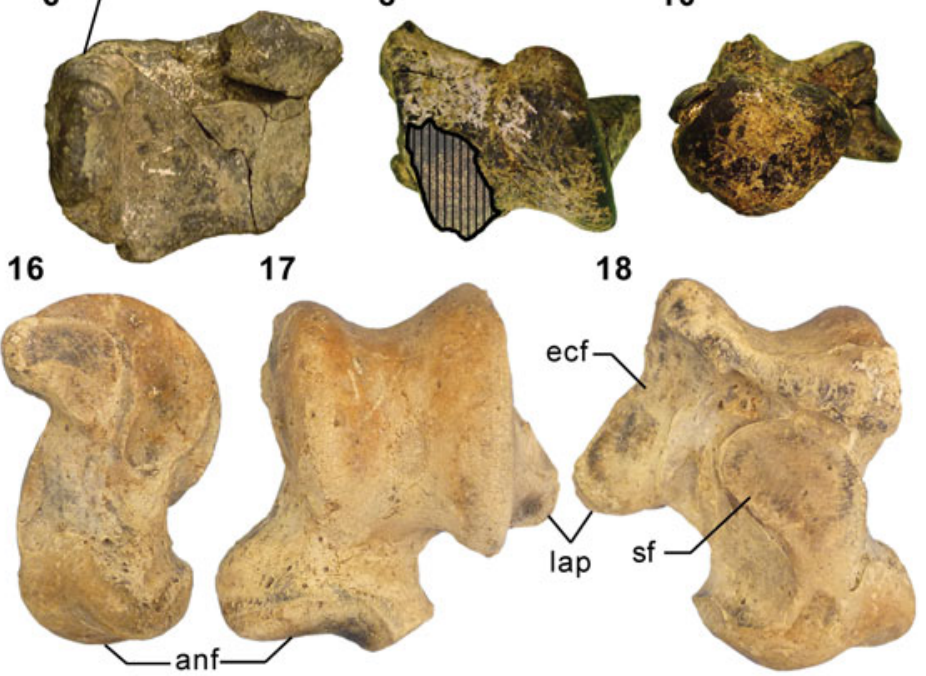

19

20

21

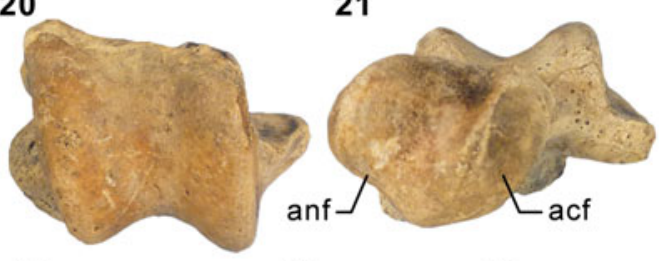

27

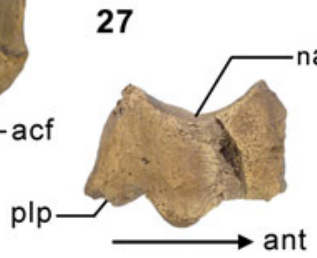

30

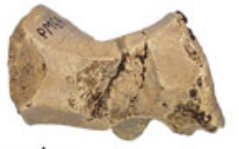

ant

28

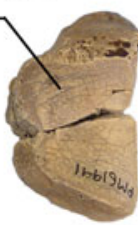

31

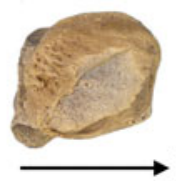

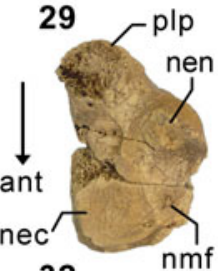

32

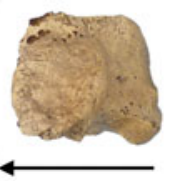

Figure 6. Additional postcranial elements of Mesonyx (from Br3) and Synoplotherium. (1) AMNH FM 12160 (Mesonyx cf. M. obtusidens), left calcaneum in medial view; (2) AMNH FM 5022 (holotype of Synoplotherium lanius), calcaneal tubercle of left calcaneum in medial view; (3, 4) FMNH PM 61291 (S. lanius), partial axis in superior (3) and anterior (4) views; (5-10) FMNH PM 61369 (S. lanius), left distal tibia in anterior (5) and distal (6; anterior to top) views and left astragalus in anterior (7), proximal (8; anterior to bottom), posterior (9), and distal (10; anterior to top) views; (11-15) FMNH PM 62063 (S. lanius), right calcaneum in lateral (11), anterior (12), medial (13), proximal (14; anterior to bottom), and distal (15; anterior to top) views; (16-21) FMNH PM 62080 (Synoplotherium sp. indet.), left astragalus of in medial (16), anterior (17), posterior (18), lateral (19), proximal (20; anterior to bottom), and distal (21; anterior to top) views; (22-26) FMNH PM 61291 (S. lanius), left distal radius in distal view (22; anterior to top), partial right calcaneum in anterior (23) and medial (24) views, proximal (25) and terminal (26) phalanges in dorsal views; (27-32) FMNH PM 61991 (Synoplotherium sp. indet.), left navicular in lateral (27; anterior to right), proximal (28; anterior to bottom), distal (29; anterior to bottom), medial (30; anterior to left), anterior (31; lateral to right), and posterior (32; lateral to left) views. Same $20 \mathrm{~mm}$ scale applies to all images. Abbreviations: acf, astragalar cuboid facet; anf, astragalar navicular facet; cdf, calcaneal distal sustentacular facet; cef, calcaneal ectal facet; cuf, calcaneal cuboid facet; ecf, astragalar ectal facet; laf, lateral fossa; lap, lateral process; luf, lunar facet; mm, medial malleolus; naf, navicular astragalar facet; nec, navicular ectocuneiform facet; nen, navicular entocuneiform facet; nmf, navicular mesocuneiform facet; odp, odontoid process; pt, peroneal tubercle; plp, plantar process; scf, scaphoid facet; sf, astragalar sustentacular facet; sus, calcaneal sustentacular facet. 


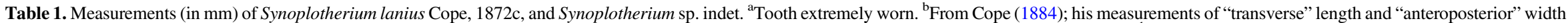

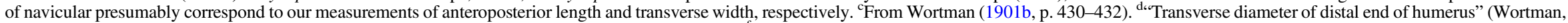
$1901 \mathrm{~b}$, p. 431), presumably excluding medial epicondyle. ${ }^{\mathrm{e}}$ Identification of tooth locus is uncertain. ${ }^{\mathrm{f}}$ Measured across alveoli or roots.

\begin{tabular}{|c|c|c|c|c|c|c|c|c|c|c|c|c|c|c|}
\hline \multirow[b]{3}{*}{ Element } & \multirow[b]{3}{*}{ Dimension } & \multicolumn{8}{|c|}{ S. lanius } & \multicolumn{5}{|c|}{ Synoplotherium sp. indet. } \\
\hline & & \multicolumn{8}{|c|}{$\mathrm{Br} 3$} & \multirow{2}{*}{ 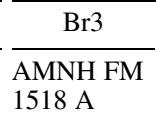 } & \multirow{2}{*}{$\begin{array}{l}\text { ?Ui1b } \\
\text { UCMP } \\
81352\end{array}$} & \multicolumn{3}{|c|}{ Uilb } \\
\hline & & $\begin{array}{l}\text { AMNH FM } \\
5022\end{array}$ & $\begin{array}{l}\text { YPM VP } \\
010935^{\mathrm{c}}\end{array}$ & $\begin{array}{l}\text { FMNH PM } \\
55316\end{array}$ & $\begin{array}{l}\text { FMNH PM } \\
62330\end{array}$ & $\begin{array}{l}\text { FMNH PM } \\
62794\end{array}$ & $\begin{array}{l}\text { FMNH PM } \\
61291\end{array}$ & $\begin{array}{l}\text { FMNH PM } \\
61369\end{array}$ & $\begin{array}{l}\text { FMNH PM } \\
62063\end{array}$ & & & $\begin{array}{l}\text { FMNH PM } \\
39952\end{array}$ & $\begin{array}{l}\text { FMNH PM } \\
62080\end{array}$ & $\begin{array}{l}\text { FMNH PM } \\
61991\end{array}$ \\
\hline$\overline{\mathrm{p} 4}$ & $\begin{array}{l}\mathrm{L} \\
\mathrm{W}\end{array}$ & $\begin{array}{l}{[19.3]^{\mathrm{a}}} \\
{[9.2]^{\mathrm{a}}}\end{array}$ & & & & & & & & $\begin{array}{l}22.4^{\mathrm{e}} \\
11.2^{\mathrm{e}}\end{array}$ & $\begin{array}{l}23.3^{\mathrm{e}} \\
11.8^{\mathrm{e}}\end{array}$ & & & \\
\hline $\mathrm{m} 1$ & $\begin{array}{l}\mathrm{L} \\
\mathrm{W}\end{array}$ & $\begin{array}{l}{[20.5]^{\mathrm{a}}} \\
{[9.2]^{\mathrm{a}}}\end{array}$ & & $\begin{array}{l}21.0^{\mathrm{f}} \\
10.1^{\mathrm{f}}\end{array}$ & & & & & & & & {$[\sim 24]^{\mathrm{f}}$} & & \\
\hline $\mathrm{m} 2$ & $\begin{array}{l}\mathrm{L} \\
\mathrm{W}\end{array}$ & {$[21.6]^{\mathrm{a}}$} & & & & & & & & & & {$[\sim 25]^{\mathrm{f}}$} & & \\
\hline $\mathrm{m} 3$ & $\begin{array}{l}\mathrm{L} \\
\mathrm{W}\end{array}$ & $\begin{array}{l}{[15.1]^{\mathrm{a}}} \\
{[7.9]^{\mathrm{a}}}\end{array}$ & & & $\begin{array}{l}15.1 \\
7.7\end{array}$ & & & & & & & $\begin{array}{l}{[22.0]^{\mathrm{f}}} \\
{[\sim 11.4]^{\mathrm{f}}}\end{array}$ & & \\
\hline \multirow{2}{*}{$\begin{array}{l}\mathrm{m} 1-3 \\
\text { Axis }\end{array}$} & $\mathrm{L}$ & {$[57.0]^{\mathrm{a}}$} & & & & & & & & & & {$[\sim 80]^{\mathrm{f}}$} & & \\
\hline & $\begin{array}{l}\text { max. width across } \\
\text { prezygapophyses }\end{array}$ & & & & & & 45.1 & & & & & & & \\
\hline Scapula & $\begin{array}{l}\text { glenoid fossa } \mathrm{L} \\
\text { glenoid fossa W }\end{array}$ & & $\begin{array}{l}38.5 \\
27\end{array}$ & & & $\begin{array}{l}38.4 \\
30.9\end{array}$ & & & & & & & & \\
\hline \multirow[t]{2}{*}{ Humerus } & $\begin{array}{l}\text { head W } \\
\text { distal W (max.) incl. medial } \\
\text { epicondyle }\end{array}$ & $41.5^{\mathrm{b}}$ & & & & $\begin{array}{l}35.6 \\
48.9\end{array}$ & & & & & & & & \\
\hline & $\begin{array}{l}\text { distal W across trochlea + } \\
\text { capitulum }\end{array}$ & & $35^{\mathrm{d}}$ & & & 37.1 & & & & & & {$[>45.5]$} & & \\
\hline Ulna & olecranon L & & 49.5 & & & 49.7 & & & & & & 33.6 & & \\
\hline \multirow[t]{5}{*}{ Radius } & $\mathrm{L}$ & & 174 & & & 184.1 & & & & & & 215.8 & & \\
\hline & head L & $16.2^{\mathrm{b}}$ & 17.5 & & & 19.6 & & & & & & 24.2 & & \\
\hline & head W & $28.2^{\mathrm{b}}$ & 26 & & & 30.5 & & & & & & 37.6 & & \\
\hline & distal L & & 22 & & & 25.2 & 21.2 & & & & & 32.1 & & \\
\hline & distal W & & 36.5 & & & 34.8 & 30.5 & & & & & 46.4 & & \\
\hline Tibia & $\begin{array}{l}\text { distal } \mathrm{L} \\
\text { distal } \mathrm{W}\end{array}$ & & 23 & & & & & $\begin{array}{r}\sim 26 \text { (est.) } \\
38.8\end{array}$ & & & & & & \\
\hline Calcaneum & $\mathrm{L}$ & & 66 & & & & & & 66.7 & & & & & \\
\hline \multirow{4}{*}{ Astragalus } & $\mathrm{L}$ & & 49 & & & & & 43.5 & & & & & 50.3 & \\
\hline & trochlear W & & & & & & & $\sim 24$ & & & & & 30.6 & \\
\hline & head L & & & & & & & 20.1 & & & & & 24.0 & \\
\hline & head W & & & & & & & 25.5 & & & & & 30.8 & \\
\hline \multirow[t]{5}{*}{ Navicular } & $\mathrm{L}$ & {$[25.5 ?]^{\mathrm{b}}$} & & & & & & & & & & & & 31.3 \\
\hline & Calcaneal facet $\mathrm{L}$ & & & & & & & & & & & & & 21.4 \\
\hline & & {$[15.5 ?]^{\mathrm{b}}$} & & & & & & & & & & & & 20.4 \\
\hline & Calcaneal facet $\mathrm{W}$ & & & & & & & & & & & & & 18.2 \\
\hline & $\begin{array}{l}\text { Proximodistal } \mathrm{L} \text { of anterior } \\
\text { surface }\end{array}$ & & & & & & & & & & & & & 17.0 \\
\hline Cuboid & anterior W & & 25 & & & & & 23.1 & & & & & & \\
\hline
\end{tabular}


As reported for YPM VP 010935 (Wortman, 1901b), the robust distal tibia of FMNH PM 61369 bears a large medial malleolus (Fig. 6.5, 6.6). The combination of the almost angular convexity of the ectal facet and the distally directed sustentacular facet of the calcaneum (Fig. 6.13, 6.24) is similar to that in M. obtusidens (Fig. 6.1). Such a configuration of articular surfaces would have limited subtalar movement and pedal inversioneversion as a consequence. The general form of the calcaneum (Fig. 6.11-6.15) is also comparable to that of Harpagolestes brevipes Thorpe, 1923a as figured by Thorpe (1923a, fig. 3), although the latter is more than $40 \%$ longer (note that $H$. brevipes is known only from the holotype YPM VP 013098 from the Uinta Formation of Utah, and is possibly conspecific with $\mathrm{H}$. immanis Matthew, 1909 according to Thorpe).

AMNH FM 13144 (see its cast, FMNH PM 22423, in Fig. 3.9, 3.10) is identified as a DP4 based on its prominent parastyle-a characteristic that is also present in AMNH FM 2959 of Pachyaena gigantea Osborn and Wortman, 1892 (Szalay and Gould, 1966, fig. 8; note incorrect labeling of DP4 as P4 contra Matthew, 1901, p. 32; see also Osborn and Wortman, 1892) and the poorly marked border between the crown and the roots, particularly on the lingual side. Its size $(\mathrm{L}=16.40$, $\mathrm{W}=12.65)$ appears compatible with the permanent molars of YPM VP 010935. The tooth is more molariform than P4 of Mesonyx obtusidens (Matthew, 1909, fig. 94) in having a welldeveloped metacone (subequal to the paracone) and a protocone positioned more posteriorly relative to the paracone. The pointed parastyle bears a weakly defined anterior ridge, and has a wingshaped outline in occlusal view. The preparacrista is sharp, and the centrocrista was likely also well defined, although the ridges are somewhat worn. The posterior slope of the metacone is slightly worn, but the tooth appears to have lacked a metastyle. The robust protocone is anteriorly inclined.

The moderately worn left $\mathrm{m} 1$ (or possibly $\mathrm{m} 2$ ) of FMNH PM 55316 (Fig. 3.14-3.16) is roughly comparable in size to that of the holotype AMNH FM 5022 (Table 1). Likewise, m3 of FMNH PM 62330 (Fig. 3.11-3.13) is referred to Synoplotherium lanius based on its nearly identical size with that of the holotype (Table 1). The paraconid forms a blunt knob, and is separated from the protoconid by a shallow but sharp notch. The protoconid is low in height and bears a weak anterior ridge and a better-defined posterior ridge; the latter is followed by a clear notch and then by an ascending cristid obliqua on the anterior slope of the talonid. The tooth is labiolingually nearly symmetrical, but the lingual slope of the talonid is shallower than the labial slope, as is generally the case for lower cheek teeth of Mesonyx. No other unworn lower cheek teeth of $S$. lanius are known.

Materials from Bridger Basin.-YPM locality described as "Henry's Fork" (Wortman, 1901b, p. 432): YPM VP 010935 (holotype of Dromocyon vorax Marsh, 1876), skull and skeleton.

AMNH locality recorded as Twin Buttes, Bridger Basin: AMNH FM 145563, left astragalus.

Materials from Washakie Basin.-FMNH locality FM-7-58WDT or FM-2-59-WDT (Twka1): FMNH PM 62794, left radius and fragmentary postcrania including left scapula, right and left humeri, right and left ulnae (missing distal portions), right distal radius, distal femur (trochlear region only), and metapodial.

FMNH locality FM-3-79-WDT (Twka1): FMNH PM 62330 , right $\mathrm{m} 3$.

FMNH locality JJF 7-27-90-1 (Twka1): FMNH PM 55316, left ? $\mathrm{m} 1$ and additional tooth fragments.

FMNH locality JJF 7-30-90-1 (Twka1): FMNH PM 62063, right calcaneum.

FMNH locality JJF 7-26-95-2 (Twka1): FMNH PM 61291, fragments of cranium, vertebrae (including axis), ribs, right and left radii, right and left calcanea, right metacarpals III-IV, left metacarpal IV, and phalanges.

FMNH locality JJF 7-30-95-3 (Twka1): FMNH PM 61369, left distal tibia, left astragalus, left navicular, additional postcranial fragments (including vertebrae, left calcaneum, left cuboid, left ectocuneiform, left mesocuneiform, left metatarsals II-V, and phalanges).

AMNH locality recorded as Overland Trail (Twka1): AMNH FM 13144, right DP4.

Remarks.-The taxonomic status of Synoplotherium lanius warrants a brief review. This species was proposed by Cope (1872c; published on August 20,1872) based on a mandible with extremely worn teeth and associated postcrania from the Washakie Basin (Figs. 3.1, 3.2, 4.2-4.6, 5.1-5.3, 5.13, 5.14, 6.2). It should be noted that, in what was otherwise a reproduction of the original paper (Cope, 1872d; published on September 19,1872), the species name was incorrectly printed as S. "canius" (p. 483); thus, S. lanius has priority over S. "canius" (contra Archibald, 1998). Four years later, Marsh (1876) named a new genus and a new species, Dromocyon vorax, based on a largely complete skeleton from the Bridger Basin without comparing it to S. lanius or any other mesonychid known at that time. Wortman (1901b) redescribed the holotype YPM VP 010935 of $D$. vorax and tentatively retained S. lanius as a distinct species, citing: (1) the peculiar orientation of the lower canines and complete absence of lower incisors in the holotype AMNH FM 5022, as noted by Cope (1872c, 1884); and (2) the provenances of the holotypes in separate basins (i.e., Bridger and Washakie). Matthew (1909) regarded the dental peculiarities of AMNH FM 5022 to be conditions of an advanced age of the individual, with no taxonomic significance (apparently age-related reduction in the number of lower incisors is also seen in YPM VP 010935; Wortman, 1901b, p. 296), and accordingly synonymized Dromocyon with Synoplotherium. Further, he questioned the distinct species status of $S$. "vorax" but stopped short of synonymizing it with S. lanius. In fact, Matthew (1909, p. 492) stated that he saw "no distinction" between AMNH FM 5022 (S. lanius) and Wortman's (1901b) description of YPM VP 010935 other than differences attributable to tooth wear, and that the limb elements "agree[d] entirely" with those of $S$. vorax. We concur with his observations and consider $S$. "vorax" to be a junior synonym of S. lanius.

Previous workers have treated Synoplotherium as a distinct genus or as a junior synonym of Mesonyx. Given the generally poor state of knowledge of middle Eocene North American mesonychids, such a taxonomic decision is inevitably subjective. Still, 
there is a longstanding consensus that $S$. lanius closely resembles M. obtusidens. Cope (1884), after initially proposing a separate genus (Cope, 1872c), reassigned S. lanius to Mesonyx, and Matthew (1909, p. 493) stated that morphological differences between the two taxa were "of hardly more than subgeneric value," although he did not synonymize the two genera. We tentatively follow Matthew (1909) in recognizing Synoplotherium as a distinct genus while noting its close (possibly sister-taxon) relationship with Mesonyx (Geisler and McKenna, 2007).

Matthew (1909) noted that reliable records of Mesonyx obtusidens were limited to the lower Bridger Formation (today recognized as the Blacks Fork Member; Murphey and Evanoff, 2007), which implies an older (middle Bridgerian) distribution than that of S. lanius, which is thus far known only from the late Bridgerian. In view of the historical taxonomic instability surrounding Synoplotherium and Mesonyx, and the limited utility of dental morphology in diagnosing mesonychid species (Szalay and Gould, 1966), we think that purported late Bridgerian and later occurrences of M. obtusidens in faunal lists (Gunnell et al., 2009) need to be reexamined.

Synoplotherium sp. indet.

Figures 3.3-3.8, 3.17-3.22, 4.17-4.20, 5.9-5.12, 5.15, 5.16, $6.16-6.21,6.27-6.32,7.4$

Description.-The squamosal glenoid region and the matching mandibular condyle of FMNH PM 39952 are robust (similar observations were made by Wortman, 1901b, on YPM VP 010935). The glenoid fossa has an anteroposterior width of $\sim 37 \mathrm{~mm}$, which is comparable to that of MPM 4595, Harpagolestes macrocephalus Wortman, 1901b from Bridger B (West, 1981, figs. 3-5; we examined a cast, FMNH PM $37370)$, but its mediolateral extent is more limited $(\sim 46 \mathrm{~mm}$ versus $\sim 64 \mathrm{~mm}$ ).

The horizontal ramus of the dentary of FMNH PM 39952 (Figs. 3.6-3.8, 7.4) maintains a nearly constant height from the anteroposterior level of $\mathrm{p} 1$ to $\mathrm{p} 4$. Its ventral border is not as strongly bowed in profile and the dentary is not as massive (deep relative to the toothrow length) as is typical in Harpagolestes (Fig. 7.1-7.3). In addition, a relatively large $\mathrm{p} 1$ and similar sizes of $\mathrm{p} 2$ and $\mathrm{p} 3$ (as inferred from their roots and alveoli; Fig. 3.8) appear to distinguish this specimen from those referred to Harpagolestes (cf., Szalay and Gould, 1966), although variations in the anterior premolars of the latter genus are poorly known. The lower teeth of UCMP 81352 (Fig. 3.20-3.22; Table 1) and AMNH FM 2304 (as inferred from broken roots; Fig. 3.3-3.5) are likely intermediate in size between their counterparts in the holotype AMNH FM 5022 of Synoplotherium lanius (taking into consideration the extreme degrees of tooth wear) and Harpagolestes. In addition, the ?p4 of UCMP 81352 closely resembles the ?p4 of AMNH FM 1518 A from the Twin Buttes Member of the Bridger Formation (Fig. 3.173.19; Table 1); thus, we tentatively regard these specimens as representing the same species. The $\mathrm{m} 3$ of FMNH PM 39952 is relatively large (ratio of $\mathrm{m} 3$ alveolar $\mathrm{L} / \mathrm{m} 2$ alveolar $\mathrm{L}=0.88$ ) compared to those of other mesonychids from the Washakie Formation, namely, S. lanius $(\mathrm{m} 3 \mathrm{~L} / \mathrm{m} 2 \mathrm{~L}=\sim 0.70$ for AMNH FM 5022) and Harpagolestes immanis (m3L/m2L $=\sim 0.69$ for AMNH FM 13143, based on Matthew, 1909, fig. 100).
Postcranial elements (Figs. 4.17-4.20, 5.9-5.12, 5.15, $5.16,6.16-6.21,6.27-6.32)$ closely resemble those of Synoplotherium lanius in form, but are substantially larger (Table 1). The astragali of YPM VP 010935 (S. lanius; Wortman, 1901b, pl. 8), FMNH PM 61369 (S. lanius; Fig. 6.7-6.10), and FMNH PM 62080 (Synoplotherium sp. indet.; Fig. 6.16-6.21) all share a proportionately longer trochlea (accounting for nearly two-thirds of the proximodistal length of the element) and a shorter neck than in Mesonyx obtusidens (e.g., AMNH FM 5021). In addition, the humerus of FMNH PM 39952 bears a supratrochlear foramen (Fig. 4.18-4.20) as in S. lanius, but unlike in Harpagolestes (Wortman, 1901b, fig. 44). The navicular and astragalus of FMNH PM 61991 and FMNH PM 62080 (Fig. 6.16-6.21, 6.27-6.32), respectively, are from different localities, but fit well to each other, so they very likely belong to the same taxon.

Materials from Washakie Basin.-AMNH locality recorded as south of Haystack Mountain (Twka1; "Lower" Washakie on specimen label): AMNH FM 2304 (previously identified in collection as "cf. Patriofelis ferox" Marsh, 1872a), left dentary fragment with roots of $\mathrm{p} 2-4$.

FMNH locality FM-2-83-KL/WT (Roehler's [1973] bed 633, Twka2): FMNH PM 39952, left radius, skeletal fragments including ?right partial squamosal, right and left dentaries (with roots of teeth), left distal humerus, and right and left proximal ulnae.

FMNH locality FM-4-75-WDT (Ui1b portion of Twka2): FMNH PM 62080, left astragalus.

FMNH locality FM-10-56-WDT (Ui1b portion of Twka2): FMNH PM 61991, left navicular.

UCMP locality V78102 ('Granger Horizon 17 General'; bed ?633, Twka2): UCMP 81352, right ?p4.

Material from Bridger Basin.-AMNH locality recorded as "Twin Buttes": AMNH FM 1518 A, left ?p4.

Remarks.-The referred specimens may belong to very large individuals of $S$. lanius or to a large, as-yet unnamed species of Synoplotherium, but the available material is insufficient for confident identification at the species level. Although pronounced sexual size dimorphism is known in one mesonychian, Ankalagon (O'Leary et al., 2000), it is concentrated in the canines and is unlikely to explain the size variations in the postcanine teeth of Synoplotherium reported here. At the stratigraphic resolution currently available, it is possible that the larger morphotype co-occurred with $S$. lanius in the late Bridgerian of the central Rocky Mountain region, but only the former appears to have persisted into the early Uintan.

Gustafson (1986, p. 12) "very tentatively" referred TMM 41576-6, a partial ?M2 from the Whistler Squat local fauna of the Devil's Graveyard Formation, Texas, to the poorly known mesonychid Hessolestes based on an intermediate size between Mesonyx (in which Synoplotherium lanius may have been included) and Harpagolestes. To date, it is the only early Uintan (Uilb-age) specimen referred to the genus, which is otherwise restricted to the late Uintan (Ui3) of Texas and the Duchesnean of Utah (Peterson, 1931; Gustafson, 
1

1

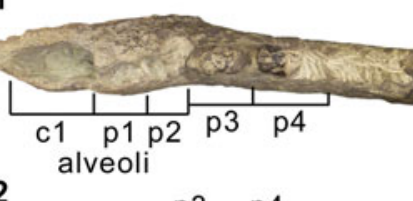

2
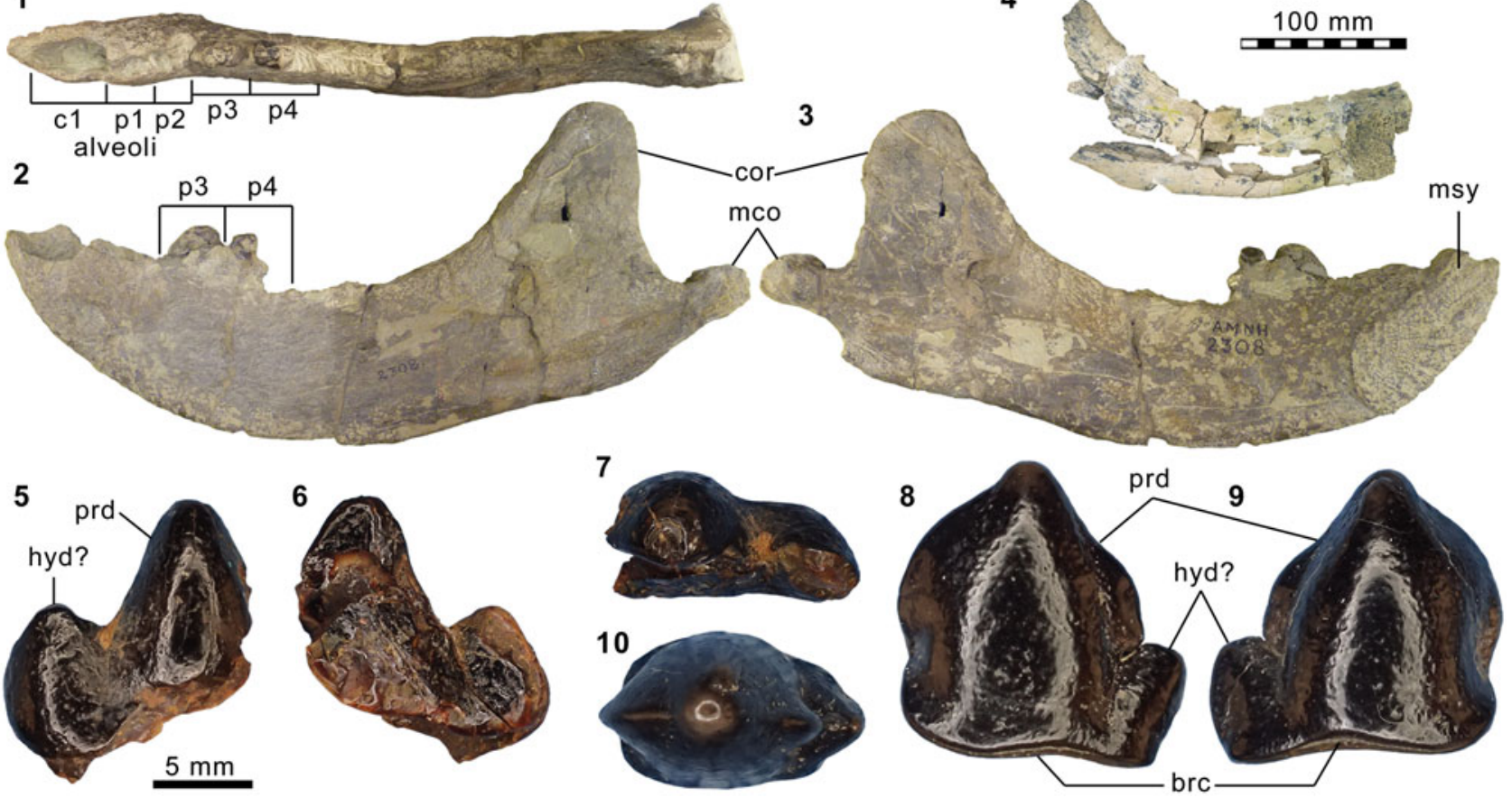

Figure 7. Mesonychid Harpagolestes Wortman, 1901b, and indeterminate ?mesonychians from the Washakie Formation. (1-3) Left dentary of AMNH FM 2308 (Harpagolestes sp. indet.) in superior (1), lateral (2), and medial (3) views; (4) left dentary of FMNH PM 39952 (Synoplotherium sp. indet.) in medial view; (5-7)? right ?dpx of UCMP 81353 (Mesonychia? gen. indet.) in labial (5), lingual (6), and occlusal (7) views; (8-10) ?left ?dpx of UCMP 81354 (Mesonychia? gen. indet.) in labial (8), lingual (9), and occlusal (10) views. Different scales apply to Figure 7.1-7.4 (100 mm) and 7.5-7.10 (5 mm). Abbreviations: brc, basal rim of crown; cor, coronoid process; mco, mandibular condyle; hyd?, basal cuspid interpreted as hypoconid; msy, mandibular symphysis; prd, protoconid.

1986; see Campisano et al., 2014, for geochronology). Although we have not been able to examine the specimen (and it may well be generically indeterminate), we note the possibility that it belongs instead to the large form of Synoplotherium reported here, which is more securely known from Uilb than Hessolestes.

Genus-level classifications of middle Eocene mesonychids remain problematic more than 50 years after the major systematic work of Szalay and Gould (1966). The isolated lower cheek teeth that we refer to the large morphotype of Synoplotherium cannot be readily distinguished from those belonging to the lost holotype of 'Harpagolestes' koreanicus from the middle or late Eocene of the Korean Peninsula (Shikama, 1943, figs. 1, 2; see also Tomida and Lee, 2004), which, in turn, may be closely related to ?Harpagolestes orientalis from the middle Eocene of east Asia (Szalay and Gould, 1966; Jin, 2005). The generic allocation of ?H. orientalis has been in doubt since the time of its original description, and Szalay and Gould (1966) noted that with regard to the morphology of the posterior portion of palatine, it resembled S. lanius more than Harpagolestes.

\section{Genus Harpagolestes Wortman, 1901b}

Type species.-Harpagolestes macrocephalus Wortman, 1901b, by original designation.

\section{Harpagolestes immanis Matthew, 1909}

1909 Harpagolestes immanis Matthew, p. 497, figs. 97-100. 1966 Harpagolestes immanis; Szalay and Gould, p. 143.
1998 Harpagolestes immanis; Archibald, p. 319.

Holotype.-AMNH FM 13143, cranium and mandible.

Locality.-AMNH locality recorded on specimen label as north side of Haystack Mountain, Washakie Basin, Sweetwater County, Wyoming. (Matthew, 1909; see also Szalay and Gould, 1966).

Horizon.-Unknown portion of Twka2 ("upper Washakie" according to Matthew, 1909, p. 490), Adobe Town Member, Washakie Formation.

Occurrence.-Twka2, Adobe Town Member, Washakie Formation, Washakie Basin, Sweetwater County, Wyoming (Matthew, 1909). Late Bridgerian (Br3) or early Uintan (Ui1b) NALMA. Known from holotype only.

Remarks.-The holotype AMNH FM 13143 was described in detail by Matthew (1909). Szalay and Gould (1966, p. 143-144) considered the morphological characteristics of Harpagolestes immanis listed by Matthew (1909) to not be reliably diagnostic at the species level, and suggested that $H$. immanis and $H$. uintensis (Scott, 1888) might be conspecific. They did not, however, formally synonymize the two taxa, citing the limited number of known specimens.

Harpagolestes sp. indet. Figure 7.1-7.3

Materials from Washakie Basin.-AMNH locality recorded as south of Haystack Mountain in "Middle Washakie" on 
specimen label (presumably Twka1; see Wood, 1927, p. 191, for discussion of "Middle Washakie" Formation): AMNH FM 2306, partly prepared partial right and left dentaries with heavily damaged teeth; AMNH FM 2307, partial right dentary with p3-4 and associated dentary fragments; AMNH FM 2308, left dentary with p3 and broken p4; AMNH FM 93453, fragments of dentary and ?right $\mathrm{c} 1$.

AMNH locality recorded as Haystack Mountain on specimen label (Twkal or Twka2): AMNH FM 145562, partial right dentary with roots of $\mathrm{c} 1-\mathrm{m} 2$.

CM locality recorded as north flank of Haystack Mountain (Twka1 or Twka2): CM 9420 (we examined its cast, FMNH PM 70166), right dentary with $\mathrm{p} 3$ to partial $\mathrm{m} 3$ and associated canine.

Remarks.-We have not attempted species-level identification of the referred specimens because of the taxonomic issues noted above (see Remarks under Harpagolestes immanis). AMNH FM 93453, consisting of highly fragmentary, partly unprepared mandibular fragments and ?right $\mathrm{cl}$, was originally cataloged as "Mesonyx" but most likely belongs to the same individual as AMNH FM 2306, which was collected under the same field number.

\section{Mesonychia? gen. indet. Figure 7.5-7.10}

Materials.-UCMP locality V78102 ('Granger Horizon 17 General'; Twka2): UCMP 81353, ?right ?deciduous premolar; UCMP 81354, ?left lower premolar or molar.

Remarks.-The two referred specimens are from the same locality and horizon (Lester Kent's 'level 2') as UCMP 81352, which we referred to Synoplotherium sp. indet. above, and it is possible, if unlikely (see below), that all three represent the same taxon. In any case, the varying dental-wear stages exhibited by the three specimens suggest that they belonged to different individuals. All three specimens are from Granger's (1909) stratum no. 17, which is equivalent to Roehler's bed 633 (Roehler, 1992) and is within the early Uintan portion of Twka2.

We tentatively interpret UCMP 81353 (Fig. 7.5-7.7) to represent a right deciduous premolar missing its anterior extremity based on the apparent absence of a sharp notch between the two preserved cuspids, which is typically present between the protoconid and hypoconid of a permanent cheek tooth in mesonychids. Nevertheless, the possibility of it being a posteriorly damaged left deciduous premolar cannot be entirely discounted. It differs from the permanent cheek teeth of Mesonyx, Synoplotherium (Fig. 3.11-3.22), and Harpagolestes (cf., Matthew, 1909; Szalay and Gould, 1966; Jin, 2005) in its labiolingually thin, anteroposteriorly symmetrical (in profile) protoconid with a nearly vertical lingual wall. In these respects, UCMP 81353 appears to resemble the dp4 of Dissacus zengi Ting et al., 2004 from the early Eocene of China (Ting et al., 2004), although the cuspids are less blade-like. The size of the tooth is roughly comparable to the known lower cheek teeth of the Bridgerian $(\mathrm{Br} 2)$ hapalodectid mesonychian Hapalorestes lovei Gunnell and Gingerich, 1996 from the Aycross Formation of northwestern Wyoming, but the protoconid of UCMP 81353 lacks the distinct leaf-shaped profile seen in the latter taxon (cf., Gunnell and Gingerich, 1996). Thus, we are unable to identify this specimen at the level of family or below.

UCMP 81354 (Fig. 7.8-7.10) is unworn and appears to represent the complete enamel layer of a hollow crown (devoid of the dentine core). The conspicuous enamel rim along the base of the crown is suggestive of a permanent tooth (in our observation, deciduous teeth of placental mammals tend to have more weakly delineated enamel-dentine junctions). However, unlike the permanent cheek teeth of Mesonyx, Synoplotherium, and Harpagolestes, the protoconid of this specimen lacks a strong posterior inclination, and the tooth bears only one basal cuspid, which we interpret as a hypoconid; this cuspid is separated from the protoconid by a small notch. The main body of the protoconid is roughly conical in form, which is in contrast to the labiolingually compressed protoconids in Hapalorestes lovei, and gives rise to expanded (though not particularly sharp) anterior and posterior ridges that give the cuspid a peculiar, leaf-shaped profile. This tooth seems compatible in size with UCMP 81353, but differs considerably in form, having an anteroposteriorly longer protoconid and a proportionately much smaller hypoconid. Deciduous cheek teeth of mesonychids, though poorly known, do not seem to differ greatly in morphology from their permanent counterparts (see e.g., Fig. 3.9, 3.10; Osborn and Wortman, 1892, fig. 12; Ting et al., 2004, fig. 5). Thus, the crown morphology also makes it unlikely that UCMP 81354 represents a deciduous tooth of a known mesonychian genus, and we tentatively regard it as a permanent lower cheek tooth of an as-yet unnamed taxon. 14.3.

Measurement of UCMP 81353: $\mathrm{L}$ of preserved portion $=$

Measurements of UCMP 81354: L x W=15.3 x 10.1.

Order Oxyaenodonta sensu Zack, 2019a (amended from Van Valen, 1971)

Family Oxyaenidae Cope, 1877

Subfamily Oxyaeninae (Cope, 1877)

Genus Patriofelis Leidy, 1870a

Type species.—Patriofelis ultra Leidy, 1870a, by monotypy.

Patriofelis ferox Marsh, 1872a

Figure 8

1872a Limnofelis ferox Marsh, p. 202.

1872a Limnofelis latidens Marsh, p. 203.

1872b Oreocyon latidens Marsh, p. 406.

1892 Patriofelis? leidyanus Osborn and Wortman, p. 98, fig. $5 \mathrm{c}$.

1896 Aelurotherium leidyanum Adams, p. 442.

1901b Aelurotherium latidens Wortman, p. 202, figs. 40, 41.

1901b Aelurotherium bicuspis Wortman, p. 205, figs. 42, 43.

1902a Patriofelis ferox Wortman, p. 117, figs. 65-68, 69-iii, 70.

1909 Patriofelis ferox; Matthew, p. 420, figs. 50-52.

1923a Patriofelis ferox; Thorpe, p. 30.

1938 Patriofelis ferox; Denison, p. 173, figs. 18a, 20b, 23b, 24b, 25c, 28b, 29b, 30b.

1998a Patriofelis ferox; Gunnell, p. 95 
Holotype-YYM VP 011865, left dentary fragment with $\mathrm{m} 2$ and cranial, vertebral, and rib fragments.

Locality.-According to Marsh (1872a, p. 203), "near Henry's Fork" Bridger Basin, Sweetwater or Uinta County, Wyoming.

Horizon.-?Twin Buttes Member (?Bridger D), Bridger Formation.

Occurrence.-Blacks Fork and Twin Buttes members, Bridger Formation, Bridger Basin, Wyoming (Matthew, 1909; Gazin, 1976); Twka1 and low in Twka2, Adobe Town Member, Washakie Formation, Washakie Basin, Sweetwater County, Wyoming (Matthew, 1909; this study). Middle to late Bridgerian (Br2-Br3) NALMA.

Materials from Washakie Basin.-AMNH locality recorded as "Haystack Mountain West" (Twka1): AMNH FM 2303, left M1.

AMNH locality recorded as north of Haystack Mountain (Twka1; "2nd Bench" north of Haystack Mountain according to W. Granger's 1906 field notes on file at AMNH): AMNH FM 13145, cranium and right and left dentaries (Matthew, 1909, fig. 50);

AMNH locality recorded as north of Haystack Mountain (Twka1; "100 feet above Brown Sandstone" [presumably referring to the Lower Brown Sandstone] according to W. Granger's 1906 field notes on file at AMNH): AMNH FM 13146, right femur, right tibia, right astragalus, right calcaneum, right navicular, right cuboid, right entocuneiform, metapodial fragments, and phalanges.

FMNH locality JJF 7-27-91-1 (Twka1): FMNH PM 58111, fragments of ?right $\mathrm{P} 2$, left $\mathrm{M} 1$, and left $\mathrm{p} 4$.

FMNH locality JJF 7-24-95-1 (Twka1): FMNH PM 61168, associated right maxilla with broken teeth, left dentary fragments with unerupted $\mathrm{c} 1$ and unerupted $\mathrm{p} 3-4$, right dentary fragments with $\mathrm{m} 1$ (missing talonid) and $\mathrm{m} 2$ (lacking enamel layer), additional cranial fragments.

FMNH locality FM-6-58-WDT (Roehler's [1973] bed 621-625 in Twka2; tentatively considered $\mathrm{Br} 3$ in age; see Remarks): FMNH PM 70167, right posterior dentary fragment with badly broken $\mathrm{m} 2$ and postcranial fragments (their association with dentary is uncertain, and this specimen as presently cataloged may include elements of additional taxa).

Remarks.-Matthew (1909) provided detailed descriptions of key specimens of Patriofelis ferox from the Bridger and Washakie formations, including AMNH FM 13145 and AMNH FM 13146. The referred FMNH specimens of this taxon closely match these AMNH specimens (Fig. 8.11-8.13) in sizes and shapes, and generally appear to be somewhat larger than the middle Bridgerian $(\mathrm{Br} 2)$ species $P$. ultra (e.g., the $\mathrm{m} 1$ trigonid alone of FMNH PM 61168 has approximately the same length as the complete $\mathrm{m} 1$ of University of Utah B50, referred to $P$. ultra by Gazin, 1957); we note, however, that $P$. ferox and $P$. ultra are distinguished only by rather minor differences (in size, p2 orientation, and retention of vestigial M2 in the latter) that might instead be interpreted as temporal variations within a single evolving lineage (Matthew, 1909).
FMNH PM 61168 (Fig. 8.5-8.10) represents a juvenile individual in which: (1) DP3-4, dc1 and dp2-4 were likely still present at the time of death (judging from their roots and alveoli); (2) unerupted (completely under the gumline) c1, p3, and $\mathrm{p} 4$ had not yet completed their formation, lacking the enamel layer toward the bases of their main cuspids; (3) M1 and $\mathrm{m} 1$ were fully erupted, the latter showing slight wear along the postparacristid and preprotocristid; and (4) $\mathrm{m} 2$ was mostly or entirely unerupted and possibly incomplete in its crown formation (only an ?endocast of the right $\mathrm{m} 2$ crown is preserved). The roots of dp2 (Fig. 8.7) indicate that this tooth was oriented obliquely against the long axis of the lower tooth row, in the anterolabial-posterolingual direction. A similar condition, though perhaps less pronounced, occurs in the dp2 of YPM VPPU 011375 (holotype of Patriofelis? leidyanus, which was synonymized with P. ferox by Matthew, 1909) and has been noted for $\mathrm{p} 2$ of $P$. ferox as a diagnostic trait of the species (Matthew, 1909).

FMNH PM 70167 (Fig. 8.1-8.4) is notable for a high degree of labial rotation of the heavily worn $\mathrm{m} 2$ (tilted from the mesiodistal plane of the horizontal ramus by $\sim 29^{\circ}$; Fig. 8.3). This condition is presumably analogous to the age-related rotation of carnassial teeth in some hyaenodontids and nimravids (all hypercarinvores), which is regarded as a compensatory mechanism (via protracted dental eruption) that preserves the shearing function in response to intense dental attrition (Mellett, 1969a, b; Bryant et al., 1995). Indeed, the shear facet on the anterolabial wall of the $\mathrm{m} 2$ trigonid is roughly parallel to the mesiodistal plane of the horizontal ramus (with a slight lingual tilt), as is typical in unrotated carnassial teeth, suggesting maintenance of the shearing function in individuals of advanced ages.

The morphology of FMNH PM 70167 is compatible with Patriofelis ferox. It represents the sole occurrence of this genus within Twka2, and adds to the mounting evidence for a $\mathrm{Br} 3$ age (or more conservatively a pre-Uilb age) of the lower portion of that unit. Its locality (FM-6-58-WDT) is positioned stratigraphically low in the unit (recorded in the FMNH database as occurring at or below Roehler's [1973] bed 625; see also Turnbull, 1978), and has yielded a referred specimen FMNH PM 44655 of the brontothere Metarhinus fluviatilis Osborn, 1908 - a species that is elsewhere known only from Uintan-aged rocks (Mihlbachler, 2008). Thus, if our interpretation is correct, the latter specimen extends the temporal range of $M$. fluviatilis into the late Bridgerian, or potentially the earliest Uintan (U1a), depending on where better faunal evidence places the Bridgerian-Uintan NALMA boundary within this formation.

Measurements of FMNH PM 58111: P2 L x W $=\sim 12.8 \mathrm{x}$ 12.3; $\mathrm{M} 1 \mathrm{~W}=\sim 18.4$; 4 labiolingual width of preserved posterior portion $=14.4$;

Measurements of FMNH PM 61168: DP4 alveolar L x W = $\sim 14$ x 15.2; M1 alveolar L x W $=\sim 31$ x $\sim 22$; dp2-4 alveolar row $\mathrm{L}=\sim 36$; $\mathrm{m} 1$ trigonid $\mathrm{L} \times \mathrm{W}=>16.3 \times 8.95$.

Measurement of AMNH FM 2303: M1 L x W=28.0 x 16.9.

Subfamily Machaeroidinae Matthew, 1909

Machaeroidinae gen. indet.

Figure 9.1-9.4 

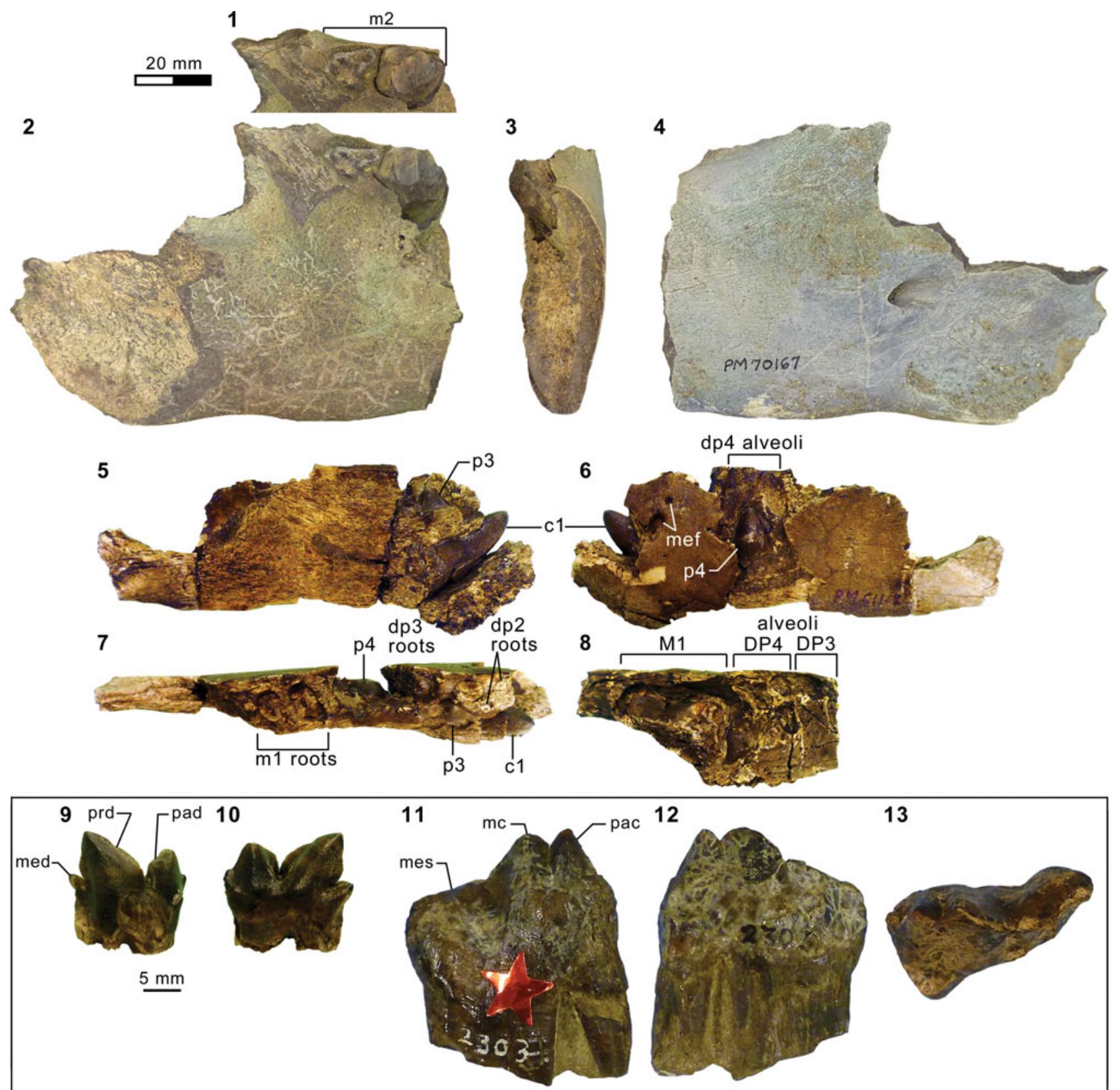

13

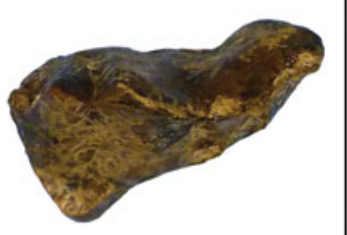

Figure 8. Oxyaenid Patriofelis ferox Marsh, 1872a, from the Washakie Formation. (1-4) posterior fragment of right dentary of FMNH PM 70167, showing occlusal view of $\mathrm{m} 2$ (1) and the whole piece in lateral (2), anterior (3), and medial (4) views; (5-10) left dentary fragment of FMNH PM 61168 in medial (5), lateral (6), and superior (7) views, right maxillary fragment in inferior view (8), and right $\mathrm{m} 1$ (missing talonid) in labial (9) and lingual (10) views; (11-13) left M1 of AMNH FM 2303 in labial (11), lingual (12), and occlusal (13) views. 8.1-8.8 and 8.9-8.13 at two different scales. Abbreviations: mc, metacone; med, metaconid; mef, mental foramina; mes, metastylar blade; pac, paracone; pad, paraconid; prd, protoconid.

Description.-FMNH PM 1506 is missing the paraconid and much of the protoconid. A vestigial metaconid is present. The peculiar talonid bears a moderately tall median ridge (= hypocristid), which is separated from the trigonid by a small notch and runs anteroposteriorly. Lingual to the hypocristid, the talonid is a largely flat, gently inclined shelf that lacks a raised lingual ridge. Measurements: length and width of preserved portion $=4.2 \times 2.8$, talonid $\mathrm{L}=2.1$.

Materials.-FMNH locality FM-6-56-WDT (Twka2): FMNH PM 1506, posterior fragment of right ?m1.
Remarks. - The pronounced labiolingual compression of the trigonid, the greatly reduced metaconid, and the lack of a lingually closed talonid basin all point to a machaeroidine affinity of FMNH PM 1506. This specimen is nevertheless clearly distinct from $\mathrm{m} 1$ of the Bridgerian taxon Machaeroides eothen Matthew, 1909 (e.g., USNM PAL 361372; Fig. 9.5, 9.6) in having a more elongate talonid and a more posterior (rather than posterolingual) orientation of the hypocristid. Additionally, FMNH PM 1506 differs from the much larger Uintan machaeroidine Apataelurus kayi Scott, 1937 in retention of a small metaconid on $\mathrm{m} 1$. 

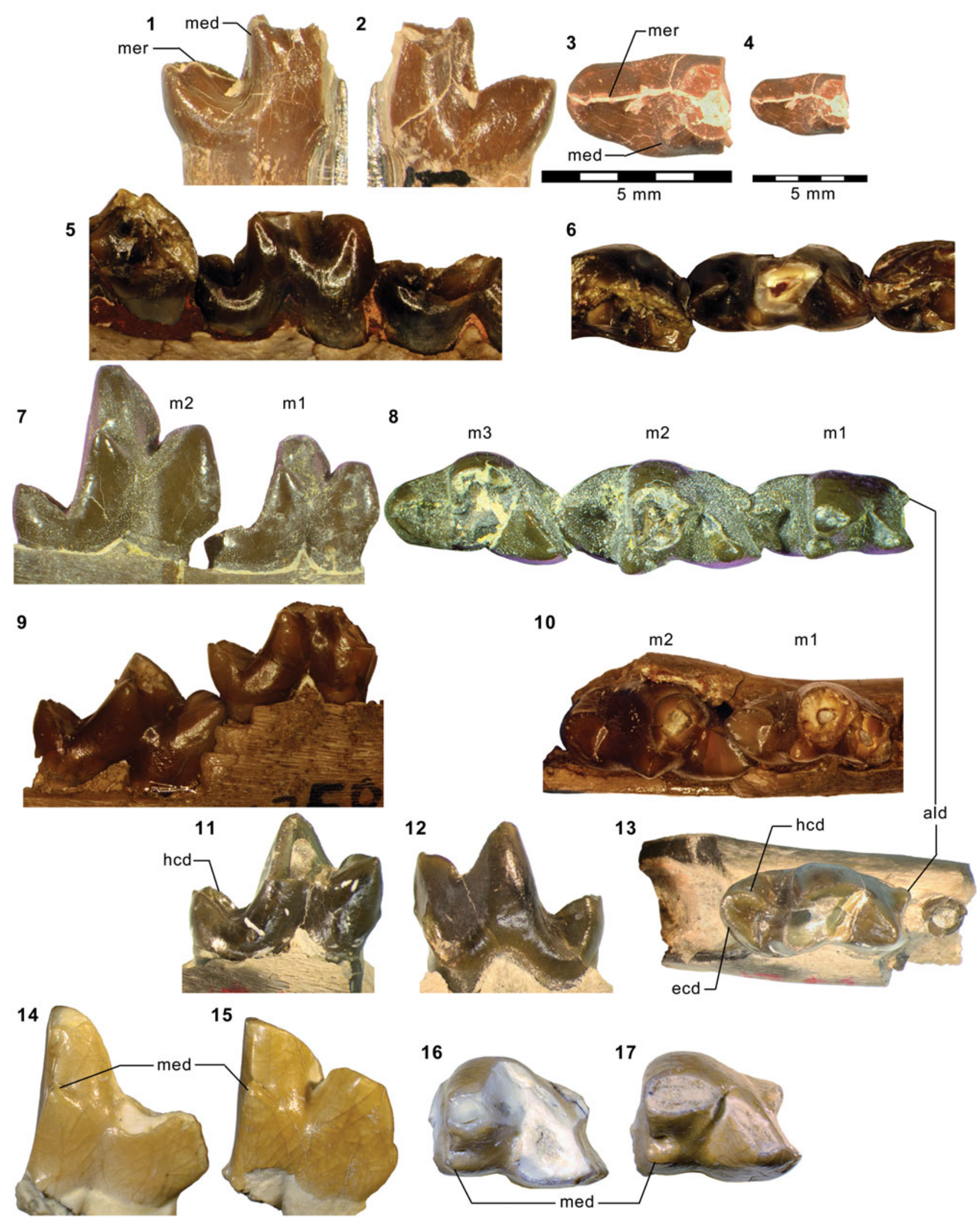

Figure 9. Comparison of machaeroidines and hyaenodontid Tritemnodon Matthew, 1906, from middle Eocene of Rocky Mountain region. (1-4) Right ?m1 of FMNH PM 1506 (Machaeroidinae gen. indet.; Twka2) in lingual (1; inverted), labial (2; inverted), and occlusal (3, 4; inverted) views (Fig. 9.4 at same scale as 9.5-9.17 for size comparison); (5, 6) right p4-m2 of USNM PAL 361372 (Machaeroides eothen Matthew, 1909; Bridger B, Br2 age) in reversed lingual (5) and occlusal (6) views; (7, 8) left m1-2 of UW 2406 (Tritemnodon sp.; Bridger A, Brlb age) in lingual view (7) and right m1-3 of same specimen in reversed occlusal view (8); (9, 10) left m1-2 of USNM PAL 361350 (T. agilis Marsh, 1872a; Bridger B, Br2 age) in lingual (9) and occlusal (10) views; (11-13) left m1 of FMNH PM 55839 (Tritemnodon sp.; Twka1, Br3 age) in lingual (11), labial (12), and occlusal (13) views; (14-17) left m2 or m3 of UW 14338 and UW 15258 (both from ?Br3 age Blue Point Marker of Absaroka Range, referred to Tritemnodon by Eaton, 1982) in lingual (14 and 15, respectively) and occlusal (16 and 17, respectively) views. Figure 9.1-9.3 and 9.4-9.17 at two different scales. Abbreviations: ald, anterolabial cingulid; ecd, entocristid; hcd, hypocristid; med, metaconid; mer, median ridge of talonid. 
SMNH P1654.345 from the ?late Uintan Swift Current Creek local fauna of the Cypress Hills Formation, Saskatchewan, Canada, was reported as an unnamed "advanced" species of the viverravid carnivoramorphan Viverravus by Storer (1984, p. 54, fig. 6C; see Storer, 1996, on biochronology). Based on the published figure, this specimen, which is represented by an isolated $\mathrm{m} 1$, does not exhibit any diagnostic feature of Viverravus or any viverravid. Instead, the combination of: (1) the presence of a cuspulid formed by the anterolabial cingulid; (2) the high degree of labiolingual compression of the trigonid with reduced metaconid; and (3) the posteriorly tapering, only weakly basined talonid with a trenchant hypocristid, as described and illustrated by Storer (1984), is suggestive of an affinity with machaeroidines or, less convincingly, hyaenodontids with hypercarnivorous tendency such as Tritemnodon (e.g., see discussion of FMNH PM 55839 below). While SMNH P1654.345 likely does not represent the same taxon as FMNH PM 1506 (the former is appreciably smaller, and the hypocristid is not as straight in occlusal view), the two specimens together provide new evidence for the presence of very small non-carnivoramorphan hypercarnivores in the Uintan of North America.

Order Hyaenodonta sensu Solé, 2013 (amended from Van Valen, 1967)

Family Hyaenodontidae Leidy, 1869

Subfamily Sinopaninae Solé, 2013

Genus Tritemnodon Matthew, 1906

Type species.-Tritemnodon agilis Marsh, 1872a, by subsequent designation (Matthew, 1909).

\section{Tritemnodon sp.}

Figure 9.11-9.17

Description.-The m1 of FMNH PM 55839 is missing the tips of the protoconid and metaconid, but otherwise is well preserved, with no sign of wear. The anterolabial cingulid is well developed and forms an incipient cuspulid (= "mesiobuccal cingulid" of Zack, 2011), but there are no other cingulids. The trigonid is roughly twice as long as the talonid, and has a widely open appearance, owing to the relatively posterior position of its posterolingual base and the predominantly anteroposterior orientation of the labial wall of the protoconid. The anterior portion of the prevallid (i.e., labial wall of the paraconid) rises vertically with little lingual inclination, making the paraconid appear robust in occlusal view. The paraconid bears a sharp postparacristid that terminates with a carnassial notch. Although the tip of the metaconid is missing, the preserved portion of the trigonid is suggestive of a metaconid that was much smaller than the paraconid. The pronounced lingual inclination of the labial wall of the talonid results in a labiolingually narrow talonid basin. The rather trenchant hypocristid and entocristid give the talonid basin a trough-like appearance. There is no sharp notch at the anterior end of the hypocristid.

Measurements: $\mathrm{m} 1 \mathrm{~L} \mathrm{x} \mathrm{W}=8.1 \times 3.9 ; \mathrm{m} 1$ trigonid $\mathrm{L}=5.8$; dentary depth below $\mathrm{m} 1$ (on lateral side at the level of junction between anterior and posterior roots) $=11.0$.
Materials from Washakie Basin.-FMNH locality FM-1-67WDT (Twka1): FMNH PM 55839, dentary fragments with left $\mathrm{m} 1$, fragments of vertebra and right ulna.

Materials from Absaroka Range.-UW locality V-78001 (Blue Point marker bed): UW 14338, trigonid of left $\mathrm{m} 2$ or $\mathrm{m} 3$; UW 15258 , trigonid of left $\mathrm{m} 2$ or $\mathrm{m} 3$.

Remarks.-The m1 of FMNH PM 55839 resembles that of the machaeroidine Machaeroides eothen (Fig. 9.5, 9.6) in its labiolingually compressed trigonid and reduced, steeply rising (in profile) talonid, but differs from that taxon in the smaller size of a shearing blade formed by the hypocristid and the lack of a deep notch at the junction of the hypocristid and trigonid. While these features frequently are obliterated in specimens with tooth wear, the specimen from Twkal shows no appreciable wear. Given these traits, we refer FMNH PM 55839 to Tritemnodon, but note that the greater anteroposterior orientation of the prevallid, very steep posterior ascent of the hypocristid, and the narrower talonid basin distinguish it from geologically older samples of that genus, such as UW 2406 (Tritemnodon sp.; Fig. 9.7, 9.8) from the Brlb-age Bridger A interval and USNM PAL 361350 (T. agilis; Fig. 9.9, 9.10) from the Br2-age Bridger B interval.

The genus Tritemnodon is poorly known from the late Bridgerian (Br3). Outside the Washakie Basin, only two partial teeth have been reported as "cf. Tritemnodon" from the Blue Point marker bed in the Absaroka Range (Eaton, 1982), which has been dated at $48.41 \pm 0.17 \mathrm{Ma}$ (close in age to the Henrys Fork tuff in Bridger C; Smith et al., 2010). We concur with Eaton's (1982) genus-level identification of the two specimens (UW 14338 and UW 15258; Fig. 9.14-9.17), although they both appear to represent the trigonids of $\mathrm{m} 2$ or $\mathrm{m} 3$ instead of $\mathrm{m} 1$ as originally suggested, judging from the greater lingual extent of the paraconid relative to that of the metaconid. These specimens may have formed the basis for the purported $\mathrm{Br} 3$ occurrence of T. agilis listed in Gunnell et al.'s (2009) faunal table. However, UW 14338 and UW 15258, as well as FMNH PM 55839, are marked by larger sizes and further-reduced, lessconical metaconids compared to specimens of Tritemnodon from the Bridger Formation, including T. agilis (USNM V 5917; horizon unknown). As such, the specimens from the Blue Point marker bed and Twkal of the Washakie Formation may represent a new species of Tritemnodon.

\section{Genus Sinopa Leidy, 1871}

Type species.—Sinopa rapax Leidy, 1871, by monotypy.

Other species._Sinopa jilinia Morlo et al., 2014, S. lania Matthew, 1909, S. longipes (Peterson, 1919) new combination (type species of Mimocyon), S. major Wortman, 1902a, S. minor Wortman, 1902a, S. piercei (Bown, 1982) new combination (type species of Proviverroides), and S. pungens (Cope, 1872e) (type species of Stypolophus).

Emended diagnosis (modified from Morlo et al., 2014).Sinopanine with $\mathrm{p} 1$ single-rooted; $\mathrm{p} 2$ smaller than $\mathrm{p} 3$; $\mathrm{p} 4$ longer than $\mathrm{m} 1$; premolars never in a crowded position; 
premolar cingulids weak if present; $\mathrm{p} 4$ with an incipient to small protostylid on the posterior slope of the protoconid; $\mathrm{p} 4$ talonid broad and with a weak basin; m3 never substantially larger than $\mathrm{m} 2$, but mostly smaller than $\mathrm{m} 1$; metaconids of $\mathrm{m} 1-3$ only slightly reduced relative to paraconids and placed directly lingual to the protoconid; talonids about as long and broad as trigonids; talonids basined with entoconid, and hypoconulid incorporated into a tall, continuous crest at the lingual talonid margin; entoconid apex indistinct; hypoconid apex well separated from hypoconulid; cristid obliqua contacting trigonid fairly labially; labial cingulid of molars extended posteriorly and surrounding the hypoconid (except in $S$. rapax and $S$. pungens); parastyles on M1-2 small and directed anteriad or anterolabiad; paracone and metacone separated almost to bases on M1-2; metastyle on M1-2 relatively short and transverse; molar conules large and triangular, with welldeveloped internal conular cristae; protocones on P4-M3 large and elongate; posterior cingulum strong on M1-2, may join with anterior cingulum lingual to protocone.

Remarks.-It is beyond the scope of this contribution to fully revise the taxonomy of Sinopa, a process begun by Morlo et al. (2014). The present contribution focuses on taxa relevant to the Washakie Formation, particularly S. lania and $S$. major. In the course of reevaluating the latter species, it became clear that two hyaenodontid genera, Mimocyon and Proviverroides, are more appropriately considered junior synonyms of Sinopa.

Proviverroides was named by Bown (1982) for a new species, $P$. piercei, from the Bridgerian Aycross Formation in north central Wyoming based on a single specimen (USGS 1984, now USNM PAL 521259) comprising much of the upper and lower cheek dentition (Figs. 11.18, 12.11). The new genus was contrasted with Arfia, Prototomus, "Proviverra" (including Sinopa, following Van Valen, 1965), and Tritemnodon. Distinctions from "Proviverra" (likely based on comparisons to Sinopa, as only species of Sinopa are referred to) were limited to larger paraconids on p3-4 and the presence of a robust $\mathrm{p} 4$ talonid. Based on our examination of USNM PAL 521259, Proviverroides piercei is very similar to Sinopa, a conclusion in agreement with Morlo et al. (2014), who described $P$. piercei as the closest relative of Sinopa and with Solé (2013), who recovered Proviverroides and Sinopa as sister taxa.

Of the features cited by Bown (1982), P. piercei does have particularly strong paraconids on $\mathrm{p} 3$ and $\mathrm{p} 4$, but the $\mathrm{p} 4$ talonid is no more robust than in other large Sinopa (e.g., $S$. major; Figs. 12, 13). Other potential distinguishing features were identified by Morlo et al. (2014), including a doublerooted $\mathrm{p} 1$, more transverse prevallid blades, and more elongate talonids. However, the first of these cannot be evaluated because p1 (or its alveoli) is not preserved in the type and only known specimen of $P$. piercei. The other two distinctions are artifacts of heavy wear in USNM PAL 521259, which has foreshortened the trigonids on $\mathrm{m} 1-2$. The single remaining diagnostic feature of large premolar paraconids is, in our opinion, not sufficient to merit generic distinction, and it is difficult to diagnose Sinopa if $P$. pierce $i$ is excluded. Accordingly, Proviverroides is placed in synonymy with
Sinopa, and Proviverroides piercei is recombined as Sinopa piercei n. comb.

Mimocyon was named by Peterson (1919) for CM 3022, comprising a dentary fragment with p4-m1 and associated canine and postcranial material, including a distal humerus and much of the pes, from Myton Pocket in the Uintan-age Uinta Formation of Utah. Peterson (1919) considered Mimocyon longipes to be a miacid, but Dawson (1980) recognized the hyaenodontid affinities of the taxon, placing Mimocyon in synonymy with "Proviverra." As with Bown's (1982) description of Proviverroides, Dawson's (1980) use of "Proviverra" appears to have followed Van Valen (1965) and included Sinopa, a synonymy that is strongly rejected by all modern phylogenetic assessments (Polly, 1996; Solé, 2013; Rana et al., 2015; Borths et al., 2016). Flynn and Galiano (1982) were more explicit, noting strong similarities of $M$. longipes to "Proviverra" major (=Sinopa major). Our own assessment of $M$. longipes, based on the type and on a maxilla from the type locality (MCZ VPM 8622), agrees with Flynn and Galiano (1982). The morphology of the species is very similar to that of large species of Sinopa, differing primarily in having a $\mathrm{p} 4$ that is relatively tall for its length. Beyond this, the preserved morphology of both specimens closely matches that of other large Sinopa. As with Proviverroides, Mimocyon is placed in synonymy with Sinopa, with $M$. longipes recombined as Sinopa longipes n. comb. This may be consistent with Dawson's (1980) intent, although she did not indicate why she considered Mimocyon a synonym of Proviverra.

\section{Sinopa lania (Matthew, 1909)}

Figures 10, 11.16, 12.12

1909 Sinopa rapax mutation lania Matthew, p. 472, pl. 45, fig. 3, pl. 47, fig. 1.

1998a Sinopa rapax (in part); Gunnell, p. 97.

2014 Sinopa lania; Morlo et al., p. 116, 119 (new rank).

Holotype.-AMNH FM 13142, cranium with right C1-M3 and left I2-M2, right dentary with i3-p1, dp3, p4-m3, left dentary with $\mathrm{c} 1, \mathrm{p} 2-\mathrm{m} 3$, partial skeleton including left ulna (missing distal end), left proximal and distal radius, left manus, right femur and tibia, left distal tibia, left pes, and $\sim 16$ vertebrae including first through 4th cervical.

Locality.-AMNH locality recorded as "east end of Haystack Mountain” Washakie Basin, Sweetwater County, Wyoming.

Horizon.-Fifteen feet below "white layer" (= Granger's [1909] stratum no. 11) according to W. Granger's 1906 field notes on file at AMNH; approximately bed 619 of Roehler (1973; see Remarks below), Twka1, Adobe Town Member, Washakie Formation (see also Matthew, 1909).

Occurrence.-Twka1, Adobe Town Member, Washakie Formation, Washakie Basin, Sweetwater County, Wyoming (Matthew, 1909). Late Bridgerian (Br3) NALMA. Known from holotype only.

Description of Basicranium.-Matthew (1909) briefly described AMNH FM 13142, emphasizing aspects of its dental morphology. However, much of the specimen has 

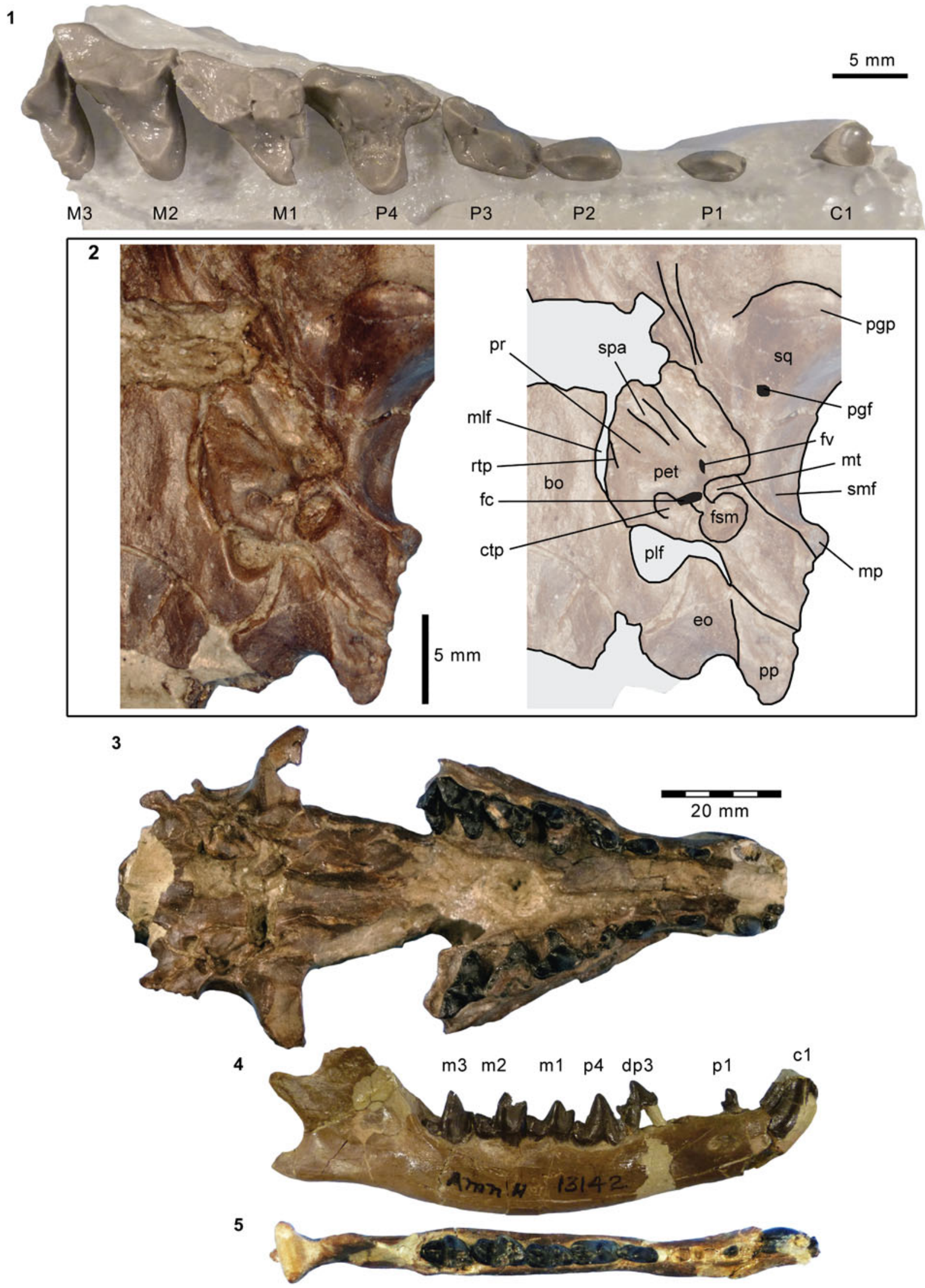
Figure 10. Skull of holotype AMNH FM 13142 of hyaenodontid Sinopa lania Matthew, 1909, from the Washakie Formation. (1) Right C1-M3 in occlusal view (cast; transparency of maxilla digitally modified to enhance visibility); (2), left auditory region (anterior to top); (3), cranium in inferior view; $(\mathbf{4}, \mathbf{5})$, right dentary in lateral (4) and superior (5; inverted) views. Same $20 \mathrm{~mm}$ scale applies to Figure 10.3-10.5. Abbreviations: bo, basioccipital; ctp, caudal tympanic process of the petrosal; eo, exoccipital; fc, fenestra cochleae; fsm, stylomastoid foramen; fv, fenestra vestibuli; mp, mastoid process; mlf, medial lacerate foramen; mt, mastoid tubercle; pet, petrosal; pgf, postglenoid foramen; pgp, postglenoid process; plf, posterior lacerate foramen; pp, paroccipital process; pr, promontorium; rtp, rostral tympanic process of the petrosal; spa, sulcus for promontory artery; sq, squamosal; smf, suprameatal fossa.

never been described, including a nearly complete, well-preserved left auditory region. Because the auditory morphology of Sinopa has only been superficially described and illustrated (Matthew, 1906), we take the opportunity to illustrate and briefly describe the basicranium of AMNH FM 13142 (Fig. 10.2).

As with most hyaenodontids, there is no evidence of an auditory bulla, indicating that the bulla was either unossified or weakly attached to the basicranium. Anterolaterally, the squamosal preserves a strong, ventrally projecting postglenoid process that curves slightly anteriorly near its tip. On the posterior surface of the postglenoid process, near its medial base, is a small postglenoid foramen. Posterior to the postglenoid process, the squamosal forms the roof of the external auditory meatus. A shallow, weakly defined suprameatal fossa is present on the posterior half of the meatus. The squamosal continues posteriorly to form a low, blunt, laterally directed mastoid process. Posterior and medial to the mastoid process, the squamosal meets the mastoid portion of the petrosal in a well-defined linear suture.

The promontorium is flat and almond shaped, with its apex directed anteriad and somewhat mediad. The anterior two thirds of the medial margin of the promontorium is thickened to form a rostral tympanic process, similar to the condition in Proviverra typica Rütimeyer, 1862 but somewhat shorter (Dubied et al., 2019). The anterior margin of the rostral tympanic process is rugose, consistent with contact with a bullar element. Anterolaterally, there is a shallow groove, presumably for the promontorial artery. There is no clear impression for the stapedial artery. Lateral to the promontorium, the petrosal forms the roof of a shallow epitympanic recess. The fenestra vestibuli is small and oriented laterad, while the fenestra cochleae is somewhat larger and oriented posteriad. Immediately posterior to the fenestra cochleae is a caudal tympanic process that helps to define the stylomastoid foramen. The lateral border and floor of the stylomastoid foramen is formed by the mastoid tubercle, which, in turn is part of the petrosal rather than the squamosal. The mastoid tubercle approaches, but does not contact, the caudal tympanic process, leaving a small gap ventromedially. Posterolaterally, there is a wide mastoid exposure of the petrosal.

The promontorium is in contact with the basioccipital posteromedially, anterior to which the promontorium and basioccipital are separated by a narrow medial lacerate foramen. Posterior to the contact is a large, well-defined posterior lacerate foramen. The latter foramen is largely circular, but there is a narrow posterolateral extension between the exoccipital and the mastoid exposure of the petrosal. The suture between the basioccipital and exoccipital is not clear. At the posterolateral corner of the skull, the exoccipital forms a small, posteriorly directed paroccipital process.

Remarks.-AMNH FM 13142 is the only reported AMNH specimen of Sinopa from the Washakie Formation. As such, it almost certainly corresponds to the specimen of Sinopa from "immediately below stratum No. 11" reported by Granger (1909, p. 20) and later by Roehler (1973, table 2) as "Sinopa sp." from approximately his bed 619. These horizons are near the top of Twka1.

Matthew (1909) considered AMNH FM 13142 to be a "mutation" (p. 472), or a unique morphotype, of Sinopa rapaxa species that otherwise is not clearly present in the late Bridgerian. Morlo et al. (2014) provisionally elevated Matthew's morphotype to a new species, Sinopa lania, distinguishing it from $S$. rapax based on more open molar trigonids, $\mathrm{m} 3$ larger than $\mathrm{m} 1$, and a shorter olecranon process of the ulna. Regarding these features, we note that: (1) the differences in trigonid openness are subtle (compared to, e.g., AMNH FM 11542; Fig. 12.13), although the labial shearing surface of the $\mathrm{m} 1$ trigonid in S. lania seems to be somewhat expanded by the more posterior orientation of the protoconid (Fig. 12.12); and (2) some individuals of $S$. rapax (e.g., AMNH FM 11542; Fig. 12.13) also possess $\mathrm{m} 3 \mathrm{~s}$ that are larger than $\mathrm{m} 1 \mathrm{~s}$, but not to the same degree as in S. lania (Table 3).

In our view, the species-level distinction between $S$. lania and $S$. rapax becomes clearer through examination of molar-size ratios relative to dental developmental models projected on morphospaces (Fig. 14.5): AMNH FM 13142 falls inside a region of morphospace that is consistent with a general inhibitory cascade model, which would predict gradual reduction or enlargement of successive molars depending on the ratio of activators and inhibitors of tooth formation (cf., Kavanagh et al., 2007; Polly, 2007); in contrast, specimens of $S$. rapax fall outside of this region (note that this observation would not be affected by sometimes heavy wear of $\mathrm{m} 1 \mathrm{~s}$, because any inflation of the ratios resulting from it would only shift the data points parallel to the isocline). The offset of $\sim 0.3$ units in the $\mathrm{m} 3 / \mathrm{m} 1$ ratio exceeds the typical intraspecific variation in that index in a wide range of mammals, including extant canids and extinct meridiungulates (Wilson et al., 2012; Asahara, 2013). The position of AMNH FM 13142 signals a potentially fundamental change in the mode of molar development (e.g., early arrest of $\mathrm{m} 3$ development is turned off; cf., Kavanagh et al., 2007), which adds to the support for recognition of a separate species. Among ancestrally carnivorous groups of mammals in which (1) the size of $\mathrm{m} 2$ exceeds that of $\mathrm{m} 1$ and (2) $\mathrm{m} 3$ is retained (e.g., dasyuromorphian marsupials, hyaenodontids, and ursids), an increase in the $\mathrm{m} 3 / \mathrm{m} 1$ size ratio appears to correspond to greater degrees of carnivory (cf., Asahara et al., 2016, fig. 1a). Thus, the relative enlargement of m3 in AMNH FM 13142 compared to geologically older $S$. major and $S$. rapax may reflect a shift toward more carnivorous diet (note that the erupting left $\mathrm{m} 3$ in Fig. 12.12 [inverted] appears smaller than its actual size; we measured the more erupted right $\mathrm{m} 3$ in Fig. 10.4, 10.5). 
1

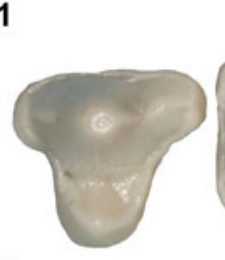

2

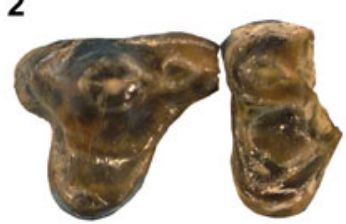

3

4

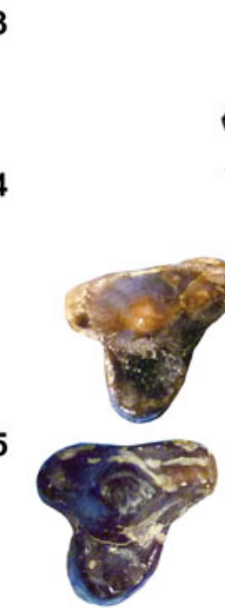

6

8

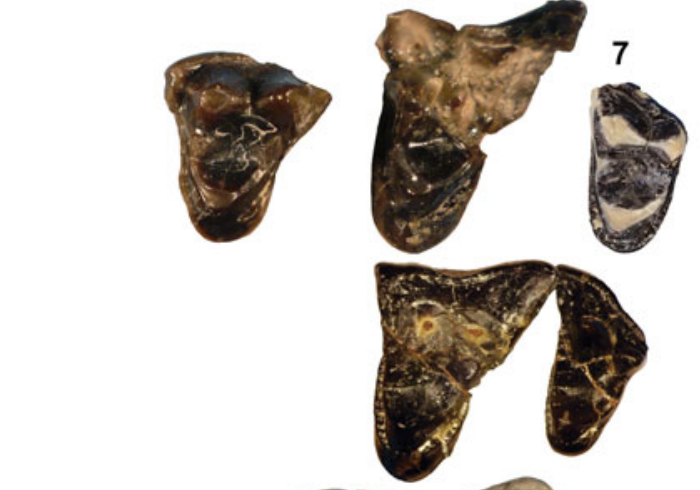

8
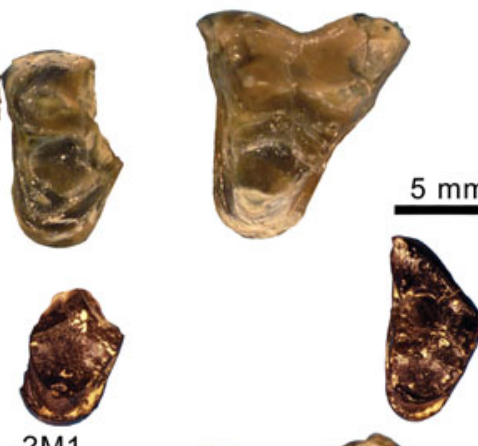

6

9

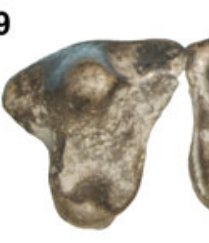

10
$5 \mathrm{~mm}$
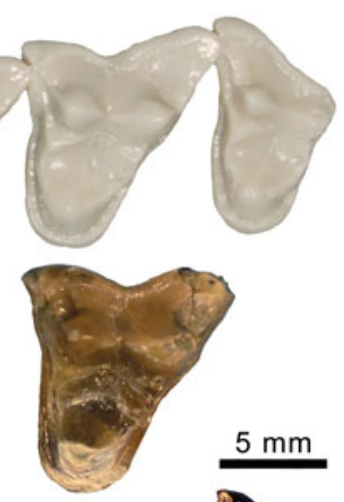

罢

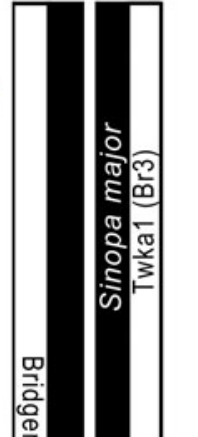

$P 4$
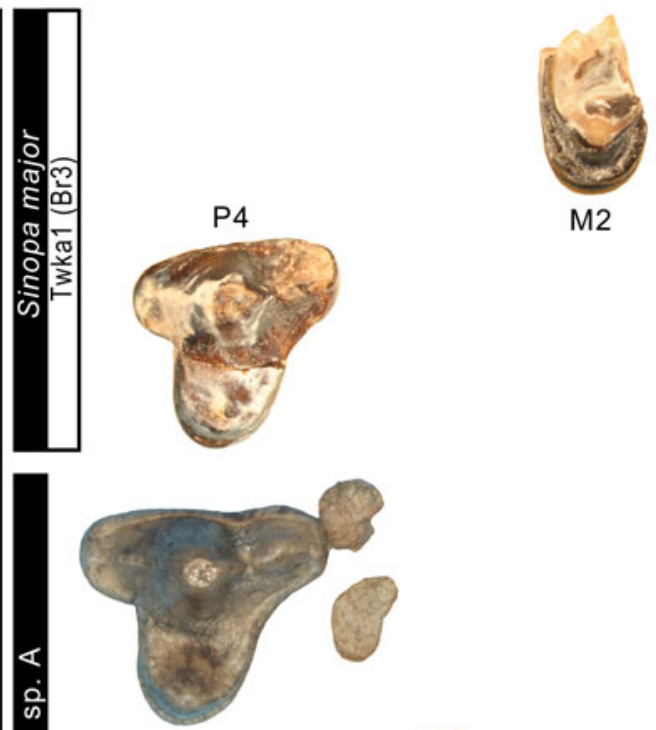

M2

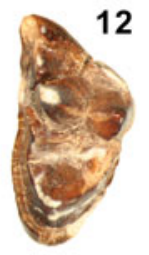

M3
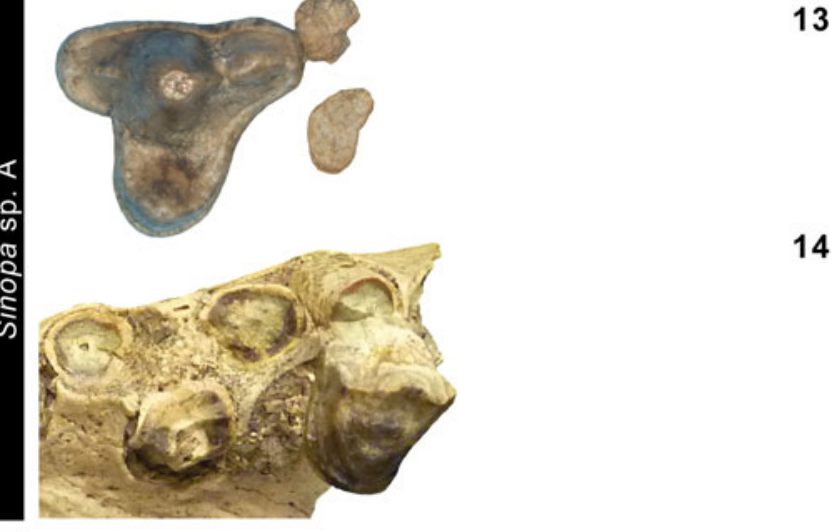

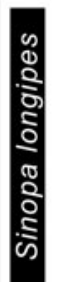

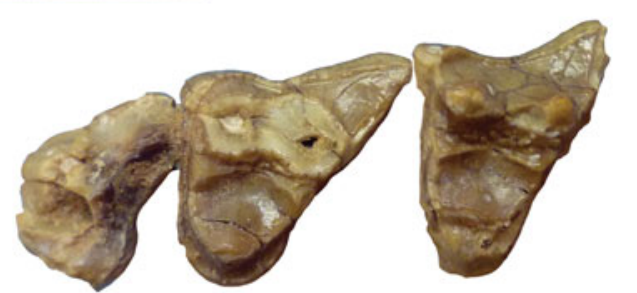

15
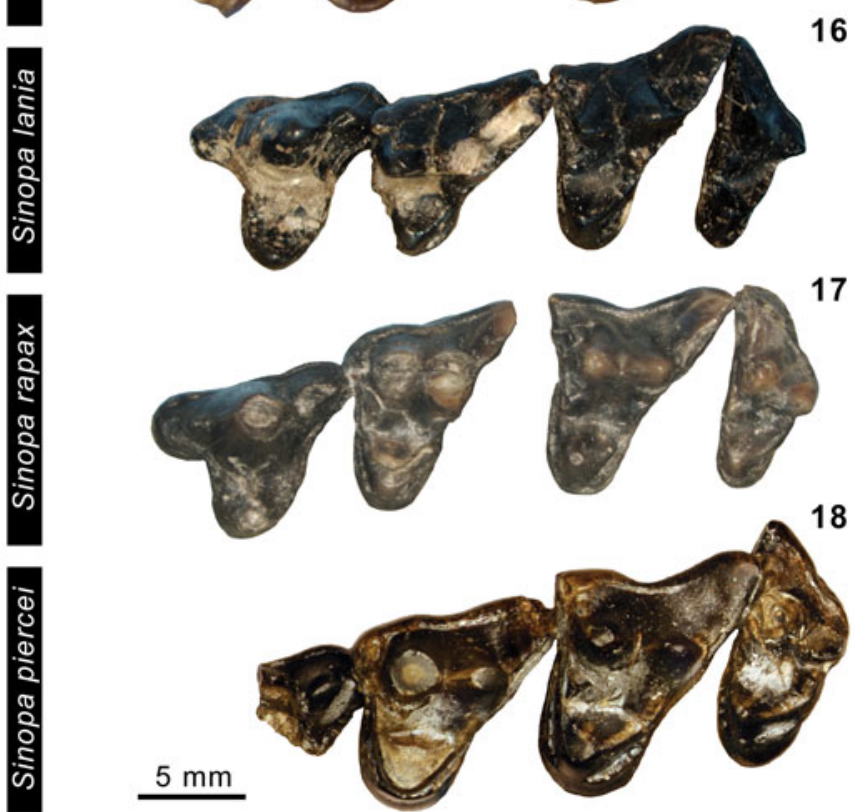

14

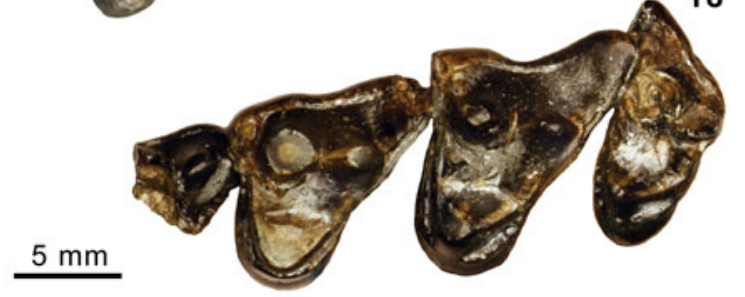

Figure 11. Upper dentitions of selected middle Eocene species of hyaenodontid Sinopa Leidy, 1871. Sinopa major Wortman, 1902a, from the Bridger Formation (left column): (1) left P4-M3 of AMNH FM 12080; (2) left P4-M2 of UWBM 73284; (3) left ?M1 fragment and M3 of USNM PAL 361297; (4) right P4-M3 (inverted) of KUVP 14151; (5) right P4 and M2-3 (inverted) of YPM VPPU 010244; (6) left M1-2 of UWBM 83503; (7) left M3 of UCMP 55594; (8) left M2-3 of USNM PAL 361295; (9) left P4-M3 of AMNH FM 11494 (cast of holotype USNM V 5341 of S. 'grangeri' Matthew, 1906); (10) left M1-3 of USNM PAL 540694. Sinopa major from the Washakie Formation (Twka1): (11) right M2 fragment (inverted) of FMNH PM 55023; (12) left P4 and M3 of FMNH PM 55170. Sinopa sp. A: (13) left P4 and M1 anterior alveoli of AMNH FM 11538; (14) left P4-M1 of FMNH PM 62725 (cf. Sinopa sp. A). Sinopa cf. S. longipes n. comb. (= 'Mimocyon' longipes Peterson, 1919): (15) left P4-M2 of MCZ VPM 8622. S. lania: (16) right P4-M3 (inverted) of holotype AMNH FM 13142. S. rapax (Leidy, 1871): (17) left P4-M3 of AMNH FM 11535. S. piercei $\mathrm{n}$. comb. (= 'Proviverroides' piercei Bown, 1982): (18) right P4 fragment and M1-3 (inverted) of holotype USNM PAL 521259. All images at the same scale. 


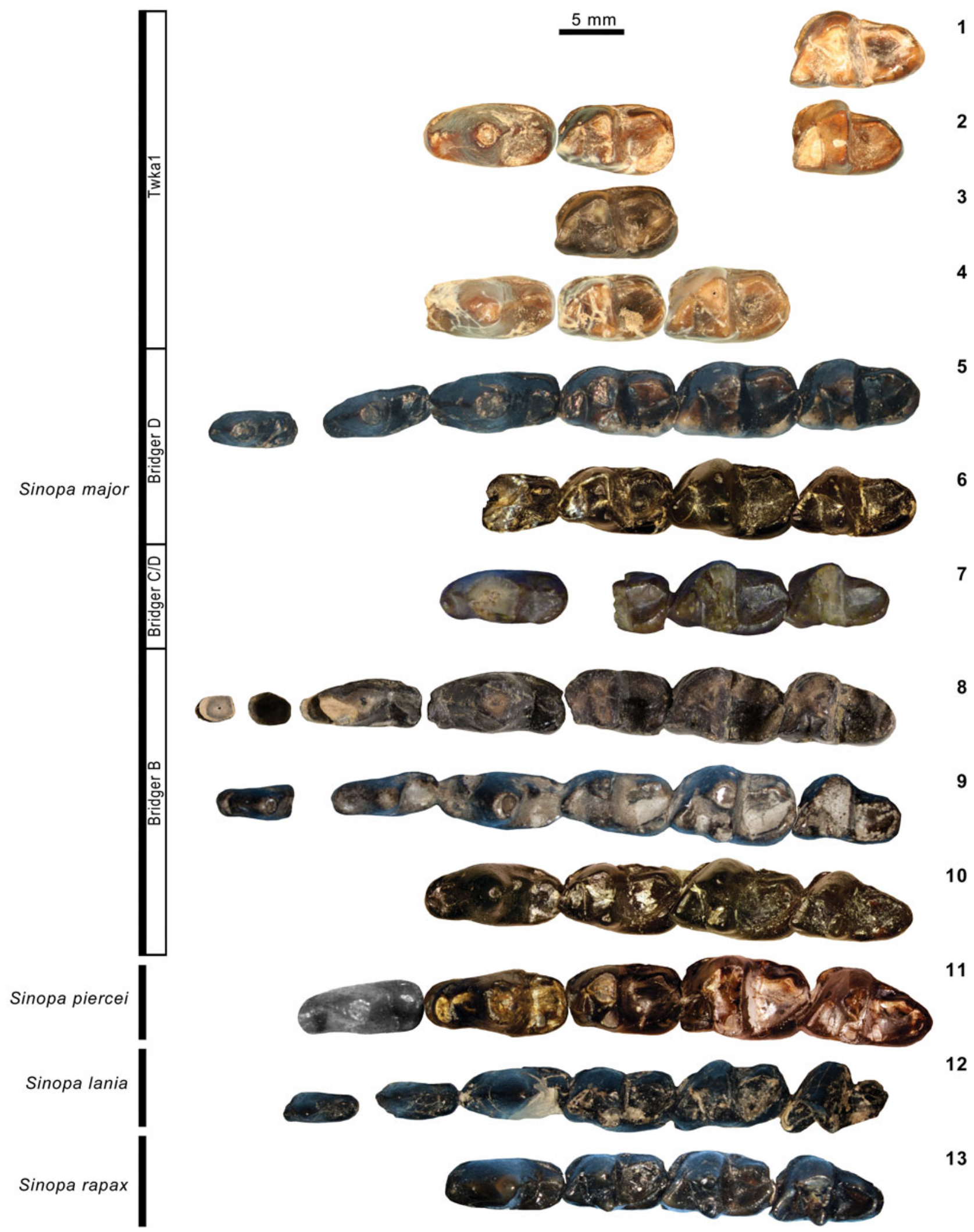

Figure 12. Lower dentitions of selected middle Eocene species of Sinopa. Sinopa major: (1) right $\mathrm{m} 3 \mathrm{of}$ FMNH PM 55023; (2) left p4, m1, and m3 (inverted) of FMNH PM 55170; (3) right m1 of FMNH PM 61376; (4) left p4-m2 (inverted) of FMNH PM 62431; (5) left p2-m3 (inverted) of AMNH FM 12079; (6) composite of left p4-m2 (inverted) and right $\mathrm{m} 3$ of USNM PAL 361297; (7) left $\mathrm{p} 4-\mathrm{m} 3$ (inverted) of YPM VPPU 010244; (8) roots of right $\mathrm{p} 2$ and right $\mathrm{p} 3-\mathrm{m} 3$ of holotype YPM VP 011878; (9) composite of right p2-m2 and left m3 (inverted) of AMNH FM 11494 (cast of holotype USNM V 5341 of S. 'grangeri' Matthew, 1906); (10) right p4-m3 of USNM PAL 540694. Sinopa piercei $\mathrm{n}$. comb. (= 'Proviveroides' piercei): (11) composite of left p3 (inverted) of AMNH FM 128624 (cast of holotype USNM PAL 521259) and left p4-m3 (inverted) of USNM PAL 521259. Sinopa lania: (12) left p2-m3 (inverted) of holotype AMNH FM 13142 (note m3 is not completely erupted). Sinopa rapax: (13) composite of right p4-m2 and left $\mathrm{m} 3$ (inverted) of AMNH FM 11542. All images at the same scale. 

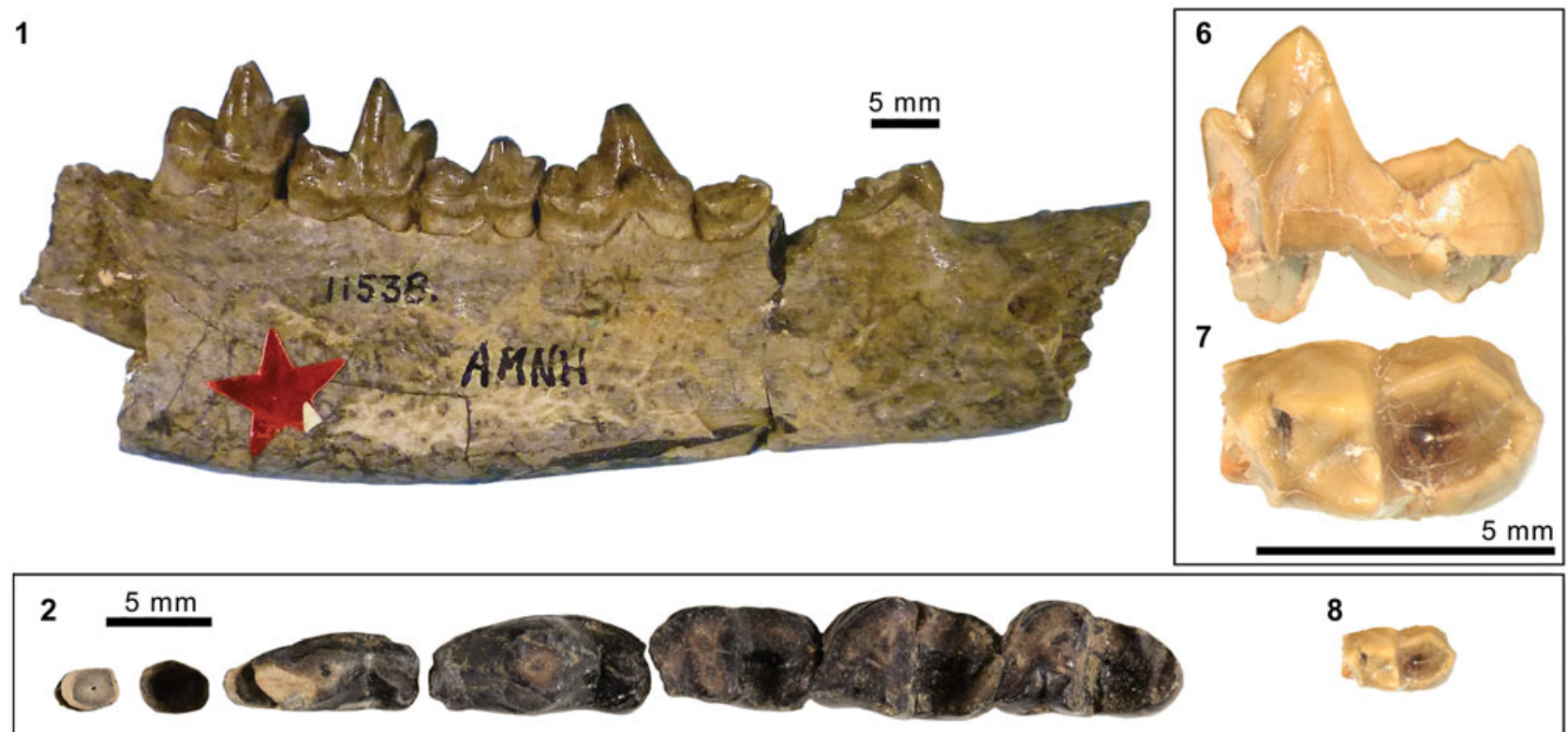

8
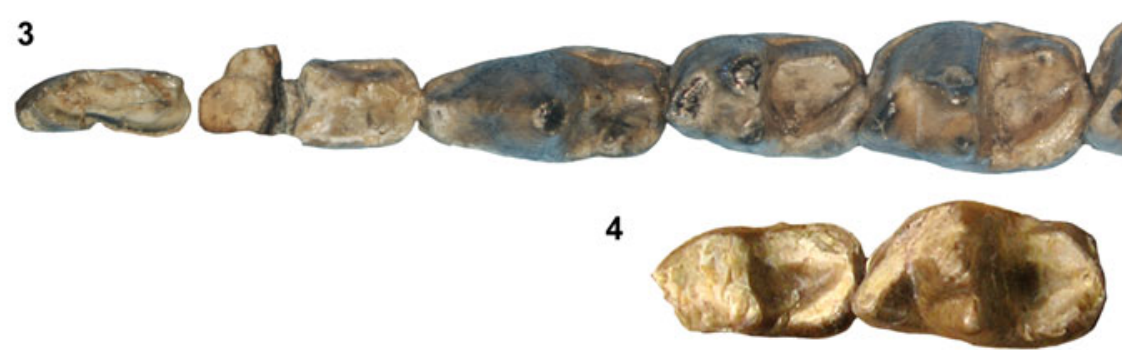

5

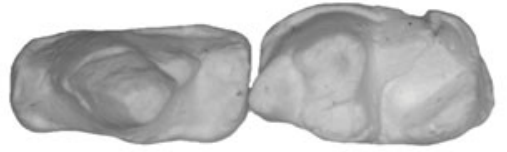

Figure 13. Lower dentitions of large middle Eocene species of Sinopa. Sinopa sp. A: (1) right partial dentary of holotype AMNH FM 11538 in lateral view; (3) right p2-m3 of holotype in occlusal view; (4) left m1-2 (inverted) of TMM 41466-9 (cf. Sinopa sp. A; rescaled from Campisano et al., 2014, after measurements provided in Gustafson, 1986). Sinopa major: (2) roots of right p2 and right p3-m3 of holotype YPM VP 011878. Sinopa longipes n. comb. (= 'Mimocyon' longipes): (5) right p4-m1 of AMNH FM 105378 (cast of holotype CM 3022). Sinopa cf. S. minor: (6) right m1 of FMNH PM 56405 from Twka1 in lingual view; (7, 8) same in occlusal view, at two different scales. Figure $13.2-13.5$ and 13.8 at the same scale.

Matthew (1909) remarked on the trenchantness of the canines of AMNH FM 13142 (hence 'mutation lania', although he recognized the trait as a general characteristic of $S$. rapax). We also note that the labial cusps of upper molars in S. lania are markedly more trenchant (i.e., labiolingually compressed) than in other species of Sinopa, forming a series of sharp preparacrista, centrocrista, and postmetacrista on each tooth (Figs. 10.1, 11.16). The protocones of M1-2 are gracile, and do not extend as far lingually as the $\mathrm{P} 4$ protocone. In the lower dentition, $\mathrm{p} 4$ appears to be shorter but more sharply pointed than in other species, and it may lack a protostylid, which is typically present in Sinopa. The taxonomic significance of these traits is uncertain, but together they appear to enhance the slicing function of the dentition in $S$. lania relative to that in the geologically older (and likely closely related) $S$. rapax. Intriguingly, similar shifts toward increased dental sectoriality are seen in other lineages of middle Eocene carnivores (see Discussion).

Although not noted in Matthew (1909), the tooth directly in front of the right $\mathrm{p} 4$ appears to represent a dp3 (Fig. 10.4, 10.5), whereas its counterpart on the left dentary is $\mathrm{p} 3$ (Fig. 12.12). The former measures: $\mathrm{dp} 3 \mathrm{~L}=7.5, \mathrm{dp} 3 \mathrm{~W}=2.8$. It is distinguished from $\mathrm{p} 3$ by posterior tapering of the tooth in occlusal view. Additional dental measurements are reported in Tables 2 and 3.

\section{Sinopa major Wortman, 1902a}

Figures 11.1-11.12, 12.1-12.10, 13.2

1902b Sinopa major Wortman, p. 18, fig. 98.

1906 Sinopa grangeri Matthew, p. 206, figs. 1b, 2c, 3-5, 7-20, pl. 16.

1909 Sinopa major (in part); Matthew, p. 473, pl. 45, fig. 4.

1923a Sinopa major (in part); Thorpe, p. 36.

1965 Proviverra? major; Van Valen, p. 640.

1965 Proviverra? grangeri; Van Valen, p. 640.

1998a Sinopa major; Gunnell, p. 97.

1998a Sinopa grangeri; Gunnell, p. 97.

2014 Sinopa major; Morlo et al., p. 116.

2014 Sinopa grangeri; Morlo et al., p. 116. 
Table 2. Upper dental measurements (in mm) of Bridgerian-Uintan specimens of Sinopa Leidy, 1871. ${ }^{\mathrm{a} P P} 3$, LP4, RM1-3. ${ }^{\mathrm{b}}$ Cast of holotype USNM PAL 521259. ${ }^{\mathrm{c}} \mathrm{Br} 1 \mathrm{~b}-\mathrm{Br} 2$ portion. ${ }^{\mathrm{d}}$ Cast of holotype USNM V 5341 of Sinopa ' grangeri.' ${ }^{\mathrm{e}}$ Measurements from digital photographs. ${ }^{\mathrm{f}} \mathrm{RP} 3$, LP4, LM3. ${ }^{\mathrm{g}} \mathrm{Alveolar}$ measurements. *Holotype or its cast. ${ }^{\dagger}$ Estimated for specimens with minor breakage or obstruction. Plus signs denote slight undermeasurements.

\begin{tabular}{|c|c|c|c|c|c|c|c|c|c|c|c|c|c|}
\hline Specimen & Taxon & Horizon & Side & P3L & P3W & P4L & $\mathrm{P} 4 \mathrm{~W}$ & M1L & M1W & M2L & $\mathrm{M} 2 \mathrm{~W}$ & M3L & M3W \\
\hline YPM VP 012860 & S. minor & Bridger A/B & $\mathrm{L}$ & 5.25 & 2.76 & 6.98 & 5.33 & & & & & & \\
\hline YPM VP 014216 & S. minor & Bridger A/B? & $\mathrm{L}$ & & & & & 6.61 & 6.43 & 6.70 & 7.12 & 3.29 & 6.48 \\
\hline AMNH FM 11532 & S. minor & Bridger B & $\mathrm{R}$ & & & 7.20 & 5.74 & 6.61 & 6.16 & 6.89 & 7.48 & & \\
\hline AMNH FM 19202 & cf. S. minor & Bridger B & $\mathrm{L}$ & & & 6.29 & 4.74 & & & 5.61 & & $\sim 3.30^{\dagger}$ & 6.24 \\
\hline AMNH FM 1718 & cf. S. minor & Bridger Fm. & $\mathrm{R}$ & & & & & $\sim 6.8^{\dagger}$ & $\sim 6.9^{\dagger}$ & 7.20 & $\sim 8.4^{\dagger}$ & & \\
\hline YPM VP 012851 & cf. S. minor & Bridger C/D & $\mathrm{R}$ & & & 6.98 & 6.58 & 6.74 & 5.75 & & & & \\
\hline YPM VP 013102 & S. rapax & Bridger $\mathrm{A} / \mathrm{B}$ & $\mathrm{R}$ & & & & & 8.27 & 8.47 & & & & \\
\hline AMNH FM 11535 & S. rapax & Bridger B & $\mathrm{L}$ & 8.65 & 3.86 & 9.56 & 7.4 & $\sim 9.2^{\dagger}$ & 8.47 & 8.49 & 10.17 & 4.79 & 9.36 \\
\hline AMNH FM $13142 *$ & S. lania & Twka1 & $\mathrm{R}+\mathrm{L}^{\mathrm{a}}$ & 8.23 & 3.77 & 9.54 & 7.81 & 8.37 & 8.34 & 8.55 & 9.24 & 4.3 & 9.78 \\
\hline AMNH FM $128624 *$ b & S. piercei n. comb. & Aycross $\mathrm{Fm}^{\mathrm{c}}$. & $\mathrm{R}$ & & & & & 9.4 & 9.26 & 9.42 & 10.91 & 5.38 & 10.92 \\
\hline AMNH FM 92768 & S. major & Bridger B & $\mathrm{L}$ & & & 8.94 & 7.36 & & & & & & \\
\hline AMNH FM $11494^{\mathrm{d}}$ & S. major & Bridger B & $\mathrm{L}$ & & & 9.09 & 8.97 & 9.43 & 10.2 & 9.58 & 11.69 & 5.32 & 9.68 \\
\hline USNM PAL 361295 & S. major & Bridger B & $\mathrm{L}$ & & & & & & & $8.52^{\mathrm{e}}$ & $10.25^{\mathrm{e}}$ & $4.31^{\mathrm{e}}$ & $8.92^{\mathrm{e}}$ \\
\hline USNM PAL 540694 & S. major & Bridger B & $\mathrm{L}$ & & & & & $\sim 8.9^{\mathrm{e} \dagger}$ & $\sim 10.4^{\mathrm{e} \dagger}$ & $\sim 8.8^{\mathrm{e} \dagger}$ & $\sim 10.4^{\mathrm{e} \dagger}$ & $\sim 4.6^{\mathrm{e} \dagger}$ & $\sim 10.0^{\mathrm{e} \dagger}$ \\
\hline UWBM 83503 & S. major & Bridger $\mathrm{C}$ & $\mathrm{L}$ & & & & & $\sim 9.5^{\dagger}$ & 9.55 & 9.67 & 11.70 & & \\
\hline UCMP 55594 & cf. S. major & Bridger $\mathrm{C}$ & $\mathrm{L}$ & & & & & & & & & 5.00 & $8.7+$ \\
\hline KUVP 14151 & cf. S. major & Bridger D & $\mathrm{R}$ & & & 8.75 & 7.62 & 8.20 & 8.67 & 8.46 & 9.81 & 4.13 & 8.52 \\
\hline YPM VPPU 010244 & S. major & Bridger C/D & $\mathrm{R}$ & & & 9.80 & 9.15 & & & & & & \\
\hline UWBM 73284 & S. major & Bridger D & $\mathrm{L}$ & & & 10.39 & 8.79 & $\sim 9.6^{\dagger}$ & 8.88 & 9.02 & 10.36 & & \\
\hline AMNH FM 12080 & S. major & Bridger D & $\mathrm{L}$ & & & 9.05 & 8.06 & 9.03 & 8.09 & 8.94 & 9.76 & 5.48 & 10.05 \\
\hline USNM PAL 361297 & S. major & Bridger D & $\mathrm{L}$ & & & & & & & & & $4.30^{\mathrm{e}}$ & $8.50^{\mathrm{e}}$ \\
\hline FMNH PM 55170 & S. major & Twka1 & $\mathrm{R}+\mathrm{L}^{\mathrm{f}}$ & 8.42 & 5.85 & 9.47 & 8.99 & & & & & 5.93 & 10.33 \\
\hline AMNH FM 11538 & Sinopa sp. A & Bridger D? & $\mathrm{R}$ & & & 11.53 & 10.02 & & & & & & \\
\hline FMNH PM 62725 & cf. Sinopa sp. A & Twka2 & $\mathrm{L}$ & & & {$[12.27]^{\mathrm{g}}$} & {$[9.92]^{\mathrm{g}}$} & & {$[10.63]^{\mathrm{g}}$} & & & & \\
\hline MCZ VPM 8622 & cf. S. longipes n. comb. & Uinta $\mathrm{C}$ & $\mathrm{L}$ & & & & & 10.91 & 10.87 & $9.5+$ & $12.3+$ & & \\
\hline
\end{tabular}

Holotype.-YPM VP 011878, partial right dentary with a root of $\mathrm{p} 2$, broken $\mathrm{p} 3$, and $\mathrm{p} 4-\mathrm{m} 3$.

Locality.-YPM locality recorded as "Church Buttes" Uinta County, Wyoming.

Horizon.-Blacks Fork Member (Bridger B), Bridger Formation (cf., Murphey and Evanoff, 2011).

Emended diagnosis.-Differs: from Sinopa rapax and S. lania in larger size (best distinguished by $\mathrm{m} 2$ width $\geq 5.5$; Fig. 14), more reduced parastylar and metastylar regions of $\mathrm{P} 4$, greater separation of paracone and metacone on M1-2, labiolingually wider and more closed $\mathrm{m} 2$ trigonid, and more lingually directed $\mathrm{m} 3$ postparacristid; from Sinopa piercei n. comb. in continuous M2 lingual cingulum around protocone, M3 lingual cingulum not enlarged, more anterior direction of M3 parastylar region, less-prominent anterior cuspulids on p3-4, shorter anterior base of $\mathrm{p} 4$, and less-pronounced posterior elongation of entocristids on $\mathrm{m} 1-3$; from $S$. minor and $S$. pungens in larger size (m3 L x W is $\geq 57 \%$ greater), reduced P4 metastylar region, better delineated M2 lingual cingulum, greater separation of paracone and metacone on M1-2, and more closed m2-3 trigonids with more lingually directed postparacristids; from Sinopa longipes n. comb. in labiolingually narrower anterior and posterior bases of $\mathrm{p} 4$ (such that $\mathrm{p} 4$ width is less uniform along its length), lower $\mathrm{p} 4$ protoconid relative to $\mathrm{m} 1$, and smaller size of $\mathrm{m} 1$ ( $\mathrm{m} 1 \mathrm{~L} \times \mathrm{W}$ is $\geq 22.4 \%$ smaller than in CM 3022).

Occurrence.-Blacks Fork and Twin Buttes members, Bridger Formation, Bridger Basin, Wyoming (Matthew, 1906, 1909); Twka1, Adobe Town Member, Washakie Formation,
Washakie Basin, Sweetwater County, Wyoming (this study) Middle to late Bridgerian (Br2-3) NALMA.

Materials from Washakie Basin.-FMNH locality FM-7-69-WDT (Twka1): FMNH PM 61718, right dentary fragment with roots of $\mathrm{p} 2-\mathrm{m} 1$ and $\mathrm{m} 2$ (missing trigonid).

FMNH locality FM-4-83-KL/WT (Twka1): FMNH PM 62431, ?left px fragment, isolated left p4-m2.

FMNH locality JJF 7-28-91-1 (Twka1): FMNH PM 55170, associated $\mathrm{C} 1$, right $\mathrm{P} 3, \mathrm{MX}$, and left $\mathrm{P} 2, \mathrm{P} 4$, and $\mathrm{M} 3$, right and left $\mathrm{c} 1$, ?left ix, left $\mathrm{p} 1-\mathrm{m} 3$ ( $\mathrm{p} 1-\mathrm{p} 3$ and $\mathrm{m} 2$ fragmentary).

FMNH locality JJF 7-30-91-3 (Twka1): FMNH PM 55023 , fragments of cranium, upper teeth, and right dentary including $\mathrm{m} 3$, axis, vertebrae, left proximal ulna, left proximal radius.

FMNH locality JJF 8-14-93-1 (Twka1): FMNH PM 56413, fragment of right $\mathrm{m} 3$ trigonid.

FMNH locality JJF 7-30-95-3 (Twka1): FMNH PM 61376, right $\mathrm{p} 4$ fragment, right $\mathrm{m} 1$, additional skeletal fragments including dentary, right and left ulna, left proximal radius.

Materials from Bridger Basin.-AMNH locality recorded as "Grizzly Buttes" (Bridger B), Uinta County, Wyoming: AMNH FM 92768, left maxillary fragment with P4, right dentary fragment.

AMNH locality recorded as "Grizzly Buttes East" (Bridger B), Uinta County, Wyoming: AMNH FM 92778, right dentary fragment with m2-3.

USNM locality recorded as Cottonwood Creek (Bridger B), Uinta County, Wyoming: USNM V 5341 (holotype of Sinopa grangeri Matthew, 1906), skull and skeleton. 
Table 3. Lower dental measurements (in mm) of Bridgerian-Uintan specimens of Sinopa.${ }^{\mathrm{a}}$ Cast of holotype USNM PAL 521259. ${ }^{\mathrm{b}}$ Cast of holotype USNM V 5341 of Sinopa 'grangeri.' ${ }^{\mathrm{c}}$ Measurements from digital photographs. ${ }^{\mathrm{d}} \mathrm{Lp} 4-\mathrm{m} 2, \mathrm{Rm} 3 .{ }^{\mathrm{e}}$ Measurements from Gustafson (1986). ${ }^{\mathrm{f}}$ Cast of holotype CM $3022 .{ }^{*} \mathrm{Holotype}$ or its cast. ${ }^{\dagger}$ Estimated for specimens with minor breakage or obstruction. Plus signs denote slight undermeasurements.

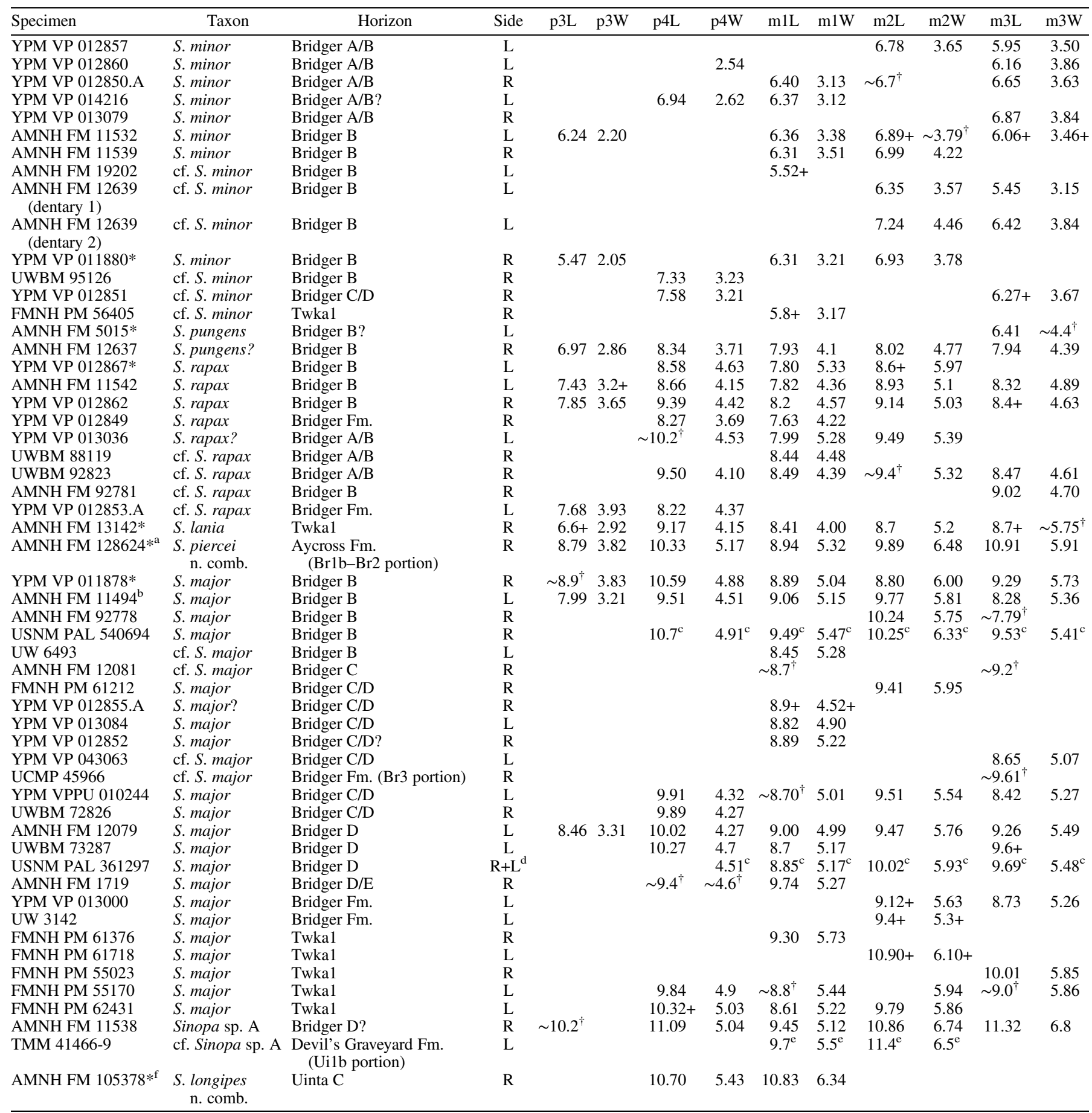

USNM unnamed locality (Bridger B), Wyoming: USNM PAL 361295, left maxillary fragment with partial P4 and M2-3.

USNM locality recorded as 4.5 miles south of Church Buttes, (Bridger B), Uinta County, Wyoming: USNM PAL 540694, left maxillary fragment with broken P4-M3, right dentary with p4-m3.

UW unnamed locality (Bridger B), Bridger Basin (county not recorded), Wyoming: UW 6493, left dentary fragment with alveoli for $\mathrm{p} 2-4, \mathrm{~m} 1$, and alveoli for $\mathrm{m} 2$.
UWBM locality C0705 (“Gargoyle NW;" Bridger C), Uinta County, Wyoming: UWBM 83503, left maxillary fragment with broken M1-2, right and left anterior dentary fragments, postcrania.

UCMP Locality V65219 ('Lonetree Level C'; Bridger C), Uinta County, Wyoming: UCMP 55594 (previously identified as "?Didymictis"), left maxillary fragment with M3 (missing anterolabial corner). 


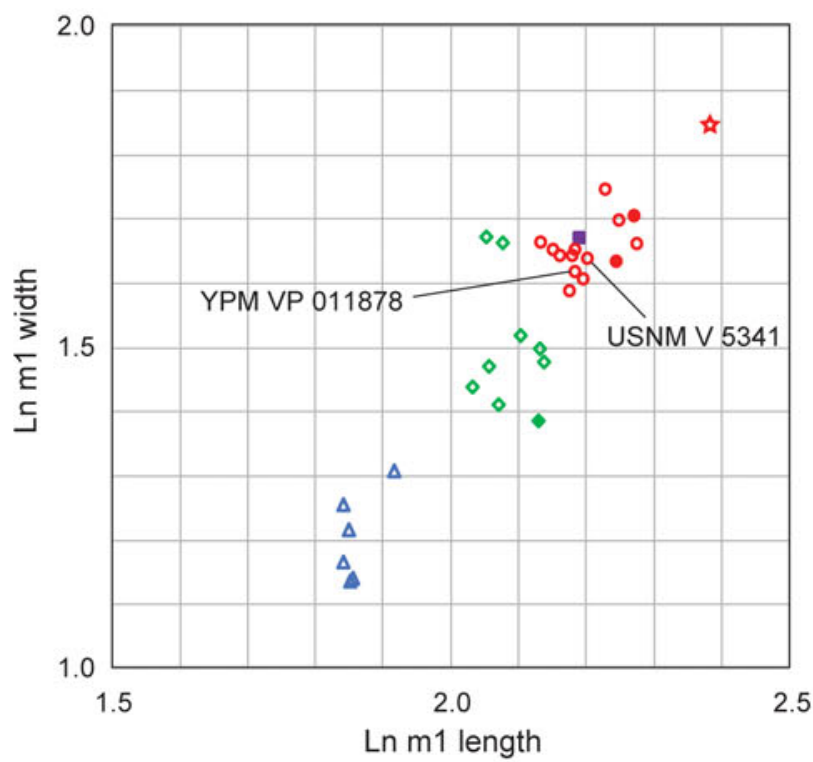

3

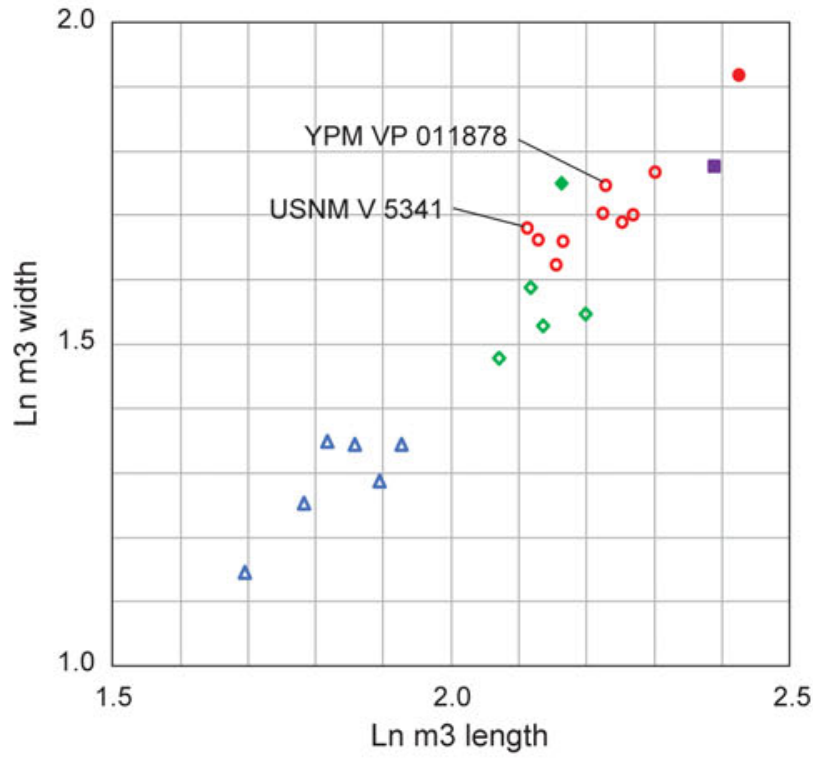

5

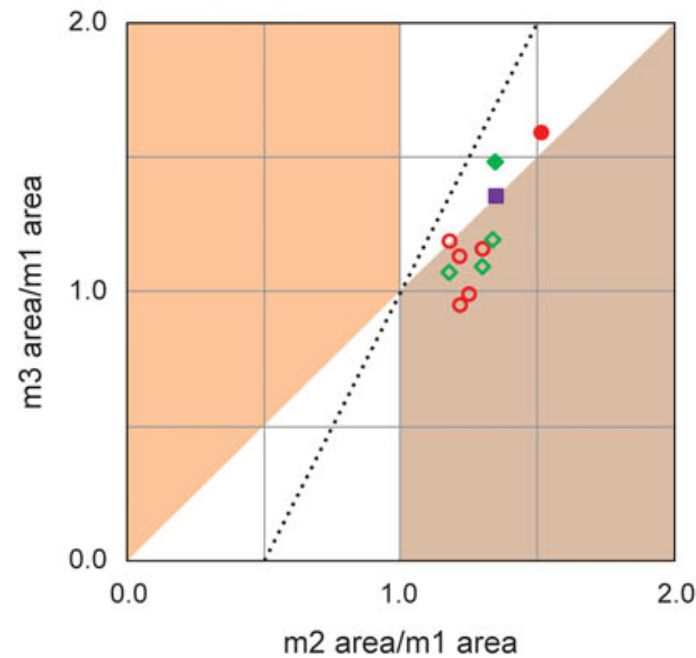

$\mathrm{m} 2$ area/m1 area
2

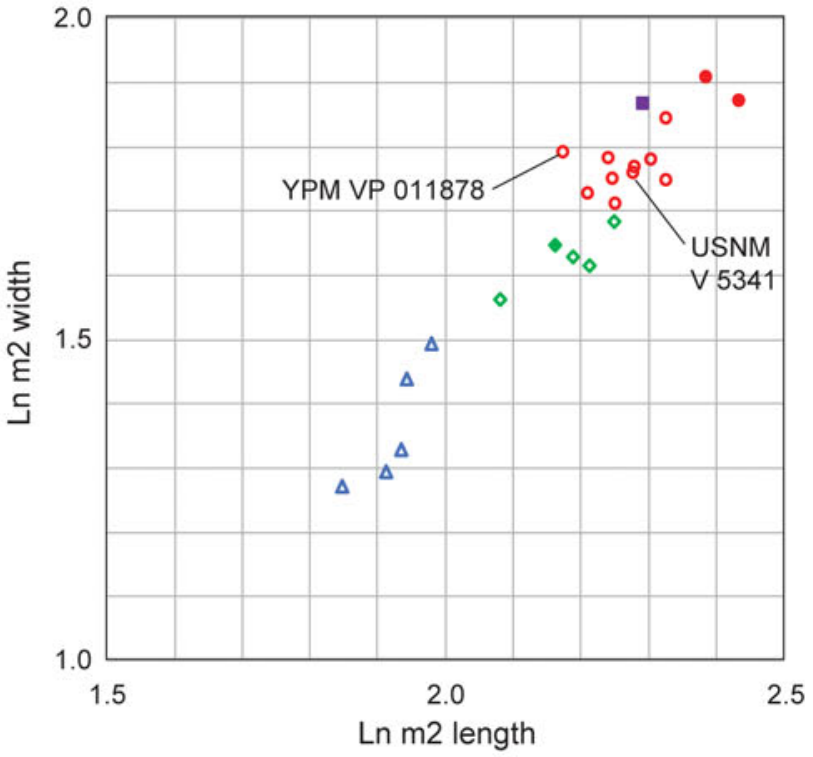

4

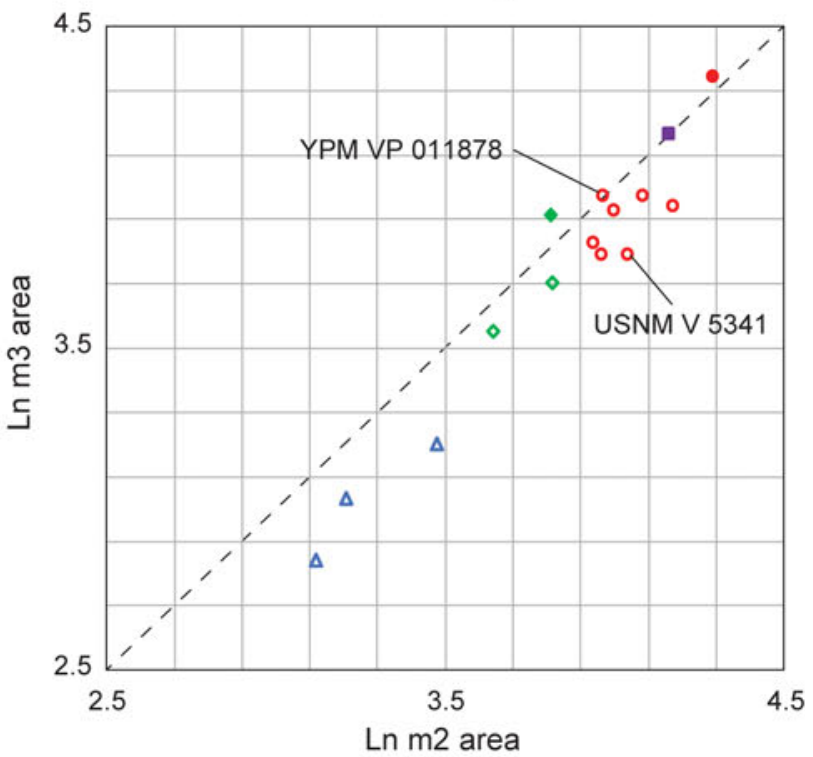

Figure 14. Tooth sizes of selected species of Sinopa. (1-4) Bivariate plots of Ln $\mathrm{m} 1$ length versus $\mathrm{Ln} \mathrm{m} 1$ width (1), Ln $\mathrm{m} 2$ lengths versus Ln $\mathrm{m} 2 \mathrm{midth}(\mathbf{2})$, Ln $\mathrm{m} 3$ length versus $\mathrm{Ln} \mathrm{m} 3$ width (3), and $\mathrm{Ln} \mathrm{m} 2$ occlusal area $(\mathrm{L} \mathrm{x} \mathrm{W})$ versus $\mathrm{Ln} \mathrm{m} 3$ occlusal area ( $\mathrm{L} \mathrm{x} \mathrm{W)} \mathrm{(4;} \mathrm{dashed} \mathrm{diagonal} \mathrm{corresponds} \mathrm{to} \mathrm{isometric} \mathrm{line).} \mathrm{(5)}$ Occlusal-area ratios plotted as in Polly (2007, fig. 3). Measurements reported in Table 3. YPM VP 011878 and USNM V5341 are holotypes of Sinopa major and $S$. 'grangeri', respectively. In (5), dotted line marks prediction of Kavanagh et al.'s (2007) additive linear-effect inhibitory cascade model; more generally, molar proportions generated by inhibitory cascade are expected to fall within white regions. 
AMNH locality recorded as "Henry's Fork" (Bridger C), Uinta County, Wyoming: AMNH FM 12081, horizontal ramus of right dentary with $\mathrm{m} 1$ talonid and $\mathrm{m} 3$ talonid.

FMNH locality JJF 7-12-95-1 (Bridger C/D), Uinta County, Wyoming: FMNH PM 61212, right dentary fragments with $\mathrm{m} 1-3$.

UCMP Locality V5626 ('Hyopsodus Hill 1'; Br3 portion of Bridger Formation; cf., Robinson et al., 2004), Sublette County, Wyoming: UCMP 45966, right dentary fragment with $\mathrm{m} 3$ talonid.

UWBM locality C0510 (“Cow Trail Washout;" Twin Buttes Member), Uinta County, Wyoming: UWBM 72826, right p4.

YPM locality recorded as "Henry's Fork" (Bridger C/D), ?Uinta County, Wyoming: YPM VPPU 010244, right maxillary fragment with P4 and M2-3, partial left dentary with broken $\mathrm{p} 4$ $\mathrm{m} 3$; YPM VP 043063, left m3 (previously identified in collection as "Uintacyon cf. U. vorax").

YPM locality of unknown location in Bridger $\mathrm{C}$ or $\mathrm{D}$ (“upper Bridger"), Wyoming: YPM VP 013084, left m1.

YPM localities recorded as "Lone Tree" (Bridger C/D), Uinta County, Wyoming: YPM VP 012852, lingual fragment of M1 or M2 and right and left $\mathrm{m} 1$.

UWBM locality C0515 ("Sheephead;" Bridger D), Uinta County, Wyoming: UWBM 73284, cranial fragments with right P2 and left P4-M2; UWBM 73287, left dentary fragments with broken $\mathrm{p} 2-3$, p4-m1, and broken $\mathrm{m} 2-\mathrm{m} 3$.

AMNH locality recorded as "Henry's Fork, Lone Tree" (Bridger D), Uinta County, Wyoming: AMNH FM 12079, left dentary with p1-m3; AMNH FM 12080, left maxillary fragment with P1, P4-M3.

KUVP locality Wyo. 48 (Lone Tree White Layer, Bridger D), Uinta County, Wyoming: KUVP 14151, right maxillary fragment with $\mathrm{P} 3-\mathrm{M} 3$.

USNM locality (Bridger D), Wyoming: USNM PAL 361297, left ?M1 lingual fragment, left M3, partial right and left dentaries (with heavily damaged right $\mathrm{p} 3-\mathrm{m} 2$, right $\mathrm{m} 3$, left $\mathrm{p} 1$, heavily damaged left $\mathrm{p} 4$ and $\mathrm{m} 2$, and left $\mathrm{m} 1$ ), additional craniomandibular fragments.

AMNH locality recorded as "Big Bone Butte" (= Sage Creek Mountain, Bridger D/E; cf., Murphey and Evanoff, 2011), Uinta County, Wyoming: AMNH FM 1719, right dentary fragment with $\mathrm{p} 4$ and $\mathrm{m} 1$.

UW locality V-57004 ("Elliot Spur;" unknown portion of Bridger Formation), Sublette County, Wyoming: UW 3142, left ?m2.

YPM locality of unknown location in Bridger Formation, Wyoming: YPM VP 013000, left dentary fragments (2 pieces) with partial p2, partial p3, $\mathrm{m} 1$ talonid, and $\mathrm{m} 2-3$.

YPM locality recorded as "Henry's Fork" (Bridger C/D), Uinta County, Wyoming: YPM VP 012855.A, left dentary fragment with partial p4-m1.

Remarks.-Our species-level identification of large Sinopa from the Washakie Formation necessitated an extensive re-examination of Bridgerian and Uintan specimens of that genus. First, we compared the holotypes YPM VP 011878 and USNM V 5341 (we examined its cast, AMNH FM 11494) of Sinopa major Wortman, 1902a and S. grangeri Matthew, 1906 (both from the the Bridger B interval) and various other specimens from the Bridger B-D intervals that have been identified as one of the two species in museum collections and publications. Differences in the sizes of individual teeth (p4-m3) between YPM VP 011878 and USNM V 5341 are less than 12\%, and would have been smaller for m1-2 had they not been so heavily worn in the holotype of $S$. major (Table 3). Also notably, the size of $m 3$ is particularly variable among otherwise similarly sized specimens of middle to late Bridgerian Sinopa. This variation is not clearly divisible into two morphotypes (Figs. 12.5$12.10,14)$ and does not appear to correlate with other variable features. Overall, YPM VP 011878 is not consistently or substantially larger or more massive, nor does it have broader talonids than USNM V 5341, as Matthew (1906) noted for $S$. major in proposing $S$. grangeri as a separate species; the remaining purported distinction-lower tooth crowns for $S$. major - cannot be evaluated for YPM VP 011878 with its heavy tooth wear.

We suspect that the long-standing taxonomic confusion surrounding S. major and S. grangeri-apparent in the uncertain or unstable identifications of many specimens in museum collections-stems from Matthew's (1906) reliance on AMNH FM 11538 as the representative specimen of S. major. Had he instead closely compared USNM V 5341 with YPM VP 011878, he might not have proposed $S$. grangeri as a new species. As discussed below, we consider the dental morphology of AMNH FM 11538 to be sufficiently distinct from that of YPM VP 011878 such that the two specimens should be assigned to separate species. Our removal of AMNH FM 11538 from S. major clarifies the latter species' range of variation, and renders the taxonomic separation of $S$. grangeri from $S$. major untenable. Thus, we consider $S$. grangeri to be a junior synonym of $S$. major, echoing the sentiments expressed by Gunnell (1998a) and Morlo et al. (2014). In our view, multiple specimens from the Bridger B and C intervals can be assigned to S. major, and we see no reason to question the recorded provenance of the holotype (Bridger B at "Church Buttes") on the basis that all the AMNH specimens that Matthew (1909) referred to $S$. major had come from Bridger D (see also Gazin, 1976, p. 10).

Middle Bridgerian $(\mathrm{Br} 2)$ specimens of $S$. major from the Bridger B interval (including the holotype and USNM V 5341; Figs. 11.8-11.10, 12.8-12.10) are distinguished from contemporaneous specimens of $S$. rapax primarily by their larger sizes. Morphological details such as the development of the M2 lingual cingulum (somewhat enlarged in USNM PAL 361295; Fig. 11.8), the angle of the M2 ectoflexus (nearly flat in USNM PAL 361295), and the shape of $\mathrm{m} 3$ talonid (elongate and tapered in USNM PAL 540694; Fig. 12.10) vary among Bridger B specimens of $S$. major, but are not clearly divisible into morphotypes above the level of individuals. The upper molars of UWBM 83503 (Fig. 11.6) - the only specimen of $S$. major so far identified definitively from Bridger $\mathrm{C}$ strata—differ little from Bridger B specimens.

YPM VPPU 010244 from the Bridger C or D interval and KUVP 14151 from the lowermost unit of Bridger D (= Lonetree limestone; Ivy, 1994; Murphey and Evanoff, 2007) are unique in their relatively small and gracile forms (Figs. 11.4, 11.5, 12.7), although their molars are still more robust (with anteroposteriorly long protocones and labiolingually wide talonids) than those of S. rapax from Bridger B strata. These specimens appear 
to signal a shift in dental morphology_- perhaps related to a temporary reduction in body size-near the boundary between Bridger C and D. Other Bridger D specimens of $S$. major are similar in their forms to YPM VPPU 010244 and KUVP 14151, but are noticeably larger (Figs. 11.1, 11.2, 12.5, 12.6): they are characterized by more robust molar protocones, larger M3 relative to $\mathrm{M} 2$, and labiolingually wider talonids of $\mathrm{m} 3$ than in Bridger B-C specimens of $S$. major. In these respects, all specimens of large Sinopa from Twkal horizons (Figs. 11.11, 11.12, 12.1-12.4; Tables 2, 3) most closely resemble large specimens of $S$. major from Bridger D. Thus, enhanced chronological resolution of the morphological evolution within $S$. major might contribute to more precise temporal correlation of the subunits of the Washakie Formation with those of the Bridger Formation.

Sinopa piercei (Bown, 1982), is known only by the holotype USNM PAL 521259 from the early to middle Bridgerian (Br1b-Br2; Robinson et al., 2004) portion of the Aycross Formation in northwestern Wyoming, $\sim 265 \mathrm{~km}$ to the north northeast of Church Butte in the Bridger Basin. In its robust molar protocones and large posterior molars, the holotype (Figs. $11.18,12.11)$ appears as an earlier morphological analog of $S$. major from the Bridger D interval, and is less comparable to the temporally proximate specimens of $S$. major from Bridger B. For this reason, we retain $S$. piercei n. comb. As a species separate from $S$. major, but, as discussed above, the observed differences are subtle enough that they should be accommodated by retention of this species within the same genus, Sinopa.

Sinopa species A

Figures 11.13, 11.14, 13.1, 13.3, 13.4

1906 Sinopa major Matthew (in part), p. 208, figs. 1c, 2 d.

1909 Sinopa major (in part); Matthew, p. 473.

1965 Proviverra? major (in part); Van Valen, p. 640.

1986 Proviverra? major (in part); Gustafson, p. 14, fig. 8.

1998a Sinopa major (in part); Gunnell, p. 97.

2014 Sinopa major (in part); Morlo et al., p. 116.

2014 Sinopa major (in part); Campisano et al., p. 16, fig. 13A, B.

Occurrence.-Twin Buttes Member, Bridger Formation, Bridger Basin, Wyoming (Matthew, 1909); low in Twka2, Adobe Town Member, Washakie Formation, Washakie Basin, Sweetwater County, Wyoming (this study); Devil's Graveyard Formation, Texas (Gustafson, 1986). Late Bridgerian to early Uintan (Br3-Ui1b) NALMA.

Materials._AMNH locality recorded as "Henry's Fork, Lone Tree" (Bridger Formation): AMNH FM 11538, left maxillary fragment with $\mathrm{P} 4$, right dentary with heavily damaged p2-3 and $\mathrm{p} 4-\mathrm{m} 3$.

TMM locality 41466 (Devil's Graveyard Formation): TMM 41466-9, partial left dentary with m1-2.

FMNH locality FM-4-81-WDT? (low in Twka2?, Washakie Formation): FMNH PM 62725, left maxillary fragment with roots of $\mathrm{P} 3-4$ and lingual portion of M1.

Remarks.-AMNH FM 11538, which was presumably found in the Bridger D interval (see Matthew, 1909, p. 300, faunal table), has traditionally been regarded as Sinopa major after Matthew (1906) figured its dentition as typical of that species. While Matthew (1909, p. 473) stated that AMNH FM 11538 "agree [d] in size with the type [of S. major, YPM VP 011878]," pronounced enlargement of $\mathrm{m} 2-3$ on the AMNH specimen relative to the sizes of $\mathrm{p} 2-\mathrm{m} 1$ clearly sets it apart from other known specimens of $S$. major, which come from Bridger B through D horizons (Figs. 12-14). For example, its [m2 L x $\mathrm{W}] /[\mathrm{m} 1 \mathrm{~L} \times \mathrm{W}]=1.51$ and $[\mathrm{m} 3 \mathrm{~L} \times \mathrm{W}] /[\mathrm{m} 1 \mathrm{~L} \times \mathrm{W}]=1.59$ compared to 1.21 and 1.13, respectively, in AMNH FM 12079 of $S$. major from Bridger D. Paralleling our earlier discussion of the species-level distinction between $S$. lania and $S$. rapax, what we here recognize as the unnamed 'species A' exhibits molar size ratios that are congruent with the general inhibitory cascade model of dental development, whereas specimens of $S$. major typically do not and are far removed from specimens assigned to the unnamed 'species A' (Fig. 14.5). Such a seemingly fundamental shift in development may be differentially diagnostic of species.

Additionally, AMNH FM 11538 differs from: (1) Sinopa rapax and $S$. lania in larger size ( $\mathrm{m} 2$ is $\geq 30 \%$ wider; Fig. 14; Tables 2, 3), proportionately wider lower molars, and $\mathrm{m} 3$ with more acute hypoconid and labiolingually wider talonid basin; (2) $S$. major in more angular hypoflexids on m1-3 with more labiolingual orientations of posthypocristids, and generally larger size (e.g., P4 L x W of the holotype is $26.5 \%$ greater than in UWBM 73284 of S. major from Bridger D); (3) S. piercei n. comb. in relatively shorter anterior base of $\mathrm{p} 4$, larger $\mathrm{m} 3$ relative to $\mathrm{m} 1([\mathrm{~m} 3 \mathrm{~L} \mathrm{x} \mathrm{W}] /[\mathrm{m} 1 \mathrm{~L} \mathrm{x} \mathrm{W}]=1.36$ in USNM PAL 521259), and comparatively wider $\mathrm{m} 3$ talonid basin (which is nearly as wide as $\mathrm{m} 2$ talonid basin); (4) $\mathrm{S}$. longipes $\mathrm{n}$. comb. in labiolingually narrower anterior and posterior bases of $\mathrm{p} 4$, and smaller size of $\mathrm{m} 1$; and (5) S. minor and $S$. pungens in larger size (m3 L x W is $\gtrsim 173 \%$ greater) and more closed $\mathrm{m} 2-3$ trigonids with more lingually directed postparacristids.

There is a substantial size difference between AMNH FM 11538 and the holotype CM 3022 of Sinopa longipes n. comb. from the late Uintan (Ui3) Myton Pocket of Uinta Basin, Utah: $\mathrm{m} 1 \mathrm{~L} \mathrm{x} \mathrm{W}$ of the former is smaller by $41.9 \%$ (Fig. 13.5). As discussed above, we consider S. longipes n. comb. to be the largest and last-surviving species of Sinopa in North America. We tentatively regard a second specimen from Myton Pocket, MCZ VPM 8622 (Fig. 11.15; identified in collection as "Oxyaenodon dysclerus" Hay, 1902, which is a junior synonym of $O$. dysodus according to Gunnell, 1998a), as belonging to $S$. longipes n. comb. The morphology of MCZ VPM 8622 resembles that of $S$. major from the Bridger D interval, but the preserved teeth are substantially larger.

In sum, AMNH FM 11538 is sufficiently distinct from known species of Sinopa that we think it should be recognized as a new species. We refrain from formally naming it, however, until the species-level classifications proposed by Ivy (1994) in his $\mathrm{Ph} . \mathrm{D}$. dissertation are comprehensively reviewed, as recommended by Gunnell (1998a).

We tentatively refer TMM 41466-9 from a Uilb horizon (the same as that of the Whistler Squat Quarry; Gustafson, 1986; Campisano et al., 2014) of the Devil's Graveyard Formation, Texas, to the same species as AMNH FM 11538, based on 
m1-2 sizes (Figs. 13.4, 14). Breakage and tooth wear make it difficult to discern morphological details of this specimen, but its occurrence is significant as the only Uintan record of Sinopa outside the Rocky Mountain region. Based on published measurements, TMM 41576-5, which comes from a similar level in the Devil's Graveyard Formation, also may represent this species, but this specimen has not been illustrated nor have we been able to examine it (Gustafson, 1986).

Our referral of FMNH PM 62725 from the Washakie Formation (Fig. 11.14) to the unnamed "species A" is based on the inferred sizes of P4 and M1, and is necessarily provisional given its fragmentary nature. The M1 of FMNH PM 62725 is distinguished from those of the similar-sized limnocyonine Limnocyon by a clearly delineated lingual cingulum, and from that of MCZ VPM 8622 (cf., Sinopa longipes n. comb.) by a less anteroposteriorly elongate protocone. The stratigraphic provenance of the specimen is uncertain from the available field notes, which record the locality as "Falcoln [sic] Butte" (W. Turnbull, 1982, on file at FMNH). Given this description, we suspect the specimen to be from FMNN locality FM-4-81-WDT, which is positioned very low in Twka2 (Roehler's [1973] bed 621-625) and likely $\mathrm{Br} 3$ in age.

This as-yet unnamed species of Sinopa may represent a phyletic descendant or close relative of S. major (Ivy, 1994), but the possibility of their temporal overlap cannot be discounted given the limited resolution of available data. It appears to reflect a general trend of body size increase within a lineage of large Sinopa beginning in the middle Bridgerian and culminating in S. longipes $\mathrm{n}$. comb. of the late Uintan.

\section{Sinopa cf. S. minor Wortman, 1902a}

Figure 13.6-13.8

1902b Sinopa minor Wortman, p. 17, figs. 96-97.

1965 Proviverra? minor; Van Valen, p. 640.

1998a Sinopa minor; Gunnell, p. 97.

2014 Sinopa minor; Morlo et al., p. 116.

Occurrence.-Blacks Fork and Twin Buttes members, Bridger Formation, Bridger Basin, Wyoming (Matthew, 1909; Gazin, 1976; Gunnell, 1998a; Gunnell et al., 2009); Twka1, Adobe Town Member, Washakie Formation, Washakie Basin, Sweetwater County, Wyoming; Elderberry Canyon local fauna, Sheep Pass Formation, White Pine County, Nevada (Emry, 1990). Early to late Bridgerian (Brlb-Br3) NALMA (Gunnell et al., 2009; this study).

Materials from Washakie Basin.-FMNH locality JJF 7-27-91-1 (Twka1): FMNH PM 56405, right $\mathrm{m} 1$ with broken paraconid.

Remarks.-Taking into account the anterior breakage of the paraconid, m1 of FMNH PM 56405 (Fig. 13.6-13.8) appears to have been at least $\sim 30 \%$ shorter than that of Sinopa lania, the smaller of the two species of Sinopa from Twkal discussed above. Compared to other middle Eocene species of the genus, this specimen is closest in size to $S$. minor, which is documented from earlier deposits in Wyoming and Nevada
(Br1b-Br2 age), although Gunnell et al. (2009) indicated the chronological range of this species as extending into $\mathrm{Br} 3$. In addition to size, the form and proportions of the trigonid and talonid are closely comparable to those of AMNH FM 11532 (S. minor) from the Bridger B interval (see also Matthew, 1909). The light color of FMNH PM 56405, which is atypical among mammalian teeth from Twka1, and the complete lack of tooth wear, which is unusual among specimens of Sinopa, suggest an unerupted tooth with possibly incomplete deposition of the enamel layer. Although the deciduous dentition of Sinopa is unknown, FMNH PM 56405 does not appear to be a dp4 given its relatively large width, the tallness of the paraconid, and the lack of posterior displacement of the metaconid (contrast with dp4s of early hyaenodontids in Smith and Smith, 2001).

Measurements: $\mathrm{m} 1 \mathrm{~L} \geq 5.8$ (missing part of paraconid); $\mathrm{m} 1 \mathrm{~W}=3.17$.

\section{Subfamily Limnocyoninae Wortman, 1902b Genus Thinocyon Marsh, 1872c}

Type species.-Thinocyon velox Marsh, 1872c, by original designation.

\section{Thinocyon velox Marsh, $1872 \mathrm{c}$}

Figure 15.1-15.4, 15.8, 15.9

1872c Thinocyon velox Marsh, p. 204.

1902a Limnocyon velox (in part); Wortman, p. 202, figs. 76, 78-80.

1909 Thinocyon velox; Matthew, p. 450, pl. 44, figs. 2, 3, text figs. 59-61.

1909 Thinocyon cledensis Matthew, p. 450.

1909 Thinocyon mustelinus Matthew, p. 461, pl. 43, figs. 2-4.

1923a Thinocyon mustelinus; Thorpe, p. 35.

1938 Thinocyon mustelinus; Denison, p. 179.

1938 Thinocyon velox; Denison, p. 179, figs. 18, 19b, 20a, 21, 23a, 24a, 25a, 30a.

1976 Thinocyon mustelinus; Gazin, p. 10.

1998a Thinocyon mustelinus; Gunnell, p. 99.

2003 Thinocyon velox; Morlo and Gunnell, p. 50, figs. 2a, 2b, 3-12.

Holotype.-YPM VP 011797, left dentary with c1-p4 and m2 talonid.

Locality._-Grizzly Buttes" (Marsh, 1872c, p. 204), Bridger Basin, Uinta County, Wyoming.

Horizon.-Blacks Fork Member (Bridger B), Bridger Formation.

Occurrence.-Blacks Fork Member and equivalent intervals, Bridger Formation, Greater Green River (including Bridger) Basin, Wyoming; Twka1, Adobe Town Member, Washakie Formation, Washakie Basin, Sweetwater County, Wyoming. Early to late Bridgerian (Br1b-Br3) NALMA (Morlo and Gunnell, 2003).

Materials from Washakie Basin.-AMNH locality recorded as "Haystack Mountain" (Twka1?): AMNH FM 13140 (we 


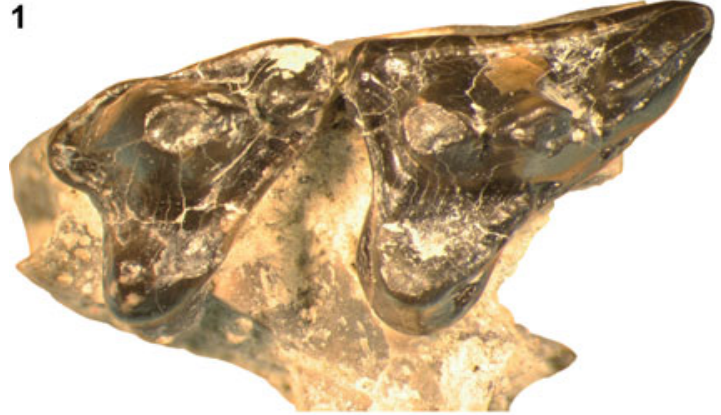

2

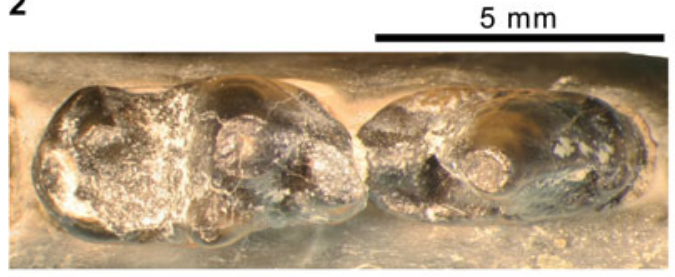

3

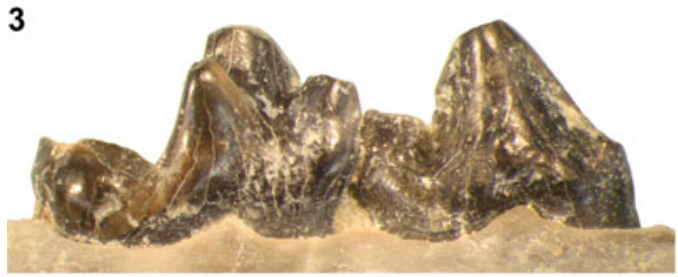

4

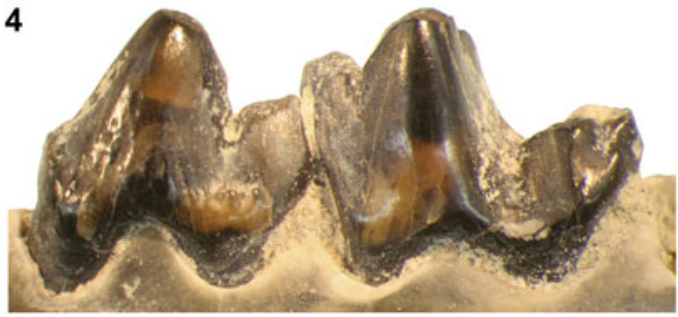

5
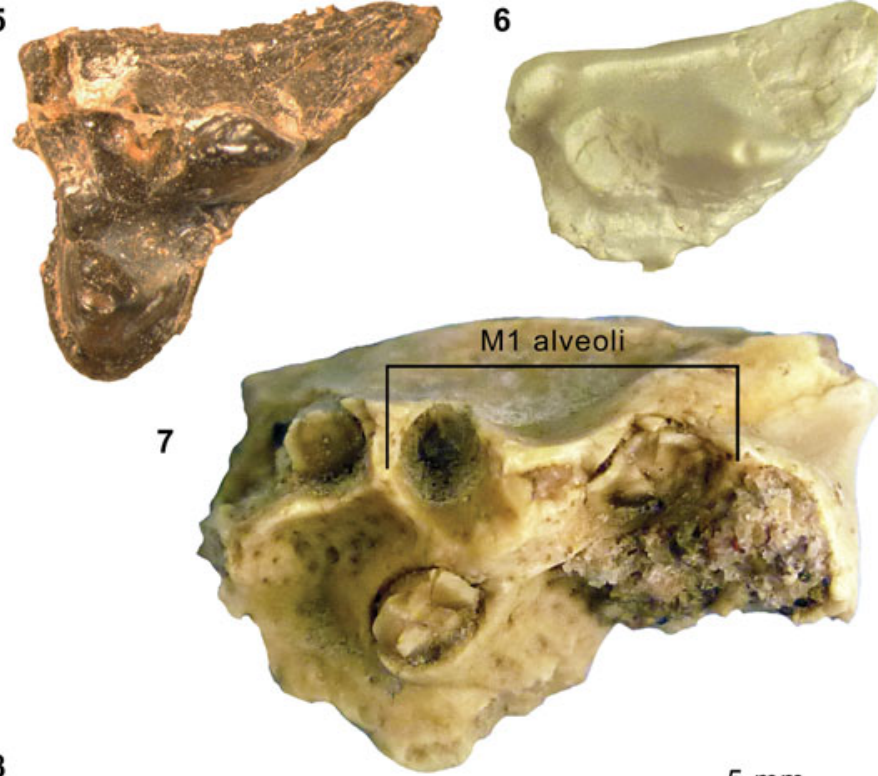

8
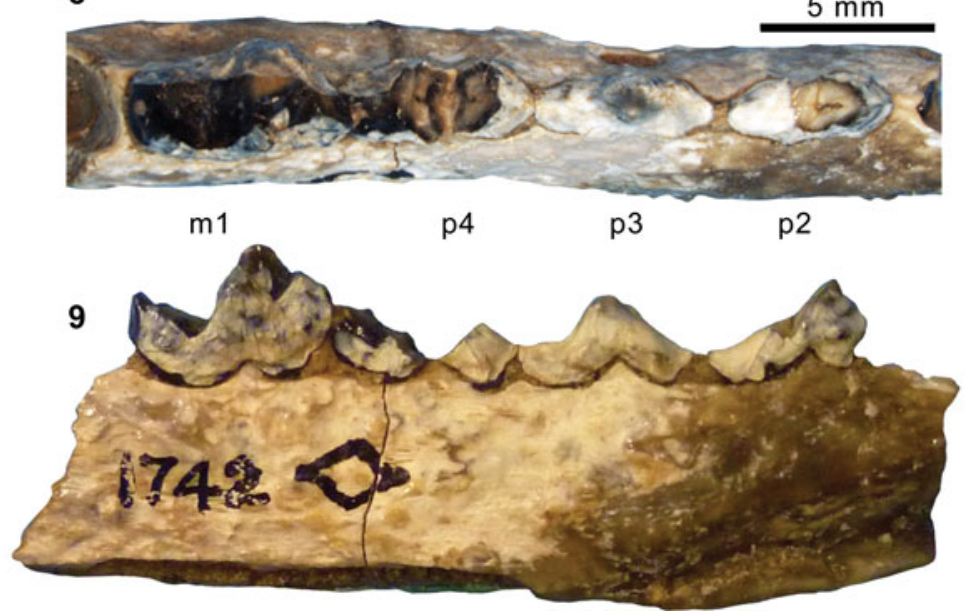

Figure 15. Hyaenodontid Thinocyon Marsh, 1872c, from the Washakie Formation. Specimens referred to Thinocyon velox Marsh, 1872c: (1-4) left maxillary fragment with P4-M1 in occlusal view (1) and left p4-m1 in occlusal (2), lingual (3), and labial (4) views of FMNH PM 61173; (8, 9) left p2-m1 in occlusal (8) and lingual (9) views of AMNH FM 1742 (holotype of T. 'cledensis' Matthew, 1909). Specimens referred to T. medius Wortman, 1902b: (5-7) left M1 of FMNH PM 1525 in occlusal view (5); left M1 fragment of FMNH PM 22432 in occlusal view (6); left maxillary fragment with alveoli for P4 (posterolabial alveolus)-M2 (partial labial alveolus) of FMNH PM 62221 (7). Different 5 mm scales apply to Figure 15.1-15.7 and 15.8, 15.9.

examined its cast, FMNH PM 22446), broken right M1, left dentary with broken $\mathrm{p} 4$ and broken $\mathrm{m} 2$.

AMNH locality recorded as "La Clede Meadows" (Twka1?): AMNH FM 1742 (holotype of Thinocyon 'cledensis'), right and left dentary fragments with right $\mathrm{p} 4-\mathrm{m} 2$ (m1-2 broken) and left $\mathrm{p} 2-\mathrm{m} 1$ ( $\mathrm{p} 2$ and $\mathrm{p} 4$ broken).

FMNH locality FM-1-58-WDT (Twka1): FMNH PM 63111, lingual fragment of right M1.

FMNH locality JJF 7-23-90-2 (Twka1): FMNH PM 55779, left $\mathrm{m} 1$ trigonid.

FMNH locality JJF 7-24-95-1 (Twka1): FMNH PM 61173, maxillary fragments with right M2 and left P4-M1, $\mathrm{C} 1$, left dentary fragment with $\mathrm{p} 4-\mathrm{m} 1$, fragmentary postcrania including vertebrae, right and left humeri, phalanges, and right femur.

FMNH locality JJF 7-30-95-3 (Twka1): FMNH PM 61399, fragments of right and left dentaries and unidentified teeth, left humerus missing proximal and distal ends.
Princeton University locality recorded as southwest of South Barrel Springs (Twka1): YPM VPPU 016101, weathered cranium with right and left P2-M2 (Ivy, 1994, p. 292, 295; Morlo and Gunnell, 2003).

Remarks.-We follow Morlo and Gunnell (2003) and treat both Thinocyon 'cledensis,' the holotype of which comes from Twka1 (Fig. 15.8, 15.9), and T. 'mustelinus' as junior synonyms of T. velox. FMNH PM 61173 (Fig. 15.1-15.4) is securely identified as $T$. velox based on its small size (see Table 4 for measurements), P4 with weakly developed parastyle, shallow dentary, low $\mathrm{p} 4$ with vestigial anterior cuspulid, and relatively gracile $\mathrm{m} 1$ hypoconid (cf., Morlo and Gunnell, 2003); other, more fragmentary specimens listed above are referred to the same species based on their comparably small sizes and pertinent morphology. Interestingly, T. velox, while common in the Blacks Fork Member ( $\mathrm{Br} 2$ in age) of the Bridger Formation, is unknown 
from the Twin Buttes Member $(\mathrm{Br} 3$ in age) of the same formation, where it apparently was replaced by $T$. medius (Matthew, 1909; Morlo and Gunnell, 2003). In contrast, we have identified both species from Twkal $(\mathrm{Br} 3$ in age) in the Washakie Formation of the Washakie Basin. These occurrence patterns may reflect environmental differences or a certain degree of dispersal limitation for this small, possibly semi-fossorial carnivore (Morlo and Gunnell, 2003) between the Bridger and Washakie basins during the late Bridgerian. Additional comments on the distribution of $T$. velox are provided in Appendix.

\section{Thinocyon cf. T. medius (Wortman, 1902a)} Figure 15.5-15.7

1902a Limnocyon medius Wortman, p. 204, figs. 81, 82.

1909 Thinocyon medius; Matthew, p. 459, text-figs. 62-70.

1923a Thinocyon medius; Thorpe, p. 34.

1938 Thinocyon medius; Denison, p. 179.

1959 Thinocyon sp.; McGrew et al., p. 169.

1976 Thinocyon medius; Gazin, p. 10.

1998a Thinocyon medius; Gunnell, p. 99.

2003 Thinocyon medius; Morlo and Gunnell, p. 64, figs. 13, $15,16$.

Occurrence.-Twin Buttes Member and equivalent intervals, Bridger Formation, Greater Green River (including Bridger) Basin, Wyoming (Morlo and Gunnell, 2003); Twka1, Adobe Town Member, Washakie Formation, Washakie Basin, Sweetwater County, Wyoming (this study). Late Bridgerian (Br3) NALMA.

Materials from Washakie Basin.-AMNH locality recorded as "Haystack Mountain, second bench" (Twka1): FMNH PM 22432 (cast of AMNH FM 13209 according to specimen label; may correspond to a tooth [presently missing from the collection] that was originally cataloged under that number with artiodactyl material), partial left M1.

FMNH locality FM-14-56-WDT (Twka1): FMNH PM 1525 , left M1 in matrix.

FMNH locality JJF 8-13-93-1 (Twka1): FMNH PM 62221, left maxillary fragment with alveoli for P4-M2, fragment of right $\mathrm{m} 2$ trigonid.

Remarks.-FMNH PM 1525 and FMNH PM 22432 (Fig. 15.5, 15.6) are referred to Thinocyon medius based primarily on their large sizes (Table 4). Additionally, the vestigial metaconule of PM 1525 is consistent with the characterization of T. medius by Morlo and Gunnell (2003, p. 65), although the orientation of the metastyle in FMNH PM 1525 and FMNH PM 22432 does not seem to differ appreciably from that in FMNH PM 61173 (referred to T. velox above; Fig. 15.1). The protocone of FMNH PM 1525 shows a proportionately greater lingual extension compared to that of FMNH PM 61173 (such that the metastylar region and the protocone form a more inflected posterolingual border of the tooth in occlusal view), but this trait also may be present on some individuals of $T$. velox and may not reliably differentiate these two species (cf., Morlo and Gunnell, 2003). FMNH PM 62221 (Fig. 15.7) is tentatively referred to T. medius based on its comparable size to FMNH PM 1525, judged from the M1 alveoli.

Genus Limnocyon Marsh, 1872a

Type species. - Limnocyon verus Marsh, 1872a, by original designation.

Limnocyon verus Marsh, 1872a

Figure 16.1-16.8, 16.10

1872a Limnocyon verus Marsh, p. 126.

1872c Limnocyon riparius Marsh, p. 203.

1899 Telmatocyon riparius; Marsh, p. 397.

1902a Limnocyon verus; Wortman, p. 198, figs. 71-75, pl. 6.

1909 Limnocyon verus; Matthew, p. 434, pl. 44, fig. 1, pl. 47, fig. 2d, text-figs. 53-58.

1923a Limnocyon verus; Thorpe, p. 32.

1998a Limnocyon verus; Gunnell, p. 99.

Lectotype.-YPM VP 013095, right I1, I2, C1 fragment, P1, P2 fragment, $\mathrm{P} 4-\mathrm{M} 2$ and additional fragments of teeth and bones.

Locality.- "Grizzly Buttes, near Fort Bridger" (Marsh, 1872a, p. 127), Bridger Basin, Uinta County, Wyoming.

Horizon.-Blacks Fork Member (Bridger B), Bridger Formation.

Occurrence.-Blacks Fork and Twin Buttes members, Bridger Formation, Bridger Basin, Wyoming (Gunnell, 1998a; Morlo and Gunnell, 2005); Twka1, Adobe Town Member, Washakie Formation, Sweetwater County, Wyoming (this study). Middle to late Bridgerian (Br2- $\mathrm{Br} 3)$ NALMA. Additionally, Krishtalka and Stucky (1984) reported Limnocyon cf. L. verus from early Bridgerian-aged deposits of the Green River Formation in the Uinta Basin, Utah, in their faunal list, but the pertinent material has yet to be described, and we deem the reported occurrence to be currently unconfirmed (cf., Gunnell, 1998a; Gunnell and Bartels, 1999; Morlo and Gunnell, 2005).

Materials from Washakie Basin.-FMNH locality JJF 7-27-91-2 (Twka1): FMNH PM 55343, right dentary fragment with roots of $\mathrm{p} 4-\mathrm{m} 2$; fragmentary teeth, including left P4-M1, px, left $\mathrm{m} 1$, and left $\mathrm{m} 2$ trigonid; additional skeletal fragments.

FMNH locality JJF 8-14-93-2 (Twka1): FMNH PM 56553, left $\mathrm{m} 1$, missing much of entocristid.

Remarks.-Marsh (1872a) named Limnocyon verus based on "remains of several individuals" (p. 126). He described one of them, "the greater portion of a skull" (= YPM VP 011796 [Wortman, 1902b, pl. 6; Thorpe, 1923a]), but did not otherwise specify the constituents of the syntype series. Later, in reviewing the specimens of $L$. verus in the YPM Marsh Collection, Wortman (1902b) apparently considered a set of right upper teeth corresponding to YPM VP 013095 as the holotype (described as the "type" in the caption for fig. 71), without noting that Marsh (1872a) had erected the species based on multiple specimens. To avoid further confusion, here we formally designate YPM VP 013095 as the lectotype and 


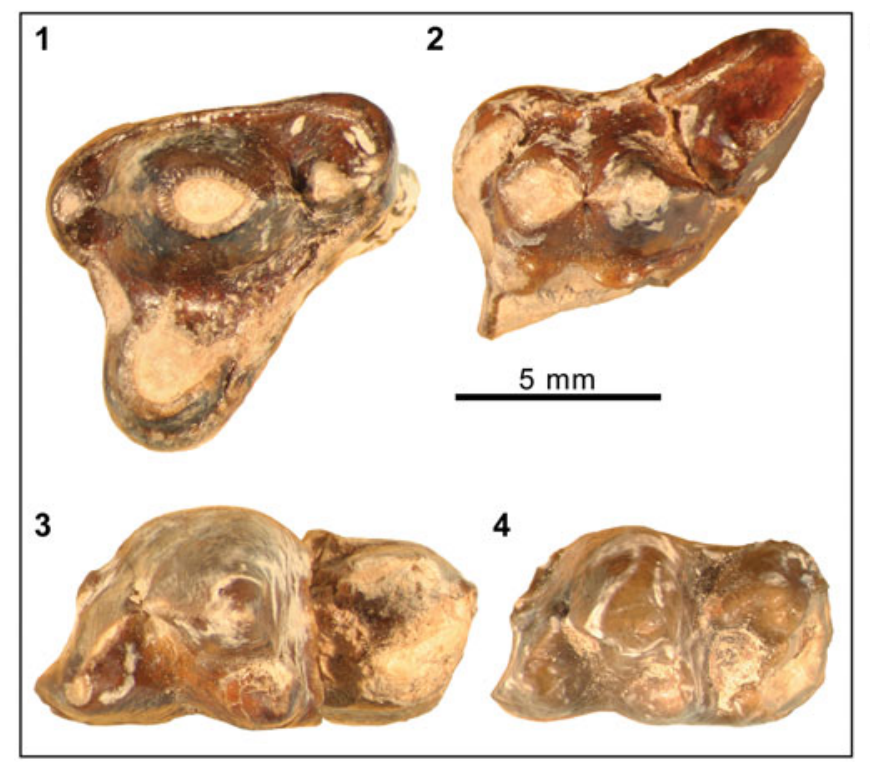

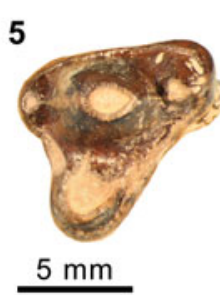
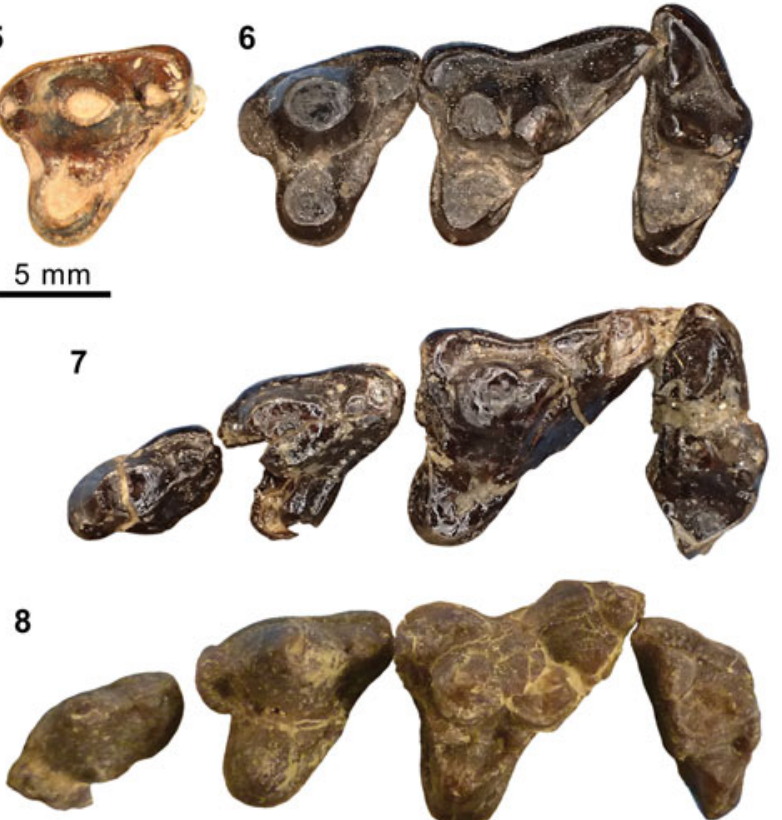

4

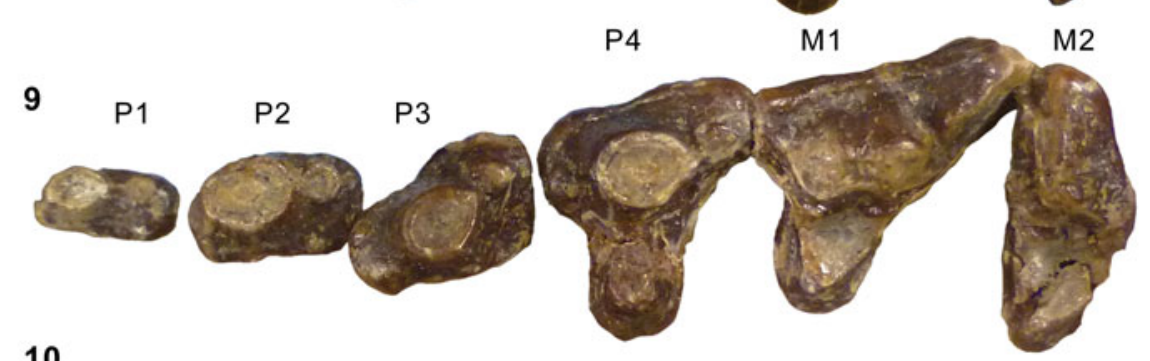

10
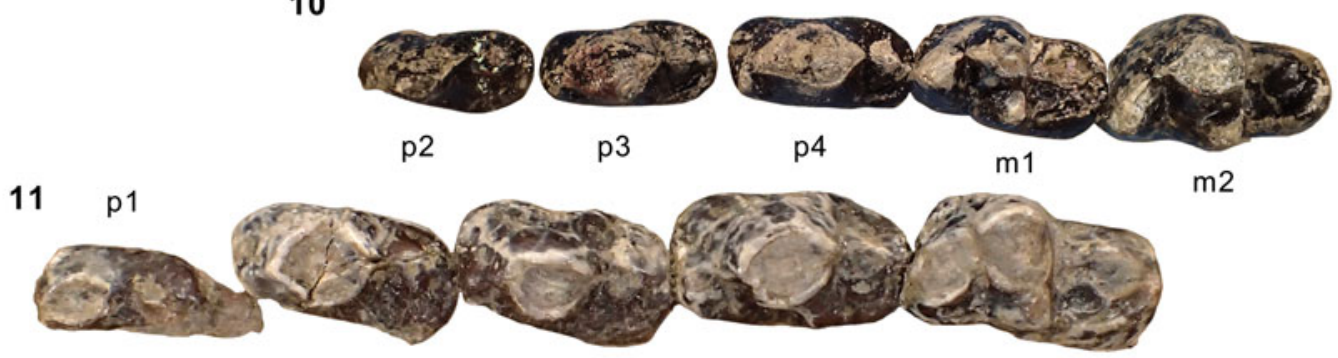

Figure 16. Dentitions of middle Eocene hyaenodontid Limnocyon Marsh, 1872a. Specimens referred to Limnocyon verus Marsh, 1872a: (1-3, 5) left P4 at two different scales (1, 5), left M1 (2), and left m1 (inverted in 3) of FMNH PM 55343 (Twka1); (4) left m1 (inverted) of FMNH PM 56553 (cf. L. verus; Twka1); (6) right P4-M2 (inverted) of AMNH FM 12155 (Bridger C); (7) left P3-M2 of AMNH FM 19199 (Bridger B); (8) left P3-M2 of KUVP 14154 (Bridger Formation); (10) right p2-m2 of AMNH FM 19200 (composite of two photographs to show m2 in occlusal view; Bridger B). Holotype AMNH FM 13138 of L. potens Matthew, 1909: (9, 11) right P1-M2 (inverted in 9) and right p1-m1 (11). All photographs in occlusal view. Figure 16.1-16.4 and 16.5-16.11 at two different scales.

YPM VP 011796 as a paralectotype of L. verus, following Article 74 of the International Code of Zoological Nomenclature (ICZN, 1999).

The referred specimens from the Washakie Formation, though fragmentary, are generally comparable in size to the Bridgerian species Limnocyon verus, and are smaller than the Uintan species L. potens Matthew, 1909 (Table 5). Further, the anterior orientation of the $\mathrm{P} 4$ protocone resembles those in L. verus (Fig. 16.6-16.8) and L. cuspidens Morlo and Gunnell, 2005 (Morlo and Gunnell, 2005, fig. 2b), and differs from the more directly lingual orientation seen in specimens of L. potens (e.g., the holotype AMNH FM 13138, Fig. 16.9). Compared to other specimens of Bridgerian ages, FMNH PM 55343 (Fig. 16.1-16.3, 16.5) is morphologically most similar to later Bridgerian specimens of $L$. verus, including AMNH FM 12155 and FMNH UC 1725 from the Bridger C and $\mathrm{D}$ intervals, respectively; this specimen from Twka1 differs from the type and only known specimen of the Br2-age L. cuspidens (AMNH FM 140004) in having a (1) smaller parastyle and metastyle of P4 and (2) shallower M1 ectoflexus owing to minimal labial projection of the parastylar region in occlusal view. The m1s of FMNH PM 55343 and FMNH PM 56553 (Fig. 16.3, 16.4; note the posterolingual breakage of the talonid in both specimens) differ from earlier Bridgerian specimens of $L$. verus (e.g., AMNH FM 19200, USNM PAL 299722) in having the paraconid larger and taller than the metaconid. Unfortunately, the $\mathrm{m} 1$ trigonids of other late Bridgerian specimens of $L$. verus and those of the early Uintan species 
L. potens that we have examined are all heavily worn, precluding comparisons.

The $\mathrm{m} 1$ of FMNH PM 56553 (Fig. 16.4) is tentatively referred to Limnocyon verus based on its relatively small size and likely late-Bridgerian $(\mathrm{Br} 3)$ age. However, we note that it cannot be directly compared with Limnocyon cuspidens (known only from the holotype of a middle Bridgerian [Br2] age), whose lower dentition is unknown. Judging from the angle of the posterolabial wall of the talonid, this specimen appears to have had a noticeably shorter talonid (even taking into consideration the posterior breakage) than other specimens of $L$. verus that we have examined, as well as $L$. potens (Fig. 16.10, 16.11).

\section{Limnocyon potens Matthew, 1909}

Figures 16.9, 16.11, 17-20

1909 Limnocyon potens Matthew, p. 447 (type not figured).

1919 Limnocyon douglassi Peterson, p. 45.

1938 Limnocyon potens; Denison, p. 179, figs. 28a, 29a.

1998a Limnocyon potens; Gunnell, p. 99.

2005 Limnocyon potens; Morlo and Gunnell, fig. 3c.

Holotype.-AMNH FM 13138, cranium with right I1-M2 and left I2, C1-P3, M1-2, right dentary with c1-m1, left dentary with $\mathrm{p} 1-\mathrm{m} 2$, partial skeleton including nearly complete presacral vertebral column and right hindlimb.

Locality.-AMNH locality recorded as northwest Haystack Mountain, Washakie Basin, Sweetwater County, Wyoming.

Horizon.-Roehler's (1973, 1992) bed 633 (= Granger's [1909] stratum no. 17), Twka2, Adobe Town Member, Washakie Formation.

Emended diagnosis.-Larger than Limnocyon verus and $L$. cuspidens; I2 enlarged, caniniform; I3 absent; cheek teeth, particularly premolars, more robust; premolars crowded (such that P2-3 and p2-3 are imbricated in some individuals); P3 with a prominent distolingual platform; m1-2 trigonids enlarged relative to talonids; m1-2 metaconids smaller, particularly on m2; M1 metastylar blade longer and less transversely oriented than in L. verus and L. cuspidens.

Occurrence.-Twka2, Adobe Town Member, Washakie Formation, Washakie Basin, Sweetwater County, Wyoming; Wagonhound Member, Uinta Formation, Uinta Basin, Utah. Early to middle Uintan (Ui1b-Ui2) NALMA (Gunnell, 1998a; Gunnell et al., 2009).

Description of postcrania.-Matthew (1909) provided a very brief description of AMNH FM 13138 and AMNH FM 13139 , focusing on the diagnostic features of the dentition and vertebral morphology. The skull and dentition of AMNH FM 13138 (Figs. 16.9, 16.11, 17) have been briefly described and partly illustrated by Denison (1938) and Morlo and Gunnell (2005). Denison (1938) also illustrated the innominate and femur of AMNH FM 13138. Still, neither specimen has been adequately illustrated, nor have most aspects of appendicular morphology been described. What follows is a brief description of significant aspects of the postcranial morphology of Limnocyon potens from the Washakie Basin. A complicating factor is that the morphology of the distal tibia, fibula, and tarsus of AMNH FM 13138 is obscured by pathology. These bone surfaces are pitted and uneven, and there are indications of healed fractures in the distal tibia and calcaneal tuber (Fig. 19.8, 19.13). As a result, the holotype does not appear to provide a reliable indicator of the normal morphology of $L$. potens. Fortunately for description of these elements, the distal crus and tarsus of AMNH FM 13139 are well preserved (Fig. 20).

The scapular glenoid fossa of AMNH FM 13139 (Fig. 18.1, 18.6) is broad with substantial ventral deflection anteriorly. The humeral head (Fig. 18.2-18.5) is strongly convex and appears to have been oriented posteriad as well as proximad. The preserved portion of the greater tuberosity suggests that this process was taller than the humeral head. The medial epicondyle is robust, but does not project strongly medially (Fig. 18.7, 18.8). An entepicondylar foramen is present. The trochlea is shallow, steep, and does not project far distally beyond the epicondyle. The olecranon fossa is deep and well defined, but it is not clear if it was perforate. There is no pit for the ulnar collateral ligament.

Ulnar fragments (Fig. 18.16-19) indicate a robust olecranon process, a laterally oriented radial facet, and a robust distal end, but little else can be said. The radial head (Fig. 18.1118.13 ) is ovoid and mediolaterally much wider than anteroposteriorly deep. The ulnar facet on the posterior surface is gently curved, but ends abruptly at the medial margin of the bone (Fig. 18.12). There is a prominent capitular eminence (Fig. 18.13). The lateral crest, for articulation with the capitular tail, is well defined. The distal radius is incomplete, but the styloid process is prominent (Fig. 18.14, 18.15).

The pelvic girdle of AMNH FM 13138 is nearly complete (Fig. 19.1, 19.2). The iliac blade is evenly divided by a longitudinal ridge into a dorsal surface for the origin of the gluteal muscles and a ventral surface for the origin of $\mathrm{m}$. iliacus. The dorsal surface is slightly larger, but not to the extent seen in Hyaenodon (Scott and Jepsen, 1936). The ridge dividing the iliac blade terminates just in front of the acetabulum, in a prominent, projecting rectus tubercle. The ischial spine is located well posterior to the acetabulum, approximately halfway to the ischial tuberosity.

The large femoral head has a small proximal extension onto the neck (Fig. 19.3, 19.6, 19.7). The neck is short and directed mediad, such that the head does not project proximally to the shaft. The greater trochanter is distinctly taller than the femoral head. The lesser trochanter is directed posteromediad and connected to the greater trochanter by a strong intertrochanteric crest. The third trochanter is proximodistally short and projects abruptly from the lateral margin of the shaft just distal to the level of the lesser trochanter. The shaft is robust and compressed anteroposteriorly. The depth and width of the distal femur are subequal (Fig. 19.4). The patellar groove projects well anterior to the condyles. The groove is relatively wide and noticeably excavated. The condyles extend well posterior to the shaft.

The proximal tibia (preserved only in AMNH FM 13138) is damaged laterally (Fig. 19.13). As with the distal femur, width and depth appear subequal. The tibial tuberosity has a conspicuous anterior projection, forming a distinct tibial fossa for origin 
1

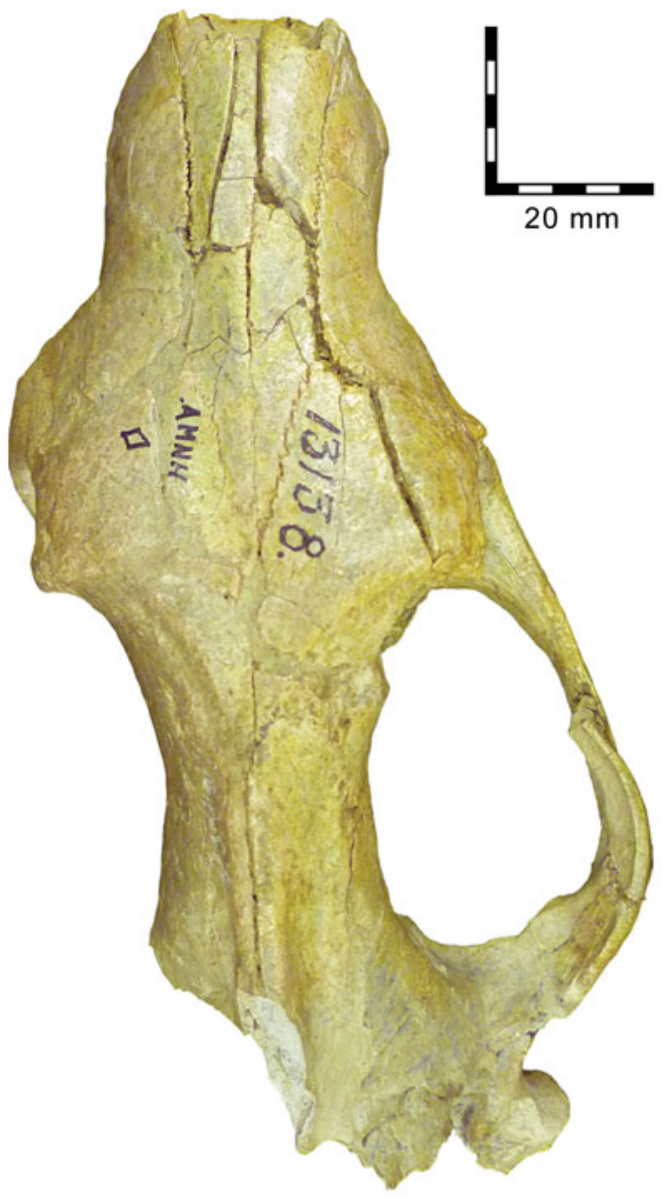

2

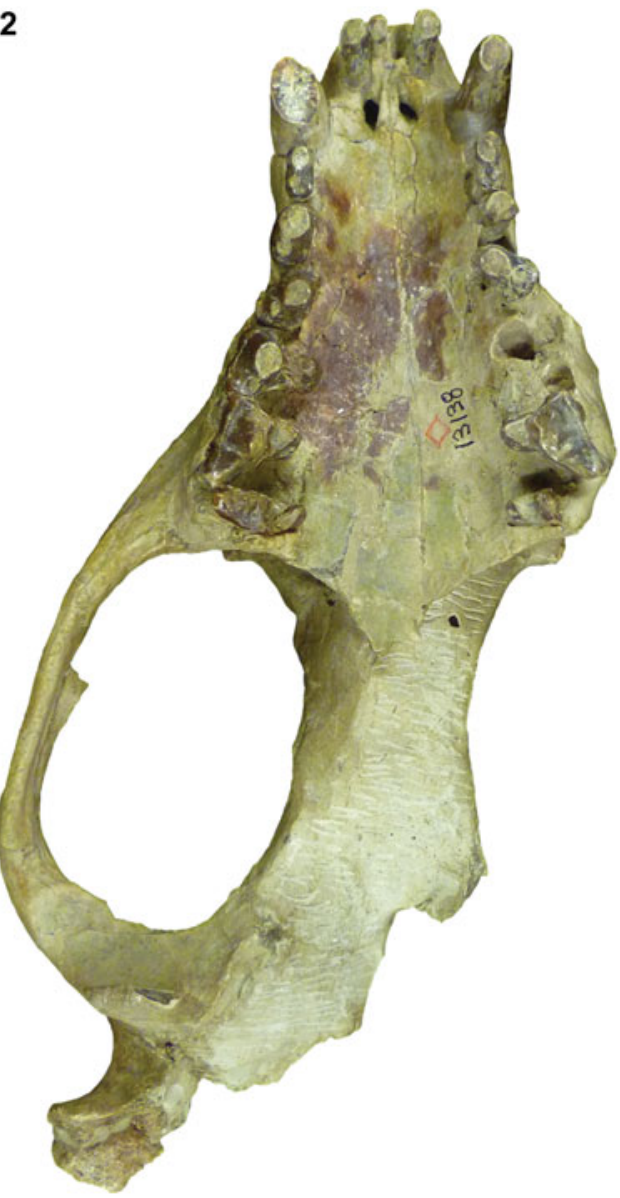

3

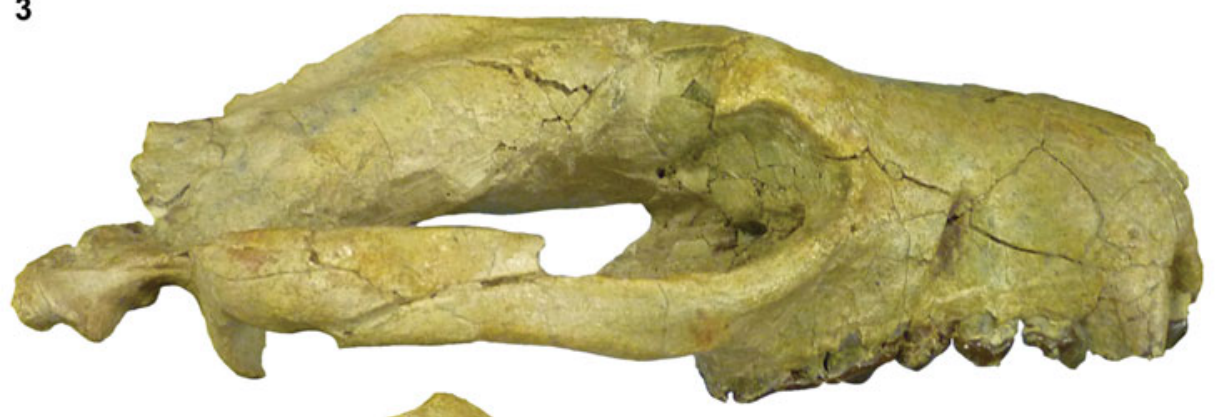

4

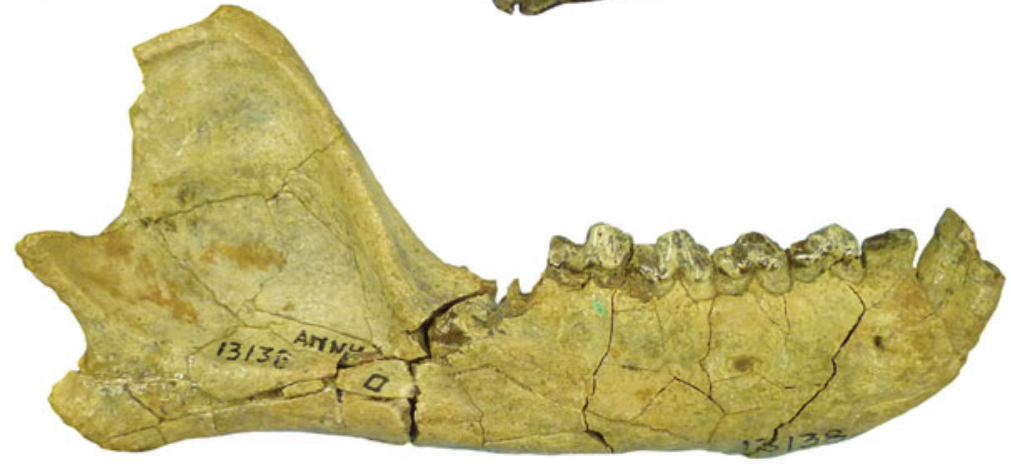

Figure 17. Skull of holotype AMNH FM 13138 of Limnocyon potens from the Washakie Formation. (1-3) Partial cranium in superior (1), inferior (2), and lateral (3) views; (4) right dentary in lateral view. Same $20 \mathrm{~mm}$ scale applies to all images. 


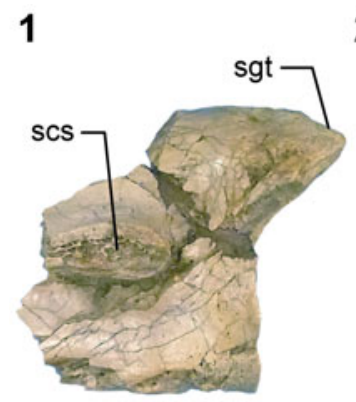

2
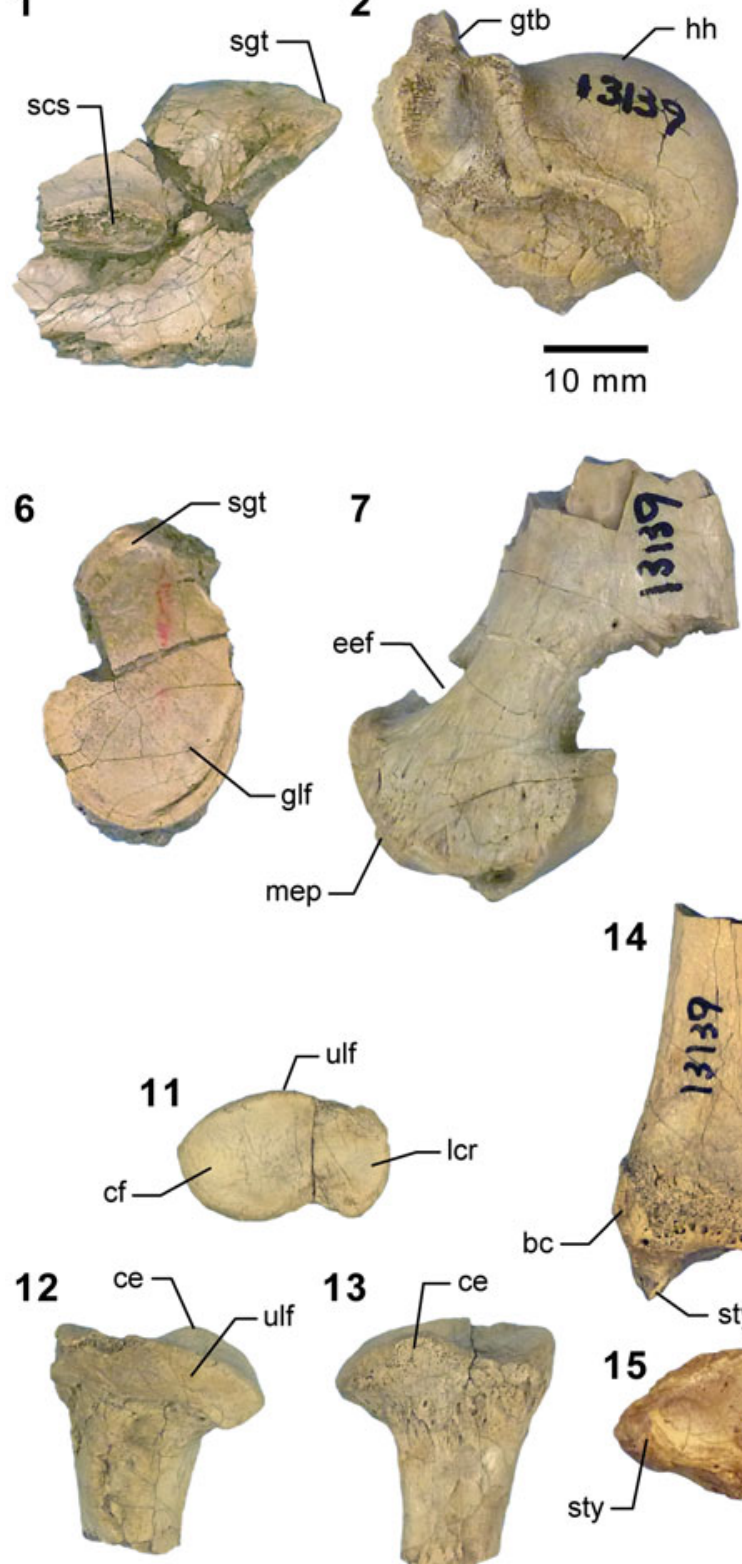

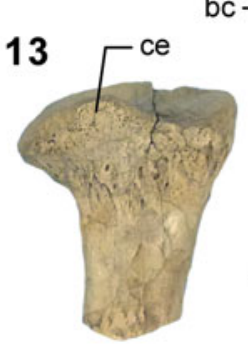

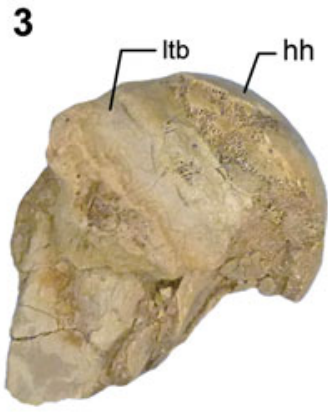
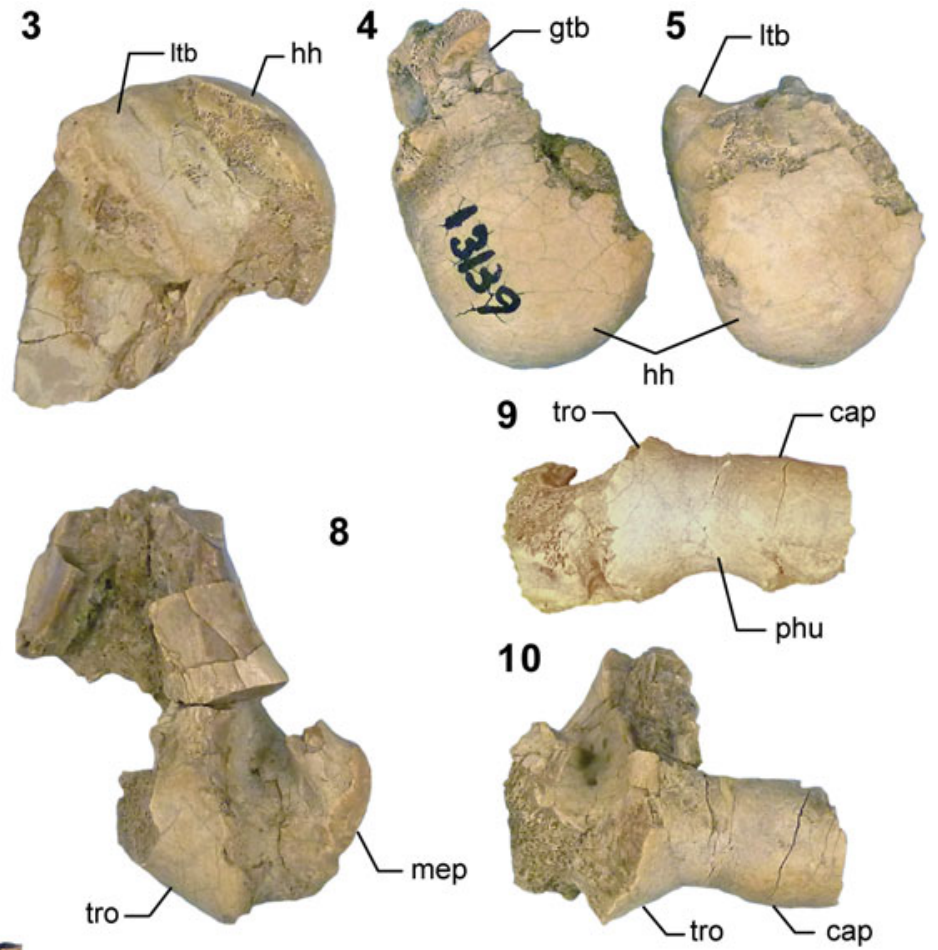

16

17

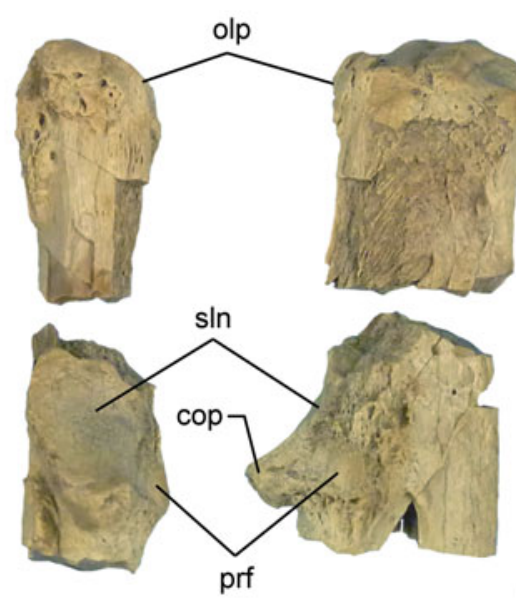

18
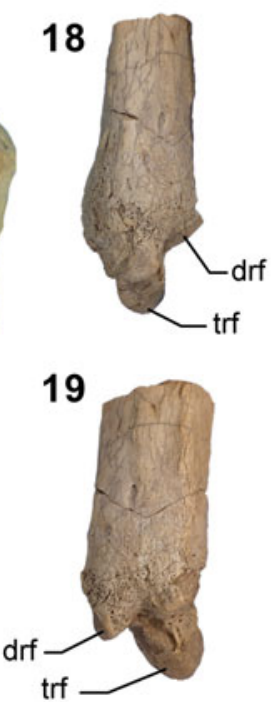

Figure 18. Pectoral girdle and front limb elements of AMNH FM 13139, Limnocyon potens. (1, 6) glenoid region of right scapula in lateral (1) and proximal (6) views; $(\mathbf{2}, \mathbf{4})$ left proximal humerus in lateral $(\mathbf{2})$ and proximal $(\mathbf{4})$ views; $(\mathbf{3}, \mathbf{5})$ right proximal humerus in medial $(\mathbf{3})$, and proximal $(\mathbf{5})$ views; $(\mathbf{7}, \mathbf{8})$ right distal humerus in anterior (8) and posterior (7) views; (9, 10) left distal humerus in anterior (10) and distal (9) views; (11-13) left proximal radius in anterior (13), posterior (12), and proximal $(\mathbf{1 1})$ views; $(\mathbf{1 4}, \mathbf{1 5})$ right distal radius in posterior $(\mathbf{1 4})$ and distal $(\mathbf{1 5}$, anterior to bottom) views; $(\mathbf{1 6}, \mathbf{1 7})$ fragments of left proximal ulna in anterior (16) and lateral $(\mathbf{1 7})$ views; $(\mathbf{1 8}, \mathbf{1 9})$ fragment of right distal ulna in anterior (18) and medial (19) views. Same 10 mm scale applies to all images. Abbreviations: bc, brachioradialis crest; cap, capitulum; ce, capitular eminence; cf, capitular facet of proximal radius; cop, coronoid process; drf, distal radial facet of ulna; eef, entepicondylar foramen; glf, glenoid fossa; gtb, greater tuberosity; hh, humeral head; lcr, lateral crest of radial head; ltb, lesser tuberosity; mep, medial epicondyle; olp, olecranon process; phu, posterior humeroulnar facet; prf, proximal radial facet of ulna; scs, scapular spine; sgt, supraglenoid tubercle; slf, scapholunar facet of distal radius; sln, semilunar notch; sty, radial styloid process; trf, triquetrum facet; tro, trochlea; ulf, ulnar facet of proximal radius.

of the m. tibialis anterior. The tibial crest extends more than halfway down the shaft. On the posterior surface of the proximal tibia, a sharp popliteal crest defines a lateral fossa for origin of the mm. flexores digitorum profundi, becoming indistinct proximal to the midshaft. As with the femur, the tibial shaft is robust and relatively short.

On the distal tibia of AMNH FM 13139 (Fig. 20.120.4), the astragalar facet is wider than long, distinctly broader medially than laterally, and inclined distolaterally. Anteriorly, a large check facet is present adjacent to the medial malleolus, and a prominent facet for the cotylar fossa occupies the anterior surface of the malleolus itself. The malleolus projects well distal to the remainder of the distal tibia. On the distal fibula (Fig. 20.5-20.8), the lateral malleolus forms a strong, finger-like process that also extends well distal to the remainder of the bone. 


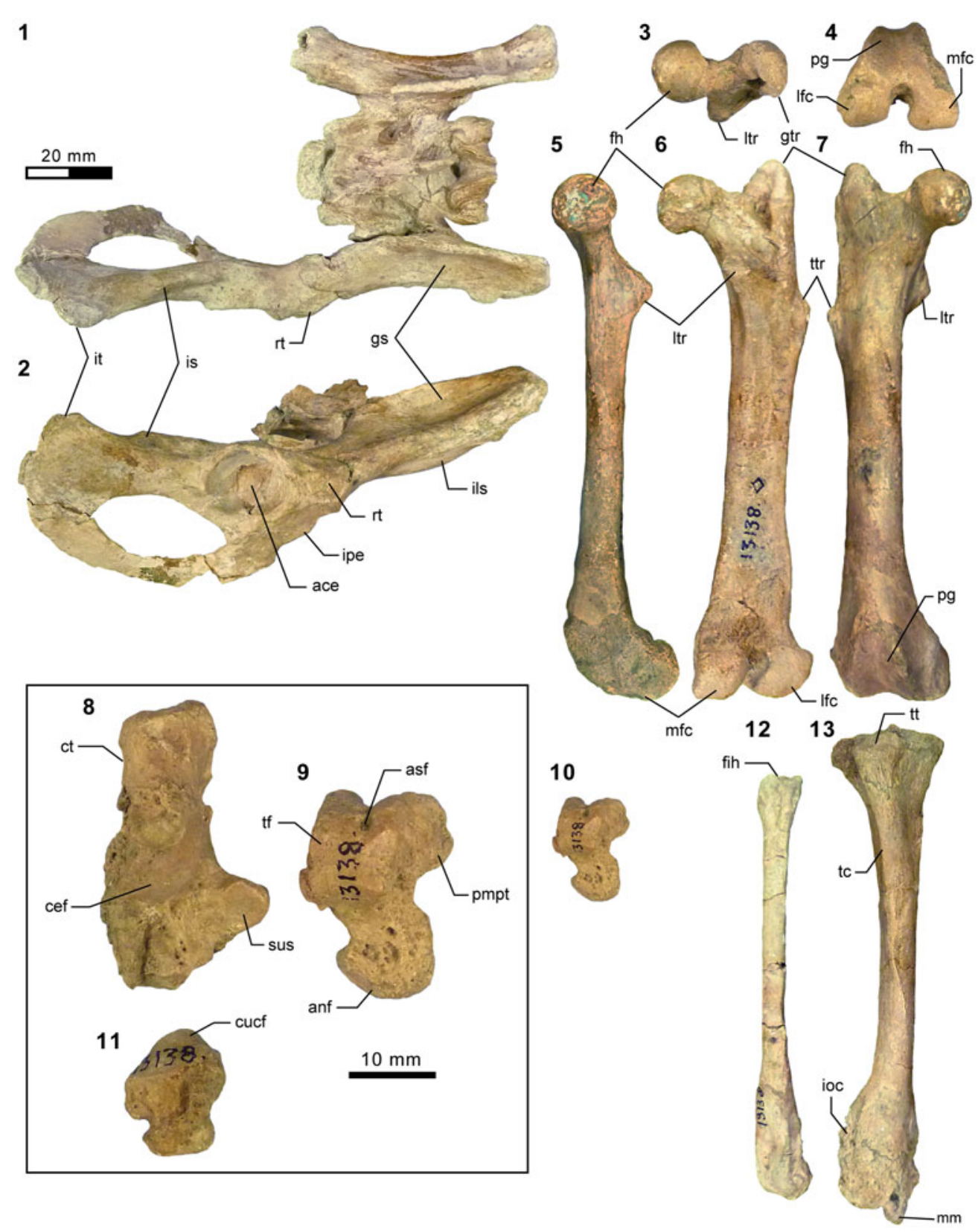

Figure 19. Pelvic girdle and hindlimb elements of holotype AMNH FM 13138 of Limnocyon potens. (1) Articulated sacrum, right pelvis and partial left pelvis in dorsal view; (2-7) right pelvis in lateral view (2); right femur in proximal (3), distal (4), medial (5), posterior $(\mathbf{6})$, and anterior (7) views; (8) right calcaneum; $(\mathbf{9}, \mathbf{1 0})$ right astragalus $(\mathbf{9}, \mathbf{1 0}$ at same scale as Fig. 19.1-19.7 and 19.12, 19.13); (11) right cuboid; (12) right fibula; (13) right tibia; $(\mathbf{8}-\mathbf{1 3})$ in anterior view. Same $20 \mathrm{~mm}$ scale applies to Figure 19.1-19.7, 19.10, 19.12, and 19.13; same $10 \mathrm{~mm}$ scale applies to Figure 19.8, 19.9, and 19.11. Abbreviations: ace, acetabulum; anf, astragalar navicular facet; asf, astragalar foramen; cef, calcaneal ectal facet; ct, calcaneal tuber; cucf, cuboid calcaneal facet; fh, femoral head; fih, fibular head; gs, gluteal surface of iliac blade; gtr, greater trochanter; ils, iliacus surface of iliac blade; ioc, interosseous crest; ipe, iliopectineal eminence; is, ischial spine; it, ischial tuberosity; lfc, lateral femoral condyle; ltr, lesser trochanter; mfc, medial femoral condyle; mm, medial malleolus; pg, patellar groove; pmpt, proximomedial plantar tuberosity; rt, rectus tubercle; sus, calcaneal sustentacular facet; tc, tibial crest; tf, astragalar tibial facet; tt, tibial tuberosity; ttr, third trochanter.

The tibial facet of the astragalus of AMNH FM 13139 (Fig. 20.9-20.15) is narrow and shallowly grooved. The medial margin has a narrow extension that continues much farther proximally than the lateral margin, which ends at the level of the astragalar foramen. The proximomedial plantar tuberosity is robust and projects ventrally and medially. A distinct cotylar fossa is not present medial to the tibial facet, but this region is abraded. The ectal facet is elongate, narrow, and strongly oblique. The sustentacular facet contacts the medial margin of the astragalar neck. A well-developed bridge facet extends from the distolateral corner of the sustentacular facet to the astragalar head. The neck is short and projects somewhat medial to the body. The lateral half of the dorsal surface of the neck is occupied by a large squatting facet, continuous with the distomedial margin of the ectal facet and nearly reaching the navicular facet distally. On the head, the long axis of the navicular facet is oblique in distal view, and the facet is deeper laterally than medially. In life, the navicular facet likely would have been 
more vertical and less transverse than is seen in Figure 20.15. The orientation of the astragalar facet on the distal tibia indicates that the tibial facet of the astragalus would have been inclined somewhat medially, rather than horizontal. The orientation of the astragalus in Figure 20.9-20.15 reflects standard orientation of hyaenodontid astragali, and is intended to facilitate comparisons with other hyaenodontids and carnivorous eutherians.

The calcaneum of AMNH FM 13139 (Fig. 20.16-20.20) bears a tuber that is moderately elongate and expanded at its proximal end. The calcaneal ectal facet is almost flat and oriented distomedially, with no dorsal component. Immediately lateral to the ectal facet is a very prominent, dorsally oriented fibular facet that is almost as large as the ectal facet. The sustentacular facet is round, with minimal development of a distal extension. This facet nearly completely overlaps the ectal facet. The peroneal tubercle is damaged on both sides of AMNH FM 13139, but does not appear to have reached the terminus bearing the cuboid facet. Ventrally, the plantar tubercle is prominent and terminally positioned, overhanging the cuboid facet. The cuboid facet is flat and faces distally and slightly medially. The length and width of the facet are subequal, with the lateral margin curved and the ventromedial margin notched.

The cuboid of AMNH FM 13139 (Fig. 20.21-20.25) is blocky, with subequal length and width. Its calcaneal facet faces proximally and somewhat laterally, with a slight dorsal tilt. The facet is much broader than deep. Its curves somewhat ventrally near its lateral margin but it does not contact the plantar tubercle. Medially, a well-defined, proximomedially oriented astragalar facet is present. Distal to the astragalar facet, the navicular and ectocuneiform facets are separated dorsally, but appear to be confluent ventrally. The ectocuneiform facet is distal to the midpoint of the bone. At the dorsodistal corner of the medial surface of the cuboid, a small accessory ectocuneiform facet is present. The plantar tubercle projects ventrally and is even with the primary ectocuneiform facet. The distomedial corner of the bone is broken, so the proportions of the metatarsal facet cannot be assessed.

Proximally, the navicular facet of the ectocuneiform (Fig. 20.26-20.30) is oriented directly proximad, and is wedgeshaped, tapering ventrally. There are three facets on the lateral surface of the ectocuneiform, a large proximal facet for the cuboid, a small distal accessory cuboid facet, and a more ventrally positioned facet for metatarsal (MT) IV. The medial surface also has three facets, a proximal facet for the mesocuneiform and two distal facets, one dorsal and one ventral, for MT II. The dorsal metatarsal facet is narrowly separated from the mesocuneiform facet. On the distal surface of the ectocuneiform is a keyhole-shaped facet for MT III. The latter facet is somewhat wider mediolaterally than the proximal navicular facet, consistent with the ectocuneiform as a whole being somewhat wider distally than proximally.

The proximal surface of the mesocuneiform (Fig. 20.3120.35 ) has a proximally and slightly medially oriented navicular facet, while the proximal half of the lateral surface is occupied by the rectangular ectocuneiform facet. On the medial surface, the entocuneiform facet is similarly positioned, but does not extend to the posterior end of the bone. The entire distal surface is occupied by the MT II facet. In addition to fragments of metatarsals and proximal and intermediate phalanges, the proximal end of a single partial ungual is preserved. The flexor tubercle is weakly defined. Dorsally, the base of a fissure appears to be present.

Materials.-From the type locality (Twka2; Matthew, 1909): AMNH FM 13139, weathered skeletal fragments including right pelvis, right proximal femur, right and left proximal and distal humeri, right scapula (glenoid region), right and left ulnae (portions bearing semilunar notches), right and left proximal radii, right distal radius, right distal tibia, ?right distal fibula, right astragalus, right and left calcaneum, trochlea of left astragalus, right cuboid, right and left ectocuneiform, left mesocuneiform, metapodials, phalanges.

Remarks.-Dental measurements are reported in Table 5. Limnocyon includes three species generally regarded as valid: the type species, L. verus (including Telmatocyon riparius [Marsh, 1872c]), L. cuspidens, and L. potens (including L. douglassi Peterson, 1919). Matthew (1909, p. 447) established the Uintan species $L$. potens and distinguished it from Bridgerian $L$. verus based on: (1) larger, more robust teeth; (2) loss of I3 and enlargement of I2; (3) labiolingually wider P4M2; (4) better developed P4 protocone (= "deuterocone") and M1 protocone; (5) relatively larger and posterolingually wider P3; (6) presence of anterior cuspulids (= paraconids) on p3-4; (7) narrower but more extended posterior ends of nasals; and (8) deeper and longer astragalar trochlea. Below we discuss these traits in detail.

As Matthew (1909) observed, Limnocyon verus and L. potens are reliably distinguished by tooth size and robusticity. Not only are Uintan Limnocyon specimens substantially larger than Bridgerian specimens, later Bridgerian $(\mathrm{Br} 3)$ specimens of Limnocyon are generally larger than earlier $(\mathrm{Br} 2)$ specimens, suggesting a sustained trend towards larger body size within the genus. Uintan specimens also generally have more robust teeth. This is particularly true of the premolars, which tend to be relatively larger and broader in Uintan than in Bridgerian specimens. For example, $\mathrm{P} 3$ has a posterolingual heel in L. potens but not in Bridgerian forms. In AMNH FM 13138, large size and crowding of the premolars lead to imbrication between $\mathrm{P} 2 / \mathrm{p} 2$ and P3/p3. CM 11439 also shows imbrication between p2 and p3, but not between P2 and P3. CM 3373 has crowded but non-imbricated premolars. Among Bridgerian-aged specimens of Limnocyon, slight imbrication is present between p2 and $\mathrm{p} 3$ of AMNH FM 12155, but is otherwise unknown.

Matthew's (1909) incisor character also appears to be valid for diagnosing species. Two specimens of Limnocyon potens, the holotype and CM 11439, preserve the upper incisors. Both have a small I1 and a large, caniniform I2, but lack I3 (Fig. 17.2). In contrast, Bridgerian Limnocyon, including both L. verus (AMNH FM 12155 and USNM PAL 299722) and L. cuspidens (AMNH FM 140004), retain three upper incisors on each side. In the two specimens of L. verus, I2 (or its alveolus) is the largest incisor, but it is only slightly larger than I1 and I3, and the crown of I2 is incisiform in USNM PAL 299722 (unknown in AMNH FM 12155). In L. cuspidens, the alveolus of I3 is larger than that of I2 (Morlo and Gunnell, 2005).

Some of Matthew's other diagnostic features do not reliably distinguish Limnocyon potens from Bridgerian Limnocyon 

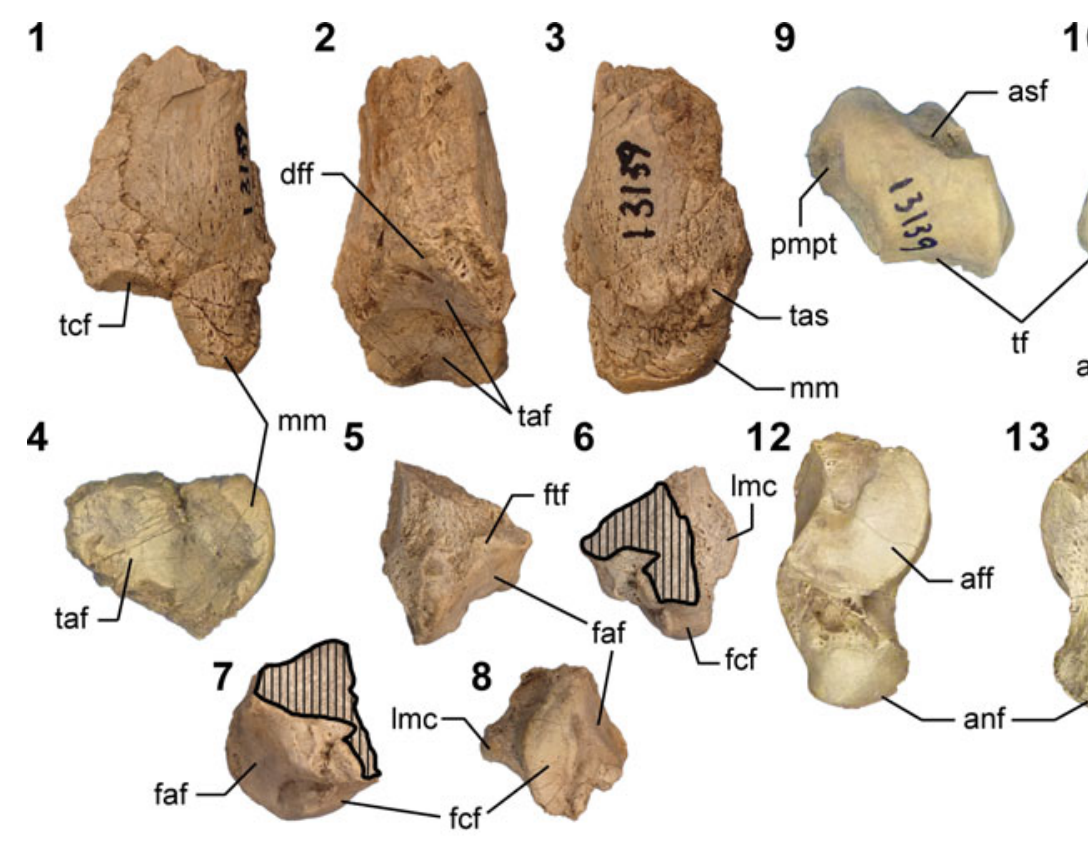

10

11
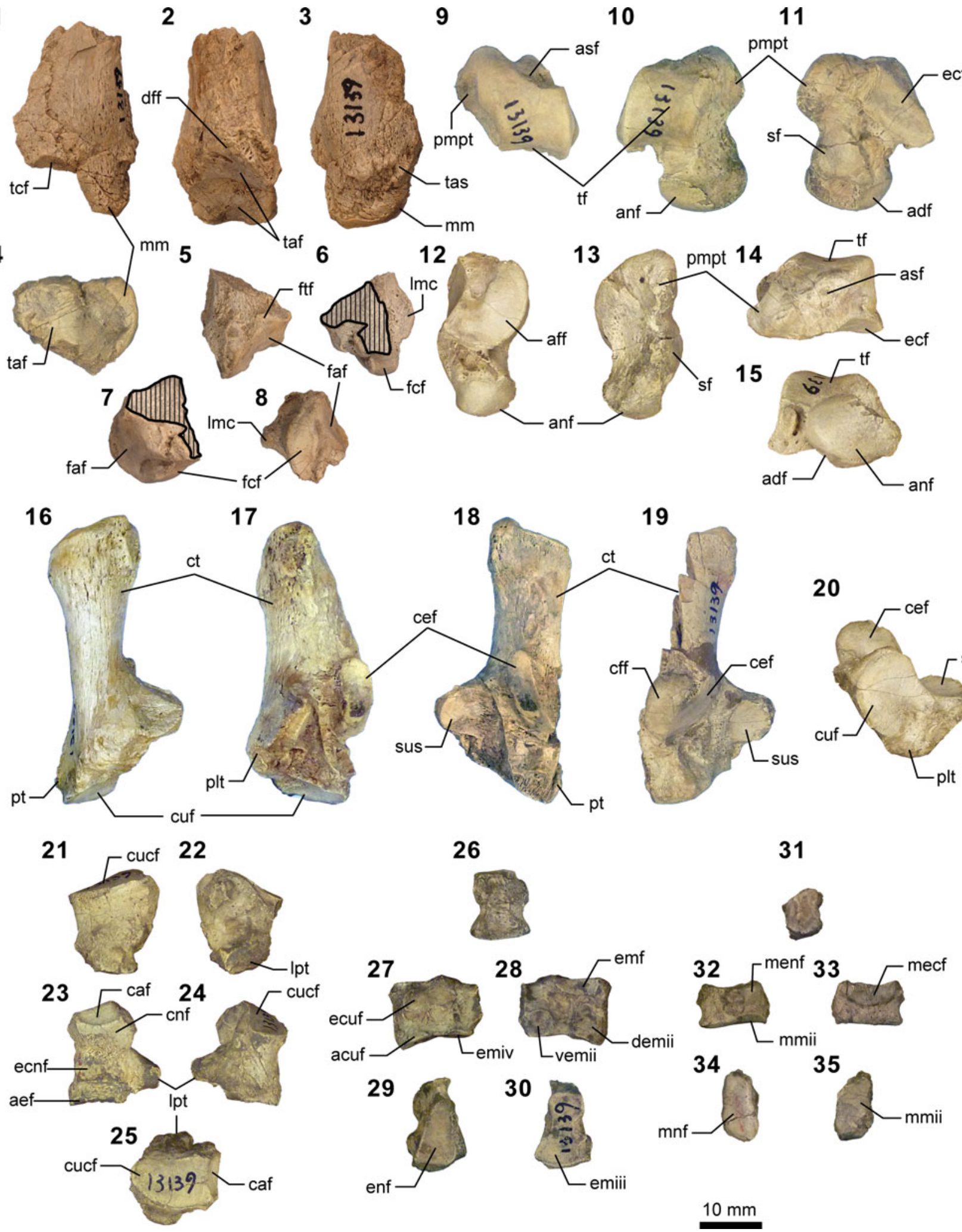
Figure 20. Additional hindlimb elements of AMNH FM 13139, Limnocyon potens. (1-4) Right distal tibia in anterior (1), lateral (2), medial (3), and distal (4, anterior to top) views; (5-8) right distal fibula in anterior (5), posterior (6), medial (7), and distal (8, anterior to top) views; (9) left astragalar body in anterior view; (10-15) right astragalus in anterior (10), posterior (11), lateral (12), medial (13), proximal (14), and distal (15) views; (16-18) left calcaneum in posterior (16), medial (17), and anterior (18) views; (19-25) right calcaneum in anterior (19) and distal (20) views; right cuboid in anterior (21), posterior (22), medial (23), lateral (24), and proximal (25, anterior to bottom) views; (26-30) left ectocuneiform in anterior (26), medial (27), lateral (28), proximal (29), and distal (30) views; (31-35) left mesocuneiform in anterior (31), medial (32), lateral (33), proximal (34), and distal (35) views. Same 10 mm scale applies to all images. Abbreviations: acuf, ectocuneiform accessory cuboid facet; adf, astragalar distal sustentacular facet; aef, cuboid accessory ectocuneiform facet; aff, astragalar fibular facet; anf, astragalar navicular facet; asf, astragalar foramen; caf, cuboid astragalar facet; cef, calcaneal ectal facet; cff, calcaneal fibular facet; cnf, cuboid navicular facet; ct, calcaneal tuber; cucf, cuboid calcaneal facet; cuf, calcaneal cuboid facet; demii, dorsal ectocuneiform metatarsal II facet; dff, distal tibial fibular facet; ecf, astragalar ectal facet; ecnf, cuboid ectocuneiform facet; ecuf, ectocuneiform cuboid facet; emf, ectocuneiform mesocuneiform facet; emiii, ectocuneiform metatarsal III facet; emiv, ectocuneiform metatarsal IV facet; enf, ectocuneiform navicular facet; faf, fibular astragalar facet; fcf, fibular calcaneal facet; ftf, distal fibular tibial facet; lmc, lateral malleolar crest; lpt, long plantar tubercle; mecf, mesocuneiform ectocuneiform facet; menf, mesocuneiform entocuneiform facet; mm, medial malleolus; mmii, mesocuneiform metatarsal II facet; mnf, mesocuneiform navicular facet; plt, plantar tubercle; pmpt, proximomedial plantar tuberosity; pt, peroneal tubercle; sf, astragalar sustentacular facet; sus, calcaneal sustentacular facet; taf, tibial astragalar facet; tas, sulcus for m. tibialis posterior; tcf, tibial check facet; tf, astragalar tibial facet; vemii, ventral ectocuneiform metatarsal II facet.

when all Uintan Limnocyon material is assessed. The two specimens from the Uinta Basin of Utah have relatively smaller protocones on P4 and M1, and correspondingly narrower teeth. In particular, the M1 protocone of CM 11439 is smaller than in most Bridgerian specimens. Lower premolar paraconid (= anterior cuspulid) development also is notably variable in the Uintan species L. potens, being strong in AMNH FM 13138, weak in CM 11439, and intermediate in CM 3373, which has a well-developed $\mathrm{p} 4$ paraconid but lacks a $\mathrm{p} 3$ paraconid. Similar variability also pertains to the Bridgerian species L. verus, with weakly developed paraconids in AMNH FM 12155, USNM PAL 299722, and YPM VP 011781, and stronger cusps on AMNH FM 19200, particularly p3. These observations fit a more general pattern of variation seen in many limnocyonines. Morlo and Gunnell (2003) documented wide variation in development of the p4 paraconid in Thinocyon velox, although they noted strong paraconid development on p3-4 in the more anatomically derived T. medius. In Wasatchian Prolimnocyon, premolar paraconid development is highly variable and does not appear to reflect specific distinctions (SPZ, personal observation). Likewise, there is much variation in the cranial robusticity within L. potens. For example, the cranium of AMNH FM 13138 (Fig. 17.1-17.3) is characterized by a particularly stout snout and a posteriorly broad palate (resulting in clear divergence of toothrows; Fig. 17.2) unlike in CM 11439 from the Uinta Basin.

As indicated in the emended diagnosis, a few additional distinctions can be identified in the dentition of Limnocyon potens. Specimens of L. potens have longer, more longitudinally oriented metastylar blades on M1 and relatively larger trigonids and smaller metaconids on lower molars, particularly $\mathrm{m} 2$, than Bridgerian Limnocyon. A complicating factor is that these distinctions are most evident when specimens of L. potens (all Uintan in age) are compared with Br2-age specimens of Limnocyon (e.g., AMNH FM 140004, USNM PAL 299722), while Br3-age specimens of Limnocyon (particularly AMNH FM 12155) are intermediate in most morphological features, just as they are in size and robusticity.

Several postcranial differences also exist between Limnocyon potens and L. verus, primarily features that suggest somewhat greater terrestrial adaptation in the former species. On the distal humerus, the medial epicondyle of L. potens is smaller and less projecting than in L. verus. The radial head is slightly broader than in L. verus with a better-developed lateral facet, both enhancing stability at the expense of supination. More distally, the radial styloid process is more projecting in L. potens than in L. verus, stabilizing the radiocarpal joint.

On the proximal femur, the greater trochanter projects above the head and the lesser trochanter projects strongly posteromedially. In Limnocyon verus, the greater trochanter is even with the head and the lesser trochanter projects more medially. In both cases, the morphology of L. potens is typical of more terrestrially adapted taxa. Proportions of the distal femora are similar, but the condyles extend farther posterior relative to the shaft in L. potens. The entire distal femur appears to be rotated to face more distally relative to the condition in L. verus.

The tibial tuberosity appears to be more projecting in Limnocyon potens than in L. verus, which would increase the leverage of the mm. quadriceps femoris. The medial malleolus is not preserved in any specimens of $L$. verus that are known to us, but the malleolus of L. potens projects much farther distally than in Prolimnocyon atavus Matthew and Granger, 1915 (Gebo and Rose, 1993) and appears to be somewhat more projecting than in Thinocyon spp. (e.g., AMNH FM 13082; Morlo and Gunnell, 2003). Similarly, while the limnocyonine distal fibula generally is poorly documented, the lateral malleolus of L. potens is much more projecting than in Galecyon spp. (Zack and Rose, 2015). As with the styloid process in the wrist, this would help stabilize the crurotarsal joint while limiting non-parasagittal movements.

The tarsal morphology of Limnocyon potens is broadly comparable to $L$. verus, but distinctions are again present. In the astragalus, the proximomedial extension of the lateral tibial facet is more elongate in L. potens, consistent with a greater range of plantarflexion. Matthew (1909, p. 447) noted that this squatting facet extends further distally in L. potens (presumably AMNH FM 13138 and AMNH FM 13139) than in L. verus (presumably AMNH FM 12155), but this is not apparent when larger samples of both species are considered. In particular, CM 11439 (L. potens) does not differ from L. verus. The navicular facet is more oblique than in L. verus, a morphology typical of extant terrestrial mammals that emphasize parasagittal mobility. The calcaneum has a more elongate tuber than in L. verus. A longer calcaneal tuber increases the leverage of the plantarflexors and is associated with terrestrial locomotion in mammals. Finally, overlap of the ectal and sustentacular facets is stronger in L. potens, restricting mobility at the subastragalar joint. The latter morphology is associated with terrestrial locomotion in rodents (e.g., Rose and Chinnery, 2004). 
Not all morphological distinctions are indicative of greater terrestriality of $L$. potens relative to $L$. verus. Most notably, the trochlea on the distal humerus is less projecting in Limnocyon potens than in $L$. verus. A projecting trochlea stabilizes the elbow joint and, as shown by Heinrich and Rose (1997), is typical of more terrestrial carnivores. Additional differences that lack a clear functional correlate are present in the tarsus, including a more prominent proximomedial plantar tuberosity, more distally positioned primary ectocuneiform facet of the cuboid, and ventrally rather than distoventrally projecting plantar tubercle of the cuboid. Finally, the tarsus of AMNH FM 13139 is more heavily built than that of either compared specimen of L. verus (AMNH FM 12155, USNM PAL 299722). This is particularly evident in the astragalus, which is considerably more robust and appears to have a shorter neck. However, the tarsus of a specimen of L. potens from the Uinta Basin (CM 11439 ) is more gracile, comparable to $L$. verus, suggesting that the robusticity of AMNH FM 13139 may not be typical of the species.

Hyaenodontidae gen. indet. Figure 21

Materials.-FMNH locality JJF 7-11-94-1 (likely Uilb portion of Twka2): FMNH PM 59529, left p3 and right p4.

Remarks.-The two partial teeth were reportedly found in association (S.M. McCarroll, 1994, field notes on file at FMNH), and the general conditions of their preservation are indistinguishable. The left premolar missing its anterior portion is tentatively identified as a p3 (Fig. 21.1-21.3). It has a low, conical main cuspid that bears well-defined anterior and posterior ridges; the latter descends to a shallow posterior basin of the tooth, where it is truncated by a sharp notch. A series of two ridges follow this notch, forming the labial border of the posterior basin. The lingual margin of the basin, in contrast, is only weakly defined and does not form an appreciable ridge, making the basin open lingually. A narrow cingulid is present along the posterolabial base of the tooth. The morphology of $\mathrm{p} 3$ is suggestive of a hyaenodontid, possibly of sinopanine affinity.

In contrast to $\mathrm{p} 3$, the right $\mathrm{p} 4$ (Fig. 21.4-21.6) is characterized by its tall main cuspid. Following a steeply descending posterior slope of the main cuspid, a short but trenchant ridge longitudinally bisects the posterior portion of the tooth in occlusal view. A clearly demarcated cingulid is present on the labial base of the crown, at least along its preserved posterior half. In profile, $\mathrm{p} 4$ somewhat resembles that of the holotype CM 3022 of Sinopa longipes n. comb. (we examined its cast, AMNH FM 105378; Fig. 13.5) from the late Uintan of Utah: the two specimens are of similar sizes and appear to share a steeply falling main cuspid, with a notch (though very small on FMNH PM 59529; Fig. 21.4, 21.5) approximately half way down its posterior slope. However, p4 from the Washakie Formation is distinct in having a more robust main cuspid with a smaller accessory cuspulid on its posterior slope, and most notably, a more lingually positioned posterior basal ridge than in $S$. longipes $\mathrm{n}$. comb. (Fig. 13.5); as a consequence, the former lacks a broad posterolingual shelf as seen in CM 3022 (Fig. 21.6). At present, we are unable to refer this $\mathrm{p} 4$ to any known taxon within Hyaenodontidae. The combination of a p3 with a relatively complex form and a simple p4 is unusual among hyaenodontids; as such, the possibility that the two teeth belong to separate taxa cannot be discounted. In any event, FMNH PM 59529 likely represents at least one hyaenodontid taxon that is not otherwise known from the Washakie Formation.

Measurements: $\mathrm{p} 3 \mathrm{~L}$ x W $=$ [9.19 for preserved portion $] \mathrm{x}$ 5.35; $\mathrm{p} 4 \mathrm{~L} \times \mathrm{W}=[10.83$ for preserved portion $] \mathrm{x} \sim 6.50$.

\section{unranked clade Carnivoramorpha sensu Bryant, 1996 (amended from Wyss and Flynn, 1993) \\ Family Viverravidae Wortman and Matthew, 1899 Genus Viverravus Marsh, 1872a}

Type species.—Viverravus gracilis Marsh, 1872a, by original designation.

Viverravus gracilis Marsh, 1872a

Figure 22.1-22.5

1872a Viverravus gracilis Marsh, p. 127.

1872c Ziphacodon rugatus Marsh, p. 216.

1872c Harpalodon vulpinus Marsh, p. 217.

1884 Didymictis dawkinsianus Cope, p. 310.

1901b Viverravus gracilis; Wortman, p. 145, figs. 18, 19, 37, 39.

1909 Viverravus gracilis; Matthew, p. 357.

1923a Viverravus gracilis; Thorpe, p. 24.

1923a Viverravus vulpinus; Thorpe, p. 24.

1998 Viverravus gracilis; Flynn, p. 116.

Holotype.-YPM VP 011836, right and left dentaries with right p3-m2 and left m2, left P4.

Locality.- "Grizzly Buttes" (Marsh, 1872a, p. 127), Bridger Basin, Uinta County, Wyoming.

Horizon.-Blacks Fork Member (Bridger B), Bridger Formation.

Occurrence.-Cathedral Bluffs Tongue, Wasatch Formation, Wyoming (Morris, 1954; but see Gazin, 1962); Willwood Formation, Wyoming (Gunnell et al., 1992); Lysite and Lost Cabin members, Wind River Formation, Wyoming (Guthrie, 1967a; Stucky, 1984); Huerfano Formation, Colorado (Robinson, 1966); Aycross Formation, Wyoming (Bown, 1982); Blacks Fork, Twin Buttes, and Turtle Bluff members, Bridger Formation, Wyoming (Matthew, 1909; Gunnell, 1998b; Murphey and Kelly, 2017); Twka1, Adobe Town Member, Washakie Formation, Wyoming (this study). Middle Wasatchian to earliest Uintan (Wa6-Uila) NALMA.

Materials from Washakie Basin.-FMNH locality FM-2-80-WDT (Twka1): FMNH PM 42036, left dentary fragment with broken p3-4; PM 59729, left dentary fragment with broken $\mathrm{m} 1$ trigonid and alveoli for $\mathrm{p} 4$ and $\mathrm{m} 2$.

FMNH locality JJF 7-28-91-1 (Twka1): FMNH PM 55169, left dentary fragment with partial p3-m1 and largely intact $\mathrm{m} 2$; PM 55241, right dentary fragment with roots of $\mathrm{p} 3-\mathrm{m} 1$; PM 
1

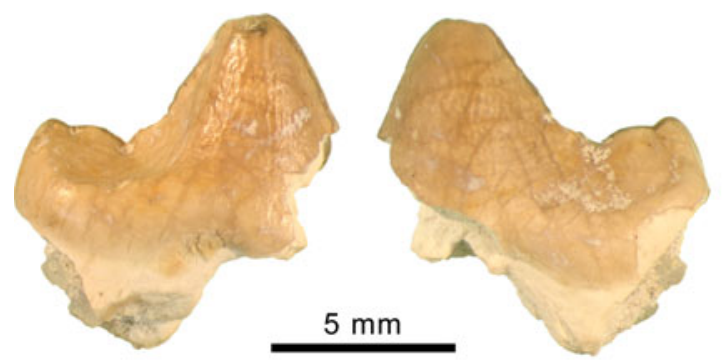

3

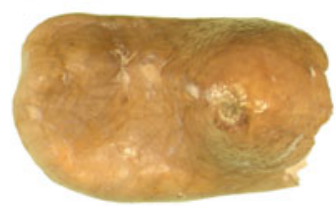

4

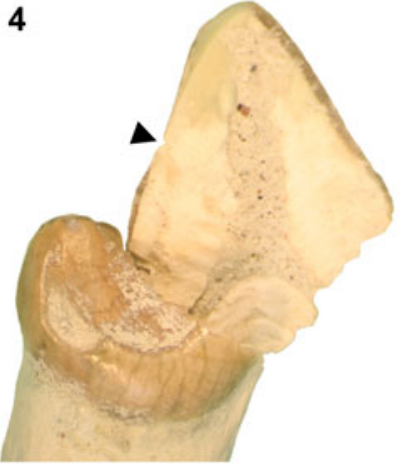

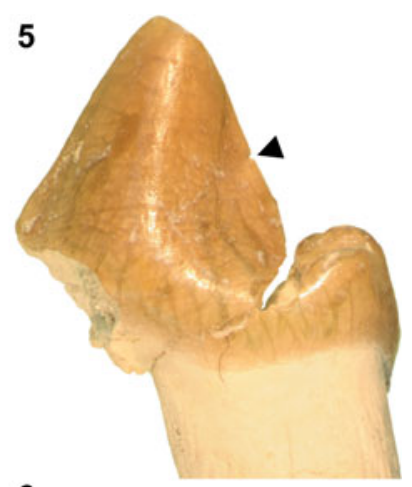

6

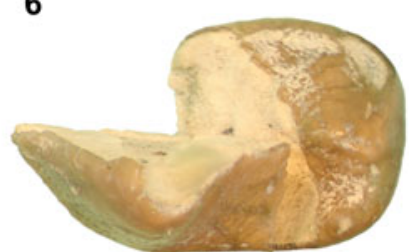

Figure 21. Indeterminate hyaenodontid (FMNH PM 59529) from the Washakie Formation. (1-3) left p3 in lingual (1), labial (2), and occlusal views (3); (4-6) right p4 fragment in labial (4), lingual (5), and occlusal (6) views. Black triangles point to small notch. Same $5 \mathrm{~mm}$ scale applies to all images.

55249, left P4 fragment, left dentary fragment with broken p3; PM 55436, right dentary fragment with broken $\mathrm{m} 1$ (missing trigonid) and roots of $\mathrm{m} 2$.

FMNH locality JJF 7-30-91-3 (Twka1): FMNH PM 55022, right $\mathrm{m} 1$ trigonid missing protoconid.

FMNH locality JJF 8-14-93-2 (Twka1): FMNH PM 56552, right dentary fragment with broken $\mathrm{p} 3-4$.

Remarks.-Matthew (1909) distinguished two species of Viverravus from the late Bridgerian portions of the Bridger Formation-V. gracilis and V. minutus-by their sizes (none was known from the Washakie Formation at the time). At least two size classes are represented in the sample of Viverravus from the Washakie Formation, and the larger individuals are here referred to V. gracilis (Table 6). We note, however, that the Washakie specimens of $V$. gracilis are generally larger than the holotype YPM VP 011836 from the middle Bridgerian Grizzly Buttes (Bridger B; Murphey and Evanoff, 2007, 2011; see Wortman, 1901b for measurements): for example, $\mathrm{m} 1 \mathrm{~s}$ of FMNH PM 59729 and FMNH PM 55169 (both broken) appear to have been $25-30 \%$ longer than that of the holotype, and comparable to AMNH FM 12623, a large individual from the Bridger D interval that was reported by Matthew (1909, p. 357) and referred to $V$. 'vulpinus' by Thorpe (1923a). There also is substantial size variation among the referred Washakie specimens. For example, m1 alveolar length of FMNH PM 59729 is $~ 14 \%$ greater than that of FMNH PM 55241.

Viverravus minutus Wortman, 1901b

Figure 22.7-22.15

1901b Viverravus minutus Wortman, p. 147, fig. 21.

1909 Viverravus minutus; Matthew, p. 357, pl. 43, fig. 1, textfigs. 9-12.

1923a Viverravus minutus; Thorpe, p. 25.

1998 Viverravus minutus; Flynn, p. 117
Holotype.-YPM VP 011837, left dentary with c1 and p2-m2. Locality.- “Dry Creek" (Wortman, 1901b, p. 148), Bridger Basin, Uinta County, Wyoming.

Horizon.-Likely Blacks Fork Member, Bridger Formation (cf., Gazin, 1976, p. 8).

Occurrence.-Wasatch Formation, Fremont and Lincoln counties, Wyoming (Zonneveld et al., 2000; Gunnell and Bartels, 2001); Blacks Fork Member, Bridger Formation, Lincoln, Sweetwater, and Uinta counties, Wyoming (Wortman, 1901b; Gunnell, 1998b); Elderberry Canyon Quarry, Sheep Pass Formation, White Pine County, Nevada (Emry, 1990); Douglas Creek Member, Green River Formation, Uintah County, Utah; Twka1, Adobe Town Member, Washakie Formation, Sweetwater County, Wyoming; questionably unresolved Washakie Formation, Moffat County, Colorado (Stucky et al., 1996). Latest Wasatchian to late Bridgerian (Wa7-Br3) NALMA.

Materials from Washakie Basin.-FMNH locality FM-7-69-WDT? (Twka1): FMNH PM 61742, left p4.

FMNH locality JJF 8-14-93-2 (Twka1): FMNH PM 56551, right dentary fragment with p4 and roots of $\mathrm{m} 1$; PM 62927, partial left P4 (missing parastyle and protocone).

UW locality V-58011 (“Six from Haystack," Twka1): UW 5760 , left p4.

Remarks. - The referred specimens of Viverravus minutus are considerably smaller than the specimens referred to $V$. gracilis above (Table 6). They also differ noticeably from one another in size and form of p4. For example, FMMN PM 61742 is 19\% longer than PM 56551, has a more prominent anterior cuspulid, and the anterior edge of its main cuspid is more curved in profile. Nevertheless, much intraspecific variation in dental form has been noted for V. minutus (Matthew, 1909, 

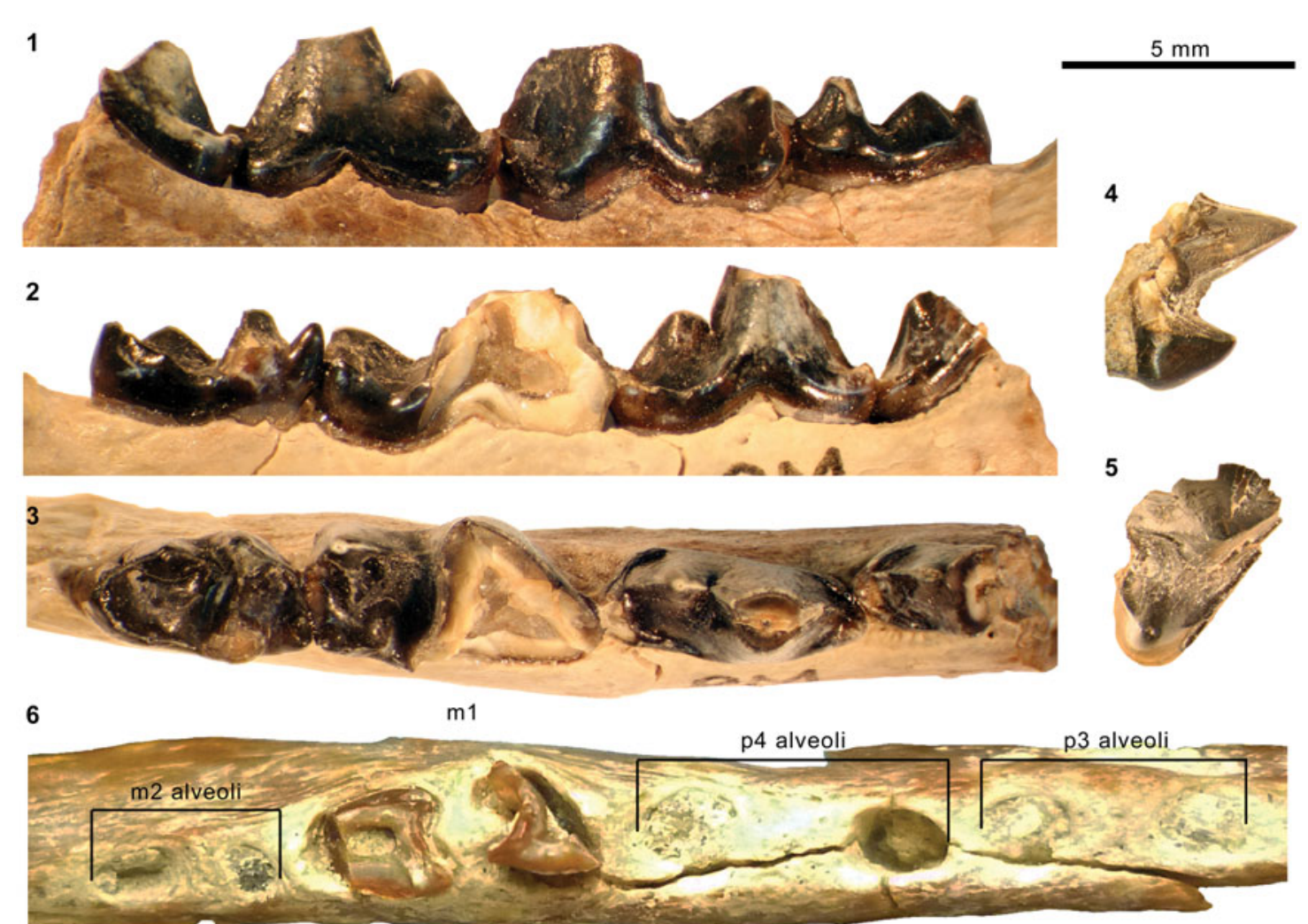

7

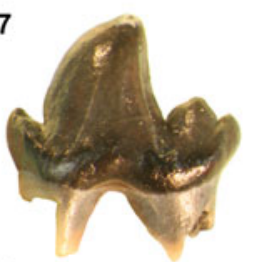

8

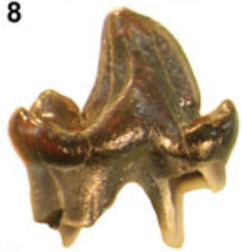

9

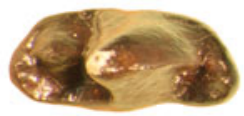

10

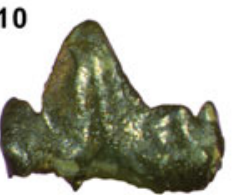

11

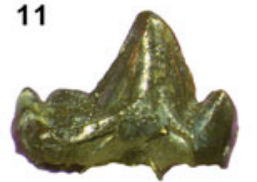

12

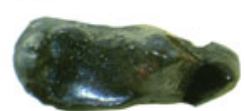

13

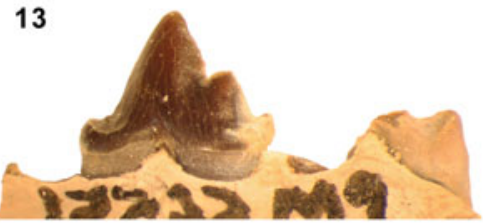

14

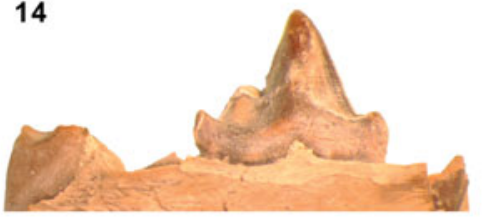

15

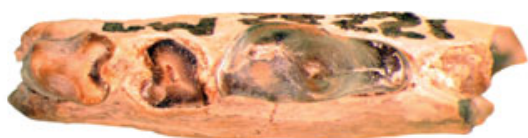

Figure 22. Dentition of species of the viverravid Viverravus Marsh, 1872a, from the Washakie Formation. Viverravus gracilis Marsh, 1872a: (1-3) left p3-m2 of FMNH PM 55169 in labial (1), lingual (2), and occlusal (3) views; $(\mathbf{4 , 5})$ left P4 fragment of FMNH PM 55249 in anterior (4) and occlusal (5) views; Viverravus sp. indet.: (6) alveoli for right p3-4, roots of $\mathrm{m} 1$, and alveoli for $\mathrm{m} 2$ of FMNH PM 61947 (inverted) in occlusal view; Viverravus minutus Wortman, 1901b: (7-9) left p4 of FMNH PM 61742 in labial (7), lingual (8), and occlusal (9) views; (10-12) left p4 of UW 5760 in labial (10), lingual (11), and occlusal (12) views; (13-15) right p4 of FMNH 56551 (inverted) in labial (13), lingual (14), and occlusal (15) views. Same 5 mm scale applies to all images.

p. 357), and we consider the three specimens to belong to the same species.

\section{Viverravus sp. indet.}

Figure 22.6

Materials.-FMNH locality FM-15-56-WDT (Br3 or Ui1b portion of Twka2): FMNH PM 61947, right dentary fragment with alveoli for $\mathrm{p} 2-\mathrm{p} 4$, badly broken $\mathrm{m} 1$, and alveoli for $\mathrm{m} 2$.
FMNH locality FM-8-57-WDT (Roehler's [1973] bed 633, Twka2): FMNH PM 61931, left dentary fragment with roots of $\mathrm{m} 1-\mathrm{m} 2$.

Remarks.-The combination of the carnassial form of $\mathrm{m} 1$, elongate $\mathrm{m} 2$ talonid (judging from the posterior alveolus of the tooth), and the absence of $\mathrm{m} 3$ indicates a viverravid affinity of FMNH PM 61931. While its lower molar lengths appear to be comparable to those of FMNH PM 55169 
Table 4. Measurements (in mm) of Thinocyon Marsh, 1872c, and Limnocyoninae gen. indet. from the Bridger and Washakie formations. ${ }^{\mathrm{a}}$ Holotype of Thinocyon

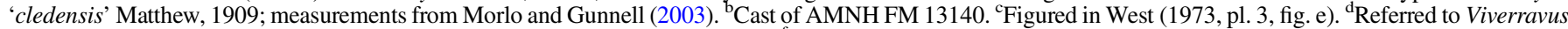

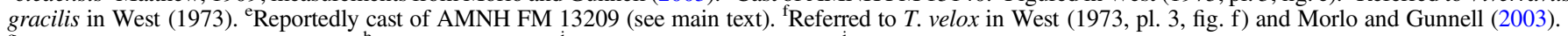
${ }^{\mathrm{g}}$ Parallel to parastyle-metastyle axis. ${ }^{\mathrm{h}}$ Parasagittal length. ${ }^{\mathrm{i}}$ Metastylar blade broken off. ${ }^{\mathrm{j}}$ At anteroposterior level of paracone as in Gingerich and Deutsch (1989, fig. 1). ${ }^{\mathrm{k}}$ Maximum transverse width of tooth including metastyle. ${ }^{\mathrm{l}}$ Measurement across alveoli (tooth or crown not preserved). ${ }^{\mathrm{m}}$ Paraconid slightly worn. ${ }^{\mathrm{n}}$ Measurement partly across alveolus/alveoli. ${ }^{\circ}$ Paraconid broken off. Abbreviations: MD, mandibular depth (measured below m1 on lateral side); TRH, trigonid height (cf., Gingerich and Deutsch, 1989, fig. 1); TRL, trigonid length.

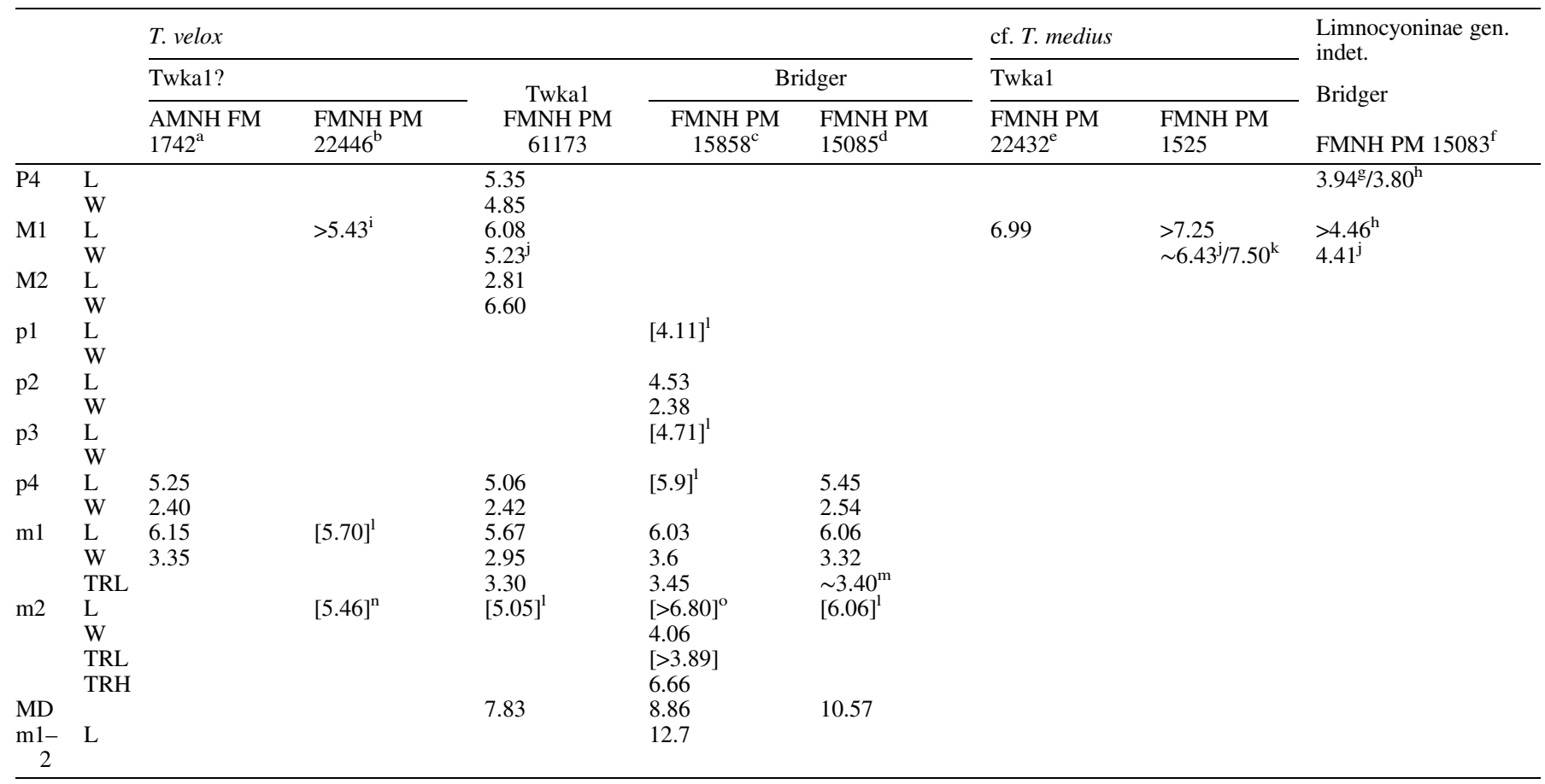

Table 5. Measurements (in mm) of Limnocyon from the Bridger and Washakie formations. See Table 3 for abbreviations. ${ }^{\mathrm{a}}$ All measurements from left side. ${ }^{\mathrm{b}}$ Measurements taken from digital photograph. ${ }^{\mathrm{c}}$ All measurements from right side. ${ }^{\mathrm{d}}$ Tooth notably worn. ${ }^{\mathrm{e}}$ Missing entocristid. ${ }^{*} \mathrm{Holotype}$. Abbreviation: TRL, trigonid length.

\begin{tabular}{|c|c|c|c|c|c|c|}
\hline & & & L. verus & & cf. L. verus & L. potens \\
\hline & & Bridger $\mathrm{C}$ & Bridger D & Twka1 & Twka1 & Twka2 \\
\hline & & AMNH FM $12155^{\mathrm{a}}$ & FMNH UC 1725 & FMNH PM 55343 & FMNH PM 56553 & AMNH FM $13138 * \mathrm{c}$ \\
\hline \multirow[t]{2}{*}{ P1 } & $\mathrm{L}$ & 6.58 & & & & 7.28 \\
\hline & $\mathrm{W}$ & 3.00 & & & & 3.80 \\
\hline \multirow[t]{2}{*}{$\mathrm{P} 2$} & $\mathrm{~L}$ & & & & & 8.86 \\
\hline & $\mathrm{W}$ & & & & & 5.08 \\
\hline \multirow[t]{2}{*}{ P3 } & $\mathrm{L}$ & 7.81 & & & & 10.03 \\
\hline & $\mathrm{W}$ & 3.88 & & & & 6.40 \\
\hline \multirow[t]{2}{*}{ P4 } & $\mathrm{L}$ & $7.7^{\mathrm{b}}$ & & 8.75 & & 10.27 \\
\hline & $\mathrm{W}$ & $8.5^{\mathrm{b}}$ & & 8.33 & & 12.54 \\
\hline \multirow[t]{2}{*}{ M1 } & $\mathrm{L}$ & $10.3^{\mathrm{b}}$ & & {$[>9.37]$} & & 12.39 \\
\hline & W & $8.8^{\mathrm{b}}$ & & & & 11.86 \\
\hline \multirow[t]{2}{*}{ M2 } & $\mathrm{L}$ & $4.7^{\mathrm{b}}$ & & & & 6.01 \\
\hline & $\mathrm{W}$ & $11.3^{\mathrm{b}}$ & & & & 13.64 \\
\hline \multirow[t]{2}{*}{$\mathrm{c} 1$} & $\mathrm{~L}$ & 7.85 & & & & {$[\sim 11.0]$} \\
\hline & W & 5.77 & & & & \\
\hline \multirow[t]{2}{*}{ p1 } & $\mathrm{L}$ & 6.25 & & & & 7.12 \\
\hline & $\mathrm{W}$ & 2.98 & & & & 3.57 \\
\hline \multirow[t]{2}{*}{$\mathrm{p} 2$} & $\mathrm{~L}$ & 7.22 & & & & 9.62 \\
\hline & W & 3.91 & & & & 5.01 \\
\hline \multirow[t]{2}{*}{ p3 } & $\mathrm{L}$ & 7.14 & 8.12 & & & 9.70 \\
\hline & W & 3.70 & 4.10 & & & 5.60 \\
\hline \multirow[t]{2}{*}{$\mathrm{p} 4$} & $\mathrm{~L}$ & 8.27 & 9.23 & & & 10.19 \\
\hline & W & 4.50 & 5.06 & & & 5.87 \\
\hline \multirow[t]{3}{*}{$\mathrm{m} 1$} & $\mathrm{~L}$ & {$[\sim 8.86]^{\mathrm{d}}$} & 9.10 & {$[\sim 10.6]$} & {$[>8.18]^{\mathrm{e}}$} & 10.78 \\
\hline & $\mathrm{W}$ & 4.75 & 5.35 & 5.51 & 4.88 & 6.13 \\
\hline & TRL & {$[\sim 5.19]^{\mathrm{d}}$} & 5.74 & 6.47 & 5.44 & {$[\sim 6.3]$} \\
\hline \multirow[t]{3}{*}{$\mathrm{m} 2$} & $\mathrm{~L}$ & 9.05 & & & & \\
\hline & $\mathrm{W}$ & 5.59 & & & & \\
\hline & TRL & & & & & \\
\hline MD & & 19.15 & 17.39 & & & 23.18 \\
\hline
\end{tabular}


Table 6. Measurements (in mm) of Viverravus Marsh, 1872a, from the Bridger and Washakie formations. ${ }^{\text {a }}$ Measured on labial side below junction of $\mathrm{m} 1$ anterior and posterior roots. 'Referred to Thinocyon velox by West (1973, table 12). 'Cast of holotype YPM VP 011809 of 'Harpalodon vulpinus' Marsh, reidentified as V. gracilis by Wortman (1901b, p. 201). ${ }^{\mathrm{d}}$ Alveolar measurements. ${ }^{\dagger}$ Estimated for specimens with minor breakage or obstruction. Plus signs denote slight undermeasurements.

\begin{tabular}{|c|c|c|c|c|c|c|c|c|c|c|c|c|c|c|}
\hline Specimen & Taxon & Horizon & p1L & $\mathrm{p} 1 \mathrm{~W}$ & p3L & $\mathrm{p} 3 \mathrm{~W}$ & $\mathrm{p} 4 \mathrm{~L}$ & $\mathrm{p} 4 \mathrm{~W}$ & $\mathrm{~m} 1 \mathrm{~L}$ & $\mathrm{~m} 1 \mathrm{~W}$ & m1TRL & $\mathrm{m} 2 \mathrm{~L}$ & $\mathrm{~m} 2 \mathrm{~W}$ & MD \\
\hline$\overline{\text { FMNH PM } 15860^{b}}$ & cf. V. gracilis & Bridger Fm. (Br1b-Br2) & 2.82 & 1.1 & & & & & 5.72 & 3.14 & 3.57 & & & 7.46 \\
\hline FMNH PM 42036 & cf. V. gracilis & Twka1 & & & 5.47 & $\sim 1.9^{\dagger}$ & & & & & & & & \\
\hline FMNH PM 55241 & cf. V. gracilis & Twka1 & & & & & & & & & & & & 8.64 \\
\hline FMNH PM 55249 & cf. V. gracilis & Twka1 & & & 5.24 & $\sim 2.1^{\dagger}$ & & & & & & & & \\
\hline FMNH PM 61931 & Viverravus sp. & Twka2 & & & & & & & & & & {$[4.37]^{\mathrm{d}}$} & & \\
\hline
\end{tabular}

Table 7. Upper dental measurements (in mm) of Bridgerian-Uintan specimens of Oodectes Wortman, 1901b, Uintacyon Leidy, 1873, and Miocyon Matthew, 1909. ${ }^{\mathrm{a}}$ Cast of holotype YPM VP 011861. ${ }^{\mathrm{b}}$ Digital measurements from microscope photographs. ${ }^{\mathrm{c}}$ Alveolar measurements. ${ }^{\mathrm{d}}$ Cast of YPM VP 013027 (referred in Thorpe, 1923a). ${ }^{~}$ RP4-M2, LM3. *Holotype or its cast. ${ }^{\dagger}$ Estimated for specimens with minor breakage or obstruction. Plus signs denote slight undermeasurements.

\begin{tabular}{|c|c|c|c|c|c|c|c|c|c|c|c|}
\hline Specimen & Taxon & Horizon & Side & P4L & $\mathrm{P} 4 \mathrm{~W}$ & M1L & M1W & $\mathrm{M} 2 \mathrm{~L}$ & M2W & M3L & M3W \\
\hline AMNH FM 105003*a & O. herpestoides & Bridger A/B & $\mathrm{R}$ & $4.60^{\mathrm{b}}$ & $3.61^{\mathrm{b}}$ & $4.16^{\mathrm{b}}$ & $5.64^{\mathrm{b}}$ & $3.03^{\mathrm{b}}$ & $5.11^{\mathrm{b}}$ & & \\
\hline FMNH PM 56362 & cf. $U$. jugulans & Twka1 & $\mathrm{R}$ & & & $4.36+$ & & & & & \\
\hline AMNH FM 11519 & M. bathygnathus & Bridger C & $\mathrm{L}$ & & & 8.2 & 12.28 & & & & \\
\hline AMNH FM $104989^{d}$ & cf. M. bathygnathus & Bridger $\mathrm{A} / \mathrm{B}$ ? & $\mathrm{R}$ & & & 9.14 & 12.48 & & & & \\
\hline
\end{tabular}

(Viverravus gracilis) from Twka1, and clearly are intermediate between the two other species known from the late Bridgerian or early Uintan, V. minutus and V. sicarius Matthew, 1909, p4 of FMNH PM 61947 (Fig. 22.6) likely was substantially longer (alveolar length alone in FMNH PM 61947 is 10\% longer than the p4 crown length of FMNH PM 55169; Table 6). Given this, we refrain from assigning the Twka2 sample of Viverravus to any known species. An unidentified species of Viverravus also has been reported from the purportedly early Uintan (Uilb) portions of the Washakie Formation in the Sand Wash Basin, Colorado (Stucky et al., 1996), but we have not been able to examine the pertinent material and confirm its identification. The only other post-Bridgerian occurrence of the genus in North America is a set of two isolated teeth (UW 13732 and UW 13995) and an incompletely prepared partial dentary (UW 41878; ST, personal observation, 2015) from the early Uintan (Ui1b) Holy City beds of the lower Tepee Trail Formation in the Absaroka Range, Wyoming (Eaton, 1985; Murphey et al., 2018; note we consider a specimen from the ? late Uintan Swift Current Creek local fauna of Canada that was previously reported as Viverravus sp. by Storer [1984] to be a hyaenodontid or oxyaenid-see Remarks for Machaeroidinae gen. indet.). FMNH PM 61931 from the likely Uilb portion of Twka2 adds to the evidence for the persistence of Viverravus into the early Uintan NALMA.

\section{unranked clade Carnivoraformes Flynn, Finarelli, and Spaulding, 2010 \\ Genus Oodectes Wortman, 1901b}

Type species.-Oodectes herpestoides Wortman, 1901b, by original designation.
Oodectes proximus Matthew, 1909

Figures 23.1-23.3, 24.2, 24.5

1909 Oodectes proximus Matthew, p. 378, text-figs. 7, 8, 18-22.

1979 Oodectes herpestoides Wortman, 1901b (in part); MacIntyre and Guthrie, p. 1035.

1997 Oodectes herpestoides (in part); Heinrich, p. 1174.

1998 Oodectes herpestoides (in part); Flynn, p. 117.

Holotype.-AMNH FM 11495, partial cranium with right and left P4-M2, partial dentaries with right $\mathrm{c} 1-\mathrm{m} 2$ and left $\mathrm{p} 3-4$ and $\mathrm{m} 2-3$, and partial postcrania including right scapula, right and left humeri, right proximal ulna, right and left femora, right tibia, right calcaneum, and additional skeletal fragments.

Locality.-AMNH locality recorded as Grizzly Buttes, Bridger Basin, Uinta County, Wyoming.

Horizon.-Blacks Fork Member (Bridger B), Bridger Formation.

Occurrence.-Blacks Fork Member (Bridger B), Bridger Formation, Uinta County, Wyoming, and Twka1, Adobe Town Member, Washakie Formation, Sweetwater County, Wyoming. Middle to late Bridgerian (Br2-Br3) NALMA.

Materials from Washakie Basin.-FMNH locality JJF 7-27-91-1 (Twka1): FMNH PM 58110, labial fragment of right M1.

Remarks.-In proposing a new species of Oodectes, O. proximus, Matthew (1909, p. 378) listed the following morphological 
distinctions from the genotypic species, O. herpestoides: (1) $\mathrm{P} 4$ with smaller and more anteriorly positioned parastyle and larger protocone ("deuterocone" in original text); (2) labiolingually shorter upper molars with more limited parastylar extensions and anteroposteriorly longer protocones; (3) smaller M3 and m3; (4) "straighter, higher and less compressed" lower premolars; (5) wider distal humerus with a broader trochlea; (6) "more robust ulna;" (7) larger fovea capitis on femoral head; (8) "more robust calcaneum with thicker sustentacular process." The postcranial traits generally reflect robusticity, and we are uncertain about their taxonomic-diagnostic values. Still, we concur with the dental morphological distinctions noted by Matthew (1909), except for the orientations of P4 parastyle in the two species (which seem comparable to us). We also note that $\mathrm{P} 4$ metastylar blade in the holotype of $O$. proximus (and previously the only known specimen of that species) is more labially directed, reflecting anteroposterior compression of the tooth (Table 7). Further, AMNH FM 11495 has an M1 lingual cingulum that is continuous around the base of protocone (Fig. 23.1), whereas that of the holotype (YPM VP 011861) of $O$. herpestoides (we examined its cast, AMNH FM 105003) is divided into pre- and postcingula by the lingual margin of the base of the protocone (Fig. 23.4) - a condition also seen in some species of Uintacyon and Gracilocyon.

These differences in the upper teeth seem to be more pronounced than are typically observed within a species of small basal carnivoraform-Dormaalocyon latouri (Quinet, 1966) (see Solé et al., 2014, fig. 4). Thus, while MacIntyre and Guthrie (1979) suggested synonymy of all named species of Oodectes (including the Wasatchian 'Paeneprolimnocyon' amissadomus Guthrie, 1967b), we consider O. proximus to be sufficiently distinct from the type species that it should be recognized as a separate species as originally proposed by Matthew (1909). Available stratigraphic data are of insufficient resolution for assessing the temporal relationship of the two species: the holotype of $O$. proximus was recovered from the middle Bridgerian ( $\mathrm{Br} 2)$ Bridger B interval at Grizzly Buttes, and $O$. herpestoides is also known from the Bridger $\mathrm{B}$ interval (Gazin, 1976). Nevertheless, the dentition of O. proximus appears to be characterized by more derived features, such as the reduced M1 parastylar region and break-down of the alignment of the parastylar ridge, apex of the protocone, and paraconule on M1 (these three features are aligned in O. herpestoides and, typically, Uintacyon).

The M1 of FMNH PM 58110 (Fig. 23.2, 23.3) more closely resembles the holotype AMNH FM 11495 of $O$. proximus than that of $O$. herpestoides in the more limited labial extension of the parastylar region and the likely less-constricted lingual portion of the tooth, as judged from the preserved outline of the labial portion. This specimen from Twkal, which we refer to O. proximus, extends the temporal range of Oodectes into the late Bridgerian $(\mathrm{Br} 3)$.

Oodectes pugnax (Wortman and Matthew, 1899)

Figure 24.1, 24.3, 24.4

1899 Uintacyon pugnax Wortman and Matthew, p. 114.

1909 Oodectes? pugnax; Matthew, p. 349.

1998 Uintacyon pugnax; Flynn, p. 119.
Holotype.-AMNH FM 1744, partial left dentary with broken $\mathrm{p} 3-4$, roots of $\mathrm{m} 1$, and $\mathrm{m} 2-3$.

Locality.-AMNH locality in Washakie Basin, Sweetwater County, Wyoming.

Horizon.-Twka1 ("Lower Washakie" according to Matthew, 1909, p. 349), Adobe Town Member, Washakie Formation.

Occurrence.-Twka1, Adobe Town Member, Washakie Formation, Sweetwater County, Wyoming. Known from holotype only. Late Bridgerian (Br3) NALMA.

Remarks.-The holotype and only known specimen of Oodectes pugnax, AMNH FM 1744, has never been figured before. Matthew (1909, p. 377) reassigned Uintacyon pugnax Wortman and Matthew, 1899, to the genus Oodectes without elaborating. His decision was questioned by Heinrich (1997, p. 1174), but no alternative generic assignment was proposed. Although the incompleteness of the holotype (in which $\mathrm{m} 2-3$ are the only well-preserved teeth) makes taxonomic evaluation difficult, the proportionately small $\mathrm{m} 1$ trigonid (judging from the sizes of the roots), posteriorly broad talonid of $\mathrm{m} 2$ (reflecting the posterolabial direction of the cristid obliqua), and the relatively unreduced $\mathrm{m} 3$ are clearly more in line with those of Oodectes than with the middle- to late-Bridgerian species of Uintacyon. Thus, we tentatively accept Matthew's (1909) reclassification of 'Uintacyon' pugnax as Oodectes pugnax. Compared to other species of Oodectes, O. pugnax is characterized by larger size and more robust dentary (cf., Matthew, 1909). The m2 of the holotype is $\sim 30 \%$ longer than that of AMNH FM 11495 (O. proximus holotype; Table 8 ) and $25 \%$ longer than AMNH FM 105003 (cast of holotype of $O$. herpestoides; Table 8). Given the substantial size difference, the holotype AMNH FM 1744 of $O$. pugnax most likely represents a different species from FMNH PM 58110, which we referred above to $O$. proximus.

Genus Uintacyon Leidy, 1873

Type species.-Uintacyon edax Leidy, 1873, by original designation.

Uintacyon jugulans Matthew, 1909

Figures 24.6, 25

1909 Uintacyon jugulans Matthew, p. 373, text-fig. 16.

1923a Uintacyon jugulans; Thorpe, p. 27.

1998 Uintacyon jugulans; Flynn, p. 119.

2008 Uintacyon jugulans; Heinrich et al., p. 157.

Holotype.-AMNH FM 12066, partial dentaries with right c1$\mathrm{p} 3, \mathrm{~m} 1, \mathrm{~m} 2$ and left $\mathrm{p} 2-\mathrm{m} 3$.

Locality._-"Henry's Fork" (Matthew, 1909, p. 373), Bridger Basin, Sweetwater or Uinta County, Wyoming.

Horizon.-Twin Buttes Member (Bridger C), Bridger Formation.

Occurrence.-Twin Buttes Member, Bridger Formation, Uinta County, Wyoming (Matthew, 1909); Twka1, Adobe Town 
1

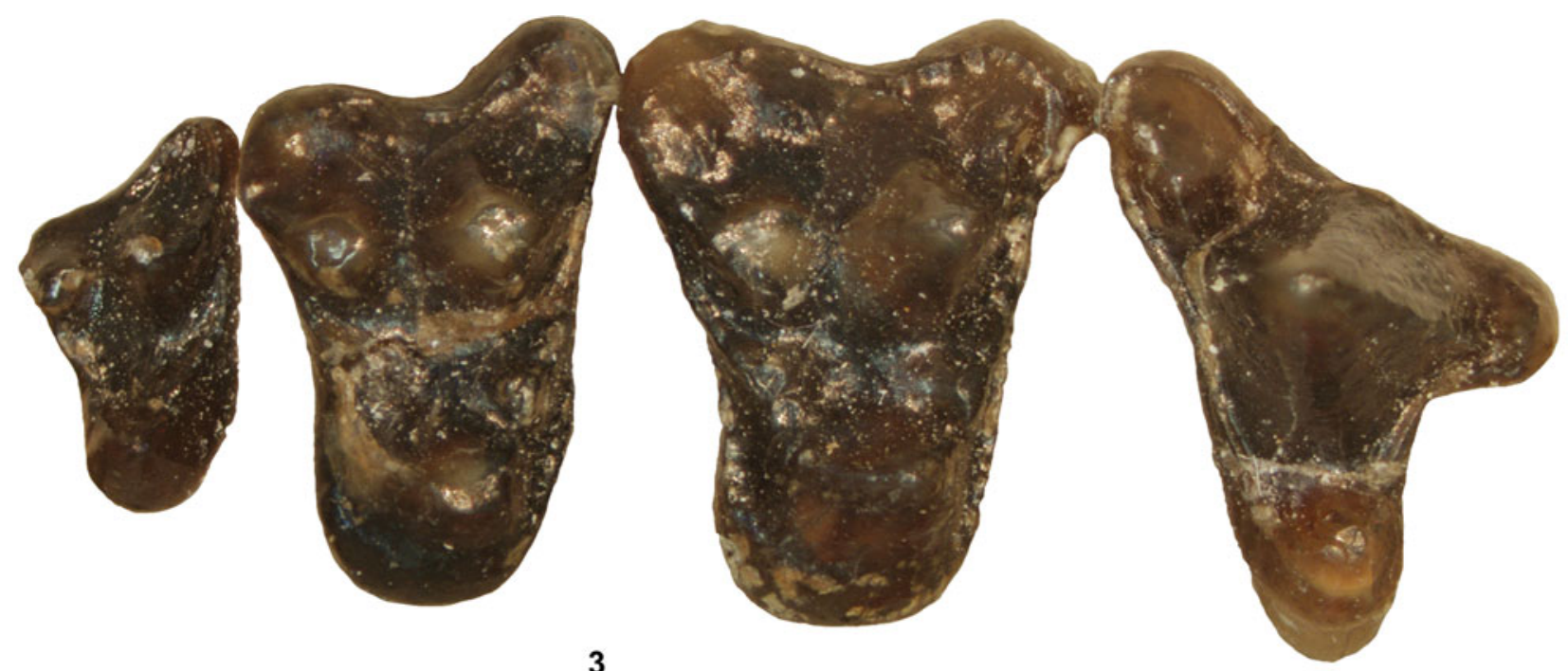

2

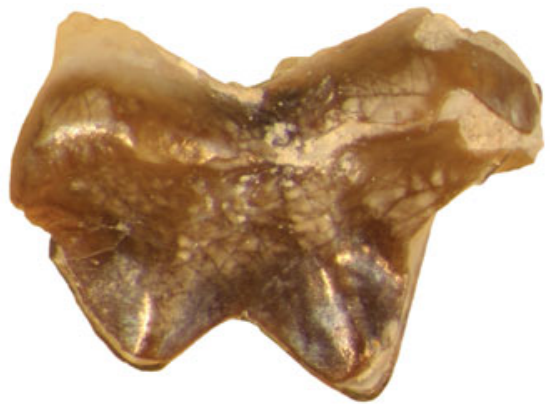

3
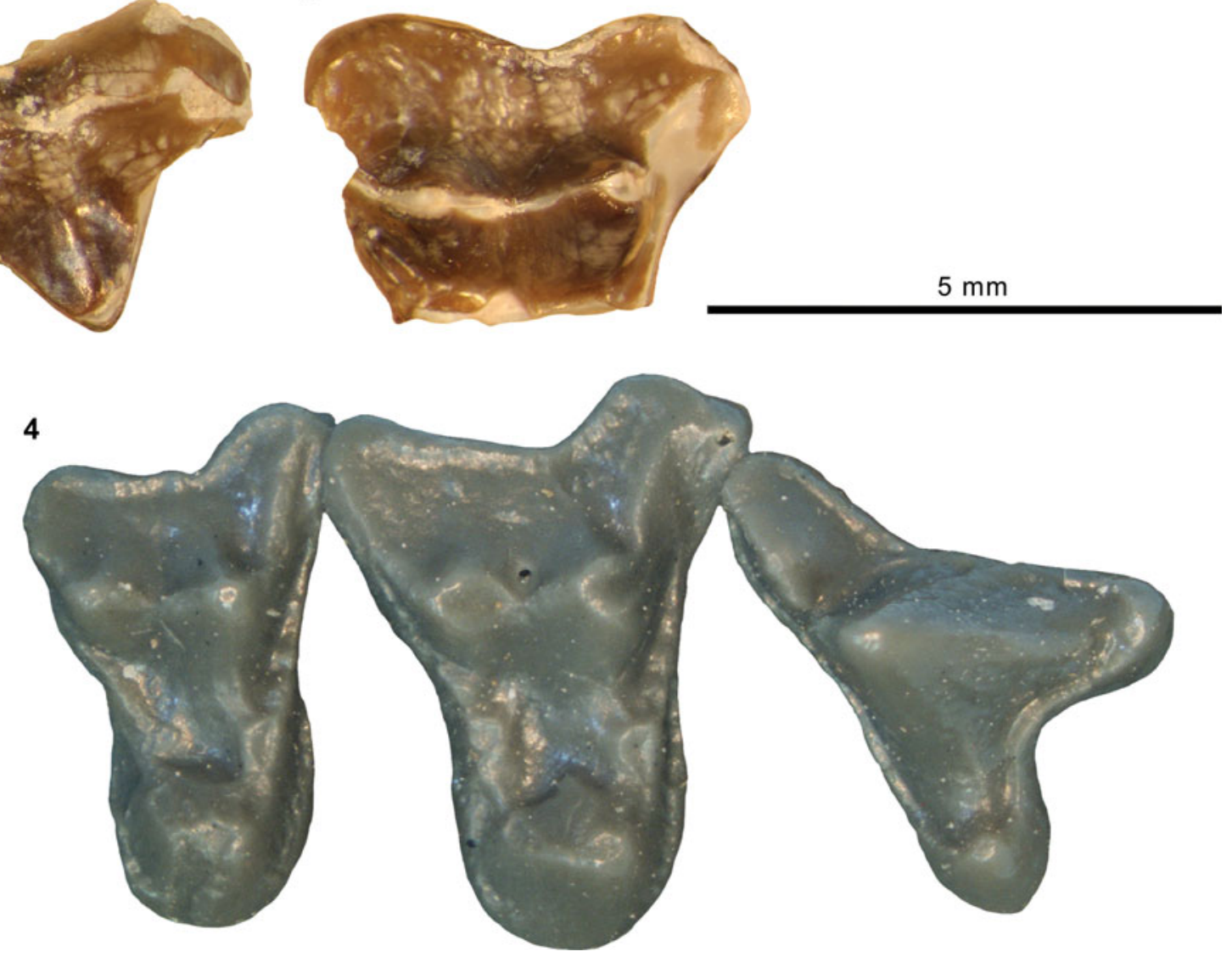

Figure 23. Comparison of species of the carnivoraform Oodectes Wortman, 1901b, from the Bridger and Washakie formations. (1) Composite of right P4-M2 and left M3 (inverted) of Oodectes proximus Matthew, 1909 (holotype AMNH FM 11495 from Bridger B), in occlusal view; (2) right M1 labial fragment of FMNH PM 58110 from Twka1 in labial view; (3) same in occlusal view; (4) right P4-M2 of O. herpestoides Wortman, 1901b (cast AMNH FM 105003 of holotype YPM VP 011861 from "Lower Bridger") in occlusal view. Same $5 \mathrm{~mm}$ scale applies to all images.

Member, Washakie Formation, Sweetwater County, Wyoming (this study). Late Bridgerian (Br3) NALMA.

Materials from Washakie Basin.-FMNH locality FM-2-82-WDT (= JJF 7-31-91-1) (Twka1): FMNH PM 62564 , left dentary fragment with $\mathrm{p} 4-\mathrm{m} 1$.

FMNH locality JJF 7-27-91-1 (Twka1): FMNH PM 56362, right $\mathrm{M} 1 \mathrm{missing}$ labial portion.
Remarks.-FMNH PM 62564 is securely identified as Uintacyon based on the relatively closed $\mathrm{m} 1$ trigonid, tall and trenchant cristid obliqua with a primarily longitudinal orientation, tapering of $\mathrm{m} 1$ talonid basin toward its posterolabial corner, and a short p4 that: (1) has a posterior basal cuspulid positioned relatively low; and (2) lacks an anterior cuspulid (Fig. 25; in contrast to Oodectes pugnax; Fig. 24.3). The $\mathrm{m} 1$ in FMNH PM 62564 is somewhat smaller 
1

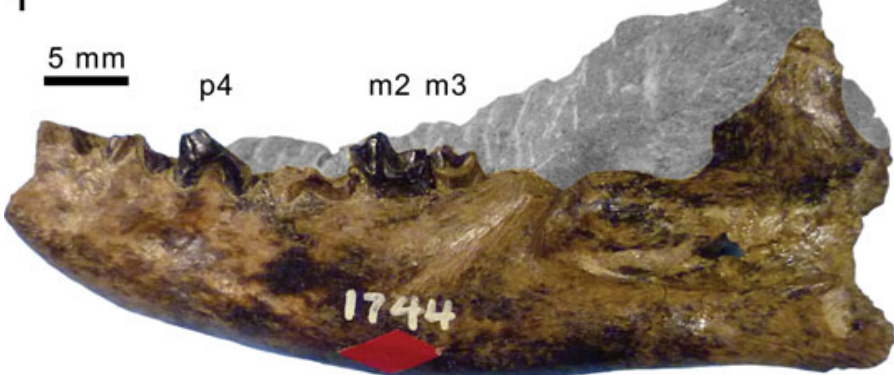

3

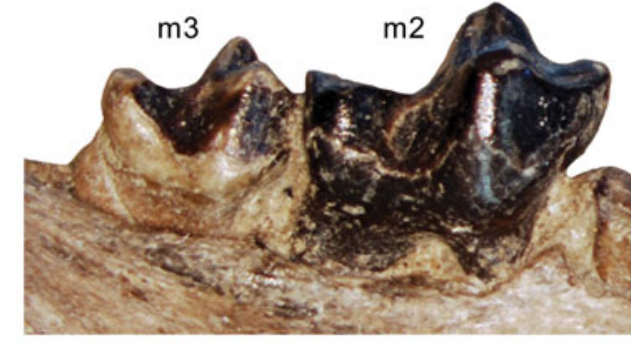

2

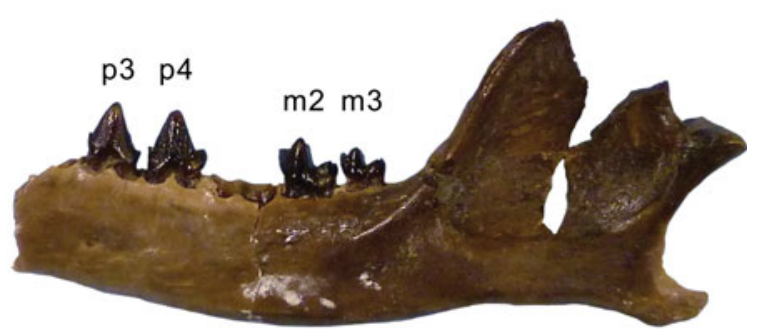

p3 roots

4

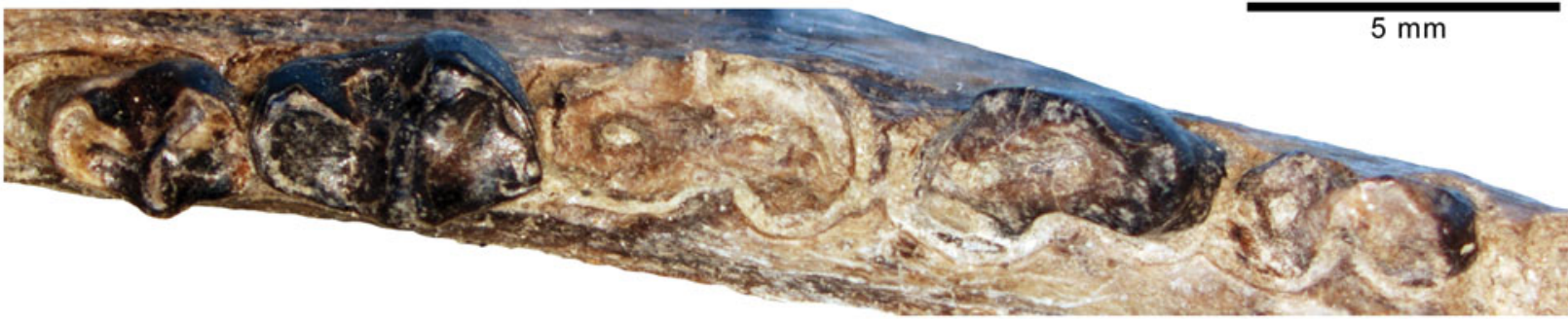

5

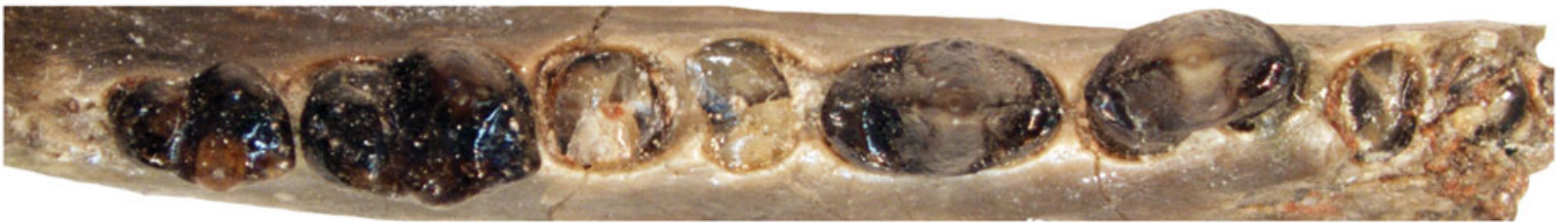

6

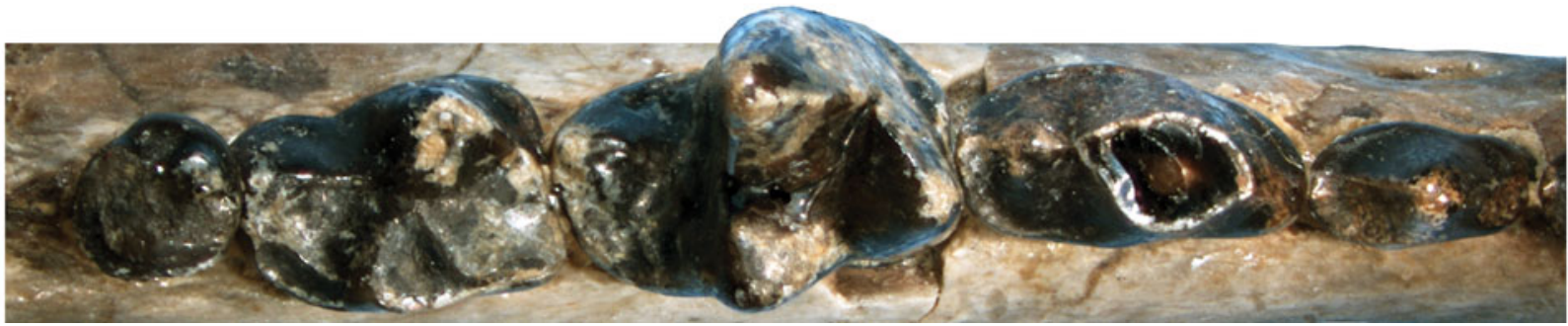

Figure 24. Comparison of carnivoraforms Oodectes spp., and Uintacyon jugulans from the Bridger and Washakie formations. (1, 3, 4) Holotype AMNH FM 1744 of Oodectes pugnax (Wortman and Matthew, 1899) from Twka1, left dentary in lateral view (1, color and transparency of matrix digitally altered to enhance visibility of specimen); 4 (broken) and m2-3 (inverted) in labial (3, inverted) and occlusal (4) views. (2,5) Holotype AMNH FM 11495 of $O$. proximus from Bridger B, left dentary in lateral view (2); left p3-4 and m2-3 in occlusal view (5). (6) Holotype AMNH FM 12066 of Uintacyon jugulans Matthew, 1909, from Bridger C, left p3$\mathrm{m} 3$ in occlusal view. Different $5 \mathrm{~mm}$ scales apply to Figure 24.1, 24.2, and 24.3-24.6.

(11\% shorter) than that of the holotype AMNH FM 12066 of $U$. jugulans from the Bridger $\mathrm{C}$ interval (Table 8), but is otherwise closely comparable to the holotype and thus referred to $U$. jugulans. The Washakie specimen differs from the $\mathrm{Br} 2-\mathrm{Br} 3$ aged species, $U$. vorax, in being much smaller (28-29\% shorter in m1L compared to AMNH FM 11507 and AMNH FM 11518; Table 8) and having a proportionately shorter $\mathrm{m} 1$ talonid. Similarly, FMNH PM 62564 is too small to represent Miocyon bathygnathus Scott, 1888 (= 'Uintacyon major' Matthew, 1909, according to Gustafson, 1986; see also
Bryant, 1992), whose holotype, YPM VPPU 010607, from the Bridger $\mathrm{C}$ interval measures $\mathrm{m} 1 \mathrm{~L}=11 \mathrm{~mm}$ and $\mathrm{m} 2 \mathrm{~L}=8 \mathrm{~mm}$ (Scott, 1888, p. 174). Another Bridgerian taxon, the genotypic species $U$. edax, is taxonomically too problematic (the holotype, now lost, had a supernumerary premolar; Leidy, 1873; Cope, 1884, p. 301-302; Scott, 1888, p. 172; Wortman and Matthew, 1899; Matthew, 1909) to permit close comparison with the Washakie specimens, although Matthew's (1909) description of a large $\mathrm{ml}$ talonid is inconsistent with the morphology of FMNH PM 62564. 
Table 8. Lower dental measurements (in mm) of Bridgerian-Uintan specimens of Oodectes, Uintacyon, and Miocyon. ${ }^{\mathrm{a} C a s t}$ of holotype YPM VP 011861. ${ }^{\mathrm{b}}$ Digital measurements from microscope photographs. ${ }^{\mathrm{C}} \mathrm{Lp} 3-4, \mathrm{Rm} 1, \mathrm{Lm} 2-3 .{ }^{\mathrm{d}}$ Alveolar measurements. ${ }^{\mathrm{e}} \mathrm{Cast}$ of holotype YPM VP $013101 .{ }^{\mathrm{f}} \mathrm{Rp} 3, \mathrm{Lp} 4-\mathrm{m} 3 .{ }^{\mathrm{g}} \mathrm{Cast}$ of holotype ANSP 10261. ' Referred to U. vorax "with doubt" in Matthew (1909, p. 374) primarily because of poor preservation of ANSP holotype, but we accept his identification. ${ }^{\mathrm{i}} \mathrm{Lp} 4, \mathrm{Rm} 1-2$. *Holotype or its cast. ${ }^{\dagger}$ Estimated for specimens with minor breakage/obstruction. Plus signs denote slight undermeasurements.

\begin{tabular}{|c|c|c|c|c|c|c|c|c|c|c|c|c|c|c|}
\hline Specimen & Taxon & Horizon & Side & p3L & $\mathrm{p} 3 \mathrm{~W}$ & $\mathrm{p} 4 \mathrm{~L}$ & $\mathrm{p} 4 \mathrm{~W}$ & $\mathrm{~m} 1 \mathrm{~L}$ & $\mathrm{~m} 1 \mathrm{~W}$ & m1TRL & $\mathrm{m} 2 \mathrm{~L}$ & $\mathrm{~m} 2 \mathrm{~W}$ & $\mathrm{~m} 3 \mathrm{~L}$ & $\mathrm{~m} 3 \mathrm{~W}$ \\
\hline AMNH FM 105003*a & O. herpestoides & Bridger A/B & $\mathrm{R}$ & & & $3.89^{\mathrm{b}}$ & $2.15^{b}$ & & & & $3.83^{b}$ & $2.62^{b}$ & $3.13^{b}$ & $2.30^{\mathrm{b}}$ \\
\hline AMNH FM 11495* & O. proximus & Bridger B & $\mathrm{R}+\mathrm{L}^{\mathrm{c}}$ & $3.60^{\mathrm{b}}$ & $2.00^{\mathrm{b}}$ & $3.88^{\mathrm{b}}$ & $2.23^{\mathrm{b}}$ & $4.55^{\mathrm{b}}$ & $2.96^{\mathrm{b}}$ & $3.23^{\mathrm{b}}$ & $3.71^{\mathrm{b}}$ & $2.56^{\mathrm{b}}$ & $2.88^{\mathrm{b}}$ & $2.11^{\mathrm{b}}$ \\
\hline AMNH FM 1744* & O. pugnax & Twka1 & $\mathrm{L}$ & & & & & {$[\sim 5.7]^{\mathrm{d}}$} & & & $\sim 4.8^{\dagger}$ & 2.95 & 3.08 & 2.23 \\
\hline AMNH FM $104992 * \mathrm{e}$ & U. acutus & Uinta Fm. & $\mathrm{L}$ & & & 4.67 & 2.83 & 5.91 & 3.6 & 3.45 & 3.94 & 3.58 & & \\
\hline AMNH FM $12066^{*}$ & U. jugulans & Bridger C & $\mathrm{R}+\mathrm{L}^{\mathrm{f}}$ & 3.47 & 1.96 & 5.63 & 2.85 & 6.87 & 4.6 & 4.52 & 5.41 & 3.68 & 2.59 & 2.58 \\
\hline AMNH FM 12070 & U. jugulans & Bridger C & $\mathrm{R}$ & & & & & & & & 4.78 & 3.61 & 2.47 & 2.49 \\
\hline YPM VP 012995 & U. jugulans & Bridger $\mathrm{A} / \mathrm{B}$ ? & $\mathrm{R}$ & & & 5.67 & 2.77 & 6.32 & 3.98 & 4.28 & 4.58 & 3.82 & & \\
\hline FMNH PM 62564 & cf. U. jugulans & Twka1 & $\mathrm{L}$ & & & 5.09 & 2.8 & 6.15 & 3.90 & 4.09 & & & & \\
\hline AMNH FM $104995^{* g}$ & U. vorax & Bridger C/D & $\mathrm{L}$ & & & & & & & & 5.89 & 4.51 & & \\
\hline AMNH FM $11507^{\mathrm{h}}$ & cf. $U$. vorax & Bridger B & $\mathrm{R}$ & & & 6.50 & 3.46 & 8.55 & 4.88 & 5.44 & {$[\sim 6.1]^{\mathrm{d}}$} & {$[\sim 4.1]^{\mathrm{d}}$} & & \\
\hline AMNH FM 12159* & M. bathygnathus & Bridger $\mathrm{C}$ & $\mathrm{R}+\mathrm{L}^{\mathrm{i}}$ & & & 9.11 & 4.49 & 11.36 & 6.92 & 7.01 & 7.6 & 6.41 & & \\
\hline
\end{tabular}

Finally, the Uintan species $U$. acutus Thorpe, 1923b closely resembles FMNH PM 62564 both in size and general form of $\mathrm{p} 4$ and $\mathrm{m} 1$, but the more pronounced posterior tapering of the $\mathrm{m} 1$ talonid in the Washakie specimen (reflecting a relatively narrow $\mathrm{m} 2$ ) better matches that of $U$. jugulans.

Identification of the partial M1 of PM 56362 as U.jugulans is based on its size, which is compatible with $\mathrm{ml}$ of FMNH PM 62564 , and is necessarily tentative because the upper dentition of $U$. jugulans has never been described or figured.

Genus Lycarion (Matthew, 1909) new genus

Type species._Lycarion medius (Matthew, 1909).

Diagnosis._As for type species.

Occurrence.-As for type species.

Etymology.-Matthew's (1909) subgenus Lycarion, whose etymology was not provided, is here elevated to the genus rank.

Remarks._Matthew (1909) grouped 'Miacis' medius and 'M.' hargeri (known from the Twin Buttes Member and less securely the Blacks Fork Member of the Bridger Formation; Thorpe, 1923a; Gazin, 1976) into a newly proposed subgenus Lycarion, but did not clearly differentiate it from another subgenus of Miacis that he proposed concurrently, Harpalodon. He noted narrow lower-molar talonids as a common characteristic of Lycarion and Harpalodon, and "vestigial" M3s as an additional characteristic of Harpalodon (Matthew, 1909, p. 365). However, given that $\mathrm{m} 3 \mathrm{~s}$ of 'Miacis' (Harpalodon) sylvestris and 'M.' (Lycarion) hargeri are equally reduced, M3 of 'M.' (Lycarion) hargeri, which is not known, also must have been vestigial.

In our view, at least one species that Matthew (1909) assigned to the subgenus Lycarion, 'M.' (L.) medius, is diagnosably distinct from all other carnivoraforms, including Harpalodon (see emended diagnosis, below). In addition, because our cladistic analysis (see Results) suggests the distinction of the ' $M$.' (L.) medius lineage from all other carnivoraforms, and does not support its placement within a Miacis clade that includes the genotypic species $M$. parvivorus Cope, $1872 \mathrm{~b}$ (see also Spaulding and Flynn, 2012; Solé et al., 2014), we recognize the validity of Lycarion as a distinct taxon including at least the species L. medius (Matthew, 1909). Although our cladistic analysis supports a close relationship between the two taxa that Matthew (1909) linked in the subgenus Lycarion, we have opted not to revise the existing classification of ' $M$.' hargeri until additional specimens of that species can be closely examined.

\section{Lycarion medius (Matthew, 1909)}

Figures 26, 27.1, 27.2, 28.1-28.3, 28.5-28.8

1909 Miacis (Lycarion) medius Matthew, p. 370, text-fig. 15. 1998 Miacis medius; Flynn, p. 117.

2008 Miacis medius; Heinrich et al., p. 155.

Holotype.-AMNH FM 13137, partial cranium with right $\mathrm{C} 1$ and left P3-M3, right dentary with heavily damaged $\mathrm{c} 1$, root of p1, heavily damaged p2-3, p4-m1, and root of $\mathrm{m} 3$, left dentary with $\mathrm{i} 3$, broken $\mathrm{c} 1$, heavily damaged $\mathrm{p} 3-\mathrm{m} 1, \mathrm{~m} 2$, and alveolus for $\mathrm{m} 3$, right humerus missing proximal portion.

Locality.-AMNH locality recorded as 3 miles $(\sim 4.8 \mathrm{~km})$ east of Kinney Ranch, Washakie Basin, Sweetwater County, Wyoming.

Horizon.-Twka1 ("Lower Washakie" according to Matthew, 1909, p. 370), Adobe Town Member, Washakie Formation.

Emended diagnosis.-Differs: from earlier-diverging carnivoraforms except Gracilocyon and Oodectes (Figs. 43, 44) in presence of p3 anterior cingular cuspulid (Character 218, State 1); from Gracilocyon and Oodectes in greater labial projection of M1 parastylar region than metastylar region (Character 44, State 1), longer P4 metastylar blade (Character 57, State 1), less well developed p4 posterolabial cingulid (Character 225, State 0), and more anteroposterior orientation of P4 metastylar blade (Character 241, State 1); and from Neovulpavus, 'Miacis' hargeri, Harpalodon, 'Miacis' uintensis Osborn, 1895, Tapocyon, 'Miacis' gracilis Clark, 1939, and crown-group carnivorans in more robust P4 protocone (Character 56, State 0).

Further differs: from Neovulpavus in subequal sizes of anterior and posterior portions of M1 lingual cingulum (Character 47, State 0), less prominent $\mathrm{p} 4$ posterior accessory cuspulid (Character 220R, State 1), enamel crenulation of M1 anterior border (Character 250, State 1); from 'Miacis' hargeri in more anterior position (above P3) of infraorbital foramen (Character 

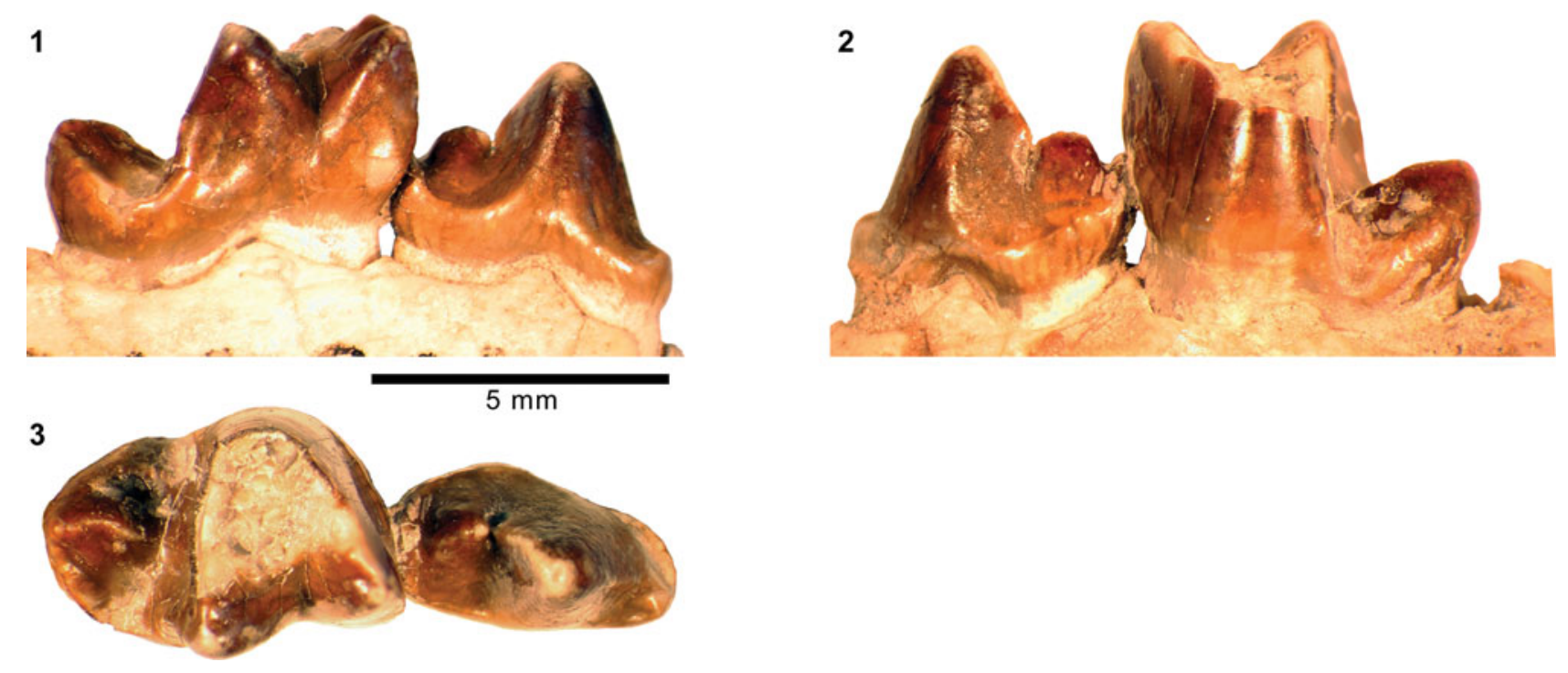

Figure 25. Dentition of carnivoraform Uintacyon jugulans from the Washakie Formation. (1-3) Left p4-m1 of FMNH PM 62564 in lingual (1), labial (2), and occlusal (3) views. Same $5 \mathrm{~mm}$ scale applies to all images.

4, State 0 ), more anteriorly oriented $\mathrm{m} 2$ postparacristid (Character 248, State 1), and relatively larger posterior molars, and more anteriorly directed $\mathrm{m} 1$ postparacristid; from 'Miacis' lushiensis in less-prominent $\mathrm{p} 4$ posterior accessory cuspulid (Character 220R, State 1) and more anteriorly oriented $\mathrm{m} 2$ postparacristid (Character 248, State 1); from 'Miacis' uintensis and Harpalodon sylvestris in reduced postorbital process (Character 8, State 1), weak anterior projection of $\mathrm{P} 4$ parastylar region (Character 249, State 1), and well developed p4 anterior cuspulid (Character 221, State 2); from Tapocyon, 'Miacis' gracilis, and crown-group carnivorans in more closed $\mathrm{m} 1$ trigonid (Character 227R, State 0); and from the genotypic species of Miacis, M. parvivorus, in presence of $\mathrm{P} 3$ posterior cuspules (Character 58, State 1), more robust P4 protocone (Character 56, State 0), less pronounced anterior projection of $\mathrm{P} 4$ parastylar region in occlusal view (Character 249, State 1), presence of enamel crenulation along anterior border of M1 (Character 250, State 1), substantial labial projection of M1 parastylar region (Character 45R, State 2), more uniform width of M1 lingual cingulum along base of protocone in occlusal view (Character 47, State 0 ), relatively smaller $\mathrm{p} 4$ posterior basal cuspulid (Character 224R, State 0), anteriorly directed $\mathrm{m} 2$ paraconid (Character 248, State 1), more vertical orientation of medial ridge of humeral trochlea in posterior view (Character 108, State 0), and posteriorly curved humeral medial epicondyle (Character 111, State 2).

Occurrence.-Twka1, Adobe Town Member, Washakie Formation, Sweetwater County, Wyoming (Matthew, 1909); above Roehler's (1973) bed 579 (= Robin's-egg-blue marker bed), undifferentiated Washakie Formation, Moffat County, Colorado (this study). Late Bridgerian ( $\mathrm{Br} 3)$ and questionably early Uintan (Uilb) NALMA.

Description.-The following descriptions supplement those by Matthew (1909). Comparisons are made with: (1) the holotype YPM VP 010071 (and its cast, AMNH FM 104959) of
'Miacis' hargeri from the Twin Buttes Member of the Bridger Formation because Matthew (1909) considered that species to be a close relative of ' $M$.' (Lycarion) medius (= Lycarion medius herein); and (2) Miacis parvivorus, the genotypic species of Miacis from the early to middle Bridgerian NALMA (Br1b-Br2; Gunnell et al., 2009). Measurements are reported in Table 9.

Of the upper teeth, P3-M3 are well preserved (Fig. 27.1, 27.2). P3 of Lycarion medius is more robust than in 'Miacis' hargeri, but as in the latter taxon and in contrast to Miacis parvivorus, bears a well-defined posterior accessory cuspule on the posterior slope of the main cusp. Part of the lingual base of the P3 crown, at a level slightly posterior to the apex of the main cusp, bulges in posterolingual direction; this bulge does not form an additional cuspule, but it makes the occlusal outline of the tooth somewhat triangular.

Like P3, P4 is characterized by its stoutness, having a relatively broad (i.e., anteroposteriorly long) protocone and a transversely wide base of the metastylar region in occlusal view. Its preparacrista is not particularly sharp, and the parastyle is absent; instead, a thick cingulum surrounds the base of the crown, except around the protocone. The parastylar region as a whole is marked by a more limited anterior projection than in Miacis parvivorus, resembling the condition in ' $M$.' hargeri. The metastylar blade of P4 is well developed and trenchant.

The M1 in occlusal view is wrapped by an essentially continuous band of thick and weakly crenulated cingulum; similar crenulation of the cingulum is observed in the holotype of 'Miacis' hargeri (Fig. 27.1, 27.3). The parastylar region extends farther labially than in Miacis parvivorus, but is proportionately not as prominent as in ' $M$.' hargeri, which has a more anteroposteriorly compressed M1. In addition, the labial outline of the parastylar region is more hook-shaped than in 'M.' hargeri. The prominent parastylar ridge stretches labiolingually, extending from the anterolabial base of paracone to approximately the labial extremity of the tooth. Other similarities to M1s of M. parvivorus and 'M.' hargeri include a wide 


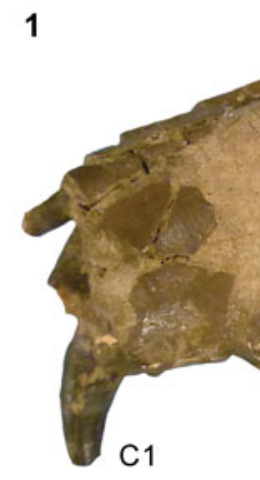

3

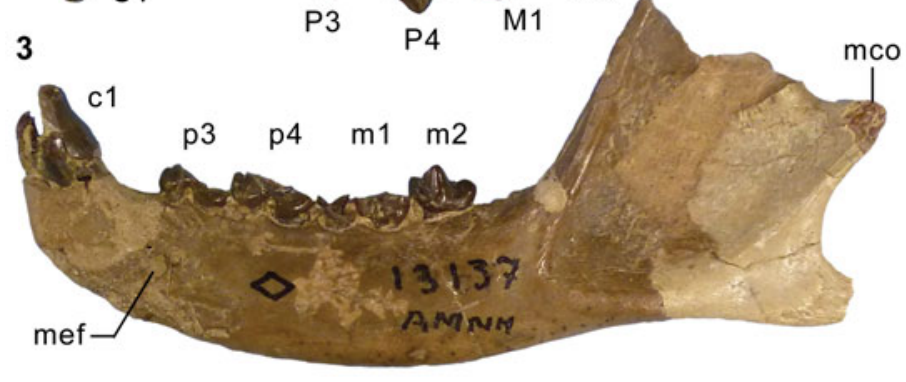

4

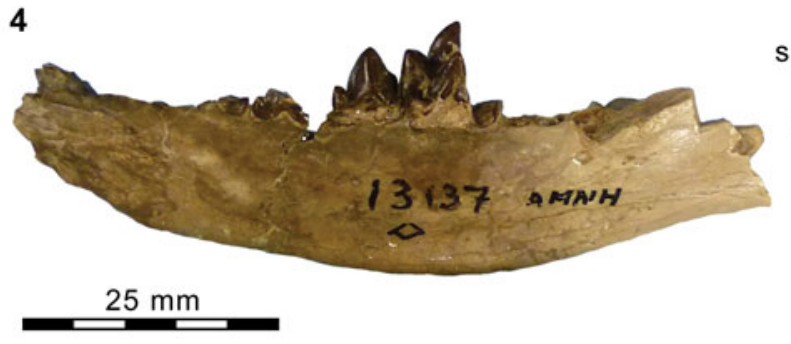

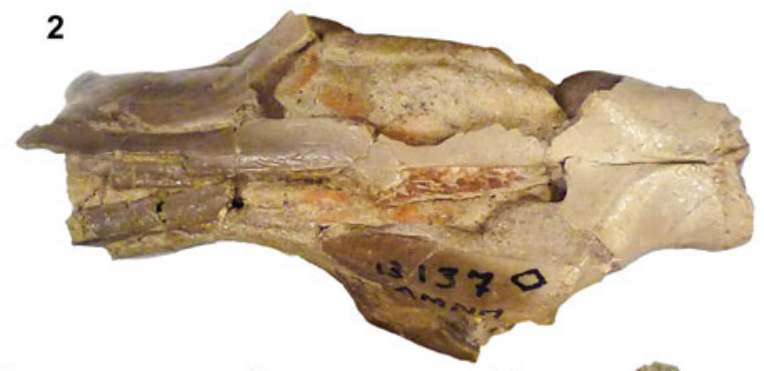

5

6

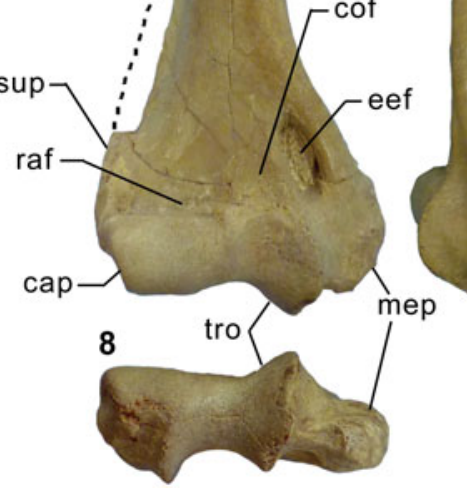

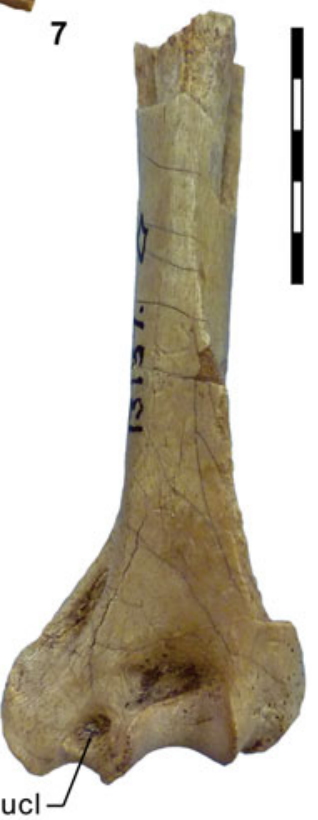

Figure 26. Holotype AMNH FM 13137 of carnivoraform Lycarion medius Matthew, 1909, from the Washakie Formation. (1-3) Cranium in lateral (1) and superior (2) views; left dentary in lateral view (3); (4) right dentary in medial view; (5-8) right humerus (missing proximal portion) in anterior $(\mathbf{5})$, medial $(\mathbf{6})$, posterior $(\mathbf{7})$, and distal (8; anterior to top) views; dashed line in (5) shows likely extent of supinator crest. Abbreviations: cap, capitulum; cof, coronoid fossa; dpc, deltopectoral crest; eef, entepicondylar foramen; mco, mandibular condyle; mef, mental foramen; mep, medial epicondyle; raf, radial fossa; sup, supinator crest; tro, trochlea; ucl, insertion site for ulnar collateral ligament. Same $25 \mathrm{~mm}$ scale applies to all images.

stylar shelf, a much greater height of the paracone compared to the metacone, and an anterior position of the protocone such that its apex is nearly aligned with that of the paracone in occlusal view. The angular paraconule is well developed, contributing to the deep appearance of the M1 trigon basin; the metaconule is less distinct and manifests chiefly as the lingual terminus of the thick posterolabial cingulum. The lingual cingulum maintains a fairly uniform width around the protocone, in contrast to the conditions in M. parvivorus, in which the expanded posterior portion is roughly twice as wide as the anterior portion, and in ' $M$. ' hargeri, in which the lingual base of the protocone nearly interrupts the continuity of the lingual cingulum.

The M2 is qualitatively characterized by the same set of features as M1, although individual traits are less developed. Comparison with M2 of ' $M$.' hargeri is complicated by the fact that the holotype of the latter in its current condition preserves only the anterolabial corner of the tooth, although Wortman's (1901a, fig. 3) original figure depicted it as complete. Judging from the still preserved portion and the relative sizes of $\mathrm{m} 1$ and $\mathrm{m} 2$
(Fig. 28.1, 28.2, 28.4; Table 9), the M2:M1 size ratio appears to have been roughly comparable between Lycarion medius ([M2 L x W]/[M1 L x W] = 0.52 in holotype) and ' $M$.' hargeri, with both taxa having relatively larger M2s compared to their close relatives Neovulpavus washakius Wortman, 1901a ([M2 $\mathrm{L} \times \mathrm{W}] /[\mathrm{M} 1 \mathrm{~L} \times \mathrm{W}]=0.41$ in AMNH FM 2305) and FMNH PM 3593 ([M2 L x W]/[M1 L x W] =0.27), which represents a new taxon described below (see also result of cladistic analysis; Figs. 43, 44).

The M3 retains a distinct paracone and metacone. The protocone is more confluent with the lingual cingulum than on M1 and M2. The paraconule and metaconule are essentially absent from M3.

With the exception of the left $\mathrm{m} 2$, all of the preserved lower postcanine teeth of the holotype are moderately to heavily damaged (Fig. 28.1, 28.2, 28.5-28.8). In addition, comparison of the right and left sides suggests the right $\mathrm{p} 4$ to be in abnormal contact with the succeeding $\mathrm{m} 1$ (apparently in vivo, not as a preservational artifact), which may have altered part of the p4 crown morphology. 
1

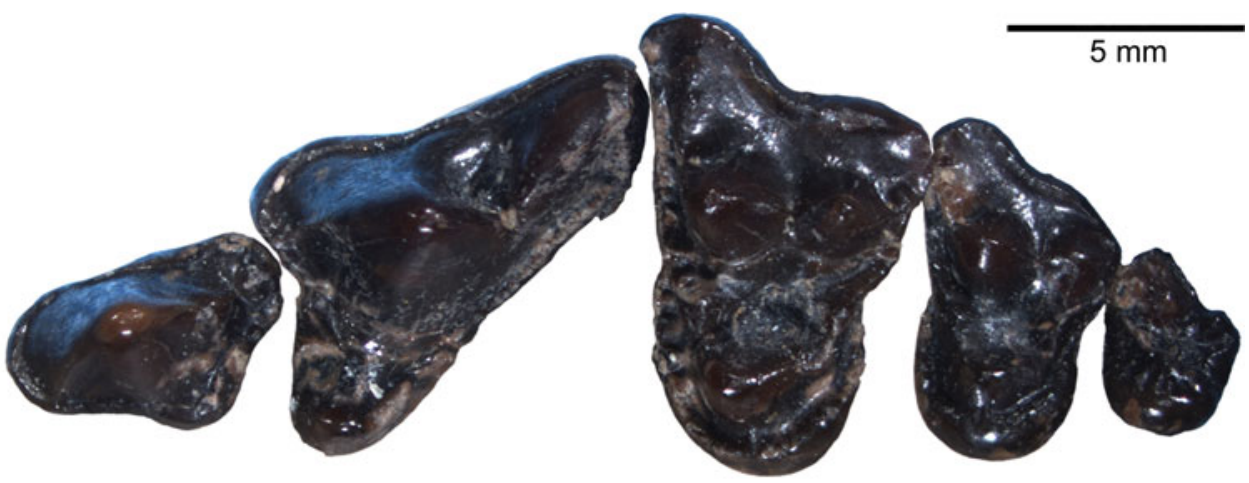

2

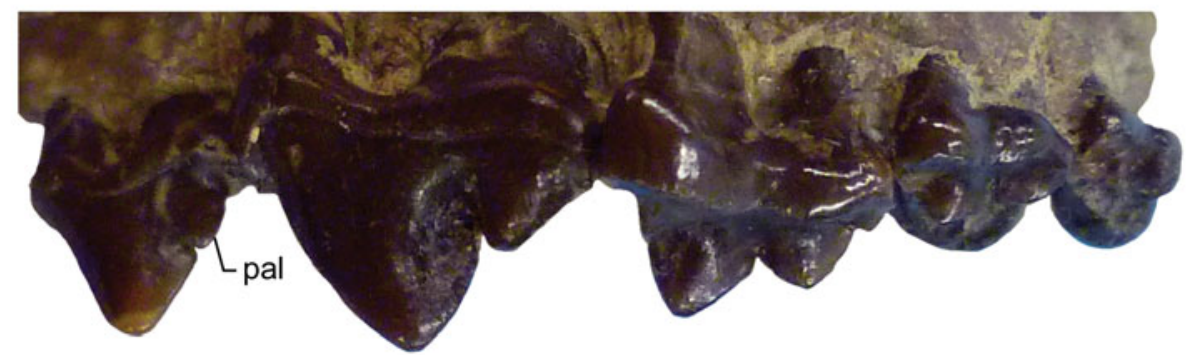

3
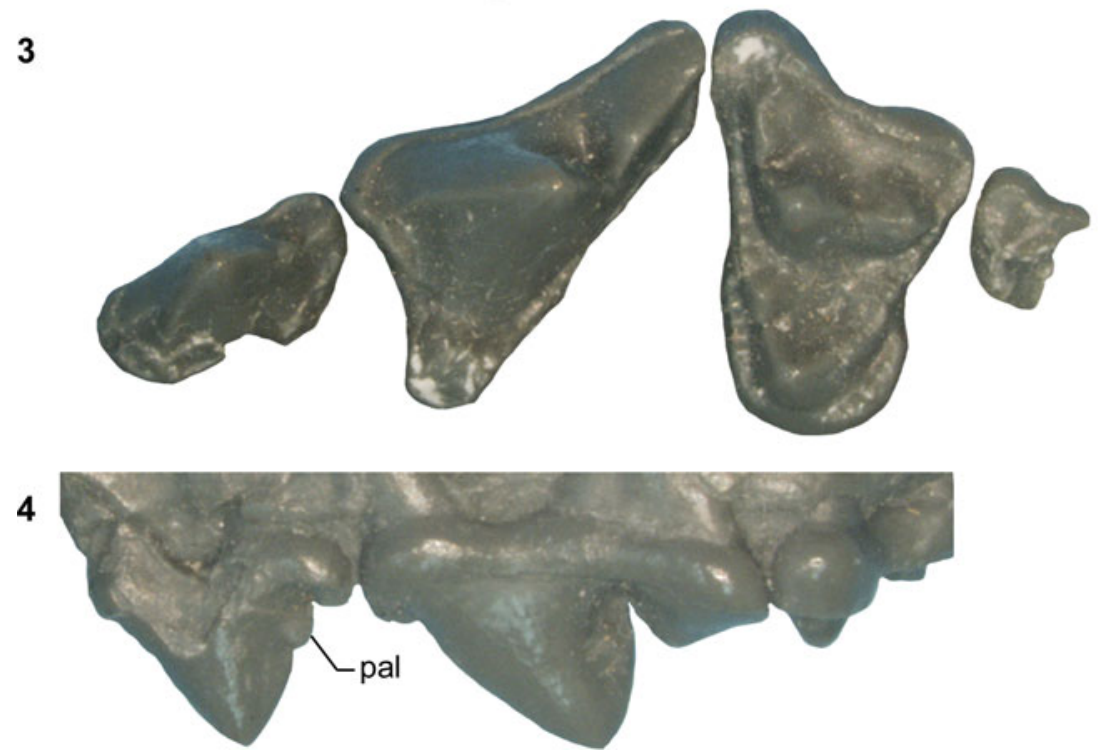

Figure 27. Upper dentitions of carnivoraforms Lycarion medius and 'Miacis' hargeri Wortman, 1901a, from the Washakie and Bridger formations. (1, 2) AMNH FM 13137 (holotype of Lycarion medius), left P3-M3 in occlusal (1) and labial (2) views; $(\mathbf{3}, \mathbf{4})$ epoxy cast AMNH FM 104959 of YPM VP 010071 (holotype of 'Miacis' hargeri), left P3-M1 and broken M2 in occlusal view (3) and left P3-M1 in labial view (4). Abbreviation: pal, posterior accessory cuspule. Same 5 mm scale applies to all images.

The crown of the single-rooted $\mathrm{p} 1$ is not preserved. This tooth locus is anteriorly separated from $\mathrm{c} 1$ by a diastema that is about as long as the $\mathrm{p} 1$ alveolus, and posteriorly from $\mathrm{p} 2$ by a shorter diastema of about half the length of the $\mathrm{p} 1$ alveolus.

The $\mathrm{p} 2$ is known only from a small portion of its posterior base. The tooth is slightly narrower than $\mathrm{p} 3$, and appears to have been roughly twice as long as $\mathrm{p} 1$.

The $\mathrm{p} 3$ is missing the main cuspid and much of the posterior portion of the crown. The remaining parts are suggestive of a tooth form that is similar to the somewhat larger $\mathrm{p} 4$. A small but well-defined anterior cuspulid is located on the anterolingual corner of the tooth, as in $\mathrm{p} 4$.
The $\mathrm{p} 4$ bears a prominent anterior cuspulid that is proportionately larger than in 'Miacis' hargeri. The anterior ridge of the main cuspid forms a gently arching outline in profile. The morphology of the tooth is otherwise closely comparable to that of ' $M$.' hargeri, including the position and the somewhat blade-like form of the posterior accessory cuspulid on the posterior slope of the main cuspid.

The $\mathrm{m} 1$ is marked by the anterior direction of the postparacristid, which makes the trigonid more open than in 'Miacis' hargeri, and labiolingually offsets the apices of the paraconid and metaconid. However, unlike in later carnivoraforms with similarly open trigonids (e.g., Procynodictis vulpiceps Wortman and Matthew, 1899 from the late Uintan; Tomiya, 2013), the 


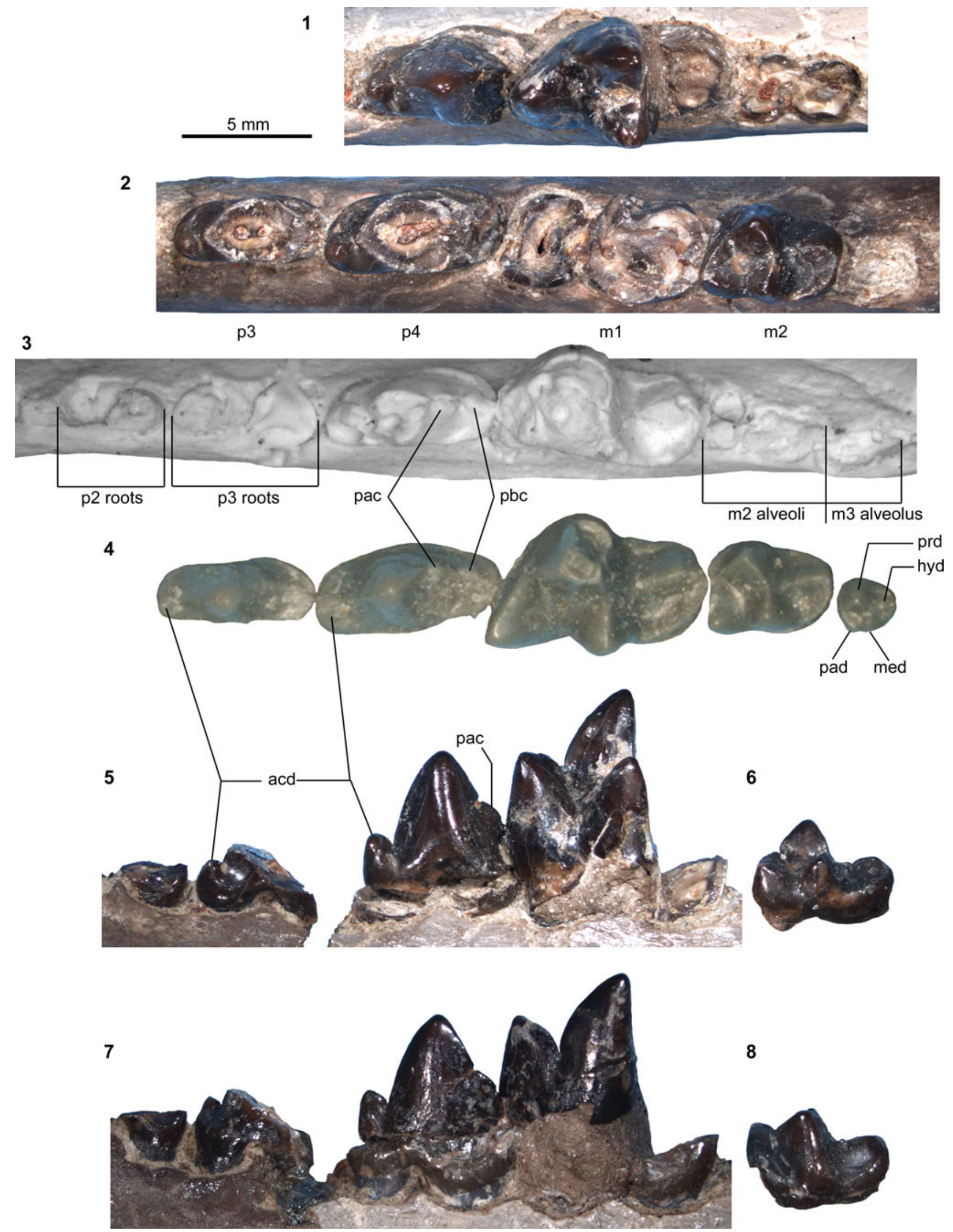


Figure 28. Lower dentitions of Lycarion medius and 'Miacis' hargeri from the Washakie and Bridger formations. AMNH FM 13137 (holotype of Lycarion medius): $(\mathbf{1}, \mathbf{2})$ right $\mathrm{p} 4, \mathrm{~m} 1$, and roots of $\mathrm{m} 2 \mathbf{( 1 )}$ and heavily damaged left $\mathrm{p} 3-\mathrm{m} 1, \mathrm{~m} 2$, and alveolus for $\mathrm{m} 3$ (inverted in $\mathbf{2}$ ) in occlusal view; $(\mathbf{5}, \mathbf{7})$ right $\mathrm{p} 2-3$ (broken) and p4-m1 in lingual (5) and labial (7; inverted) views; (6, 8) left m2 in lingual (6; inverted) and labial (8) views. Plaster cast AMNH FM 105385 of CM 23191 (“Uintacyon vorax" of West and Dawson, 1975; here tentatively referred to L. medius): (3) roots of p2-3, broken p4-m1, and alveoli for m2-3 in occlusal view. Epoxy cast AMNH FM 104959 of YPM VP 010071 (holotype of 'Miacis' hargeri): (4) left p3-m3 (inverted) in occlusal view. Same 5 mm scale applies to all images. Abbreviations: acd, anterior cuspulid; hyd, hypoconid; med, metaconid; pac, posterior accessory cuspulid; pad, paraconid; pbc, posterior basal cuspulid; prd, protoconid. Same scale applies to all images.

Table 9. Measurements (in mm) of 'Miacis' hargeri Wortman, 1901a, Lycarion medius Matthew, 1909, Neovulpavus washakius Wortman, 1901a, and Harpalodon sylvestris Marsh, 1872c, from the Bridger and Washakie formations. ${ }^{a}$ Cast of holotype YPM VP 010071. ${ }^{b}$ Measurements taken from digital photographs. ${ }^{c} \mathrm{Cast}$ of CM 23191 referred to Uintacyon vorax by West and Dawson (1975). ${ }^{\mathrm{d}}$ Cast of AMNH FM 129284. ${ }^{\mathrm{e}}$ Alveolar measurements. ${ }^{\mathrm{f}}$ Missing epiphysis on calcaneal tubercle. *Holotype or its cast. "Estimated for specimens with minor breakage or obstruction. Plus signs denote slight undermeasurements.

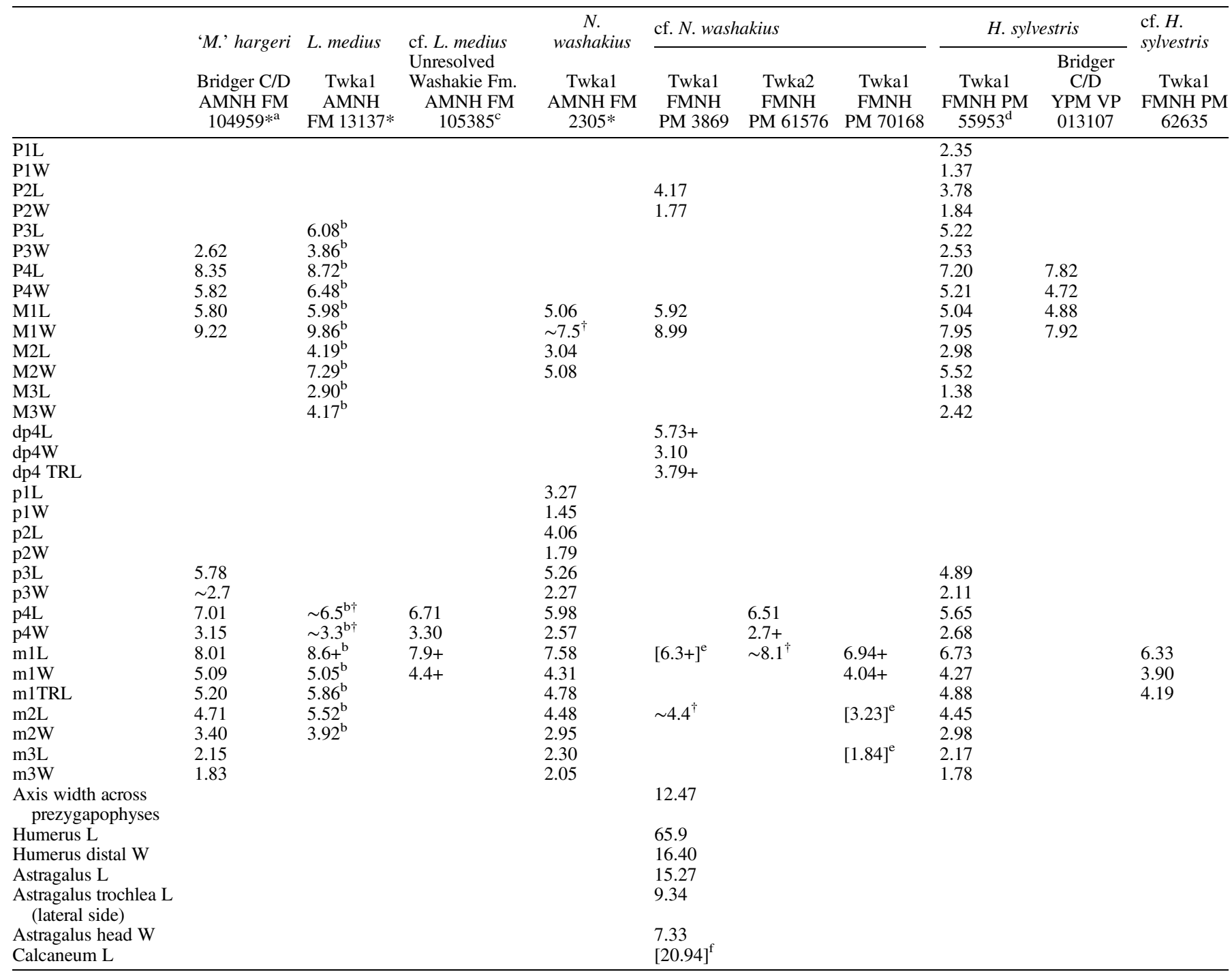

metaconid of Lycarion medius is little reduced relative to the paraconid. Details of the $\mathrm{m} 1$ talonid morphology cannot be inferred from the holotype, but the talonid basin appears to have been moderately wide across its length, lacking the degree of posterior tapering seen in 'M.' hargeri. This form of the $\mathrm{m} 1$ talonid would be consistent with (1) the shallower angle of the M1 postprotocrista (against the tooth row axis) in L. medius compared to 'M.' hargeri, and (2) a similarly shallow angle seen more definitively in the $\mathrm{m} 2$ talonid morphology.
The $\mathrm{m} 2$ is overall similar to that of ' $M$.' hargeri, but the postparacristid is somewhat more anteriorly directed, mirroring the condition in $\mathrm{m} 1$, and as noted above, the talonid basin is posteriorly less tapered, having a more squared-off appearance in occlusal view. The hypoconid and entoconid are not recognizable as distinct cuspids; rather, they form the labial and lingual portions of the continuous rim of the talonid basin, respectively. The open trigonid is in stark contrast to the closed one in Miacis parvivorus, in which the postparacristid is oriented nearly perpendicular to the tooth row. 
The $\mathrm{m} 3$ is known only from its single, broken root. Judging from the size of the alveolus, the crown would have been approximately the same size as, or slightly smaller than, the $\mathrm{m} 2$ talonid.

Matthew (1909) mentioned the existence of a humerus as part of the holotype, but did not describe its morphology. Similar to the humerus of the early carnivoraforms Vulpavus (USGS 25219, tentatively referred to V. australis Matthew and Granger, 1915 or V. canavus (Cope, 1881) by Heinrich and Rose [1997, text-fig. 2A, 2B]), the partial right humerus of AMNH FM 13137 (Fig. 26.5-26.8) bears a tall deltopectoral crest that terminates rather abruptly at its distal end (Fig. 26.6), and the radial and coronoid fossae are shallow and indistinct (Fig. 26.5). On the other hand, the humerus of Lycarion medius exhibits more limited medial protrusion of the medial epicondyle, a lessrounded capitulum, and a steeper angle between the long axis of the capitulum and the medial rim of the trochlea. The lateral margin of the supinator crest is missing for the most part, but the outline of the intact distal portion suggests that this crest was not particularly expansive. The insertion site for the ulnar collateral ligament is marked by a prominent fossa (Fig. 26.7). A supratrochlear foramen is lacking. Overall, the morphology of the distal humerus is closely comparable to that of 'Miacis' hargeri (Wortman, 1901a, fig. 9) and is suggestive of a generalized scansorial locomotor mode compared to inferences of a more arboreal locomotion for Uintacyon massetericus (Cope, 1882) (USGS 21910; Heinrich and Rose, 1997, text-fig. 2C), terrestrial locomotion for Didymictis (USGS 27585, cf. D. protenus in Heinrich and Rose [1997]), or to the distinct morphology in extant semi-fossorial taxa such as Taxidea taxus (Schreber, 1777).

Materials. - CM Sand Wash Basin Locality 4 (also known as "Clay Buttes locality"; undifferentiated Washakie Formation) of West and Dawson (1975): CM 23191, right dentary fragment with broken $\mathrm{p} 4$ and $\mathrm{m} 1$.

Remarks.-Matthew (1909) provided a brief description of the holotype and listed the following as diagnostic features of 'Miacis' (Lycarion) medius (p. 365): (1) a "heavy cingulum on M1-2 but no distinct hypocone;" and (2) "M2-3 moderately reduced, not compressed." Indeed, the posterior molars and their main cusps are notably well developed, especially in comparison to those of typical carnivoraforms from the succeeding early Uintan NALMA (see e.g., Tomiya, 2013). The perceived taxonomic significance of the robust posterior molars, however, is somewhat tempered by substantial variations in the relative sizes of M2 in other early carnivoraforms such as Dormaalocyon latouri (Solé et al., 2014) and Miacis parvivorus (e.g., USNM PAL 214706 vs. USNM PAL 362796).

Lycarion medius was so far known only from the holotype. Here, we reidentify CM 23191 (we examined its cast, AMNH FM 105385; Fig. 28.3) from an exposure of the Washakie Formation in the Sand Wash Basin of Colorado, which was previously referred to Uintacyon vorax (West and Dawson, 1975, p. 238, fig. 3), as cf. L. medius. In contrast to $U$. vorax, and species of Uintacyon in general, this specimen is characterized by: (1) proportionately longer p3-4 (length across p3-4 is roughly equal to, rather than clearly shorter than, length across m1-2); (2) p4 with a dorsally positioned posterior accessory cuspulid (absent in Uintacyon), followed by a small second notch and a blade-like posterior basal cuspulid; (3) m1 with a more open trigonid, and a posteriorly broader talonid basin with a more angular hypocristid in occlusal view; and (4) labiolingually narrower $\mathrm{m} 2$ relative to $\mathrm{m} 1$. In all of these traits, $\mathrm{CM}$ 23191 is comparable to L. medius. Further, the sizes and spacing of the teeth on CM 23191 (in part judging from the alveoli) more closely match those of the holotype AMNH FM 13137 than any other known carnivoraform from the late Bridgerian, with the exception of ' $M$.' hargeri, which it also resembles (Fig. 28.4; Table 9). CM 23191 differs from the holotype of ' $M$.' hargeri in ways that are subtle but make it more consistent with L. medius, namely (1) the more anterior direction (so far as can be discerned from the broken trigonid) of the $\mathrm{m} 1$ paraconid; (2) posteriorly wider $\mathrm{m} 1$ talonid and talonid basin; and (3) more distinctly cuspidate hypoconids on lower molars (note that, while the $\mathrm{m} 1$ hypoconid is obliterated on the holotype of L. medius, we expect it to have closely resembled the form of the intact $\mathrm{m} 2$ hypoconid, as is generally the case with early carnivoraforms). With this reidentification of CM 23191, there is no longer a valid record of Uintacyon vorax from the Washakie Formation.

The age of the locality that yielded CM 23191 (Sand Wash Basin Locality 4 of West and Dawson, 1975) is uncertain. The horizon is reportedly above the Robin's-egg-blue marker bed (= Roehler's [1973] bed 579), but the lithostratigraphy of the Sand Wash Basin is not yet sufficiently resolved to assign this locality to either the late Bridgerian or the earliest/early Uintan NALMA (Murphey et al., 2018). West and Dawson (1975) reported an occurrence of the equid Orohippus sylvaticus (Leidy, 1870b) at Locality 4 and accepted it as a Bridgerian taxon following Kitts (1957). However, O. sylvaticus also is reported from Sand Wash Basin Locality 3 of West and Dawson (1975), which Stucky et al. (1996) considered to be early Uintan in age based on undescribed material of the agriochoerid artiodactyl Protoreodon - a taxon that is otherwise unknown from the Washakie Formation. If the latter assessment is correct, the purported occurrence of $O$. sylvaticus at Locality 4 does not resolve its NALMA assignment. On the other hand, Murphey et al. (2018) argued that the equid materials from the Sand Wash Basin are generically indeterminate and may in part belong to the Uintan genus Epihippus instead of Orohippus. More generally, Gunnell et al. (2009) and Murphey et al. (2018) followed Stucky et al. (1996) and considered at least part of the Washakie Formation exposed in the Sand Wash Basin to be potentially early Uintan (Ui1b) in age, but they emphasized the need for additional biostratigraphic work. As is the case with the Washakie Basin, the Sand Wash Basin has not yielded any index taxon of the earliest Uintan NALMA (Uila; Murphey et al., 2018).

\section{Genus Neovulpavus Wortman, 1901a}

Type species.-Neovulpavus washakius Wortman, 1901a, by original designation.

Other species.-Neovulpavus mccarrolli $\mathrm{n}$. sp. 
Emended diagnosis.—Differs: from 'Miacis' hargeri, 'Miacis' lushiensis, Harpalodon sylvestris, and earlier-diverging carnivoraforms (Figs. 43, 44) in presence of p3 posterior accessory cuspulid (Character 219, State 1); from Lycarion medius and 'Miacis' hargeri in posterior enlargement of M1 lingual cingulum (Character 47, State 1), well developed p4 posterior accessory cuspulid (Character 220R, State 2), absence of enamel crenulation of M1 anterior border (Character 250, State 0); from 'Miacis' uintensis in predominantly labial projection of M1 parastylar region (Character 45R, State 2), less expansive humeral supinator crest (Character 114, State 1), less prominent humeral tricipital line (Character 124, State 1), $\mathrm{m}$. brachialis insertion on medial margin of ulnar shaft (Character 128, State 1), anterior orientation of radial notch on ulna (Character 138, State 0), dorsoventrally low level of astragalar head in distal view (Character 177, State 1), clearly demarcated and somewhat convex sustentacular facet on astragalus (Character 181, State 0), well developed p4 anterior cingular cuspulid (Character 221, State 2); and from Tapocyon robustus (Peterson, 1919), 'Miacis' gracilis, and crown-group carnivorans in more closed $\mathrm{m} 1$ trigonid (Character 227R, State 0).

Further differs: from 'Miacis' lushiensis in anteriorly directed $\mathrm{m} 2$ postparacristid (Character 248, State 1); and from the genotypic species of Miacis, M. parvivorus in substantial labial projection of M1 parastylar region (Character 45R, State 2), presence of $\mathrm{p} 3$ anterior cuspulid (Character 218 , State 1 ), relatively smaller $\mathrm{p} 4$ posterior basal cuspulid (Character 224R, State 0), equal heights of p3 and p4 (Character 226, State 2), anteriorly directed $\mathrm{m} 2$ paraconid (Character 248 , State 1), more vertical orientation of medial ridge of humeral trochlea in posterior view (Character 108, State 0), and posteriorly curved humeral medial epicondyle (Character 111, State 2), reduced humeral tricipital line (= deltoid crest; Character 124, State 1), more medial position of $\mathrm{m}$. brachialis insertion site on humeral shaft (Character 128, State 1), and smaller anteromedial protuberance of distal ulna (Character 135, State 1)

Neovulpavus washakius Wortman, 1901a Figures 29-33

1899 Vulpavus palustris Marsh, 1871; Wortman and Matthew, p. 118, figs. 4-6.

1901a Neovulpavus washakius Wortman, p. 445.

1909 Miacis (Harpalodon) washakius; Matthew, p. 370, textfig. 15.

1998 Miacis washakius; Flynn, p. 117.

2008 Miacis washakius; Heinrich et al., p. 155.

Holotype.-AMNH FM 2305, cranial fragment with right maxilla (with M1-2) and jugal; left maxillary fragment with $\mathrm{C} 1$; right dentary fragment with broken $\mathrm{c} 1, \mathrm{p} 1$, and $\mathrm{p} 3-4$; left dentary with $\mathrm{p} 2-\mathrm{m} 3$; right petrosal; fragmentary postcrania including: vertebral centrum, right humerus (missing distal end), left humerus (missing proximal end), right radius (proximal and distal pieces), right proximal ulna (missing olecranon process), left distal ulna, and right distal femur.

Locality.-AMNH locality recorded on specimen label as south of Haystack Mountain (reported as "middle horizon near the extreme southern limits of the Washakie Basin" in Wortman and Matthew, 1899, p. 119), Washakie Basin, Sweetwater County, Wyoming.

Horizon.-Twka1, Adobe Town Member, Washakie Formation.

Emended diagnosis.-Differs: from all other non-carnivoran Carnivoraformes in the features diagnosing Neovulpavus; and from N. mccarrolli n. sp. in vertical orientation of posteromedial edge of humeral trochlea (Character 108, State 0 ), presence of ridge extending distally from lesser tuberosity of humerus (Character 115, State 0), humeral greater tuberosity angled away from humeral head in proximal view (Character 121, State 0), dorsoventrally shallow astragalar head (Character 176, State 1), subequal heights of medial and lateral borders of astragalar trochlea (Character 186, State 0), and presence of $\mathrm{p} 3$ anterior cingular cuspulid (Character 218, State 1).

Occurrence.-Twka1 and Twka2, Adobe Town Member, Washakie Formation, Sweetwater County, Wyoming (Matthew, 1909; this study). Late Bridgerian (Br3) NALMA.

Description.-We first provide a brief description of the holotype AMNH FM 2305 of Neovulpavus washakius that supplements those of Wortman and Matthew (1899) and Matthew (1909). The right petrosal (Fig. 29.4) was not reported by previous authors. Its omission from Matthew (1909) is perplexing given his recognition of the value of petrosal morphology in mammalian systematics (p. 326), but it should be noted that neither of the earlier works listed the complete content of the specimen, which also includes a number of indeterminate skeletal fragments. Here we accept the petrosal cataloged under AMNH FM 2305 as belonging to the same individual as the rest of the specimen (collected and cataloged under this single number), with which the size and preservational qualities are consistent. In comparison to other early carnivoraforms with well-preserved basicrania, this petrosal shows notable similarities with that of Harpalodon sylvestris (= 'Miacis' sylvestris) in: (1) the oblong shapes of both the fenestra cochleae and fenestra vestibuli; (2) relatively flat anterior portion of the promontorium; and (3) somewhat rugose area along the ventromedial portion of the promontorium ("R" in Fig. 29.4) that is laterally bounded by a distinct ridge (cf., Wang and Tedford, 1994, fig. 3). The latter is interpreted as an area of attachment for a bullar element, possibly a caudal entotympanic (cf., Wang and Tedford, 1994; see also Hunt, 1977). Such a clearly demarcated attachment area is absent in earlier-diverging carnivoraforms such as Vulpavus profectus (Matthew, 1909) and Miacis parvivorus (Wang and Tedford, 1994), although roughness on the anteromedial surface of the promontorium is more broadly present in, and represents a possible synapomorphy of, Carnivoraformes (Wesley-Hunt and Flynn, 2005), and has been interpreted as indicative of rostral, rather than caudal, entotympanic attachment (Character 30, State 1 of Wesley-Hunt and Flynn, 2005; but see Hunt, 1977, p. 831, regarding evidence for rostral entotympanic attachment in fossil carnivorans). The promontorium of $N$. washakius, however, is not anteriorly elongate as in H. sylvestris, and the 

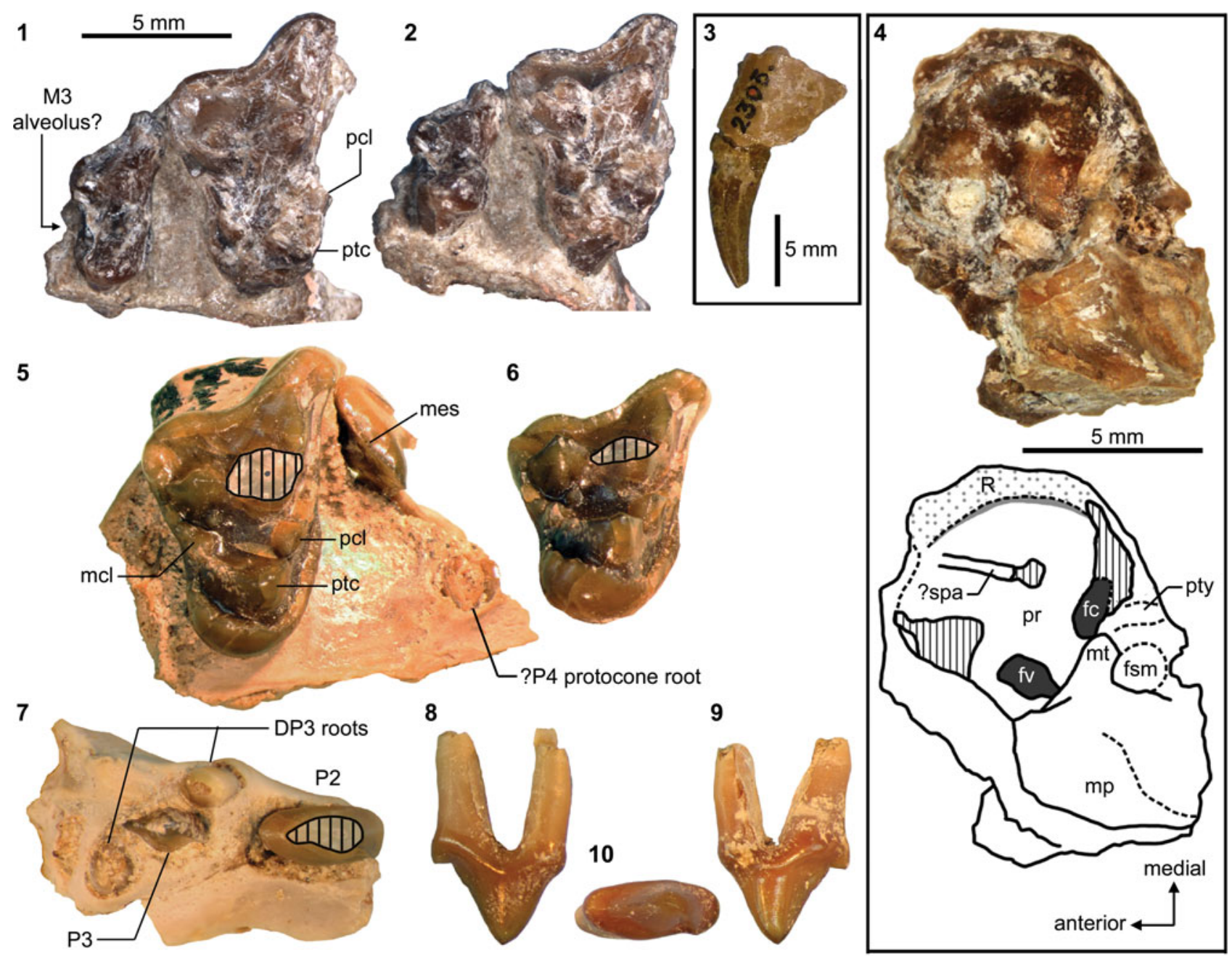

Figure 29. Upper-dental and basicranial material of carnivoraform Neovulapvus washakius Wortman, 1901a, from the Washakie Formation. Holotype of Neovulapvus washakius, AMNH FM 2305: (1-3) right maxillary fragment with M1-2 in occlusal (1) and oblique lingual (2) views; left maxillary fragment with C1 in lateral view $(\mathbf{3})$; (4) right petrosal-mastoid complex (vertical stripes indicate damaged surface; photography by Haibing Wang; light gray area indicates raised ridge on promontorium). cf. $N$. washakius, FMNH PM 3869: (5, 6) left maxillary fragment (inverted) with broken P4 and M1 in occlusal (5) and oblique lingual (6) views; (7-10) left maxillary fragment (inverted) with broken P2, roots of DP3, and erupting P3 in occlusal view (7); right P2 in labial (8), lingual (9), and occlusal (10) views. Boxes indicate images at different scales from the rest of the figure. Abbreviations: fc, fenestra cochleae; fsm, fossa for stapedius muscle; fv, fenestra vestibuli, mcl, metaconule; mes, metastylar blade; $\mathrm{mp}$, mastoid process (partial); mt, mastoid tubercle; pcl, paraconule; pr, promontorium; ptc, protocone; pty, process for tympanohyoid attachment; R, rugose area (stippled) for possible attachment of bullar element; ?spa, faint groove possibly representing sulcus for promontory artery.

ventromedial rugose area is proportionately narrower. Lateral to the promontorial ridge is a faint, anteroposteriorly oriented groove. We interpret this groove as the sulcus for the promontory artery ("?spa" in Fig. 29.4), indicating a transpromontorial passage of the internal carotid artery-a primitive condition for the Carnivoramorpha (Wang and Tedford, 1994; Wesley-Hunt and Flynn, 2005; Polly et al., 2006). No groove for the stapedial artery can be clearly identified. The fenestra cochleae and fenestra vestibuli are oriented such that their long axes form a nearly perpendicular angle. As in $H$. sylvestris, a round process presumably for attachment of the tympanohyoid ("pty" in Fig. 29.4; Wang and Tedford, 1994) is located posterior to the fenestra cochleae. Directed toward this process is the mastoid tubercle, which provides another attachment site for the tympanohyoid (Wang and Tedford, 1994). While the mastoid tubercle appears to be completely preserved, the fragmentary nature of the material combined with the lack of sutures precludes determination of whether the tubercle is composed of the squamosal or petrosal (= temporal). A blunt ventral inflation lateral to the mastoid tubercle constitutes the mastoid process. The fossa for the stapedius muscle is clearly delineated as a shallow depression with a roughly circular outline. The tegmen tympani area appears to have been well ossified, at least in the preserved area immediately anterolateral to the promontorium.

The proximal humerus of AMNH FM 2305 bears a moderately large greater tuberosity that is intermediate in both its size and orientation $\left(\sim 54^{\circ}\right.$ relative to parasagittal plane, in proximal view; Fig. 31.7) between those of cf. Vulpavus australis/canavus ( $\sim 0^{\circ}$ in USGS 25219; Heinrich and Rose 1997, text-fig. 2a) and cf. Didymictis protenus $\left(\sim 40^{\circ}\right.$ in USGS 5024; Heinrich and Rose, 1997, text-fig. 2d), two early carnivoramorphans with postcranial traits that have been interpreted as typical of arboreal 
1
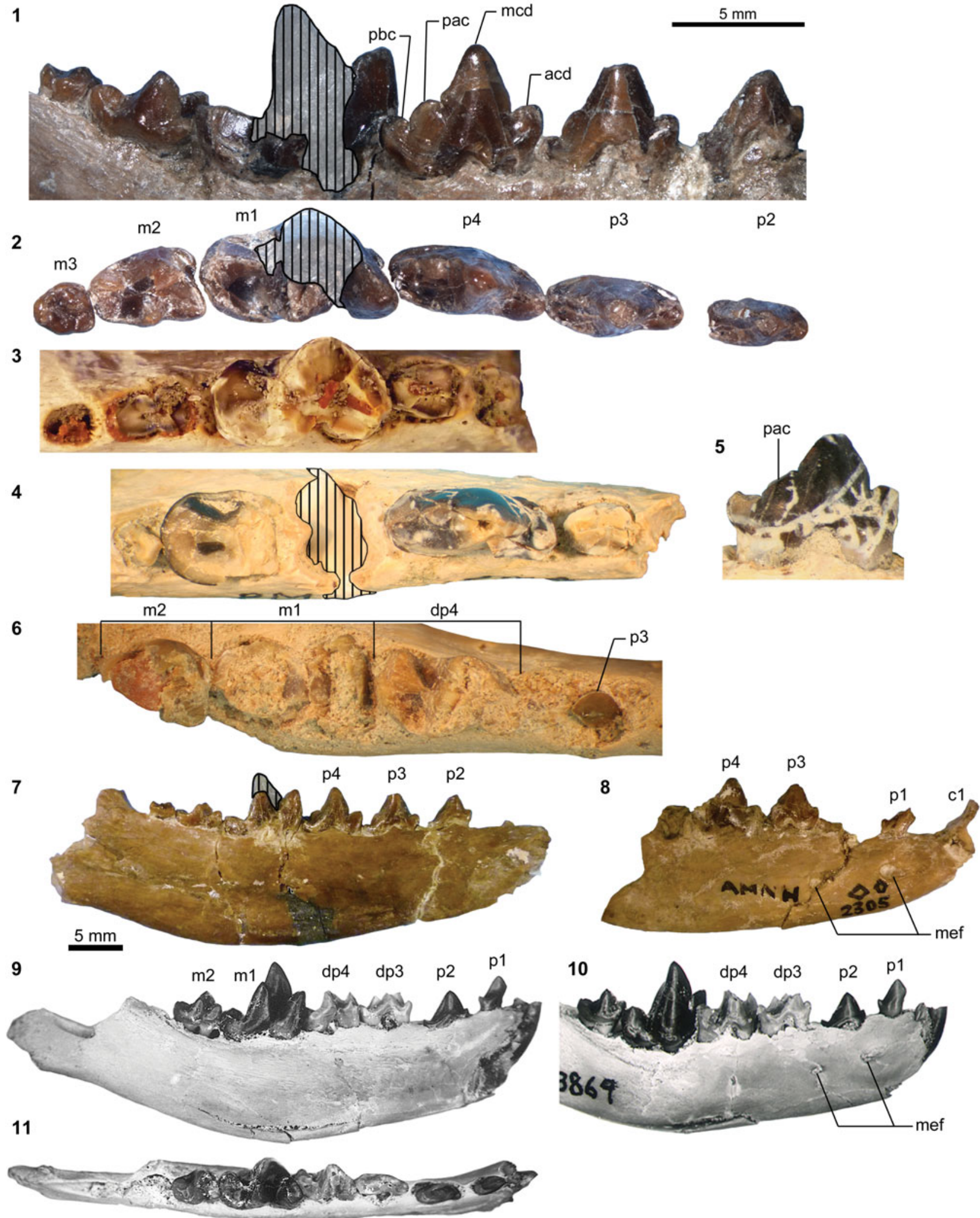

Figure 30. Lower dental and mandibular material of Neovulapvus washakius. Parts of holotype AMNH FM 2305, including: (1, 2) left p2-m3 in labial (inverted in 1) and occlusal (2) views (vertically hatched areas correspond to reconstructed $\mathrm{m} 1$ protoconid); (7) left dentary in medial view; (8) right anterior dentary fragment with c1 (broken), p1, p3-4, and anterior root of m1. cf. $N$. washakius, FMNH PM 3869: (6) left dentary fragment with broken dp4 and heavily damaged m1-2 in occlusal view; (9-11) right dentary (currently missing from FMNH collection) with broken c1, p1-2, dp3-4, and m1-2 in lingual (9, inverted), labial (10), and occlusal (11, inverted) views. cf. N. washakius, FMNH PM 70168: (3) roots of p4, heavily damaged m1, and roots of m2-3 in occlusal view. cf. N. washakius, FMNH PM 61576: $(\mathbf{4 , 5})$ posterior root of $\mathrm{p} 3, \mathrm{p} 4$, and $\mathrm{m} 1$ talonid in occlusal view $(\mathbf{4}$; note plaster filling [vertically hatched] connecting anterior and posterior fragments of dentary, which may have inflated the apparent length of $\mathrm{m} 1$ ); and $\mathrm{p} 4$ in labial view (inverted in 5). Figure 30.1-30.6 and 30.7-30.11 at two different scales. Abbreviations: acd, anterior cuspulid; mcd, main cuspid; mef, mental foramina; pac, posterior accessory cuspulid; pbc, posterior basal cuspulid. 

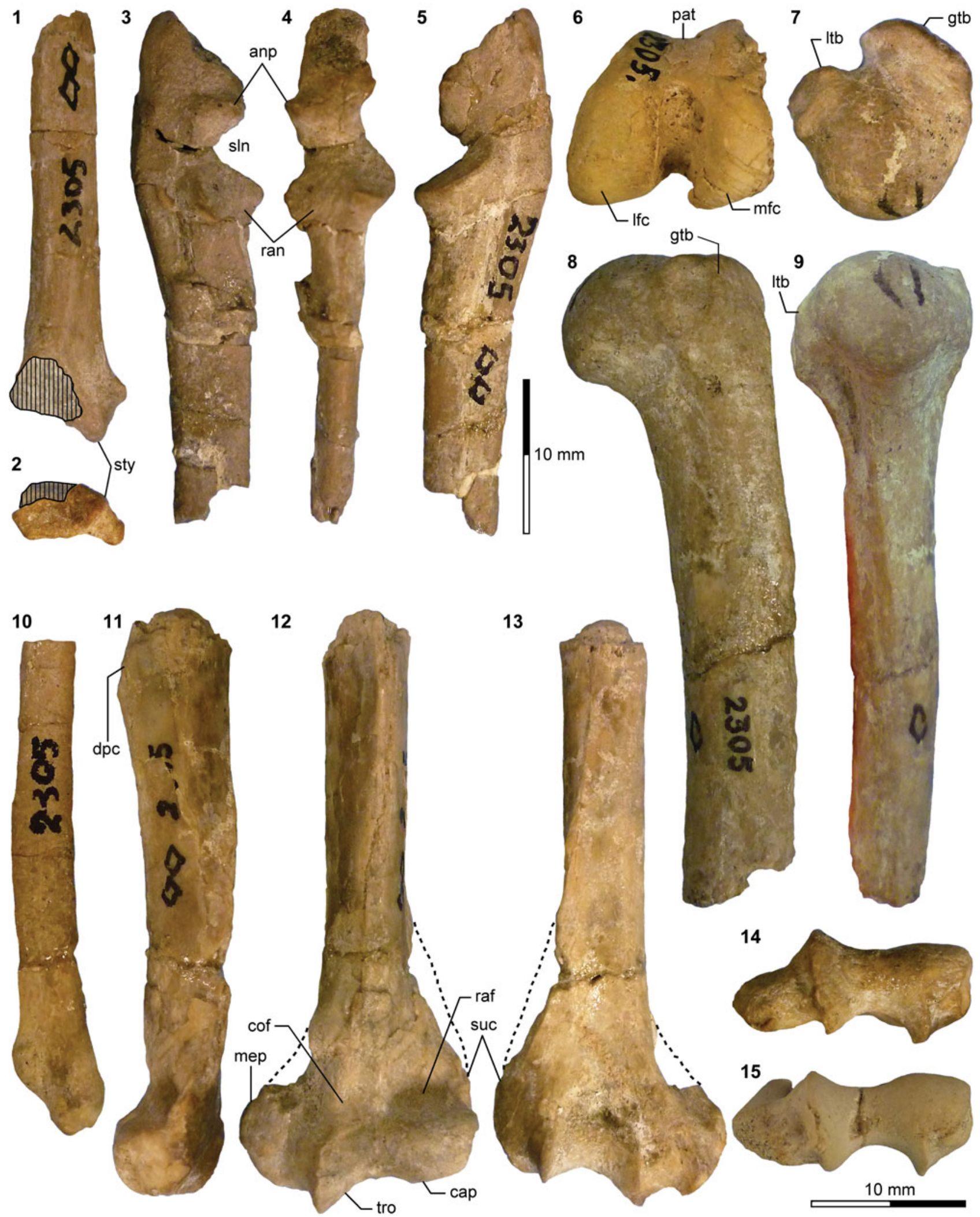

Figure 31. Selected postcranial elements of Neovulapvus washakius. Holotype AMNH FM 2305: (1, 2) right distal radius in anterior (1) and distal (2; anterior to top) views; (3-5) right proximal ulna in lateral (3), anterior (4), and medial (5) views; (6) right distal femur in distal view; (7-9) right humerus lacking distal portion in proximal (7; anterior to top), lateral (8), and posterior (9) views; (10) left distal ulna in lateral view (anterior to left); (11-14) left humerus lacking proximal portion in lateral (11), anterior (12), posterior (13), and distal (14; anterior to top) views. cf. N. washakius, FMNH PM 3869: (15) left distal humerus in distal view. Same 20 mm scale applies to all images. Dashed lines indicate original outlines reconstructed from preserved portions. Abbreviations: anp, anconeal process; cap, capitulum; cof, coronoid fossa; dpc, deltopectoral crest; gtb, greater tuberosity; lfc, lateral femoral condyle; ltb, lesser tuberosity; mep, medial epicondyle; mfc, medial femoral condyle; pat, patellar groove; raf, radial fossa; ran, radial notch; sln, semilunar notch; sty, radial styloid process; suc, supinator crest; tro, trochlea. 

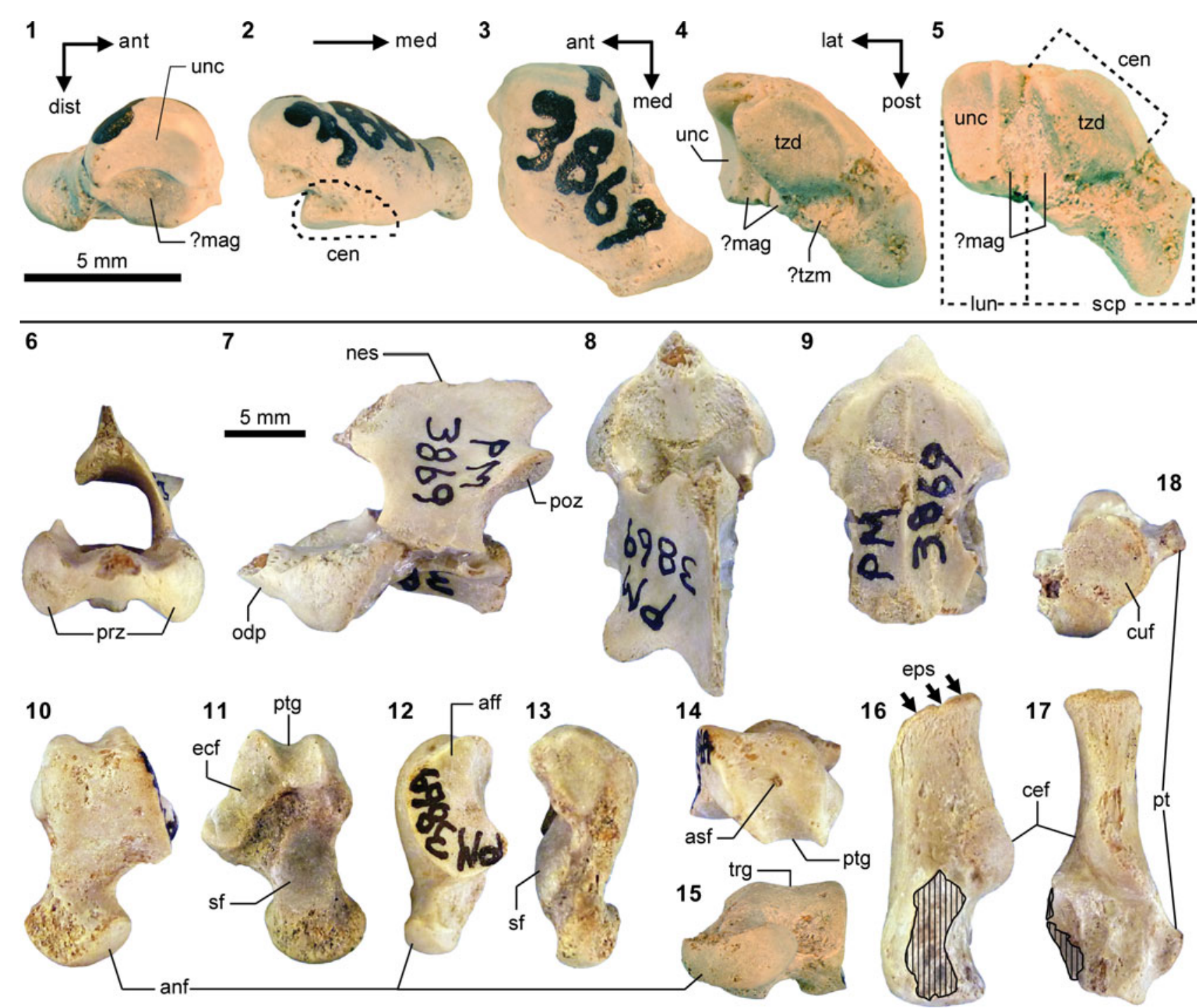

Figure 32. Additional postcranial elements of FMNH PM 3869 (cf. Neovulapvus washakius) from the Washakie Formation. (1-5) Right scaphocentrale-lunar (partially fused) complex in lateral (1), anterior (2), proximal (3), distal (4), and distolateral (5) views (precise extent of fused centrale is unknown); (6-9) axis in anterior (6), lateral (7), superior (8), and inferior (9) views; (10-15) left astragalus in superior (10), inferior (11), lateral (12), medial (13), proximal (14), and distal (15) views; (16-18) left calcaneum in medial (16), superior (17), and distal (18) views (vertical stripes indicate damaged surface). Different $5 \mathrm{~mm}$ scales apply to Figure 32.1-32.5 and 32.6-32.18. Abbreviations: aff, astragalar fibular facet; anf, astragalar navicular facet; asf, astragalar foramen; cef, calcaneal ectal facet; cen, centrum (fused to scaphoid); cuf, calcaneal cuboid facet; ecf, astragalar ectal facet; eps, epiphyseal suture; lun, lunar; mag, magnum facet; nes, neural spine; odp, odontoid process; poz, postzygapophysis; prz, prezygapophysis; pt, peroneal tubercle; ptg, plantar tendinal groove; scp, scaphoid; sf, astragalar sustentacular facet; trg, trochlear groove; tzd, trapezoid facet; tzm, trapezium facet; unc, unciform facet.

and terrestrial locomotor adaptations, respectively (Heinrich and Rose, 1997). Proximally, the greater tuberosity does not protrude beyond the extremity of the humeral head (Fig. 31.8, 31.9), similar to the condition in Vulpavus (USGS 25219; Heinrich and Rose, 1997, text-fig. 2b). In contrast, the limited flaring associated with the insertion site for the muscles teres major and latissimus dorsi is more comparable to that of Didymictis (USGS 5024; Heinrich and Rose, 1997, text-fig. 2e). Likewise, the deltopectoral crest, while showing the abrupt distal termination that is common in early carnivoraforms, has a low height as in Didymictis and in contrast to the much taller one in Vulpavus (Fig. 31.11; Heinrich and Rose, 1997, text-fig. 2b, 2e). The distal humerus is largely complete, and its preserved portions are suggestive of a supinator crest that was moderately expanded, likely more so than was depicted by Wortman and Matthew
(1899, fig. 6). Unlike in Uintacyon massetericus (USGS 21910; Heinrich and Rose, 1997, text-fig. 2c), the medial epicondyle lacks expansion along its medial margin, and its overall shape (having a relatively low ratio of transverse width to proximodistal length) appears to have been closer to that of cf. Didymictis protenus (USGS 27585; Heinrich and Rose, 1997, text-fig. 2f). The size and shape of the entepicondylar foramen is obscured by breakage (but see description of FMNH PM 3869 below). The coronoid fossa is shallow and poorly delineated, whereas the deeper radial fossa is more readily identified. The capitulum is more cylindrical than bulbous (Fig. 31.12, 31.14, 31.15). Compared to Uintacyon massetericus (USGS 21910; Heinrich and Rose, 1997, text-fig. 2C), the medial trochlear facet of AMNH FM 2305 is proportionately wider in its mediolateral direction ( $64 \%$ of the transverse width of the 

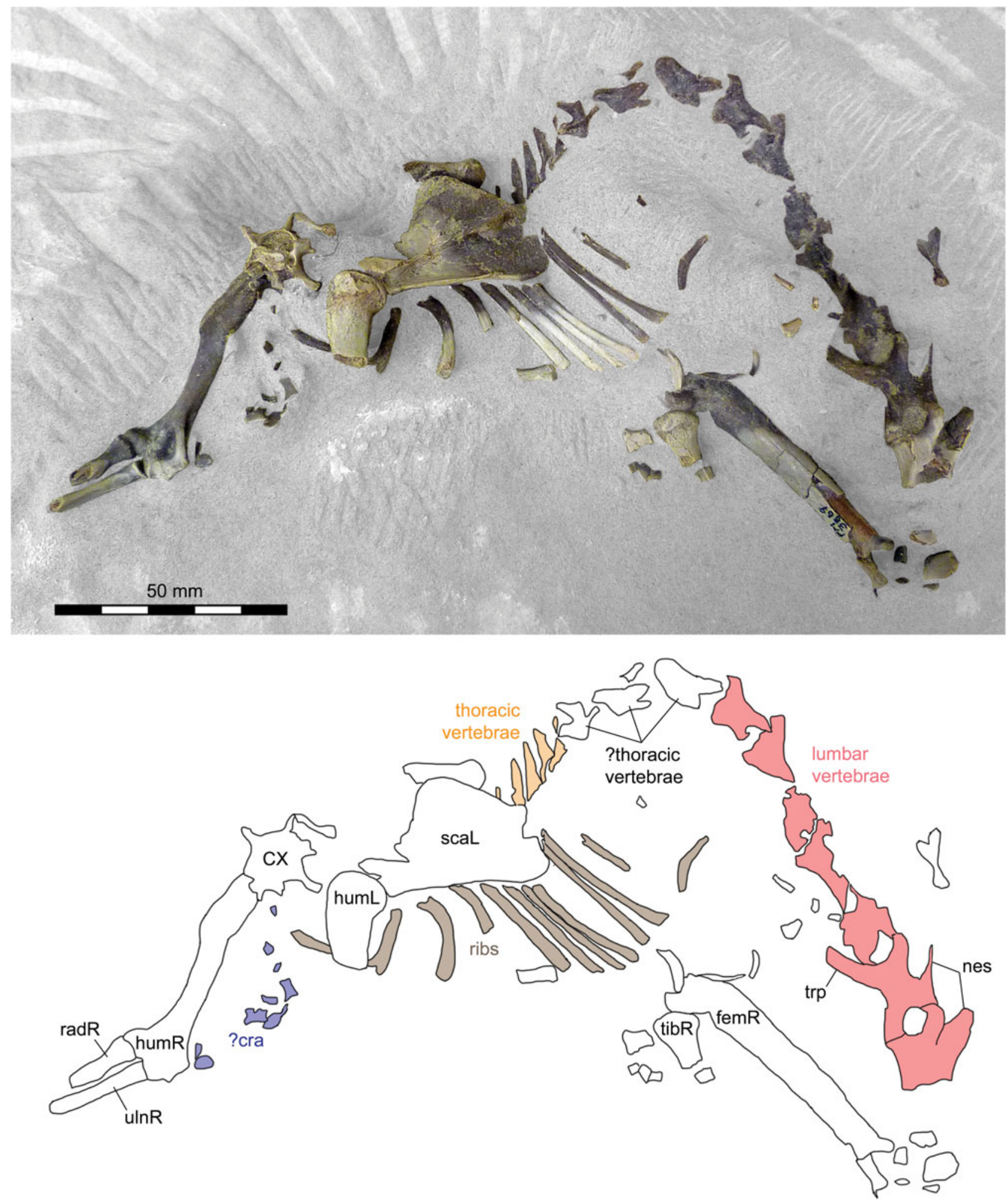

Figure 33. Postcranial skeleton of FMNH PM 3869 (cf. Neovulpavus washakius). Transparency and color of matrix digitally modified to enhance bone visibility. Abbreviations: CX, undetermined cervical vertebra (C3, 4, 5, or 6); fem, femur; hum, humerus; L, left; nes, neural spine; R, right; rad, radius; sca, scapula; tib, tibia; trp, transverse process; uln, ulna; ?cra, possible cranial fragments.

capitulum) and projects farther distally (beyond the distal extremity of the capitulum) at a steeper angle $\left(\sim 140^{\circ}\right.$, or $\sim 40^{\circ}$ if measured as in Heinrich and Rose [1997, text-fig. 2]) to the transverse axis of the distal humerus (Fig. 31.12).
The distal radius of AMNH FM 2305 (Fig. 31.1, 31.2) is missing its anterodistal end, where the extensor tubercle would have been located, but the general structure of the remaining portion is similar to the distal radius of cf. Vulpavus australis/ 
canavus (USGS 25219; Heinrich and Rose, 1997, text-fig. 4b) and quite distinct from that of cf. Didymictis protenus (USGS 25039; Heinrich and Rose, 1997, text-fig. 4f). In distal view, it has an anteroposteriorly shallow facet for articulation with the scaphoid and lunar (likely fused as a scaphocentrale-lunar complex, as described below for FMNH PM 3869) and a relatively prominent medial projection bearing the brachioradialis crest. The styloid process is well developed. In addition to the distal radius, the holotype of $N$. washakius includes a poorly preserved possible proximal radius, which offers little morphological information of systematic or functional-anatomical value.

The proximal ulna of the holotype of $N$. washakius (Fig. 31.3-31.5) is missing the end of the olecranon process, whose original extent cannot be discerned from the preserved portion. The semilunar notch has a considerably smaller radius of curvature than that of cf. Vulpavus australis/canavus (USGS 25219; Heinrich and Rose, 1997, text-fig. 4c), and the radial notch faces more anteriorly. The right distal ulna (Fig. 31.10) is moderately robust, maintaining the anteroposterior length of $\sim 4-5 \mathrm{~mm}$ along the distal $33 \mathrm{~mm}$ of shaft; distally, it terminates with a flat medial facet for articulation with the distal radius.

Of the hindlimb elements, only a distal femur (Fig. 31.6) is identifiable among the postcranial material belonging to AMNH FM 2305. In distal view, it is rather deep anteroposteriorly and with a deeper patellar trochlea than seen in cf. Vulpavus australis/canavus (USGS 7143; Heinrich and Rose, 1997, text-fig. 7c), but is more symmetrical across the medial and lateral condyles than in cf. Didymictis protenus (USGS 25040; Heinrich and Rose, 1997, text-fig. 7g).

The remainder of this section provides the first detailed description of the referred specimen FMNH PM 3869. This specimen represents a juvenile or subadult in which dp3-4 have yet to be replaced by p3-p4 (Fig. 30.6, 30.9-30.11), and likely represents the "fine specimen of a miacine" mentioned by MacIntyre, 1966, p. 192-193), which he noted was to be described by W. Turnbull.

The right P2 (Fig. 29.8-29.10) lacks an anterior cingulum, but a vestigial cuspule is present at the anterolingual base of the anterior ridge of the main cusp. The main cusp is roughly as tall as it is long; both the anterior and posterior ridges are sharp. The lingual wall of the tooth is slightly concave except directly above the apex of the main cusp. The small posterior cingulum is not clearly delineated; it forms a pointed cuspule with a sharp ridge that immediately follows the posterior ridge of the main cusp.

The left P3 and the left $\mathrm{p} 3$ are at comparable stages of eruption; only the tips of their main cusp and cuspid are externally visible. The P4 (Fig. 29.5), which may not have fully erupted at the time of the animal's death, is mostly broken off the maxilla, but a long and trenchant metastylar ridge bearing a labial cingulum is preserved.

The M1 (Fig. 29.5, 29.6) is marked by a combination of an elongate parastylar region, prominent paraconule, steeply rising (in occlusal view) protocone resulting in a deep trigon basin, and somewhat enlarged posterior lingual cingulum that bulges primarily in the lingual direction (compare with the more posterior directions in e.g., 'Miacis' hargeri; Fig. 27.3). As in the holotype, the stylar shelf is broad, and the labial cingulum is thick.
The apex of protocone appears to have been located at about the same anteroposterior level as that of the largely missing paracone, but not as anteriorly as it appears in the heavily damaged AMNH FM 2305 (Fig. 29.1, 29.2) or its illustration in Wortman and Matthew (1899, fig. 5). The M1 protocone region of the holotype is thus inferred to have been anteriorly displaced by breakage.

Although M2 is not preserved in FMNH PM 3869, the steep narrowing of the maxilla posterior to M1, in ventral view, suggests that M2 was much smaller than M1, as seen in the holotype. The angle of the labial border of the maxilla is comparable between FMNH PM 3869 and AMNH FM 2305.

The right dentary is presently missing from the FMNH collection, but existing photographs of it (Fig. 30.9-30.11) permit the following observations: (1) posterior cingulids form acute cuspulids on $\mathrm{p} 1$ and $\mathrm{p} 2$; (2) $\mathrm{p} 2$ and dp 3 each bear a pointed anterior cuspulid; and (3) the preprotocristid of $\mathrm{m} 1$ may have been more lingually and less anteriorly directed, and consequently the trigonid more closed, than they appear in the holotype with its apparently reconstructed $\mathrm{m} 1$ protoconid. The molars on the left dentary fragment (Fig. 30.6) are so heavily damaged that few morphological details are discernible. The molariform dp4 (briefly mentioned in Morlo and Gunnell, 2003) is marked by the posterolabial deflection of its talonid (necessitated by the imbricating $\mathrm{m} 1$ paraconid; Fig. 30.11) and the posterior placement of the metaconid relative to the protoconid; these features are also seen in a few other early carnivoraforms (ST, personal observation; see description of UWBM 38976 below), but differ from the conditions in the early Eocene viverravid Didymictis protenus (Zack, 2012, fig. 4a).

Because the bulk of the postcranial skeleton of FMNH PM 3869 has yet to be fully prepared (Fig. 33), we here describe only select elements that already have been extracted from the matrix.

The axis (Fig. 32.6-32.9) is characterized by a short centrum, as seen in extant mustelids and felids, and the element as a whole has similar proportions to those of the fisher Pekania pennanti (Erxleben, 1777). In comparison, axes of extant canids typically bear proportionately longer centra. We have not examined the axis of the holotype of Oodectes herpestoides, YPM VP 011861, which was described by Wortman (1901b, p. 151) as having a "rather long" centrum. The prezygapophyses, on the other hand, resemble those of the extant canids more closely, both in their posterior inclination and piriform outlines in lateral view. The lateral walls of the centrum surrounding the transverse foramina are damaged, but the foramina do not appear to have been as prominent as in felids. The tip of the odontoid process, anterior portion of the spine, and transverse processes (the original extent of which is unclear) are broken off.

The distal humerus (Fig. 31.15; see also Fig. 33) and distal femoral epiphysis (not figured) of FMNH PM 3869 are closely comparable to those of the holotype AMNH FM 2305. The former shows the presence of a large entepicondylar foramen.

The isolated left astragalus (Fig. 32.10-32.15) is rather gracile, with a proximally narrower trochlea (bearing a consequently deeper plantar tendinal groove), relatively narrower ectal facet, and more constricted neck than in Vulpavus sp. from the Bridger B interval (USNM 362847; Heinrich and Rose, 1997, text-fig. 8c) and Dawsonicyon isami (Spaulding et al., 2010, text-fig. 7b). As is typical among contemporaneous 
carnivoraforms, the trochlear groove is very shallow. A small astragalar foramen is present near the proximal extremity of the trochlea. The outline of the weakly convex sustentacular facet is an ovoid to rounded diamond shape. The navicular facet appears to have been largely restricted to the distally facing surface of the astragalar head, with a small portion extending onto the anterolateral surface, as in Dawsonicyon. The primarily mediolateral orientation of the long axis of astragalar head is roughly comparable to the condition in Vulpavus (Heinrich and Rose, 1997, text-fig. 8c).

The left calcaneum is missing the epiphysis of the calcaneal tubercle, and the sustentacular facet is broken off (Fig. 32.1632.18). The forms and proportions of the preserved parts are generally comparable to the corresponding features of cf. Vulpavus australis/canavus (USGS 7143 and USGS 25186; Heinrich and Rose, 1997, text-fig. 8d) and Dawsonicyon isami Spaulding, Flynn, and Stucky, 2010 (Spaulding et al., 2010, text-fig. 7a), but more closely resembles those of $D$. isami in having a more gracile calcaneal tubercle and somewhat more medially facing ectal facet. The laterally projecting peroneal tubercle is distinct but perhaps not as prominent as in Vulpavus (Heinrich and Rose, 1997, text-fig. 8d).

The scaphocentrale-lunar complex of FMNH PM 3869 (Fig. 32.1-32.5) is somewhat larger than would be expected for the holotype based on the distal radius of the latter (Fig. 31.1, 31.2); this size difference is consistent with the larger teeth of FMNH PM 3869 compared to AMNH FM 2305. The scaphoid and lunar portions are fused proximally (Fig. 32.2, 32.3), but a suture separating them is visible on the distal side (Fig. 32.4, 32.5); this suture may reflect the young age of the individual represented by the specimen. We interpret the wedgeshaped (especially in anterior view) anterodistal portion of this carpal complex to be the centrale, which is proximally fused to the scaphoid - an interpretation derived from comparison with published accounts of carpal elements in other early carnivoraforms (Matthew, 1909; Heinrich and Rose, 1997, text-fig. 4). The form and position of the centrale, as well as the more advanced state of fusion of the scaphoid to the centrale than to the lunar, are all closely comparable to the conditions in Palaearctonyx meadi (Matthew, 1909, fig. 44), another late Bridgerian carnivoraform from the Rocky Mountain region. The following facets for articulation with adjacent carpal elements are provisionally identified: (1) a broad lateral facet of the lunar for articulation with the unciform ("unc" in Fig. 32.1, 32.4, 32.5); and (2) distal facet of the centrale for articulation with the trapezoid ("tzd" in Fig. 32.4, 32.5). In addition, the distal facet of the lunar and the lateral facet of the centrale may have contacted the magnum ("?mag" in Fig. 32.1, 32.4, 32.5; see forms and configurations of distal carpal bones in 'Miacis' uintensis illustrated in Spaulding and Flynn, 2009, fig. 1f), and the small, flat surface posterior to the trapezoid facet may have articulated with the trapezium ("?tzm" in Fig. 32.4).

Materials.-FMNH locality FM-4-57-WDT (Twka1): FMNH PM 3869, partial skeleton including: partly articulated postcrania (embedded in matrix), left maxillary fragments (with broken P2, roots of DP3, erupting P3, broken P4, and M1), partial right dentary (with p1-2, dp3-4, and m1-2), left dentary fragment with heavily damaged teeth $(\mathrm{c} 1, \mathrm{p} 1, \mathrm{p} 2$, erupting $\mathrm{p} 3$, dp4, $\mathrm{m} 1-2)$, left ?DC1, right $\mathrm{P} 2$, axis, fragment of ?left pelvis, left distal humerus, right scaphocentrale-lunar complex, left distal femoral epiphysis, left astragalus, left calcaneum, and additional postcranial fragments.

FMNH locality FM-6-58-WDT (Roehler's [1973] bed 621 625, Twka2; likely Br3 in age): FMNH PM 61576, left dentary fragment with broken $\mathrm{p} 3-\mathrm{m} 1$.

FMNH locality FM-6-83-KL/WT (Twka1): FMNH PM 70168 , left dentary fragment with roots of p4, heavily damaged $\mathrm{m} 1$, roots of $\mathrm{m} 2$, and alveolus for $\mathrm{m} 3$.

Remarks.-The holotype AMNH FM 2305 was first described by Wortman and Matthew (1899) as belonging to Vulpavus palustris Marsh, 1871. We note the following discrepancies between the specimen in its current condition and their original figures, which depict a right maxillary fragment with apparently well-preserved M1-2, the horizontal ramus of a left dentary with a complete set of teeth, and two pieces (proximal and distal) of the right humerus (Wortman and Matthew, 1899, figs. 4-6): (1) the lingual part of M1 is heavily damaged, possibly by poor preparation, such that the forms of the paraconule and metaconule ("a distinct anterior and posterior intermediate" in Wortman and Matthew, 1899, p. 119) are barely discernible, and the protocone and paracone both appear to have shifted anteriorly following their breakage from the rest of the tooth (Fig. 29.1, 29.2), making us question the extreme anterior position of the protocone as originally illustrated; (2) c1 and p1 are not preserved on the left dentary, although the right dentary retains a small portion of $\mathrm{c} 1$ and a slightly broken p1; (3) p4 posterior accessory cuspulid is larger than it appears in Wortman and Matthew (1899, fig. 4); (4) $\mathrm{m} 1$ protoconid appears to be largely reconstructed with black plaster or plaster-like material (corresponding to dotted lines in Matthew, 1909, fig. 15); and (5) the distal humerus comes from the left side and not the right side as was originally illustrated. While damages to the specimen since the time of description by Wortman and Matthew (1899) cannot be entirely discounted, we suspect that the original illustration involved some artistic reconstruction that was not mentioned in their text.

Shortly after Wortman and Matthew's (1899) publication, Wortman (1901a) recognized AMNH FM 2305 to be distinct from Vulpavus palustris in lacking M3, and he proposed a new genus and species, Neovulpavus washakius, on that ground alone. Subsequently, however, Matthew (1909) reported an M3 alveolus situated at the posterior end of the maxilla of the holotype. The latter author reclassified N. washakius and 'Miacis' sylvestris (= Harpalodon sylvestris Marsh, 1872c) as the constituent species of the subgenus Harpalodon in the genus Miacis, even suggesting the possibility of their conspecificity (p. 371). In Matthew's (1909, p. 365) view, 'M.' washakius was characterized by: a small M1 "hypoconid" (= somewhat enlarged posterior portion of the lingual cingulum); anteroposteriorly compressed M2; greatly reduced M3; and welldeveloped "accessory cusp" (posterior accessory cuspulid in our terminology) on $\mathrm{p} 4$. We concur with these observations, except for the supposed presence of M3: while posteriorly open alveoli for M3 are known in some basal carnivoraforms 
with reduced posterior molars (Tomiya, 2011, 2013), the preservational quality of AMNH FM 2305 does not allow for confident interpretation of the posterior maxillary indentation as an M3 alveolus (Fig. 29.1, 29.2).

Until now, 'Miacis' washakius was known only from the holotype. Here, we report additional specimens from the Washakie Formation, the most significant of which is FMNH PM 3869. The taxonomic identification of this specimen is based on our observations that it differs: (1) from Lycarion medius and ' $M$.' hargeri in smaller M2 relative to M1 (as judged from the steep medial incline of the lateral border of the maxilla posterior to the level of M1) and overall smaller size; (2) additionally from ' $M$.' hargeri in M1 with a steeper labial slope of the protocone and more enlarged posterior lingual cingulum (compare Fig. 29.1, 29.5 with Fig. 27.3), and somewhat more anteriorly directed $\mathrm{m} 2$ postparacristid (so far as can be discerned from the available photograph; Fig. 30.11); and (3) from Harpalodon sylvestris in having M1 with an inflated posterior lingual cingulum and larger paraconule relative to the metaconule, and a better developed $\mathrm{p} 1$ anterior cuspulid (Fig. 30.9, 30.10). Except for the larger size, the morphology of PM 3869 is closely comparable to, or at least compatible with, that of the holotype AMNH FM 2305. PM 3869 greatly clarifies the morphology of M1 and $\mathrm{M} 2$, which are poorly preserved in the holotype, and helps refine the differential diagnosis of the species. This specimen also is significant in that, to our knowledge, it represents one of the earliest carnivoraform fossils that preserves a deciduous dentition (the earliest may be the deciduous teeth of the earliest Eocene Dormaalocyon latouri reported by Solé et al., 2014). Although damaged, the dp3 and dp4 may, when studied in detail, help reconstruct the ancestral morphology of those teeth for crown-clade Carnivora.

Of the two tentatively referred specimens, FMNH PM 70168 (Fig. 30.3) is nearly indistinguishable from the holotype in the sizes and proportions of $\mathrm{p} 4$ through $\mathrm{m} 3$, as judged from their preserved portions (mostly roots). Referral of FMNH PM 61576 (Fig. 30.4) to Neovulpavus washakius is less secure, and is based on the morphology of $\mathrm{p} 4$, which closely resembles that of AMNH FM 2305 with regard to the forms and sizes of accessory cuspulids. It should be noted that, while the size of the $\mathrm{m} 1$ talonid is roughly comparable between PM 61576 and the holotype, the apparent length of $\mathrm{m} 1$ is considerably greater on the former. We suspect that the plaster filling (hatched area in Fig. 30.4) that was used to connect two broken pieces of the dentary artificially inflated the distance between $\mathrm{p} 4$ and the posterior portion of $\mathrm{m} 1$ in PM 61576.

Matthew's (1909) reassignment of Neovulpavus washakius to the genus Miacis has not received cladistic support: no analysis to date has recovered all or most of the species typically assigned to Miacis as a monophyletic group that includes the genotypic species M. parvivorus and 'M.' washakius (Spaulding and Flynn, 2012; Solé et al., 2014). Accordingly, we regard Wortman's (1901a) Neovulpavus to be a more appropriate generic classification of the latter species based on our phylogenetic analysis (see Results and Figs. 43, 44), and to be tested further by future systematic work. The above-noted similarities in petrosal morphology between N. washakius and Harpalodon sylvestris is consistent with Matthew's (1909) observation that the postcrania of both taxa are gracile, and suggest the possibility of a close phylogenetic relationship within a clade that excludes the more plesiomorphic genotypic species, M. parvivorus (see Results and Figs. 43, 44).

Postcranial data from FMNH PM 3869 were included in the cladistic analysis of Spaulding and Flynn (2012) and were assigned to an OTU (mistakenly reported as "PM 3868") distinct from 'Miacis' washakius because the authors were not then aware of the dental material directly associated with the postcrania. In our analysis, the OTU representing Neovulpavus washakius incorporates character states of both the holotype AMNH FM 2305 and the referred specimen FMNH PM 3869 (i.e., scores from Spaulding and Flynn [2012] were supplemented with our new observations).

\section{Neovulpavus mccarrolli new species \\ Figures 34, 35.1-35.5, 36-38}

Holotype-FMNH PM 3593, partial cranium (with right and left I1-M2 except right I1), right partial squamosalalisphenoid complex, right and left dentaries in articulation (with right i2, c1, p2-4, and $\mathrm{m} 2$, and left $\mathrm{i} 2-3, \mathrm{c} 1, \mathrm{p} 4$, and $\mathrm{m} 2$ ), isolated i1 (side unknown), right $\mathrm{i} 3$, left $\mathrm{p} 1-2$, right $\mathrm{m} 1$, left $\mathrm{m} 1$ trigonid (broken), articulated trunk vertebrae, caudal vertebra, rib fragments, partial right pelvis, right humeral shaft fragment, partial right and left ulnae (missing proximal and distal ends), partial right tibia, partial right and left pedes (missing phalanges).

Locality.-FMNH locality FM-8-57-WDT ("Protoptychus locality" of Turnbull, 1991), Washakie Basin, Sweetwater County, Wyoming.

Horizon.-Approximately Roehler's (1973) bed 633, Twka2 (cf., Turnbull, 1991), Adobe Town Member, Washakie Formation.

Diagnosis.-Differs: from all other non-carnivoran Carnivoraformes in the features diagnosing Neovulpavus; and from $N$. washakius in slanting of posteromedial edge of humeral trochlea (Character 108, State 1), absence of ridge extending distally from lesser tuberosity of humerus (Character 115 , State 1), humeral greater tuberosity more flush with outline of humeral head in proximal view (Character 121, State 1), dorsoventrally deep astragalar head (Character 176, State 0), lateral border of astragalar trochlea dorsoventrally taller than medial border (Character 186, State 1), absence of $\mathrm{p} 3$ anterior cingular cuspulid (Character 218, State 0), and a substantially larger size ( $\mathrm{m} 1$ of holotype FMNH PM 3593 is $31 \%$ longer than that of holotype AMNH FM 2305 of $N$. washakius).

Occurrence.-Twka2, Adobe Town Member, Washakie Formation, Sweetwater County, Wyoming. Early Uintan (Uilb) NALMA.

Description.-Unless otherwise noted, descriptions below pertain to the holotype. Measurements are reported in Table 10.

Cranium.-The holotype lacks the posterior portion of its braincase and much of the basicranium (Fig. 34.1, 34.2, 34.5). The left half of the cranium (including the facial region, zygomatic arch, and part of the braincase) shows minor deformation 
in the ventrolateral direction, somewhat exaggerating the cranial width. The snout region is robust, moderately long, wide, and tall. In these respects, Neovulpavus mccarrolli n. sp. closely resembles the Bridgerian 'Miacis' hargeri (Wortman, 1901a, pl. 5) and, to a lesser extent, Civettictis among extant carnivorans. Compared to other carnivoraforms from the Washakie Formation, the rostral region of $N$. mccarrolli $\mathrm{n}$. $\mathrm{sp}$. is proportionately longer than in Lycarion medius (Fig. 26.1) and Harpalodon sylvestris. The dorsal border of the anterior cranium (rostrum to orbit) slopes more steeply than in the middle Bridgerian carnivoraforms Vulpavus profectus and Oodectes herpestoides, and the transverse narrowing of the rostrum relative to the cranial width at the level of orbits is more abrupt compared to those taxa (Matthew, 1909, figs. 23, 24; Wesley-Hunt and Flynn, 2005, fig. 1). Preservation of turbinate bones cannot be assessed without a computed tomography scan.

The thin strip of premaxilla is partially preserved. Its sutural contact with the maxilla is difficult to identify, but its posterior extent seems to have reached the level of the posterior end of the upper canine (Fig. 34.2, 34.5; the black markings previously made on the specimen appear to follow very faint sutures). The pair of largely complete nasals are long, and begin to taper past the level of the infraorbital foramina, converging to a point slightly $(2-3 \mathrm{~mm})$ posterior to the level of the anterior extremities of the orbits (Fig. 34.2). Such posterior tapering of nasals is lacking in Vulpavus profectus and Oodectes herpestoides (Matthew, 1909, fig. 24; Wesley-Hunt and Flynn, 2005, fig. 1). The rather large and somewhat oblong (taller than wide) infraorbital foramen is located above the posterior portion of $\mathrm{P} 3$ and $\sim 3 \mathrm{~mm}$ anterior to the anterior extremities of the orbits (Fig. 34.5). The proximity of the infraorbital foramen to the orbit is comparable to that in 'M.' hargeri (Wortman, 1901a, pl. 5) and differs from $V$. profectus, in which the orbit is more posteriorly located (Matthew, 1909, fig. 23).

The orbit is of moderate size, as in 'M.' hargeri, and not enlarged as in the middle Bridgerian Oodectes herpestoides (Wesley-Hunt and Flynn, 2005, fig. 1). The precise location and morphology of the lacrimal foramen are unclear because of damage to the pertinent facial region. Medial to the orbit and roughly at the anteroposterior level of M1, a pair of adjacent foramina are located (Fig. 34.10). We consider the larger dorsal foramen to be the sphenopalatine foramen, and the much smaller ventral one possibly to be the caudal palatine foramen. The postorbital processes, the tips of which are broken off on both sides of the cranium, give rise to a pair of weakly defined ridges that converge and connect to the sagittal crest in the anterior portion of the braincase. Only the anteriormost part of the sagittal crest is preserved, where it is very low in height but clearly defined. The jugal forms a moderately deep anterior portion of the zygomatic arch, and makes a sharp upward turn behind the level of M1 (Fig. 34.5). The jugal-squamosal, maxillo-frontal, and frontoparietal sutures are all closed.

The moderately broad palate (Fig. 34.1) is largely complete, but its preservation is not sufficient for clear identification of sutures and small foramina. Anteriorly, the pair of incisive foramina ( $\sim 3 \mathrm{~mm}$ in length) are aligned with the I1s, but they diverge from each other posteriorly, and their posterior portions overlap in extent with the anterior half of the upper canines. The posterior extremity of the midline of the palate appears somewhat damaged, but likely was located at the level of M2s. Posterior to the palate, a pair of deep pterygoid processes run anteroposteriorly and subparallel to each other. A deep canal $\sim 4.2 \mathrm{~mm}$ in length is located posterolateral to the pterygoid process. This canal presumably bore the caudal alar foramen (i.e., posterior opening of the alisphenoid canal) at its front end and the foramen ovale at its rear end (cf., Wang and Tedford, 1994), but the two foramina cannot be individually identified given the state of preservation. Anterior to the canal and posteroventral to the orbit, a pair of moderately large foramina occur, separated by a thin bony septum (Fig. 34.9, 34.10). We interpret the medial foramen as the sphenorbital fissure and the lateral one as the rostral alar foramen (i.e., anterior opening of the alisphenoid canal) based on comparison to primitive eutherian conditions (cf., Novacek, 1986). A similar configuration of the sphenorbital fissure and rostral alar foramen (alternatively reported as the foramen rotundum) is seen in the extant feliform carnivoran Nandinia binotata (Gray, 1830) (Wible and Spaulding, 2013). The proximity of the rostral and caudal alar foramina implies a short alisphenoid canal. A small hole dorsomedial to the sphenorbital fissure may represent a remnant of the optic foramen, but poor preservation of this region precludes confident identification.

Only very limited observations can be made on the basicranium, based primarily on an isolated right partial squamosal-alisphenoid complex that was collected with the skull and postcrania (Fig. 34.8). The morphology of the squamosal-alisphenoid complex is indistinguishable from that of the corresponding, less well-preserved portion of the left side of the cranium, and we consider its association with the holotype to be secure. The outline of the postglenoid foramen is oblong and not circular as in Vulpavus profectus (Matthew, 1909) or teardrop-shaped as in Harpalodon sylvestris (Wang and Tedford, 1994, fig. 3). Medial to the postglenoid foramen, the moderately wide $(\sim 1.53 \mathrm{~mm}$ at the level of the anterior end of the postglenoid foramen) and open Glaserian fissure runs anteroposteriorly. In early carnivoramorphans, the squamosal-alisphenoid suture in this region typically runs along the medial border of the Glaserian fissure (Wang and Tedford, 1994; Wesley-Hunt and Flynn, 2005), but the suture cannot be clearly identified on the right squamosal-alisphenoid fragment of FMNH PM 3593. A shallow, trough-like depression is present medial to the Glaserian fissure, at the level of postglenoid foramen. Anteroventral to this depression, a broad and rather flat surface is present on the alisphenoid. This surface and a much smaller flat surface immediately posterior to the postglenoid foramen ("?cab" in Fig. 34.8) are suggestive of contact with the anterior portion of the auditory bulla (cf., Hunt, 2001, fig. 11), but evidence for strong attachment of the bulla is lacking. Unlike in H. sylvestris (Wang and Tedford, 1994), there is no clear depression indicating the presence of an anterior loop of the internal carotid artery.

Mandible.-The right dentary is largely complete, although the angular process is broken off and the mandibular condyle is damaged (Fig. 34.3, 34.6). The horizontal ramus is moderately robust and gradually tapers toward its anterior end. The ventral border of the horizontal ramus makes a rather sharp dorsal turn at the level of $\mathrm{m} 1$, forming a wide $\mathrm{V}$-shape. The two mental foramina are positioned below the anterior edge of p2 and below the main cuspid of p3. The ascending 


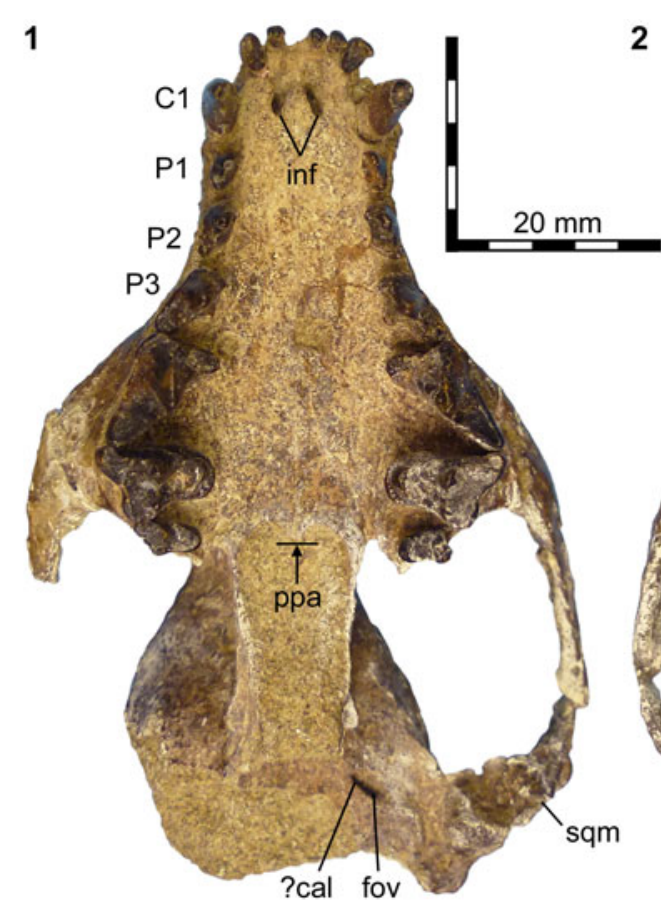

4

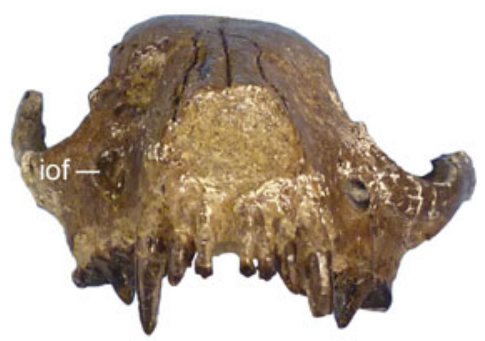

2
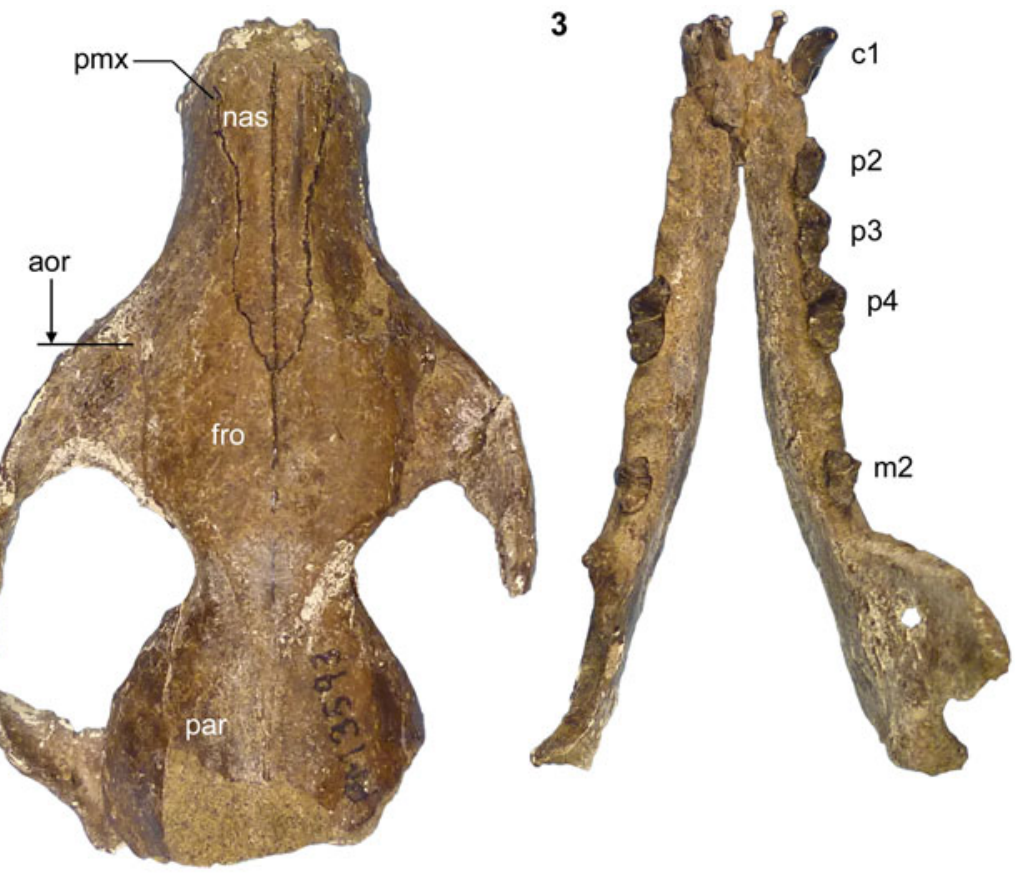

5

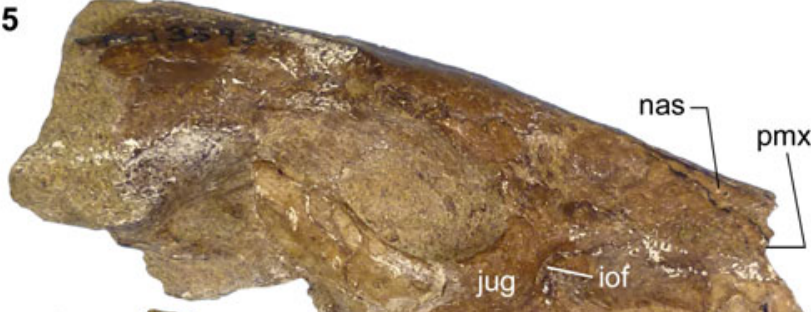

6
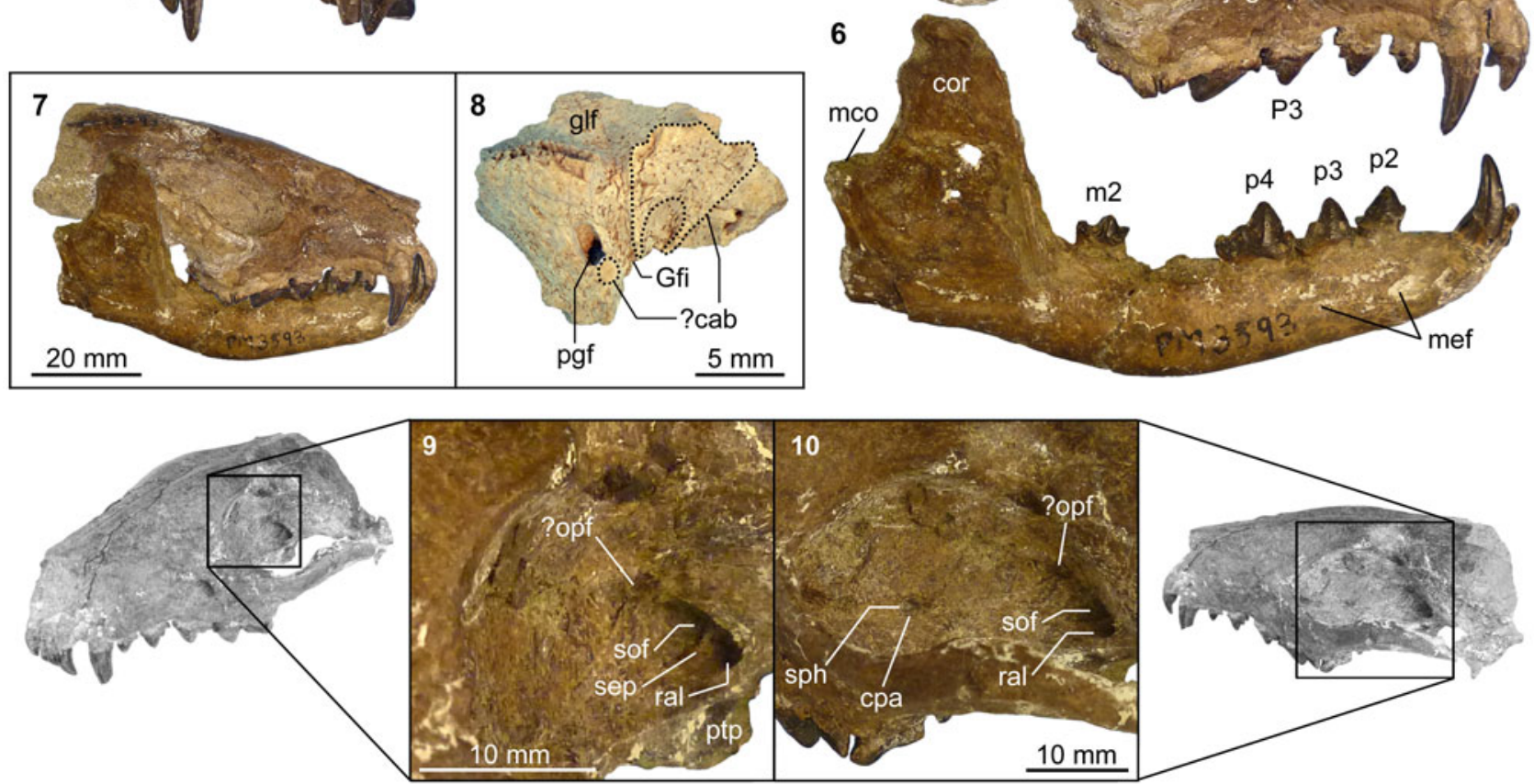

Figure 34. Skull of holotype FMNH PM 3593 of carnivoraform Neovulpavus mccarrolli $\mathrm{n}$. sp. from the Washakie Formation. (1, 2, 4, 5) Cranium in inferior (1), superior (2), anterior (4), and right lateral (5) views; $(\mathbf{3}, \mathbf{6})$ mandible in superior $(\mathbf{3})$ and right lateral (6) views; (7) cranium and mandible (digitally superimposed); (8) fragment of right squamosal-alisphenoid complex; $(\mathbf{9}, \mathbf{1 0})$ parts of left facial region in oblique anterior (9) and lateral (10) views. Figure 34.1-34.6 (same scale), 34.7, 34.8, 34.9, and 34.10 at five different scales. Abbreviations: aor, level of anterior extremity of orbit; ?cab, possible contact surfaces for anterior portion of auditory bulla; cal, caudal alar foramen; cor, coronoid process; cpa, caudal palatine foramen; fov, foramen ovale; fro, frontal; Gfi, Glaserian fissure; glf, glenoid fossa; inf, incisive foramina; iof, infraorbital foramen; jug, jugal; mco, mandibular condyle; mef, mental foramina; nas, nasal; opf, optic foramen; par, parietal; pgf, postglenoid foramen; pmx, premaxilla; ppa, posterior end of palatine midline; ptp, pterygoid process; ral, rostral alar foramen; sep, bony septum; sph, sphenopalatine foramen; sof, sphenorbital fissure; sqm, squamosal. 

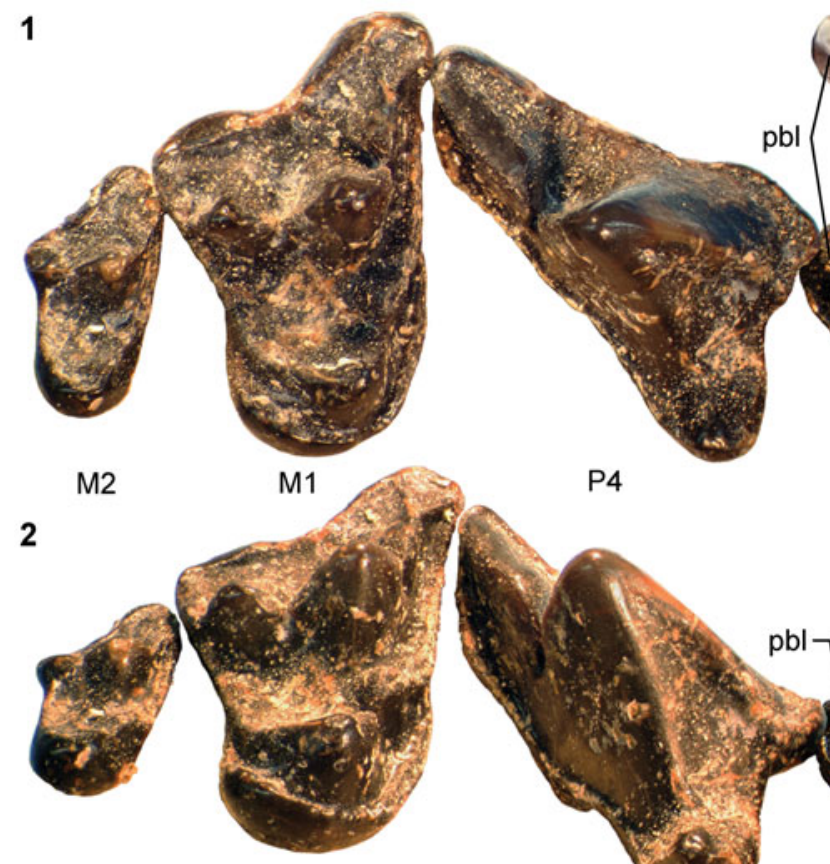

P4

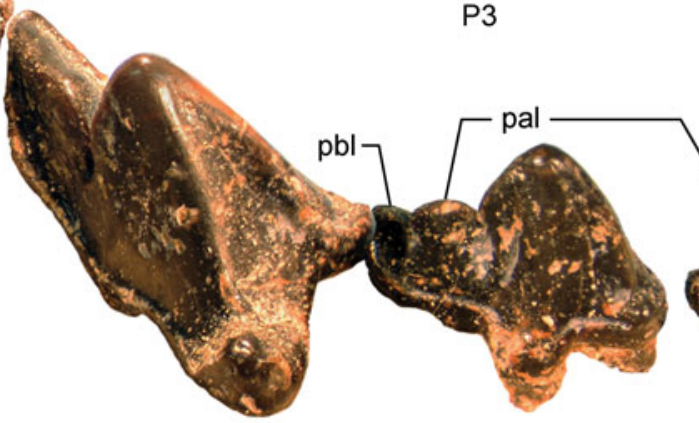

P2
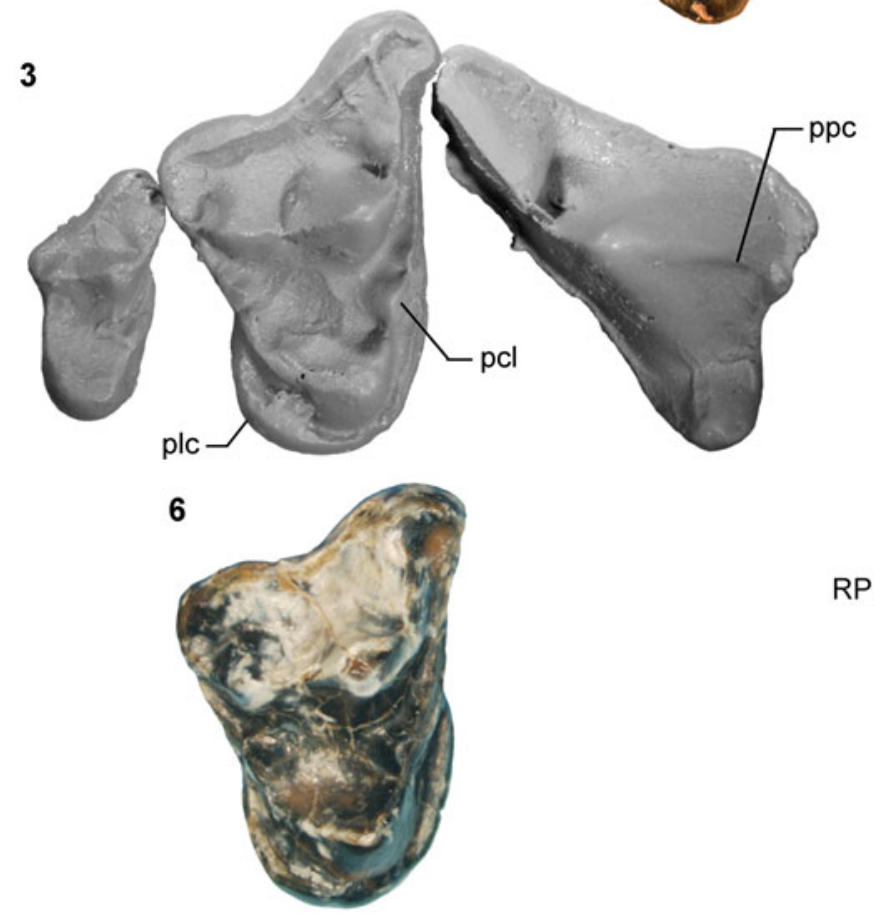

4
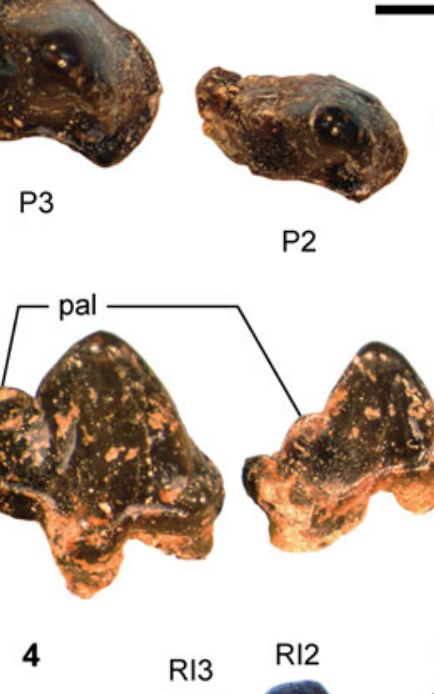

$5 \mathrm{~mm}$

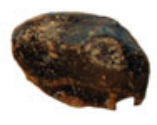

P1

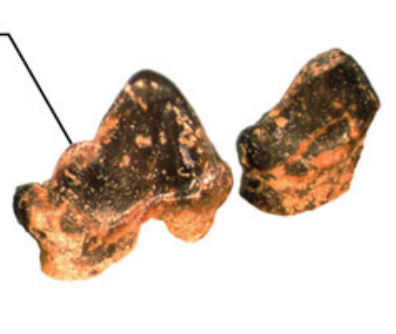

Figure 35. Upper dentitions of Neovulpavus mccarrolli $\mathrm{n}$. sp. and 'Miacis' invictus Matthew and Granger, 1925. Holotype FMNH PM 3593 of N. mccarrolli $\mathrm{n}$. sp.: $(\mathbf{1 , 2})$ right P1-M2 in occlusal (1) and lingual (2) views; (3) epoxy cast of right P4-M2 in occlusal view; (4) right I2-P1 and left I1-P1 in occlusal view. Referred specimen UCMP 81355 of $N$. mccarrolli n. sp.: (5) right P2-P3 in occlusal view. Holotype of 'Miacis' invictus, AMNH FM 20137: (6) left M1 in occlusal view (inverted). Same $5 \mathrm{~mm}$ scale applies to all images. Abbreviations: pal, posterior accessory cuspule; pbl, posterior basal cuspule; pcl, paraconule; plc, posterior lingual cingulum; ppc, preparacrista.

ramus is tall and bears a deep masseteric fossa bordered anteriorly by a sharp ridge. The dorsal border of the coronoid process, although somewhat damaged, appears to have been roughly parallel to the posteroventral border of the dentary. The posterior dentary foramen (not figured) is located on the medial side of the dentary approximately halfway across the anteroposterior length of the ascending ramus and slightly below the level of the tooth row.

Dentition.-All teeth except $\mathrm{m} 3$ are known from at least one side. The M3 likely was absent, judging from the smooth posterior margin (lacking any visible groove or alveolus for an M3) of the left maxilla, which appears mostly intact 


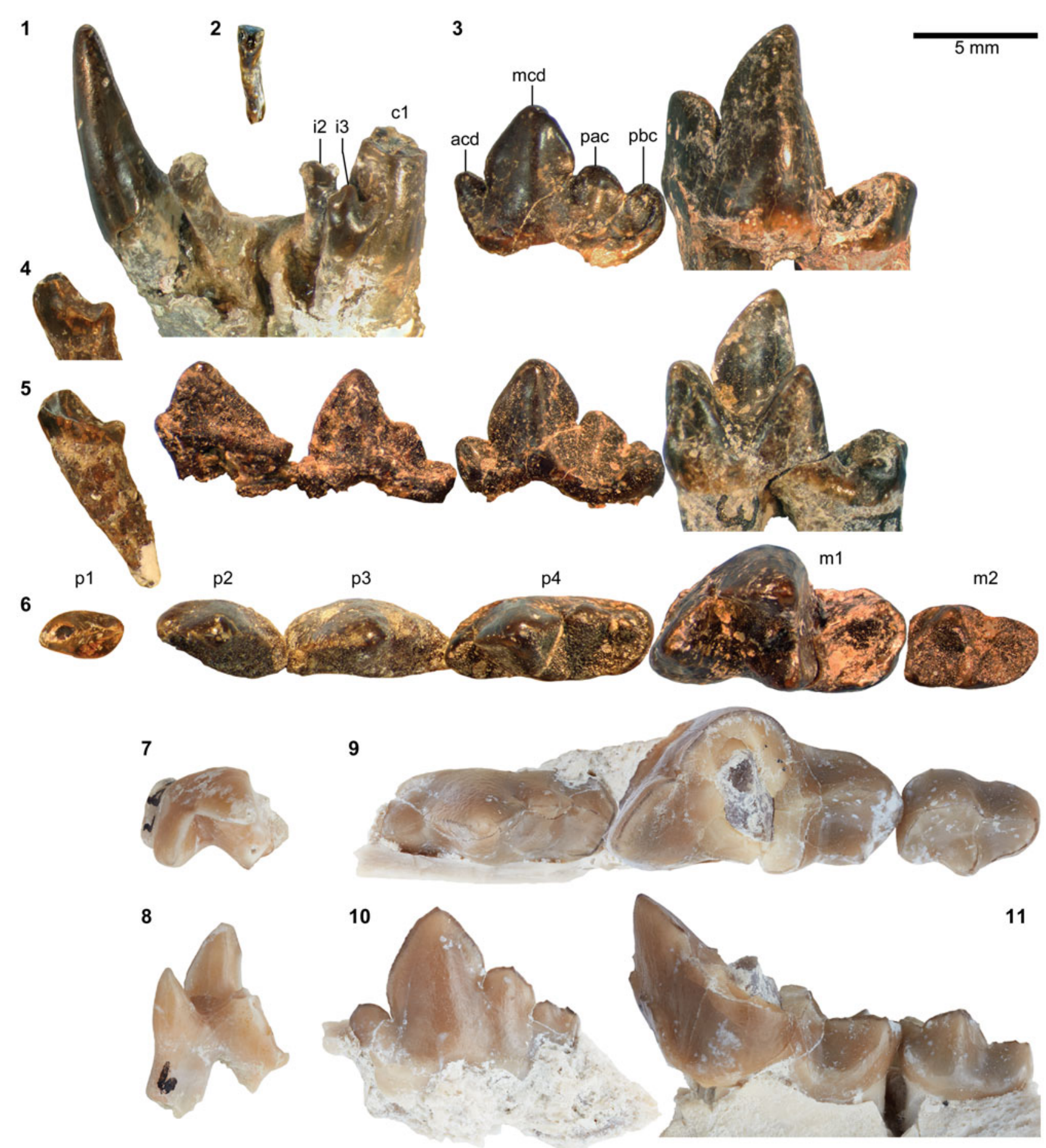

Figure 36. Lower dentition of Neovulpavus mccarrolli $\mathrm{n}$. sp. Holotype of Neovulpavus mccarrolli $\mathrm{n}$. sp., FMNH PM 3593 : (1) right i2 and c1 and left i2-c1 in anterior view; (2) i1 (side indeterminate) in posterior view; (3) composite of left p4 and right m1 (inverted) in labial view; (4) left p1 in labial view; (5) composite of left $\mathrm{p} 1$ (inverted), right p2-3, left $\mathrm{p} 4$ (inverted), and right $\mathrm{m} 1$ in lingual view; (6) same in occlusal view. Neovulpavus mccarrolli n. sp., UWBM 38976: (7) right dp4 trigonid in occlusal view; (8) same in lingual view; (9) composite of left p4-m2 (inverted) in occlusal view; (10) left p4 in labial view; (11) left m1-2 in labial view. Same $5 \mathrm{~mm}$ scale applies to all images. Abbreviations: acd, anterior cuspulid; mcd, main cuspid; pac, posterior accessory cuspulid; pbc, posterior basal cuspulid.

(Fig. 34.1); thus the dental formula for Neovulpavus mccarrolli n. sp. is 3.1.4.2/3.1.4.3 as in many early carnivoraforms.

The small I1 and I2 (Fig. 35.4) have essentially the same forms, and are distinguished mainly by their sizes. Their crowns are somewhat spatulate in anterior view, but are anteroposteriorly rather deep toward their bases. On both I1 and I2, a large central cuspule is flanked by smaller cuspules; the three cuspules are transversely arranged along the anterior edges of the teeth and face posteriorly. The posterior slopes of I1 and I2 are moderately worn, creating more or less flat and vertical walls, except for the somewhat rounded bases of the teeth. The recurved I 3 is substantially larger than I 2 and is caniniform in shape, bearing a 


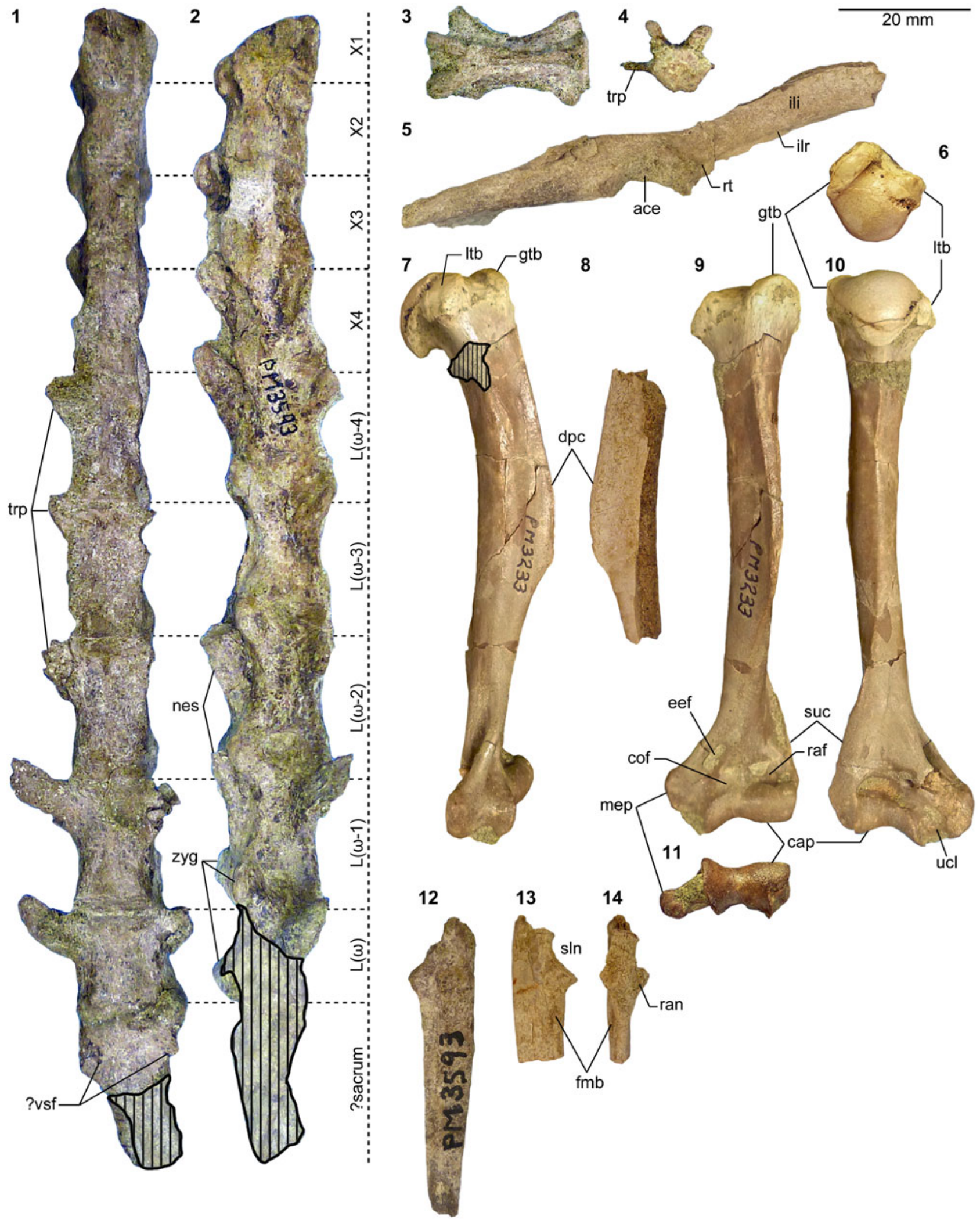

Figure 37. Postcranial material of Neovulpavus mccarrolli $\mathrm{n}$. sp. Parts of holotype of Neovulpavus mccarrolli $\mathrm{n}$. sp., FMNH PM 3593: (1, 2) partial vertebral series in ventral $(\mathbf{1}$, anterior to top) and right lateral $(\mathbf{2})$ views; $(\mathbf{3}, \mathbf{4})$ caudal vertebra in superior $(\mathbf{3})$ and anterior $(\mathbf{4})$ views; $(\mathbf{5})$ partial right pelvis in lateral view; (8) right humeral fragment in medial view; (12-14) partial right ulna in medial view (12) and partial left ulna in medial (13) and anterior (14) views. cf. $N$. $m c c a r r o l l i \mathrm{n}$. sp., FMNH PM 3233: (6, 7, 9-11) left humerus in proximal (6), medial (7), anterior (9), posterior (10), and distal (11) views. Same $20 \mathrm{~mm}$ scale applies to all images. Abbreviations: ace, acetabulum; cap, capitulum; cof, coronoid fossa; dpc, deltopectoral crest; eef, entepicondylar foramen; fmb, fossa for m. brachialis; gtb, greater tuberosity; ili, ilium; ilr, lateral ridge of iliac blade; L, unambiguous lumbar vertebra; ltb, lesser tuberosity; mep, medial epicondyle; nes, neural spine; raf, radial fossa; ran, radial notch; rt, rectus tubercle; sln, semilunar notch; suc, supinator crest; trp, transverse process; ucl, insertion site for ulnar collateral ligament; vsf, ventral sacral foramen; X, vertebra of uncertain type (thoracic or lumbar); zyg, pre/postzygapophysis. 


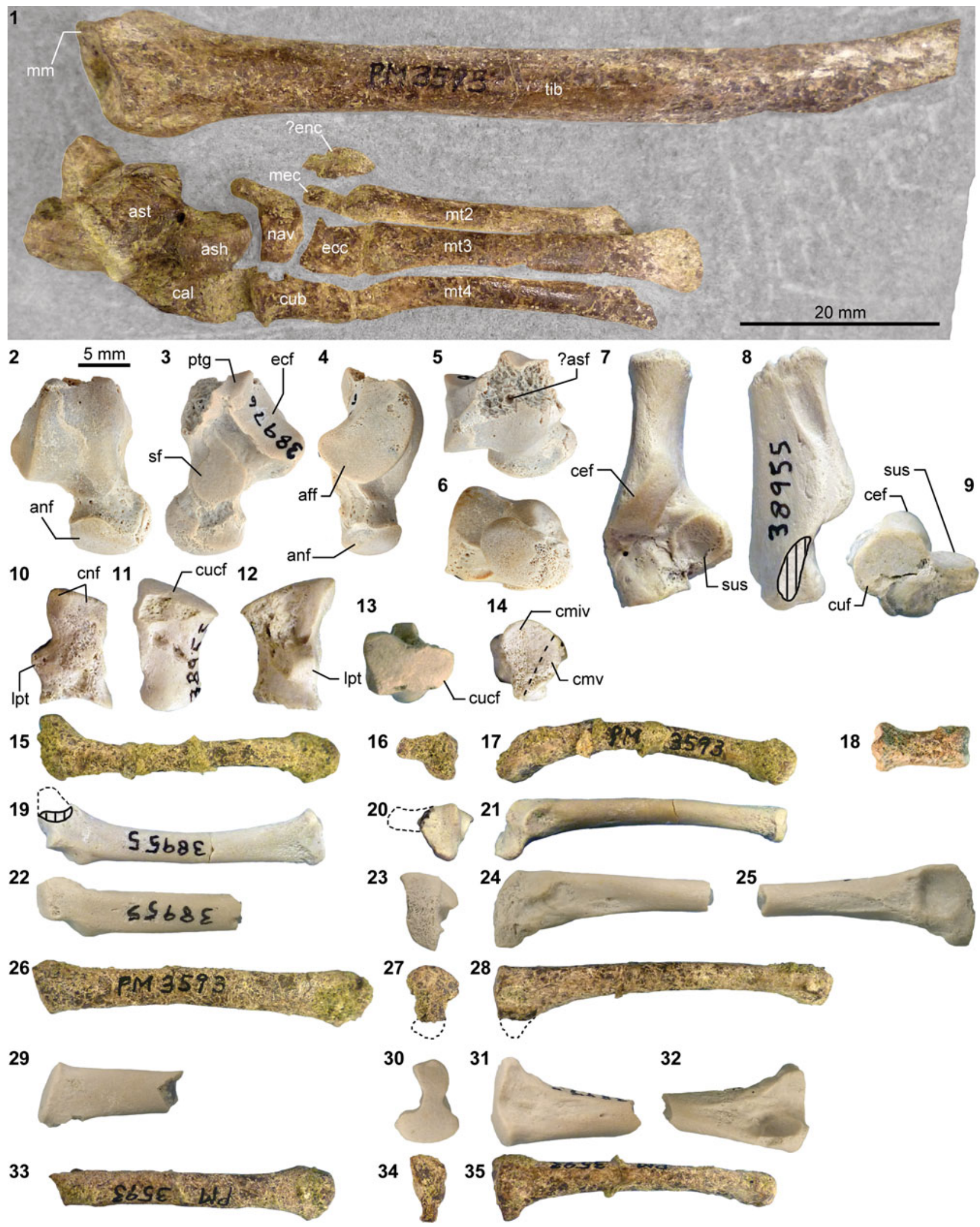


Figure 38. Additional postcranial material of Neovulpavus mccarrolli $\mathrm{n}$. sp. Parts of holotype of Neovulpavus mccarrolli n. sp., FMNH PM 3593: (1) right partial tibia in posterior view and semi-articulated partial right foot in superior view (transparency and color of matrix digitally modified to enhance bone visibility); (15-17) left metatarsal V in anterior (15, lateral to top), proximal (16, anterior to top), and medial (17, anterior to top) views; (26-28) left metatarsal III in anterior (26), proximal (27), and medial (28) views; (33-35) left metatarsal II in anterior (33), proximal (34, anterior to top), and medial (35) views. cf. N. mccarrolli n. sp., FMNH PM 61966: (18) middle phalanx of indeterminate side in superior view. Neovulpavus mccarrolli n. sp., UWBM 38976 (n.b., postcranial elements figured here except for the right astragalus were originally cataloged as part of UWBM 38955 and were labeled as such when they were photographed, but they have since been reassigned to UWBM 38976; see text): (2-6) right astragalus in anterior (2), posterior (3), lateral (4), proximal (5, anterior to bottom), and distal (6) views; (7-9) right calcaneum in anterior (7), lateral (8), and distal (9, anterior to top) views; (10-14) left cuboid in medial (10), anterior (11), posterior (12), proximal (13), and distal (14) views; (1921) left metatarsal $V$ in anterior (19), proximal (20, anterior to top), and medial (21) views; (22-25) left metatarsal IV fragment in anterior (22), proximal (23, anterior to top), medial (24), and lateral (25) views; (29-32) right metatarsal III in anterior (29), proximal (30, anterior to bottom), medial (31), and lateral (32) views. Same 5 mm scale applies to Figure 38.2-38.35. Abbreviations: aff, astragalar fibular facet; anf, astragalar navicular facet; asf, astragalar foramen; ash, astragalar head; ast, astragalus; cal, calcaneum; cef, calcaneal ectal facet; cmiv, cuboid metatarsal IV facet; cmv, cuboid metatarsal V facet; cnf, cuboid navicular facet; cub, cuboid; cucf, cuboid calcaneal facet; cuf, calcaneal cuboid facet; ecc, ectocuneiform; ecf, astragalar ectal facet; enc, entocuneiform; lpt, long plantar tubercle; mec, mesocuneiform; mm, medial malleolus; mt2-4, metatarsals II-IV; nav, navicular; ptg, plantar tendinal groove; sf, astragalar sustentacular facet; sus, calcaneal sustentacular facet; tib, tibia.

pointed apex that is followed by a sharp posterior ridge. Similar to the lingual wall of $\mathrm{C} 1$, its mesial wall is rather flat, whereas the posterior base of $\mathrm{I} 3$ bears a flat ascending slope unlike in $\mathrm{C} 1$. The apex of I3 is labially deflected.

The $\mathrm{C} 1$ (Fig. 35.4), which is separated from I3 by a short diastema of $\sim 2 \mathrm{~mm}$ (approximately equivalent to the anteroposterior length of I3), is slender and only slightly recurved. Its flat lingual wall is anteriorly and posteriorly demarcated by sharp edges. Unlike the lower canine, the upper canine does not show appreciable bulging toward its base.

The anterior premolars gradually increase in size and complexity (Fig. 35.1, 35.2). The P1 completely lacks an anterior cingulum, whereas vestigial anterior cingula are present on P2-3. The lingual cingulum is not clearly defined on P1, but is well delineated on P2-4, in which it is a thin band. The posterior cingulum forms a small cuspule with a short longitudinal ridge on P1-3. Additionally, a well-developed posterior accessory cuspule is present on $\mathrm{P} 2-3$. The posterior accessory cuspule on $\mathrm{P} 3$, which is separated from the main cusp and the posterior basal cuspule by a pair of deep notches, is somewhat blade-like, mirroring the prominent posterior accessory cuspulid on $\mathrm{p} 4$. The middle portion of the lingual base of P3 bulges lingually without forming a distinct cuspule; whether this tooth has more than two roots is unclear from its external appearance. In all upper premolars, the lingual walls are nearly vertically oriented, while the labial walls are more inclined toward the apices of the main cusps. In addition, all upper premolars bear a sharp anterior ridge that runs from the tip of the main cusp to the anterolingual base of each tooth; in P2-4, this ridge terminates in a small notch that is formed with an adjacent anterolingual cuspule. The P4 is marked by strong posterior slanting of the preparacrista, followed by a trenchant postparacrista and metastylar blade, with the latter two features separated by a deep carnassial notch and incision; the parastyle is essentially absent, and the moderately developed protocone is located well anterior to the apex of the paracone, close to the level of the anterior edge of the tooth.

The form of M1 (Fig. 35.1-35.3) is generally similar to that of the substantially smaller FMNH PM 3869 (cf., Neovulpavus washakius) in its proportions and detailed features. The elongate parastylar region forms a shallow ectoflexus, followed by a somewhat rounded posterolabial corner of the tooth. From the anterolabial base of the paracone, the parastylar blade extends labiad, then bends slightly posteriorly and continues to the labial margin of the tooth. This terminal segment of the parastylar blade, together with the anterolabial cingulum, forms a continuous ridge with a hooked appearance in occlusal view. The moderately broad stylar shelf is labially demarcated by a slightly raised ridge. The paracone is roughly twice as tall as the metacone. The preparacrista, centrocrista, and postmetacrista comprise a series of trenchant ridges. The paraconule is robust, as in FMNH PM 3869, and is approximately three-fourths the height of the protocone, from which it is separated by a deep incision. Labially, the paraconule smoothly merges with the well-defined cingulum anterior to the paracone. In contrast, the metaconule is hardly discernible, and may be considered essentially absent; this is the most conspicuous difference from M1 of FMNH PM 3869, in which the metaconule is a distinct cuspule that clearly rises above the level of the trigon basin. The teeth of FMNH PM 3593 generally do not show much wear, so the apparent difference in metaconule development is unlikely to be explained simply by dental attrition or abrasion. The protocone is anteriorly positioned, such that its apex is approximately at the same anteroposterior level as that of the paracone. Whereas the preprotocrista runs primarily labiolingually, the postprotocrista is oriented more anteroposteriorly, giving the trigon basin an asymmetrical appearance in occlusal view. The lingual cingulum is continuous around the protocone but is thin anteriorly. The margin of the relatively broader posterior lingual cingulum forms a low, raised ridge, as in FMNH PM 3869, but lacks the crenulation seen in FMNH PM 3593.

The M2 (Fig. 35.1-35.3) is greatly reduced relative to M1 $([\mathrm{M} 2 \mathrm{~L} \mathrm{x} \mathrm{W]} /[\mathrm{M} 1 \mathrm{~L} \mathrm{x} \mathrm{W]}=0.267)$ and is more anteroposteriorly compressed. Thin but clearly defined cingula are present labially and anterior to the paracone, but not lingually. Although the parastylar ridge is sharp, it is directed anterolabiad and ends on the anterior rather than labial edge of the tooth, unlike on M1. The paracone is substantially taller than the metacone and retains the form of a distinct cusp. In contrast, the metacone lacks a pointed apex and manifests mainly as a raised ridge that follows the postparacrista. A small, roughly triangular facet anterolingual to the base of paracone appears to represent a vestigial paraconule, while the metaconule is completely absent. A smooth, moderately concave trigon basin forms the labial slope of the protocone, and is much shallower than on M1. The lingual margin of the trigon basin appears to be slightly worn.

A partial deciduous tooth is known from the referred specimen UWBM 38976. This dp4 (Fig. 36.7, 36.8) is missing the talonid and the apex of the metaconid. The preserved trigonid is approximately two-thirds the size of the $\mathrm{m} 1$ trigonid, and is considerably more closed than the latter because the paraconid 
Table 10. Measurements (in mm) for Neovulpavus mccarrolli, $\mathrm{n}$. sp. Measured side is indicated (where known) in parentheses. ${ }^{\mathrm{a}}$ Between anterior extremities of right and left orbits in superior view. ${ }^{b}$ From anterior base of $\mathrm{c} 1$ to posterior point of mandibular condyle, parallel to tooth row. ${ }^{\mathrm{c}}$ See Fig. 37.1 , 37.2 for notations. ${ }^{\mathrm{d}}$ Missing epiphysis of calcaneal tubercle. *Holotype. ${ }^{\dagger}$ Estimated for elements with minor breakage or obstruction. Plus signs denote slight undermeasurements. Abbreviations: TRL, trigonid length; TRW, trigonid width.

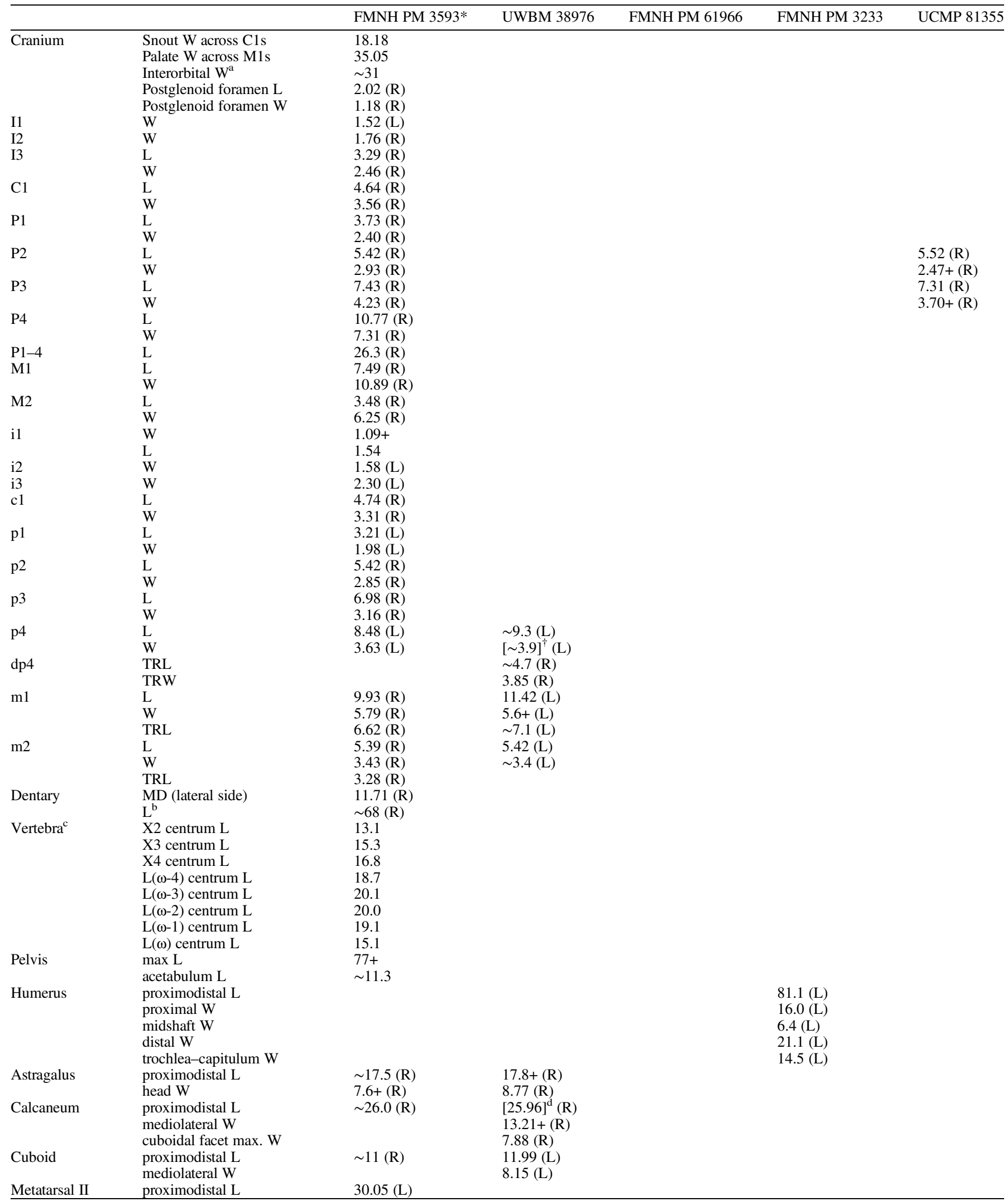


Table 10. Continued.

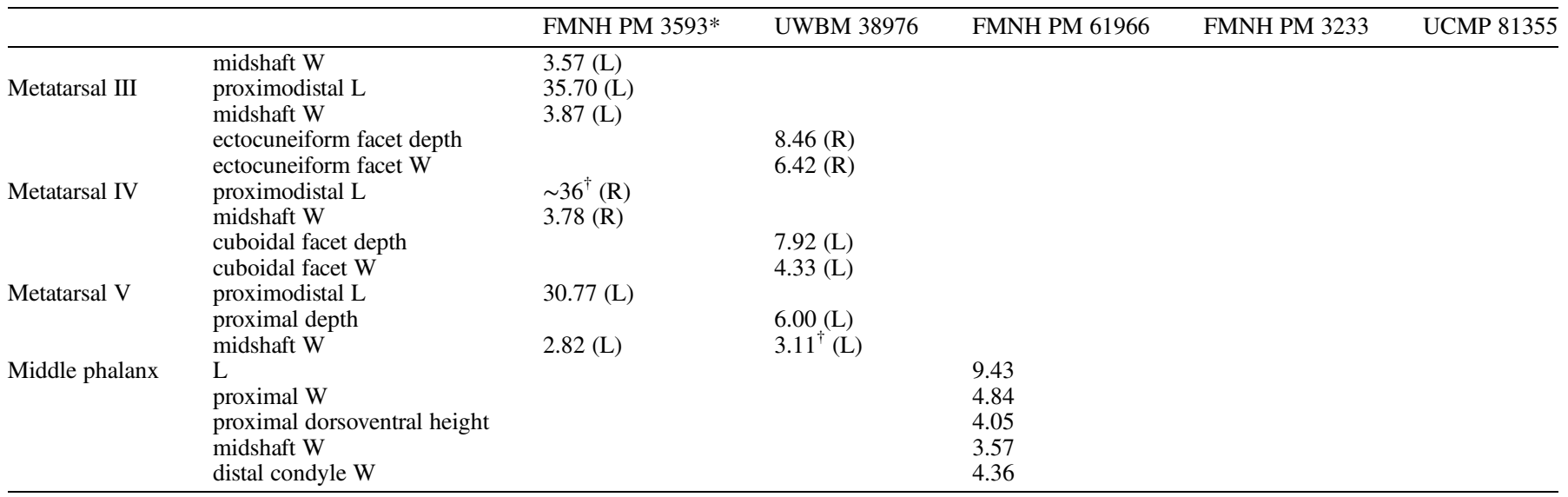

is more lingually directed; this contrast is the opposite of the pattern in the viverravid Didymictis protenus, in which the trigonid of dp4 is substantially more open than that of $\mathrm{m} 1$ (Zack, 2012, fig. 5). The protoconid of dp4 in UWBM 38976 is more lingually inclined than in $\mathrm{m} 1$ of the holotype, and the apex of the metaconid appears to have been more posteriorly positioned than that of the protoconid. No major difference in the form of trigonid is apparent between dp4 of UWBM 38976 and that of FMNH PM 3869 (cf., Neovulpavus washakius; Fig. 30.930.11 ), although heavy damage to the latter precludes detailed comparison.

The lower incisor series of the holotype (Fig. 36.1, 36.2) is mesiodistally compressed, such that $\mathrm{i} 2$ is positioned behind the row of i1 and i3. The minute i1 and the somewhat larger i2 are both worn, but appear to have had similar bicuspidate forms, each having a pair of transversely arranged, posteriorly pointing cuspulids. The much larger i3 likewise bears two cuspulids, but the crown is more asymmetrical in anterior view because the mesial cuspulid is slightly wider. The moderately robust $\mathrm{c} 1$ has a bulging posterior base that is inclined anteriad (Fig. 34.6). Away from the base, the crown of c1 rapidly changes its direction to assume a vertical orientation. A sharp posterior ridge runs along the length of the $\mathrm{c} 1$ crown.

The p1 (Fig. 36.4-36.6) lacks an anterior cingulid. Its main cuspid is strongly tilted anteriad. A sharp ridge descends along the posterior slope of the main cuspid to its base, where it is followed by another, much shorter ridge on the posterior cuspulid. This series of ridges is directed toward the posterolabial corner of the tooth in occlusal view, forming the lateral border of the somewhat concave posterolingual surface of the tooth.

Unlike p1, p2 (Fig. 36.5, 36.6) bears a small but distinct anterior cuspulid (more clearly seen on the isolated left p2), which is positioned at the anterolingual corner of the tooth. As on $\mathrm{p} 1$, the main cuspid is anteriorly tilted, and the slope of the anterior ridge is much steeper than that of the posterior ridge. The posterior ridge of the main cuspid forms an incipient posterior accessory cuspulid (discernible only as a minor bulge) toward its base, where it terminates in a small notch leading to the apex of the posterior basal cuspulid. A series of longitudinal ridges runs from the anterior slope of the main cuspid to the tip of the posterior cingular cuspulid. The p3 shares a similar general structure with the smaller $\mathrm{p} 2$, but its main cuspid is less anteriorly inclined, and the better-developed posterior accessory cuspulid has a step-like appearance in profile.

The morphology of p4 (Fig. 36.3, 36.5, 36.6, 36.9, 36.10) includes the most diagnostic features of Neovulpavus mccarrolli n. sp. The well-developed anterior cuspulid bears a short, anterolingually directed ridge. The main cuspid has a leaf-shaped outline in profile, with trenchant anterior and posterior ridges. A prominent, somewhat blade-like posterior accessory cuspulid is positioned posterolateral to the main cuspid. Posterior to this cuspulid is an additional small cuspulid with a short ridge that rises above the posterior cingulid. The posterolingual slope of the tooth is concave.

The $\mathrm{m} 1$ (Fig. 36.3, 36.5, 36.6, 36.9, 36.11) has a moderately open trigonid with a thin anterolabial cingulid. The protocone rises vertically with little tilt. The paraconid and metaconid are subequal in height. Both the talonid and its basin are moderately broad. The talonid basin forms a transversely more or less symmetrical, U-shaped valley with its long axis pointing posterolabiad toward a somewhat open border. As is typical in middle Eocene carnivoraforms, the hypoconid is discernible only positionally as the raised posterolabial corner of the talonid basin, rather than as a distinct cuspid, and neither the hypoconulid nor the entoconid can be identified as distinct cuspids; instead, these structures are incorporated into the continuous raised rim of the talonid basin. A weakly defined cingulid wraps the labial base of the talonid.

The small m2 (Fig. 36.6, 36.9, 36.11) has an open trigonid with low cuspids. The paraconid is particularly low in height and appears to form (even without appreciable tooth wear) a rather flat, shelf-like surface that occludes with the postprotocrista of M1. A well-developed anterolabial cingulid is present. The talonid tapers toward its posterolabial end, and bears a shallowly concave basin. None of the talonid cuspids is individually recognizable.

Presence of a minute, single-rooted $\mathrm{m} 3$ is indicated by an alveolus ( $\sim 1.5 \mathrm{~mm}$ in length) on the right dentary (Fig. 34.3), but the tooth itself is not preserved.

Postcrania.- The following descriptions of the postcrania of FMNH PM 3593 are preliminary because the specimen has yet to be fully prepared. 
The axial skeleton is represented by fragments of ribs, a series of 10 or 11 transversely compressed, post-cervical trunk vertebrae in articulation, two articulated and heavily damaged ? thoracic vertebrae, and one isolated caudal vertebra. Identification of the individual vertebrae in the long articulated series is difficult because the elements are compressed and damaged, but at least five lumbar vertebrae are recognized based on the presence of transverse processes (" $\mathrm{L}(\omega-4)$ " through " $\mathrm{L}(\omega)$ " in Fig. 37.1, 37.2). The last unquestionable lumbar vertebra is followed by an element (possibly two fused vertebrae) that is dorsoventrally short and lacks prominent processes. The anterior portion of this element exhibits rather abrupt narrowing of the centrum and possible ventral foramina, suggesting that it belongs to the anteriormost segment of the sacrum. Considering that the number of lumbar vertebrae is six to seven in the Br2-age carnivoraform Vulpavus ovatus Matthew, 1909 and generally in extant carnivorans (with rare exceptions; Narita and Kuratani, 2005), the first four elements of the long articulated series ("X1" through "X4" in Fig. 37.1, 37.2) likely include one to two additional lumbar vertebrae and two to three thoracic vertebrae.

Partially due to damage, the vertebrae appear fairly homogeneous, with some of the lumbar elements distinguished only by anteriorly directed transverse processes (Fig. 37.1). These processes are relatively thinner than in Vulpavus ovatus, more closely resembling those of the Br2-age carnivoraform Dawsonicyon isami (Spaulding et al., 2010). The neural spines of the lumbar vertebrae are roughly subequal in length to the transverse processes. The neural spines of the lumbar vertebrae project anteriad at a sharp angle. All the vertebral centra are dorsoventrally shallow as in Dawsonicyon, and without signs of major deformation. Successive centra within the anterior portion of the series steadily increase in length (Table 10), as seen in the thoracic-lumbar transition in Dawsonicyon (Spaulding et al., 2010).

The isolated caudal vertebra (Fig. 37.3, 37.4) is likely from the anterior portion of the tail, given its fully formed articular processes, relatively well-developed transverse processes, and centrum shape. It is much longer (24.3 mm in length) than wide, and wider than tall. It has a bowtie shape in dorsal/ventral view because of its transverse processes, which project laterad by $\sim 5 \mathrm{~mm}$ from the centrum.

The partial right pelvis (Fig. 37.5) includes the ilium and ischium, while the pubis is largely or entirely missing. The dorsal and ventral edges of the iliac blade are both broken off, such that the degree of anterior expansion of the blade is indeterminate. The anteroposteriorly running ridge on the lateral side of the iliac blade is more dorsally positioned than in most crown carnivorans (cf., Spaulding and Flynn, 2012). The rectus tubercle (= "caudal iliac tubercle" of Spaulding and Flynn, 2012) is moderately developed and less prominent than in Dawsonicyon isami. The roof of the acetabulum is roughly even with the dorsal surface of the pelvis, and not sunken ventrally as in several lineages of crown carnivorans (cf., Spaulding and Flynn, 2012). A damaged ischial spine is located relatively far posterior from the acetabulum. The ischial tuberosity region is partially broken, but it does not appear to have been particularly well developed.

The isolated left humerus represented by the referred specimen FMNH PM 3233 is essentially complete and shows little sign of postmortem distortion (Fig. 37.6, 37.7, 37.9-37.11). Its referral to Neovulpavus mccarrolli $\mathrm{n}$. sp. is based on comparison with a fragmentary shaft of a right humerus associated with the holotype (Fig. 37.8), which is essentially a mirror image of FMNH PM 3233 and comes from approximately the same horizon within Twka2. The form of the gracile humerus is overall very similar to those of Neovulpavus washakius (Fig. 31.8, 31.9, 31.11-31.15), Lycarion medius (Fig. 26.5-26.8), and the paratype YPM VP 011839 of 'M.' hargeri (Wortman, 1901a, fig. 9). In proximal view, the greater tuberosity is more anteriorly directed (forming an angle of $\sim 43^{\circ}$ with the anteroposterior axis of the humeral head) than in cf. Vulpavus australis/canavus (USGS 25219; Heinrich and Rose, 1997, text-fig. 2a). The deltopectoral crest is somewhat lower in height than in Vulpavus (USGS 25219; Heinrich and Rose, 1997, text-fig. 2b), Lycarion medius (Fig. 26.6), and YPM VP 011839. Likewise, the degree of the supinator crest development is modest and comparable to those in the closely related carnivoraforms, such as ' $M$.' hargeri, $N$. washakius, and L. medius. The shallow coronoid fossa and the radial fossa are weakly defined, and there is no supratrochlear foramen. On the other hand, the olecranon fossa is moderately deep and slot-like. The medial epicondyle is fairly robust, and bears a large entepicondylar foramen. The medial wall of the trochlea is proportionately longer than in Vulpavus profectus (Matthew, 1909), with a moderate degree of distal protrusion, and its distal border forming an angle of $\sim 27^{\circ}$ with the transverse axis of the distal humerus. As in N. washakius, the capitulum is more cylindrical than spherical.

Most of the proximal half of the right ulna (missing the anconeal and olecranon processes) and a smaller portion of the left ulna are preserved (Fig. 37.12-37.14). The distal border of the semilunar notch is flat, unlike in Vulpavus, but agreeing with the holotype CM 11900 of 'Miacis' gracilis. A clear slit for insertion of $\mathrm{m}$. brachialis occurs on the medial surface of the mediolaterally compressed, straight shaft, as in other stem carnivoramorphans. The radial notch faces anterolaterally and is flat, matching the condition in other early carnivoraforms such as Vulpavus and Dawsonicyon isami, but in contrast to the curved morphology in 'M.' gracilis and most crown carnivorans (Spaulding et al., 2010; Spaulding and Flynn, 2012).

All but the proximal end of the right tibia is preserved (Fig. 38.1), although the anterior aspect of this element is still embedded in the matrix. A sharp crest runs down the exposed posterolateral surface of the shaft. Distally, the medial malleolus is well developed and accompanied by a distinct bone spur on the posterior margin of the articular surface with the astragalus.

The holotype preserves right tarsal bones in near articulation (Fig. 38.1), and the disarticulated and fully prepared elements of UWBM 38976 permit additional observations (Fig. 38.2-38.14). The astragalar trochlea is very weakly grooved, and is longer than wide. Its weakly defined medial border is longer than the sharp lateral border. The fibular facet has a somewhat arched, rectangular shape. As is typical in early carnivoraforms, no fossa is seen on the posterolateral edge of the fibular facet. Although poorly preserved, a small astragalar foramen appears to have been present proximal to the trochlea (Fig. 38.5). On the ventral side, a moderately long and gently concave ectal facet is present, and is proximally bordered by a clearly defined plantar tendinal groove (Fig. 38.3). Distally, the ectal facet 
extends well past the level of the proximal border of the sustentacular facet. The nearly flat sustentacular facet is positioned roughly at the midpoint between the proximal and distal ends of the astragalus. The astragalar neck is slender. The compact astragalar head is on the same plane as the main body ventrally, but in distal view, its long axis points dorsolaterad and away from the ventral plane (Fig. 38.1, 38.6). The navicular facet extends over the dorsolateral, distal, and ventral surface of the astragalar head. In these respects, the astragalus of Neovulpavus mccarrolli n. sp. closely resembles that of $N$. washakius (Fig. 32.10-32.15) and, to the limited extent that comparison can be made, to 'Miacis' hargeri (Wortman, 1901a, fig. 10). The only notable differences in astragalar morphology between $N$. mccarrolli $\mathrm{n}$. sp. and $N$. washakius are the more pronounced difference in dorsoventral depths of the lateral (deeper) and medial walls of the main body, dorsoventrally deeper head, and teardrop-shaped sustentacular facet of the former. Both of these taxa are distinguished from the middle Bridgerian-age (Br2) Dawsonicyon isami and the Uintan-age (Ui2-Ui3) 'Miacis' uintensis in the relatively more proximal position of the sustentacular facet, such that its proximal end is located well proximal to the distal end of the ectal facet (Spaulding and Flynn, 2009, fig. 2; Spaulding et al., 2010, text-fig. 7). The astragali of $N$. mccarrolli $\mathrm{n}$. sp. and $N$. washakius also differ from that of the Uintan-age (?Ui1b-Ui3) 'Miacis' gracilis in having a shallow trochlear groove.

The calcaneum of the holotype appears to be largely complete, while that of UWBM 38976 is missing the peroneal tubercle and the epiphysis of the calcaneal tubercle (Fig. 38.1, 38.738.9). The calcaneal tubercle accounts for the majority of the length of this element, and it is mediolaterally narrower than is dorsoventrally deep. A wide and deep lateral fossa is present on the proximolateral half of the calcaneal tubercle (Fig. 38.8). The ectal facet is proximodistally convex, but transversely less so. No fibular facet is present. The sustentaculum is positioned near the distal margin of the bone, and bears an anteriorly facing, weakly concave sustentacular facet with a roughly circular outline. The form of the peroneal tubercle is unclear in the holotype in its current state of preparation. The distal portion of calcaneum bearing the cuboid facet is proximodistally short (shorter than the greatest length of the ectal facet) and mediolaterally rather narrow, such that the distolateral margin of the cuboid facet is slightly more medially located than that of the ectal facet (Fig. 38.7). Again, these traits are shared with Neovulpavus washakius (Fig. 32.16-32.18).

A full complement of more distal tarsals is preserved in the right pes of the holotype, and the surrounding matrix has maintained their near articulation (Fig. 38.1). The navicular in anterior view is much shorter proximodistally than it is wide mediolaterally. In medial view, its articular facet with the astragalar head is deeply concave (much more so than in Vulpavus represented by USGS 5025) and its ventromedial portion is proximally extended, possibly giving rise to a large tuber tibialis (it is only partially exposed at the current stage of preparation). This proximoventral extension matches the ventromedially extensive navicular facet on the astragalus of UWBM 38976 (Fig. 38.3).

The cuboid is roughly rectangular in anterior view, and the configurations of its articular facets (visible in UWBM 38976;
Fig. 38.10-38.14) are broadly comparable to those in Vulpavus (Heinrich and Rose, 1997, text-fig. 8), but the calcaneal facet in Neovulpavus mccarrolli $\mathrm{n}$. sp. is less steeply inclined (against the latitudinal plane), and the bone is transversely more compressed. A small astragalar facet appears to be present at the anterior margin of the medial surface of the cuboid, anterior to the navicular facets. Comparison with the proximal surface of metatarsal IV (Fig. 38.23) suggests that only a small portion (perhaps one-fourth to one-third) of the distal facet of the cuboid was in contact with metatarsal V (Fig. 38.14; Character 195, State 0; see also Fig. 38.1). So far as can be discerned, the general forms of the ento-, meso-, and ectocuneiforms, as well as those of other tarsals, appear similar to those of the paratype YPM VP 011839 of 'Miacis' hargeri described and illustrated by Wortman (1901a, fig. 10).

Metatarsal I is unknown but inferred to have been present and not greatly reduced, judging from the moderately large entocuneiform, as in Vulpavus profectus (for which MT I is known; Matthew, 1909). In the holotype, right metatarsals II-IV are preserved in situ, but are distally broken (Fig. 38.1), whereas left metatarsals II (Fig. 38.33-38.35), III (Fig. 38.26-38.28), IV (embedded in matrix and not figured), and V (Fig. 38.1538.17) are largely complete. The relative lengths of these metatarsals (MT II $\approx$ MT V < MT III $\approx$ MT IV) are similar to those in 'Miacis' hargeri (Wortman, 1901a, fig. 10) and V. profectus (Matthew, 1909, fig. 31). Among extant carnivorans, the mustelid Pekania pennanti has metatarsals of similar lengths to those of FMNH PM 3593, but the bones are more slender in P. pennanti. As seen in metatarsals III-V of UWBM 38976 (Fig. 38.19-38.25, 38.29-38.32; originally cataloged as part of UWBM 38955), the basic configurations of articular facets on the proximal metatarsals are comparable to those in extant carnivorans. The shafts of metatarsals II-IV are nearly straight, while that of metatarsal $\mathrm{V}$ is somewhat bowed (Fig. 38.17, 38.19).

The middle phalanx of referred specimen FMNH PM 61966 (Fig. 38.18) is characterized by strong asymmetry of the shaft in superior view, in which one side (medial or lateral is unknown) is nearly vertically oriented, whereas the opposite side forms a longer and shallower, superiorly facing concave facet. This minor excavation of the phalangeal shaft, also seen in the early caniform carnivoran Lycophocyon hutchisoni Tomiya, 2011, is associated with partially retractile claws in extant carnivorans (Wang, 1993; Wesley and Flynn, 2003).

Etymology.-Specific name after the late Steven M. McCarroll of FMNH in recognition of him as a friend, and in honor of his invaluable contributions to the study of the mammalian biostratigraphy of the Washakie Formation through many years of fieldwork, paleontological specimen collecting, fossil preparation, collections management, and research.

Materials.-FMNH locality FM-6-57-WDT (Twka2): FMNH PM 3233, left humerus.

FMNH locality FM-7-57-WDT or FM-8-57-WDT (Twka2): PM 61966, middle phalanx (unknown side).

UWBM locality A8143 ('Haystack Mountain West'; likely Twka2): UWBM 38976 (see Remarks regarding catalog 
number), left maxillary fragments with $\mathrm{I} 3$ and $\mathrm{C} 1$, right $\mathrm{i} 3$, trigonid of right $\mathrm{dp} 4$, right $\mathrm{m} 1$ protoconid, left dentary fragments (with partially erupted $\mathrm{p} 4$, broken $\mathrm{m} 1$, and $\mathrm{m} 2$ ), right astragalus, right calcaneum, left astragalus, left calcaneum, left cuboid, right proximal metatarsal III, left proximal metatarsal IV, and left metatarsal $\mathrm{V}$ missing distal epiphysis, and postcranial fragments including right distal tibia.

UCMP locality V83217 ('Haystacks General'; Twka2): UCMP 81355, right maxillary fragment with $\mathrm{P} 2-3$ and other ?cranial fragments.

Remarks.-We proposed the new species Neovulpavus mccarrolli given the substantial array of diagnostic features distinguishing this taxon from other early carnivoraforms, and assign it to Neovulpavus based on the topology of the consensus tree obtained from our cladistic analysis, in which it forms a sister-taxon relationship with $N$. washakius (see Results and Figs. 43, 44). The two species of Neovulpavus occur successively within the Adobe Town Member of the Washakie Formation.

The dental and postcranial elements of UWBM 38976 are confidently referred to Neovulpavus mccarrolli n. sp. based on the forms of p4-m2 (Fig. 36.9-36.11). The only notable difference between that specimen and the holotype FMNH PM 3593 is the larger size of the former, with $\mathrm{m} 1$ being $15 \%$ longer. Parts of UWBM 38976 were originally cataloged as parts of UWBM 38955 (right $\mathrm{m} 1$ fragment and all postcranial elements listed above except the right astragalus) and UWBM 38977 (left dentary fragment with $\mathrm{m} 1$ talonid); these elements were extracted and incorporated into UWBM 38976 after identification by one of us (ST) because: (1) their forms are consistent with the same elements of FMNH PM 3593; (2) they exhibit juvenile conditions in common; and (3) the left $\mathrm{m} 1$ talonid (originally part of UWBM 38977) perfectly fit the left $\mathrm{m} 1$ trigonid fragment of UWBM 38976 (they have since been glued back together, as seen in Fig. 38.9, 38.11). The remaining UWBM 38955 contains artiodactyl skeletal elements, and both UWBM 38955 and UWBM 38977 currently include taxonomically indeterminate elements.

Tomiya (2013) tentatively referred five isolated teeth from the early Uintan (Ui1b) of southern California to the carnivoraform Procynodictis, while noting their apparently plesiomorphic forms compared to the corresponding teeth of known species of Procynodictis, which are geologically younger than the material from southern California. However, the dental morphological similarities and differences between those specimens and late-Uintan species of Procynodictis $(P$. vulpiceps and $P$. progressus) also apply to comparison with the dentition of Neovulpavus mccarrolli n. sp. As such, a close relationship between the early Uintan taxon from California and the approximately coeval $N$. mccarrolli $\mathrm{n}$. sp. is at least equally likely, and the former is best regarded as an unnamed carnivoraform of uncertain affinity until additional material is discovered.

UCMP 81355 is referred to Neovulpavus mccarrolli n. sp. based on the dimensions of P2-3 (Fig. 35.5; Table 10) and the presence of two prominent posterior cuspules on $\mathrm{P} 3$ as in the holotype. On both P2 and P3, the main cusp and posterior cuspules are heavily worn, and the enamel layer on the labial wall is largely missing; still, well-defined lingual cingula as seen in the holotype are preserved. The occlusal outlines of the two teeth also closely resemble those of the holotype, except for the absence of the low bulge on the lingual base of P3-a feature that we interpret to be variable within the species. Precisely where this specimen was collected on Haystack Mountain (noted as Lester Kent's level 5) in the Washakie Basin is unknown, although it is likely from Granger's (1909) stratum no. 17 (= Roehler's [1973, 1992] bed 633) or nearby horizons, according to a letter from Malcolm C. McKenna to Howard J. Hutchison, dated June 29, 1977, and on file at UCMP.

Although secure records of Neovulpavus mccarrolli n. sp. are currently restricted to the early Uintan (Uilb) portion of the Washakie Formation, we note that AMNH FM 105371 from Bone Bed A (also early Uintan in age; cf., Flynn, 1986; Murphey et al., 2018) of the Tepee Trail Formation in the Absaroka Range of Wyoming shows some resemblances to N. mccarrolli $\mathrm{n}$. sp. This specimen-a dentary fragment with $\mathrm{p} 4$ and the posterior root of $\mathrm{p} 3$ - was originally assigned to the hypodigm of the viverravid Protictis (subgenus Protictoides) aprophatos (Flynn and Galiano, 1982) as possibly even belonging to the same individual as the holotype AMNH FM 97701 (Flynn and Galiano, 1982, figs. 2, 6). That assignment was based partly on the conservative presumption of only a single carnivoramorphan species occurring at the holotype locality, where the two specimens had been collected within meters of each other in an apparently single, extremely thin andesitic tuff layer of unclear lateral extent (possibly a lenticular infilling of a localized pond deposit). Additionally, Flynn and Galiano (1982) noted closely matching sizes and occlusal compatibility of p4 of AMNH FM 105371 with P4 of the holotype. Later, Gingerich and Winkler (1985) considered both specimens to be possibly viverravid but generically indeterminate. We consider the viverravid affinity of the holotype to be indisputable given the welldeveloped parastyle (cf., Wesley-Hunt and Flynn, 2005), but as for AMNH FM 105371, its p4 morphology (e.g., prominent blade-like cuspulids, leaf-shaped main cuspid, and moderately elevated posterior accessory cuspulid) also seems compatible with $N$. mccarrolli $\mathrm{n}$. sp. Thus, although it remains most likely that the two specimens from Bone Bed A both pertain to $P$. aprophatos, we also recognize the possibility that they belong to two different taxa. Further assessment must await inclusion of each specimen in a comprehensive phylogenetic analysis of Carnivoramorpha to better discern synapomorphic versus homoplasic similarities in the lower teeth, as well as future discovery of additional material of these forms.

The M1 of Neovulpavus mccarrolli $\mathrm{n}$. sp. closely resembles that of 'Miacis' invictus from the middle Eocene Irdin Manha Formation of Inner Mongolia, China, particularly with regard to the forms, relative sizes, and configuration of its cusps (Fig. 35.6). 'M.' invictus is distinguished by the more limited labial elongation of parastylar region, which is suggestive of relatively larger posterior molars than in N. mccarrolli n. sp., but other morphological differences are minor. Although Matthew and Granger (1925) noted similarities of 'M.' invictus to the Bridgerian taxon M. parvivorus, M1 of the former appears more derived in its greater labial projection of the parastylar area (such that the labial border of the tooth forms an appreciable 
ectoflexus in occlusal view) and anteroposteriorly broader trigon region resulting in a more anteroposterior orientation of the postprotocrista. A close relationship between $N$. mccarrolli $\mathrm{n}$. sp. and ' $M$.' invictus, if supported by additional fossil material (note that the latter species is known only by a single tooth) and a comprehensive phylogenetic analysis, would be consistent with the early to middle-Uintan-equivalent age of the Irdin Manha Formation (Bai et al., 2017).

\section{Genus Harpalodon Marsh, 1872c}

Type species.-Harpalodon sylvestris Marsh, 1872c, by original designation.

Remarks._'Harpalodon' vulpinus Marsh, 1872c, is a junior synonym of Viverravus gracilis according to Wortman (1901b).

\section{Harpalodon sylvestris Marsh, 1872c}

Figures 39, 40

1872c Harpalodon sylvestris Marsh, p. 216.

1901b Harpalodon sylvestris; Wortman, p. 201, fig. 38 (type figured).

1909 Miacis (Harpalodon) sylvestris; Matthew, p. 370, textfig. 15.

1923a Miacis (Harpalodon) sylvestris; Thorpe, p. 26.

1994 'Miacis' sylvestris; Wang and Tedford, p. 11, fig. 3.

1998 Miacis sylvestris; Flynn, p. 117.

2008 Miacis sylvestris; Heinrich et al., p. 155.

Holotype.-YPM VP 011808, left dentary fragment with p3-4 and partial $\mathrm{m} 1$.

Locality.-YPM locality reported as "near Henry's Fork" (Marsh, 1872a, p. 217), Uinta or Sweetwater County, Wyoming.

Horizon.-Twin Buttes Member ("Upper Bridger"), Bridger Formation (Matthew, 1909).

Emended diagnosis.-Differs: from 'Miacis' uintensis and earlier-diverging carnivoraforms in presence of deep indentation on squamosal or alisphenoid marking contact with anterior portion of ectotympanic (Character 32, State 1); from 'Miacis' gracilis and crown carnivorans in more closed $\mathrm{m} 1$ trigonid (Character 227R, State 0).

Further differs: from Dawsonicyon isami and earlierdiverging carnivoraforms in position of infraorbital foramen above P3 (Character 4, State 0); from the genotypic species of Miacis, M. parvivorus in elongate (Character 3, State 0) and more anteriorly positioned infraorbital foramen (Character 4 , State 0 ), prominent mastoid process projecting ventrally (Character 14, State 1), foramen ovale and alisphenoid canal separated only by a thin wall (Character 19, State 1), facial nerve canal in tegmen tympani area covered by bony sheath (Character 20, State 2), presence of impression on basisphenoid left by anterior loop of internal carotid artery (Character 23, State 1), presence of small suprameatal fossa (Character 24 , State 1), presence of small flange formed by lateral edge of basioccipital (Character 34, State 1), substantial labial projection of M1 parastylar region (Character 45R, State 2), more uniform width of M1 lingual cingulum along base of protocone (Character 47, State 0), subequal sizes of M1 paraconule and metaconule (Character 49, State 1), presence of vestigial/incipient $\mathrm{p} 4$ posterior accessory cuspulid (Character 220R, State 1), relatively smaller p4 posterior basal cuspulid (Character 224R, State 0), more anteriorly directed $\mathrm{m} 2$ paraconid (Character 248, State 1), and shorter height of $\mathrm{p} 4$ (such that crown is not taller than long), more open m1-2 trigonid, and longer than wide m1-2 talonid basin; from Neovulpavus washakius, N. mccarrolli n. sp., Lycarion medius, and ' $M$.' hargeri in poorly developed $\mathrm{p} 4$ anterior cingular cuspulid (Character 221, State 0); from 'M.' uintensis in posterior lacerate foramen represented by vacuity between petrosal promontorium and basioccipital (Character 17, State 0), middle lacerate foramen represented by vacuity, lacking clearly defined border (Character 40, State 0), substantial labial projection of M1 parastylar region (Character 45R, State 2), and incipient or vestigial p4 posterior accessory cuspulid (Character 220R, State 1); and from ' $M$.' gracilis in elongate infraorbital foramen (Character 3, State 0), condyloid foramen farther from posterior lacerate foramen (Character 15 , State 0 ), posterior lacerate foramen represented by vacuity between petrosal promontorium and basioccipital (Character 17, State 0), more uniform width of M1 lingual cingulum along base of protocone (Character 47, State 0), absence of posterior accessory cuspule on P3 (Character 58, State 2), absence of $\mathrm{p} 3$ posterior accessory cuspulid (Character 219, State 0 ), incipient or vestigial p4 posterior accessory cuspulid (Character 220R, State 1), poorly developed p4 anterior cingular cuspulid (Character 221, State 0), p4 taller and longer than $\mathrm{p} 3$ (Character 226, State 0), more anteriorly directed $\mathrm{m} 2$ paraconid (Character 248, State 1), and strong anterior projection of $\mathrm{P} 4$ parastylar region in occlusal view (Character 249, State 0).

Occurrence.-Portions of the Blacks Fork and Twin Buttes members, Bridger Formation ("near the top of Lower Bridger" and "Upper Bridger" of Matthew, 1909, p. 370), Wyoming (Gazin, 1976); Twka1, Adobe Town Member, Washakie Formation, Sweetwater County, Wyoming (Wang and Tedford, 1994; this study). Middle to late Bridgerian (Br2Br3) NALMA.

Description.-The exceptionally preserved basicranial morphology of AMNH FM 129284 was described in detail by Wang and Tedford (1994). Its cast is figured here to illustrate the dentition of this important specimen for the first time (Figs. 39.1-39.3, 40.1, 40.2). While P4-M3 and c1-m2 of Harpalodon sylvestris were known from specimens described by Wortman (1901b) and Matthew (1909), AMNH FM 129284 is notable for preserving $\mathrm{m} 3$. The crown of this minute, single-rooted tooth has an oval outline in occlusal view. Although greatly reduced, its trigonid cuspids and talonid basin are individually recognizable (Fig. 40.1, 40.2), mirroring the condition in M3 (Fig. 39.2), with which m3 occludes. In contrast to the more anterior molars, m3 essentially lacks an anterolabial cingulid.

The $\mathrm{p} 4$ bears a small, pointed cuspulid at the posterior base of the main cuspid (Fig. 40.1). This posterior basal cuspulid is consistently present across specimens of $H$. sylvestris 

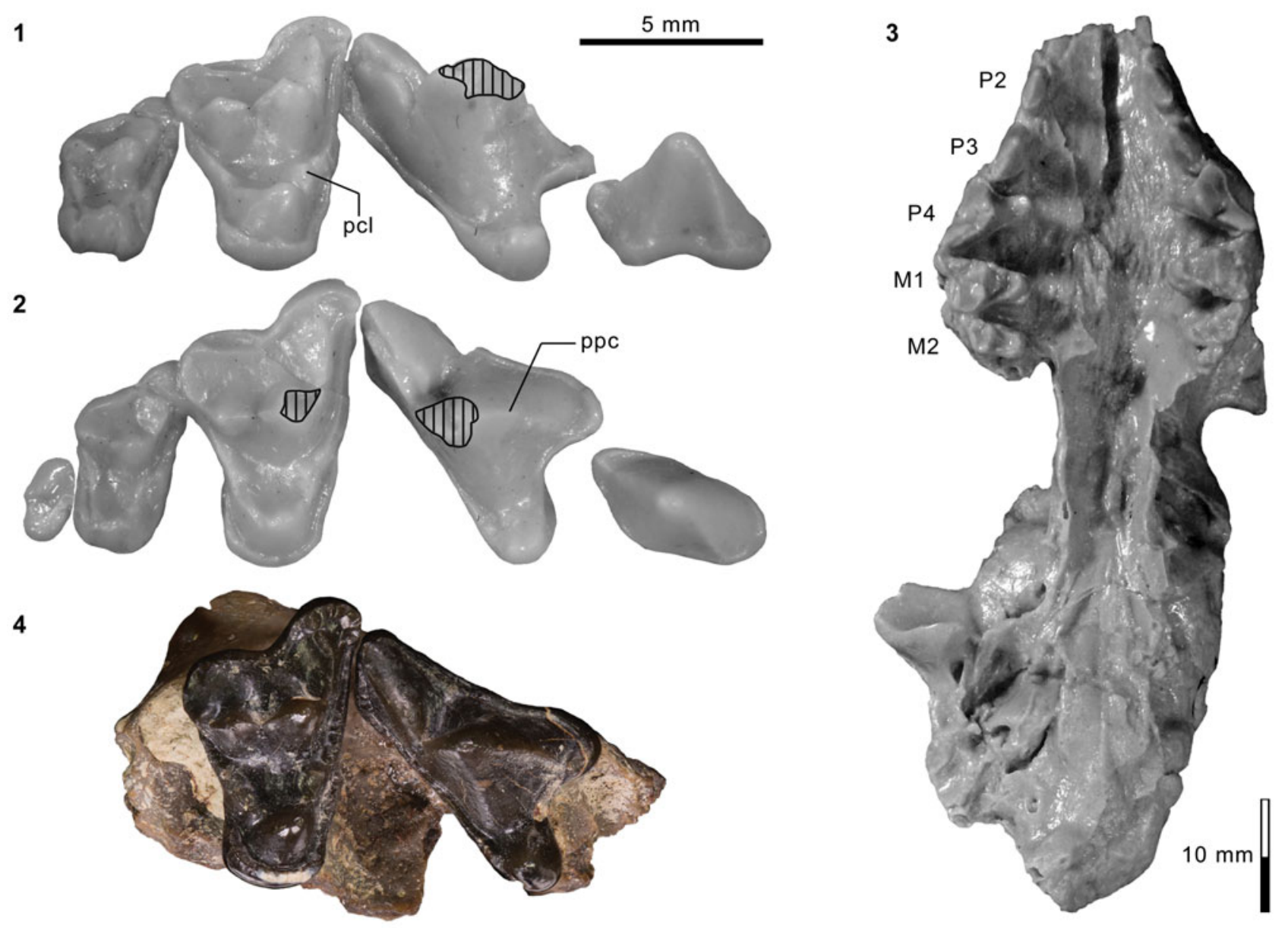

Figure 39. Cranium and upper dentition of carnivoraform Harpalodon sylvestris Marsh, 1872c, from the Washakie and Bridger formations. Cast FMNH PM 55953 of AMNH FM 129284, Harpalodon sylvestris, from Twka1, Washakie Formation: (1, 2) right P3-M2 in oblique lingual view (1) and composite of right P3-M2 and left M3 (inverted) in occlusal view (2); (3) cranium in inferior view. YPM VP 013107 from Bridger C or D ("Upper Bridger"): (4) right maxillary fragment with P4 M1 in occlusal view (courtesy of Division of Vertebrate Paleontology, YPM; photography by Jamie Henderson). Same 5 mm scale applies to Figure 39.1, 39.2, and 39.4. Abbreviations: pcl, paraconule; ppc, preparacrista.

(Fig. 40.8; see also Wortman, 1901b, fig. 38). Matthew (1909, p. 370) reported absence of premolar "accessory cusps" in $H$. sylvestris presumably because he distinguished-as we do here-the $\mathrm{p} 4$ posterior basal cuspulid from posterior accessory cuspulids in some other taxa that he had assigned to the genus Miacis. Importantly, we observe distinct thinning of a portion of the posterior slope of the main cuspid in AMNH FM 129284 ("ipac" in Fig. 40.1; orange area in Fig. A1) that corresponds both in position and extent (on the posterior slope of the main cuspid) to the posterior accessory cuspulids in late-diverging, non-carnivoran carnivoraforms and early crown carnivorans. We interpret this structure in $H$. sylvestris to represent an incipient or vestigial posterior accessory cuspulid.

FMNH PM 62635 (Fig. 40.3-40.5), an isolated $\mathrm{m} 1$, is referred to Harpalodon sylvestris based on the characteristic talonid with a trenchant cristid obliqua combined with a shallow basin (Wortman, 1901b; Matthew, 1909). As in other specimens, the apex of the metaconid is located slightly more posteriorly than that of the protoconid, contributing to the moderately open appearance of the trigonid despite the very lingually oriented postparacristid.
Materials from Washakie Formation.-Unnamed AMNH locality $\sim 1.6 \mathrm{~km}$ east of Salazar Butte (Twka1): AMNH FM 129284 (we examined its cast, FMNH PM 55953), cranium with right $\mathrm{P} 2-\mathrm{M} 2$ and alveolus of $\mathrm{M} 3$ and left $\mathrm{P} 1-\mathrm{M} 3$, right dentary with $\mathrm{p} 4-\mathrm{m} 3$, left dentary with $\mathrm{p} 3-\mathrm{m} 1$ and $\mathrm{m} 3$.

FMNH locality FM-7-58-WDT (Twka1): FMNH PM 62635 , right $\mathrm{m} 1$.

Remarks. - In addition to the narrow $\mathrm{m} 1$ talonid, as pointed out by Wang and Tedford (1994), the characteristically small (likely vestigial) $\mathrm{p} 4$ posterior basal cuspulid unites this specimen with the holotype YPM VP 011808 (Wortman, 1901b), and we consider the referral of AMNH FM 129284 to H. sylvestris to be secure.

Matthew (1909) reassigned Harpalodon sylvestris Marsh, 1872c, to the genus Miacis and relegated Harpalodon to the subgeneric rank. In his classification, Miacis (Harpalodon) consisted of $M$. (H.) sylvestris and $M$. (H.) washakius (= Neovulapvus washakius). However, cladistic analyses to date do not support monophyletic grouping of the genus Miacis that unites 'M.' sylvestris with the genotypic species M. parvivorus or species of Neovulpavus (e.g., Wesley-Hunt and Flynn, 2005; 

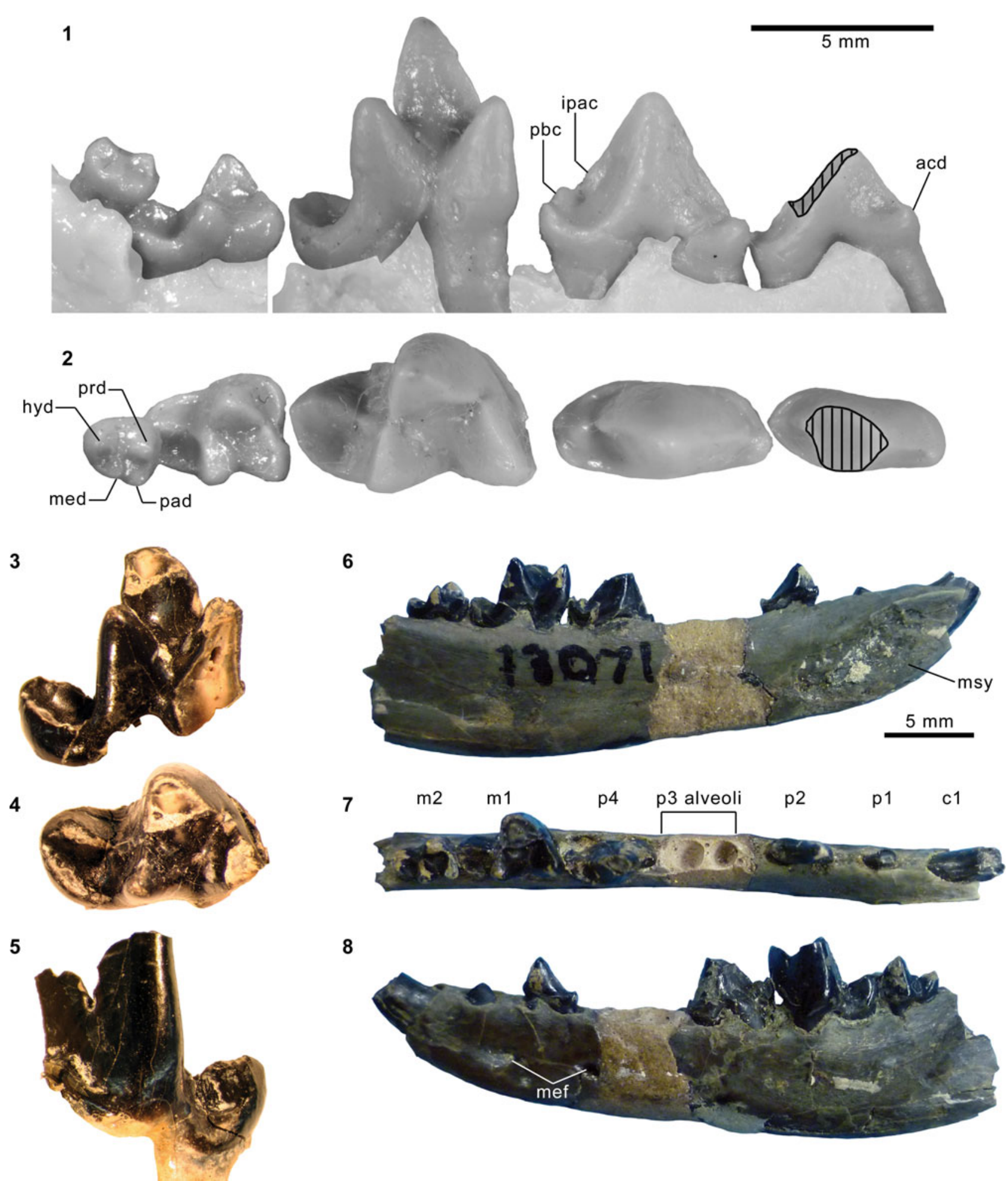

Figure 40. Lower dental and mandibular material of cf. Harpalodon sylvestris. Cast FMNH PM 55953 of AMNH FM 129284, Harpalodon sylvestris: (1, 2) composite of left $\mathrm{p} 3-\mathrm{m} 1$ and right $\mathrm{m} 2-3$ (inverted) in lingual (1; color and transparency of dentary were digitally altered to enhance visibility of teeth) and occlusal (2) views. cf. H. sylvestris, FMNH PM 62635: (3-5) right m1 (inverted) in lingual (3), occlusal (4), and labial (5) views. cf. H. sylvestris, AMNH FM 13071: (6-8) left dentary with broken $\mathrm{c} 1-\mathrm{p} 1, \mathrm{p} 2$, and p4-m2 in medial (6), superior (7), and lateral (8) views. Different $5 \mathrm{~mm}$ scales apply to Figure 40.1-40.5 and 40.6-40.8. Abbreviations: acd, anterior cuspulid; hyd, hypoconid; ipac, distinctly thin area of posterior slope of main cuspid interpreted as incipient posterior accessory cuspulid; med, metaconid; mef, mental foramina; msy, mandibular symphysis; pad, paraconid; pbc, posterior basal cuspulid; prd, protoconid.

Tomiya, 2011; Spaulding and Flynn, 2012; Solé et al., 2014; this study, Figs. 43, 44), hence we propose restoration of the genus Harpalodon and recognize $H$. sylvestris as its sole constituent species.
YPM VP 013107 from the Bridger C or D interval (Fig. 39.4) was identified by Malcolm R. Thorpe as 'Miacis' hargeri (according to the specimen label), and is likely one of 
the "several other specimens" referred to that taxon by Thorpe (1923a, p. 26), although he did not provide their catalog numbers. We reidentify this specimen as Harpalodon sylvestris based on its close similarities to AMNH FM 129284 in size (P4 and M1 are labiolingually 19\% and 14\% narrower, respectively, than in the holotype of ' $M$. ' hargeri), pronounced anterior projection of the $\mathrm{P} 4$ parastylar region (contrast with ' $M$.' hargeri in Fig. 27.3), anteroposteriorly constricted lingual portion of M1 with uniform development of the lingual cingulum around the protocone (i.e., lacking expansion of the postcingulum relative to the precingulum), and greatly reduced M1 paraconule and metaconule (the latter is barely discernible and may be considered essentially absent). YPM VP 013107 is nevertheless distinct from AMNH FM 129284 in the extensive enamel crenulation along the margins of $\mathrm{P} 4$ and $\mathrm{M} 1$, and in its somewhat broader M1 lingual cingulum.

\section{Carnivoraformes gen. indet., species A Figure 41.1-41.3}

Description.-This taxon, represented by FMNH PM 61314, differs from other known carnivoraforms from the Washakie Formation in the large size of $\mathrm{m} 2$ relative to $\mathrm{m} 1([\mathrm{~m} 2 \mathrm{~L} \mathrm{x}$ $\mathrm{W}] /[\mathrm{m} 1 \mathrm{~L} \mathrm{x} \mathrm{W}]=0.61)$. In that respect, it is similar to some individuals of Miacis parvivorus from the middle Bridgerian (e.g., $[\mathrm{m} 2 \mathrm{~L} \times \mathrm{W}] /[\mathrm{m} 1 \mathrm{~L} \times \mathrm{W}]=0.59$ for USNM PAL 214706). However, it differs from M. parvivorus in the more anteriorly directed postparacristid and the somewhat longer talonid. The $\mathrm{m} 1$ also resembles that of Harpalodon sylvestris in the orientation of the prevallid, but differs in: (1) closer anteroposterior alignment of the apices of the protoconid and metaconid (metaconid projects more posteriorly in $H$. sylvestris); (2) less steep descent of the posterior wall of trigonid into the talonid basin $\left(\sim 71^{\circ}\right.$ in lingual view compared to $\sim 90^{\circ}$ in $H$. sylvestris); and (3) anteriorly broader talonid basin owing to the more labial position of the anterior portion of the cristid obliqua (compare Fig. 41.3 with Fig. 40.2, 40.4).

In addition to its large size, $\mathrm{m} 2$ is characterized by the very low height of protoconid, and a closed trigonid in which the postparacristid and postmetacristid are oriented in parallel to each other and approximately perpendicular to the long axis of the tooth. Compared to $\mathrm{m} 2$ of Miacis parvivorus, the paraconid is more reduced. The anterolabial cingulid is poorly defined and essentially confluent with the anterior base of the protoconid. The talonid is nearly as large as the trigonid and bears a broad, if shallow, talonid basin bordered by a continuous rim; none of the talonid cuspids is clearly identifiable. The cristid obliqua in occlusal view forms a shallow angle with the long axis of tooth (Fig. 41.3).

Measurements: $\mathrm{m} 1 \mathrm{~L}=\sim 7.4 ; \mathrm{m} 1 \mathrm{~W}=4.79 ; \mathrm{m} 1$ trigonid $\mathrm{L}=\sim 5.1 ; \mathrm{m} 1$ trigonid height $=\sim 7.8 ; \mathrm{m} 2 \mathrm{~L}=5.57 ; \mathrm{m} 2 \mathrm{~W}=$ 3.91; $\mathrm{m} 2$ trigonid $\mathrm{L}=3.76$.

Materials.-FMNH locality JJF 7-27-95-1 (between Roehler's [1973] beds 620 and 644 in Twka2, Adobe Town Member, Washakie Formation; likely Br3 in age): FMNH PM 61314, tooth fragments including left $\mathrm{p} 4$, nearly complete left $\mathrm{m} 1$, complete left $\mathrm{m} 2$.
Remarks. - The similarities with Miacis parvivorus suggest a possibly close affinity with that species, although taxonomic resolution must await recovery of more material and its inclusion in a comprehensive phylogenetic analysis of Carnivoramorpha. To our knowledge, the taxon represented by this specimen is not known elsewhere, including the more fossiliferous Twka1 in the Washakie Basin or the Twin Buttes Member of the Bridger Formation. While the precise stratigraphic position of the FMNH locality JJF 7-27-95-1 within Twka2 is unknown, occurrences there of such taxa as the hyopsodontid Hyopsodus, adapiform primate Notharctus, and equid Orohippus strongly suggest a $\mathrm{Br} 3$ age of the fossil assemblage (see Comments on biostratigraphy in Appendix).

Carnivoraformes gen. indet., species B

Figure 41.4-41.6

Description.-Compared to other carnivoraforms of early Uintan or older NALMAs, the m1 trigonid of PM 61335 is notably more open (prevallid and postvallid form an angle of $\sim 70^{\circ}$ in occlusal view) and labiolingually compressed (Fig. 41.4), approaching the conditions in geologically younger carnivoraforms such as Procynodictis vulpiceps and 'Miacis' gracilis (both known from the late Uintan). The height of $\mathrm{m} 1$ protoconid appears to have been slightly lower in PM 61335 than in the holotype CM 11900 of 'M.' gracilis. In contrast to $\mathrm{m} 1, \mathrm{~m} 2$ bears an anteroposteriorly compressed trigonid in which the postparacristid runs nearly perpendicular to the long axis of the tooth (Fig. 41.4); this condition is comparable to that in ' $M$.' gracilis, whereas $\mathrm{m} 2$ of $P$. vulpiceps is characterized by a more anteriorly oriented postparacristid, as in Lycarion medius, Neovulpavus washakius, and N. mccarrolli n. sp.

Measurements: $\mathrm{m} 1 \mathrm{~W}=4.09 ; \mathrm{m} 1$ trigonid $\mathrm{L}=5.02 ; \mathrm{m} 2 \mathrm{~L}=$ $4.31 ; \mathrm{m} 2 \mathrm{~W}=3.13$.

Materials.-FMNH locality JJF 7-27-95-1 (between Roehler's [1973] beds 620 and 644 in Twka2, Adobe Town Member, Washakie Formation; likely Br3 in age): FMNH PM 61335, right $\mathrm{m} 1$ trigonid (missing metaconid) and left $\mathrm{m} 2$.

Remarks.-The referred specimen is too incomplete for definitive taxonomic identification. Nevertheless, compared to other similarly sized carnivoraforms from the Washakie Formation, PM 61335 is distinct in its relatively derived form (i.e., open $\mathrm{m} 1$ trigonid and reduced $\mathrm{m} 2$ ) that presages the late Uintan 'Miacis' gracilis from the Myton Member of the Uinta Formation, Utah (Clark, 1939; Friscia and Rasmussen, 2010).

\author{
Eutheria order indet. \\ Genus Simidectes Stock, 1933 \\ aff. Simidectes? \\ Figure 42.1-42.6
}

Description.-The isolated lower molar of FMNH PM 61190 is marked by the low heights of trigonid cuspids in general and the protoconid in particular. The paraconid has approximately the same height as the metaconid, but is only about half as long as the latter (Fig. 42.2, 42.5). The trigonid is rather open in 


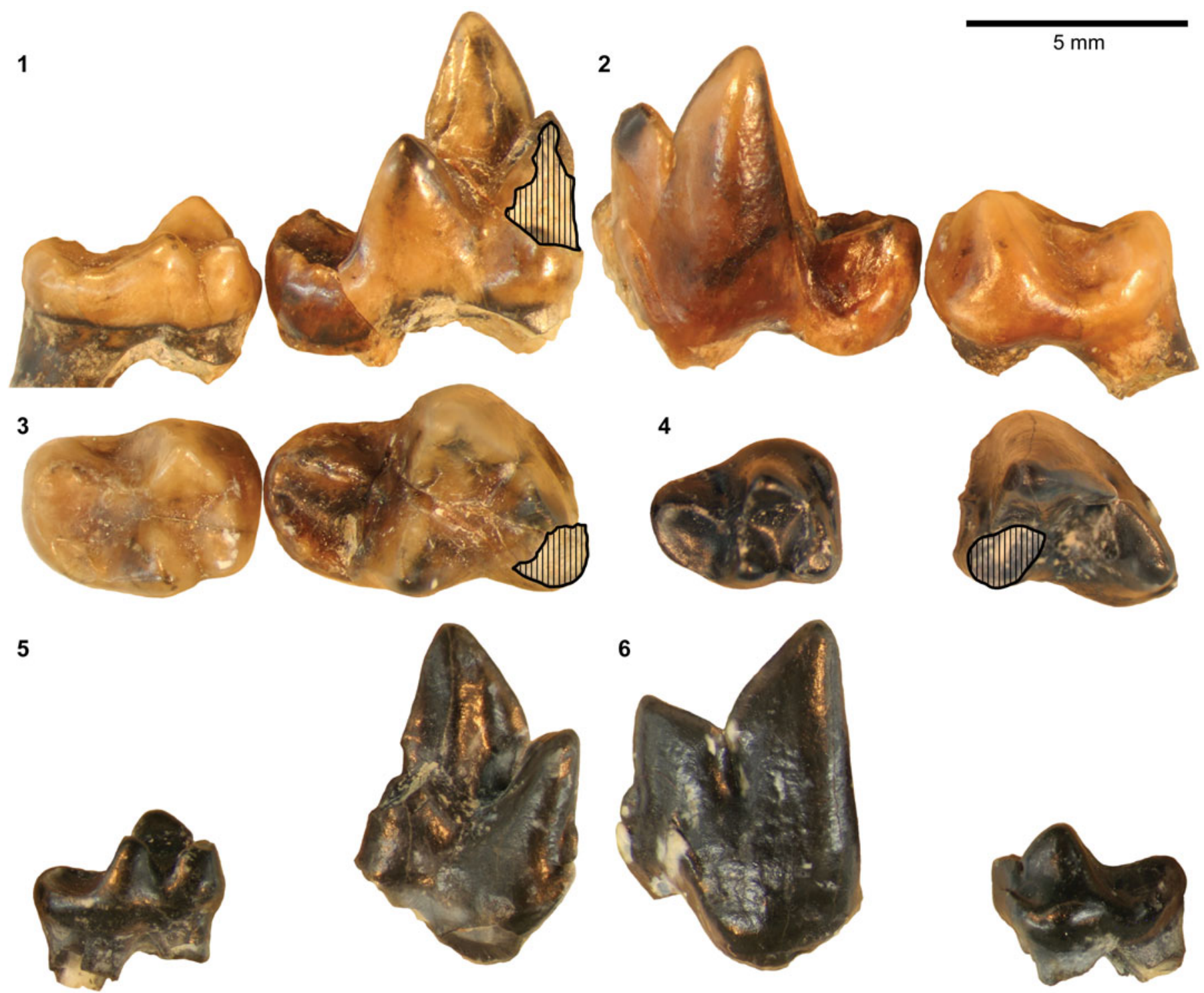

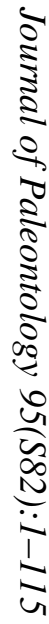

Figure 41. Dental material of undetermined carnivoraforms from the Washakie Formation. FMNH PM 61314 (Carnivoraformes gen. indet., sp. A): (1-3) left m1 and m2 in lingual (1), labial (2), and occlusal (3) views. FMNH PM 61335 (Carnivoraformes gen. indet., sp. B): (4-6) right $\mathrm{m} 1$ trigonid (inverted) and left $\mathrm{m} 2$ in occlusal (4), lingual (5), and labial (6) views. Same $5 \mathrm{~mm}$ scale applies to all images. 
occlusal view $\left(\sim 60^{\circ}\right.$ between the prevallid and postvallid) because the protoconid is positioned well anterior to the metaconid (Fig. 42.1, 42.4). The preprotocristid and postparacristid are separated by a carnassial notch (Fig. 42.3, 42.6). A weakly developed anterolabial cingulid is present. The postparacristid is subtly divided into two segments that are distinguished by a shift in the slope of the ridge (Fig. 42.1, $42.3,42.4,42.6)$. The talonid as a whole is nearly as wide as the trigonid, but the talonid basin is anteriorly narrow because the cristid obliqua is steeply angled on the occlusal plane against the long axis of the tooth. This configuration also results in the strong lingual tilt of the labial wall of the talonid. The sharply defined rim of the talonid basin is separated by a shallow, posterolabially positioned notch into the labial and posterolingual segments as in some hyaenodontids. The labial segment of this rim marks the extent of the hypoconid. The hypoconulid and entoconid are not clearly identifiable as individual cuspids, and appear to have been incorporated into the crenulated posterolingual segment of the talonid rim.

Materials.-FMNH locality JJF 7-24-95-1 (Twka1): FMNH PM 61190, left ?m1.

Remarks.-This peculiar tooth from the late Bridgerian portion of the Washakie Formation shares notable similarities with $\mathrm{m} 1$ of the enigmatic genus Simidectes, known from the Uintan and Duchesnean NALMAs of the Rocky Mountain region, southern California, and Texas (Coombs, 1971). For example, the degree of reduction seen in the trigonid cuspids of FMNH PM 61190 is comparable to those of the m1 of SDSNH 32172 (Simidectes sp.) from the late Uintan/early Duchesnean portion (informally known as "member C") of the Santiago Formation, California (Fig. 42.7-42.9). In addition, the form of the hypoconid, the strong lingual inclination of the prevallid, and the extent of the somewhat crenulated posterolingual rim of the talonid basin (in which the hypoconulid and entoconid are not clearly distinguishable) closely resemble those in SDSNH 32172. These features are also present in some early hyaenodontids (e.g., Prototomus, Gazinocyon, Sinopa, and Galecyon), with which Simidectes appears to share a number of postcranial synapomorphies (preliminary work of Zack and Tomiya, 2016). At present, we are unable to assign FMNH PM 61190 to a specific eutherian order but suggest its possible affinity with the geologically younger Simidectes.

Measurements: $\mathrm{m} 1 \mathrm{~L}=6.23 ; \mathrm{m} 1 \mathrm{~W}=3.69 ; \mathrm{m} 1$ trigonid $\mathrm{L}=3.99$.

\section{Results}

Our examination of mammalian carnivore material from the Washakie Formation-including newly cataloged specimens that had been collected decades ago-resulted in substantial modification and expansion of previous faunal lists (Tables $11,12)$. We now recognize a total of at least 27 taxa from Twka1 and Twka2, tripling the taxic diversity reported in the most recent review of the fauna (McCarroll et al., 1996b). Although many of the taxa are still poorly known, our detailed taxonomic analysis and expanded character and occurrence data sets make it more feasible to statistically reconstruct the trajectory of carnivore diversity within the Washakie Formation. No other intrabasinal record of comparable carnivore diversity exists in North America that captures the period from the late Bridgerian (Br3) to early Uintan (Ui1b) NALMAs.

Cladistic analyses of early carnivoraforms.-With the viverravid Didymictis spp. as the outgroup, we obtained 616 most parsimonious trees (MPTs) with 605 steps, ensemble consistency index of 0.375 , and ensemble retention index of 0.591 (Figs. 43, 44). The alternative analysis, with the limnocyonine hyaenodontid Thinocyon sp. as the outgroup, yielded a strict consensus tree with an identical topology and distribution of synapomorphies for the carnivoraforms, so it will not be discussed further in this paper.

Similar to the results of previous studies including Carnivoraformes (e.g., Wesley-Hunt and Flynn, 2005; Spaulding and Flynn, 2012; Solé et al., 2014; unless otherwise noted, we restrict comparisons to strict consensus trees) and analyses of other clades that integrate fossil and extant taxa (with many fossils represented solely or primarily by dental features), internal nodes, especially those outside crown Carnivora, generally have low nodal support values. In this tree, all Uintan and older taxa, other than the caniform Lycophocyon hutchisoni (from the late Uintan or early Duchesnean of California; Tomiya, 2011), are located outside crown-clade Carnivora, and the branching patterns are broadly concordant with the geologic ages of taxa (Fig. 43).

The genotypic species of Miacis, M. parvivorus, does not clearly form a monophyletic group with any other species that is currently classified in the same genus, implying that the species historically assigned to this genus are still in need of a thorough taxonomic revision (Spaulding and Flynn, 2012; Solé et al., 2016), and many species likely pertain to other distinct lineages (as with species now shown to ally with Lycarion and Neovulpavus). Two distinct, intercontinental clades of early Cenozoic carnivoraforms are identified here (Figs. 43, 44; Table 13). One of them (Clade C), consisting of various species of 'Miacis', Dormaalocyon, Vassacyon, and Vulpavus, is united by a single dental synapomorphy (with a reversal in the lineage leading to Vulpavus). A compatible clade was previously identified in the majority-rule consensus tree of Solé et al. (2016) but not in their strict consensus tree. The other intercontinental clade (Clade B) contains Uintacyon, Quercygale, Oodectes, and Gracilocyon, and is united by derived states of M1 morphology (with some reversals). Grouping Q. angustidens (Filhol, 1872) with Clade D (later-diverging carnivoraforms that include crown-group carnivorans) would increase the minimum tree length by five steps (to a total of 610 steps). Constraining it to form a monophyletic group with crown carnivorans and nimravids, as has been found in some previous studies (Wesley-Hunt and Werdelin, 2005; Spaulding and Flynn, 2012; Solé et al., 2014), would increase the minimum tree length by nine steps (to a total of 614 steps).

Also identified in the strict consensus tree is a clade that includes crown-group carnivorans and originated by the late Bridgerian (Clade D in Figs. 43, 44; Table 13). This clade, which is united by the presence of a 33 anterior cingular cuspulid 
1

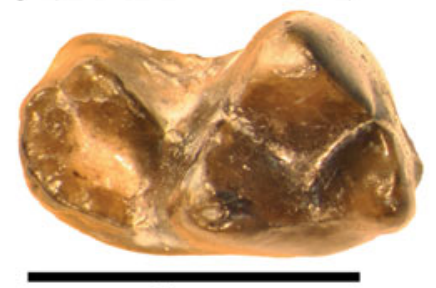

$5 \mathrm{~mm}$
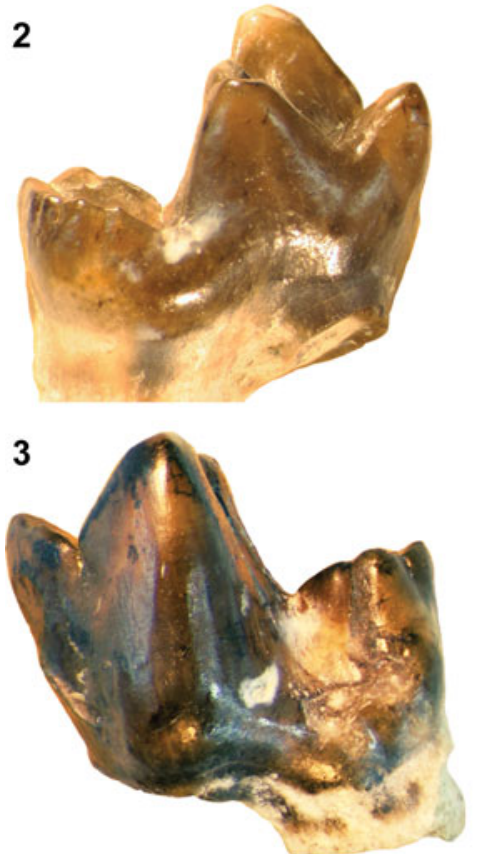

4

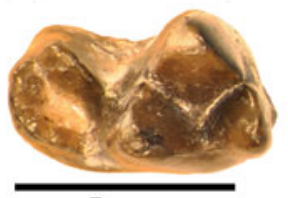

$5 \mathrm{~mm}$

5

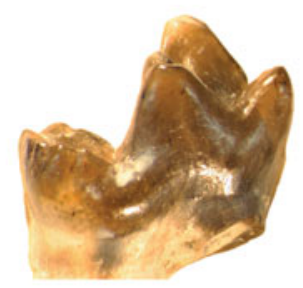

6

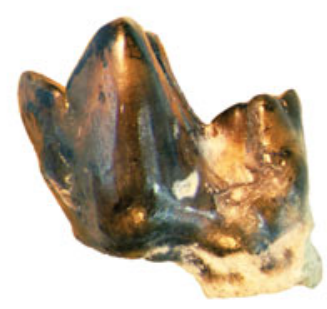

7

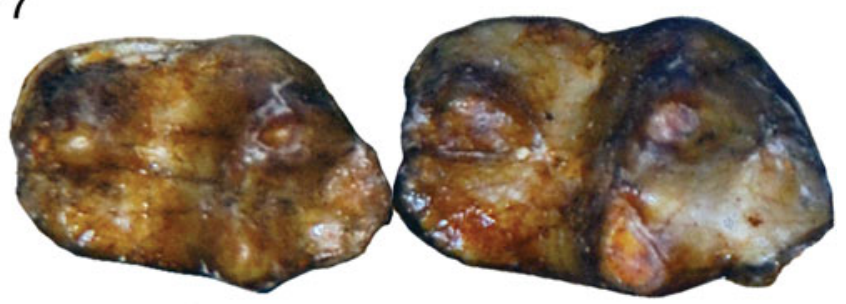

$\mathrm{m} 2$

$\mathrm{m} 1$

8

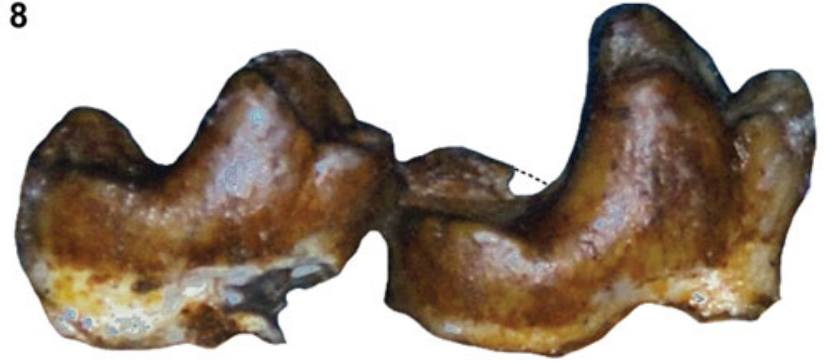

9

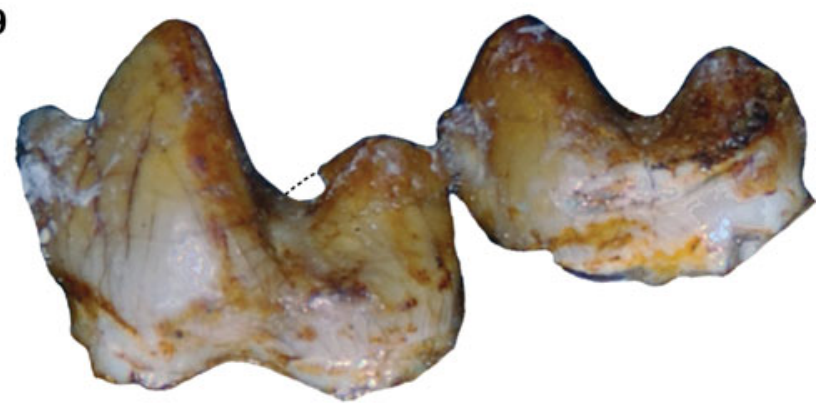

Figure 42. Comparison of FMNH PM 61190 (aff. Simidectes?) from the Washakie Formation with Simidectes Stock, 1933, from the Santiago Formation (California). FMNH PM 61190: (1-6) left $\mathrm{m} 1$ in occlusal $(\mathbf{1}, \mathbf{4})$, lingual $(\mathbf{2}, \mathbf{5})$, and labial $(\mathbf{3}, \mathbf{6})$ views at two different scales. SDSNH 32172 (Simidectes sp.) from late Uintan/early Duchesnean 'member C' of Santiago Formation, San Diego County, California: (7-9) m1-2 in occlusal (7), lingual (8), and labial (9) views. Different 5 mm scales apply to Figure 42.1-42.3 and 42.4-42.9.

(Character 218, State 1; but note subsequent reversals), contains some of the Washakie carnivoraforms. Neovulpavus washakius and N. mecarrolli n. sp., which are known from Twkal and Twka2, respectively, are recovered as sister taxa. Lycarion medius, which occurs in Twka1, is most closely related to 'Miacis' hargeri (so far known only from the Bridger Formation), supporting Matthew's (1909) classification of the two species in the subgenus Lycarion and our recognition of Lycarion as a valid taxon including at least the type species $L$. medius. On the other hand, the current consensus tree does not support exclusive grouping of $N$. washakius and Harpalodon sylvestris, as originally conceptualized in the subgenus Harpalodon of Matthew (1909), long before information on the basicranial morphology of $H$. sylvestris became available (Wang and Tedford, 1994). Clade D also includes 'Miacis' lushiensis, a middle Eocene taxon from east Asia, as one of its early-diverging members (the holotype IVPP V4811 is likely of an Irdinmanhan age, which is approximately equivalent to an early-to middle Uintan age [Chow, 1975; Tsubamoto et al., 2004; Bai et al., 2017]).

Crown-group Carnivora (Clade E in Figs. 43, 44; Table 13) is united by seven cranial, dental, and postcranial synapomorphies, one of which is unique to this clade in the present analysis (absence of posterior bone spur on distal tibia; Character
170, State 1). The taxonomic composition and relationships among crown carnivorans recovered here closely match those of Tomiya (2011) and Tomiya and Tseng (2016), except for the exclusion of Quercygale angustidens, Harpalodon sylvestris, 'Miacis' gracilis, 'M.' uintensis, and Tapocyon robustus; of these, all but $Q$. angustidens are still recovered as the closest outgroups to the crown group. Exclusion of the two nimravids from Carnivora- as has been suggested by some recent studies (e.g., Spaulding and Flynn, 2012; Solé et al., 2014, 2016; but see Wesley-Hunt and Werdelin, 2005; Tomiya, 2011; Wang and Zhang, 2015)—would increase the minimum tree length by nine steps and place them near the origin of crown-group Carnivora.

Carnivore diversity dynamics within Washakie Basin.-Of the four multispecies occupancy-detection models examined, Models 1 and 4 had relatively high posterior probabilities, while Models 2 and 3 received substantially less support than the most probable model as measured by the Bayes factors (Jeffreys, 1961; Table 15). Estimates of parameters and derived values were broadly similar between the most probable models (Table 16). Under the most probable model, Model 4, the $95 \%$ highest posterior density intervals (HPDIs) 
Table 11. Updated list of mammalian carnivores from Twka1 and Twka2.

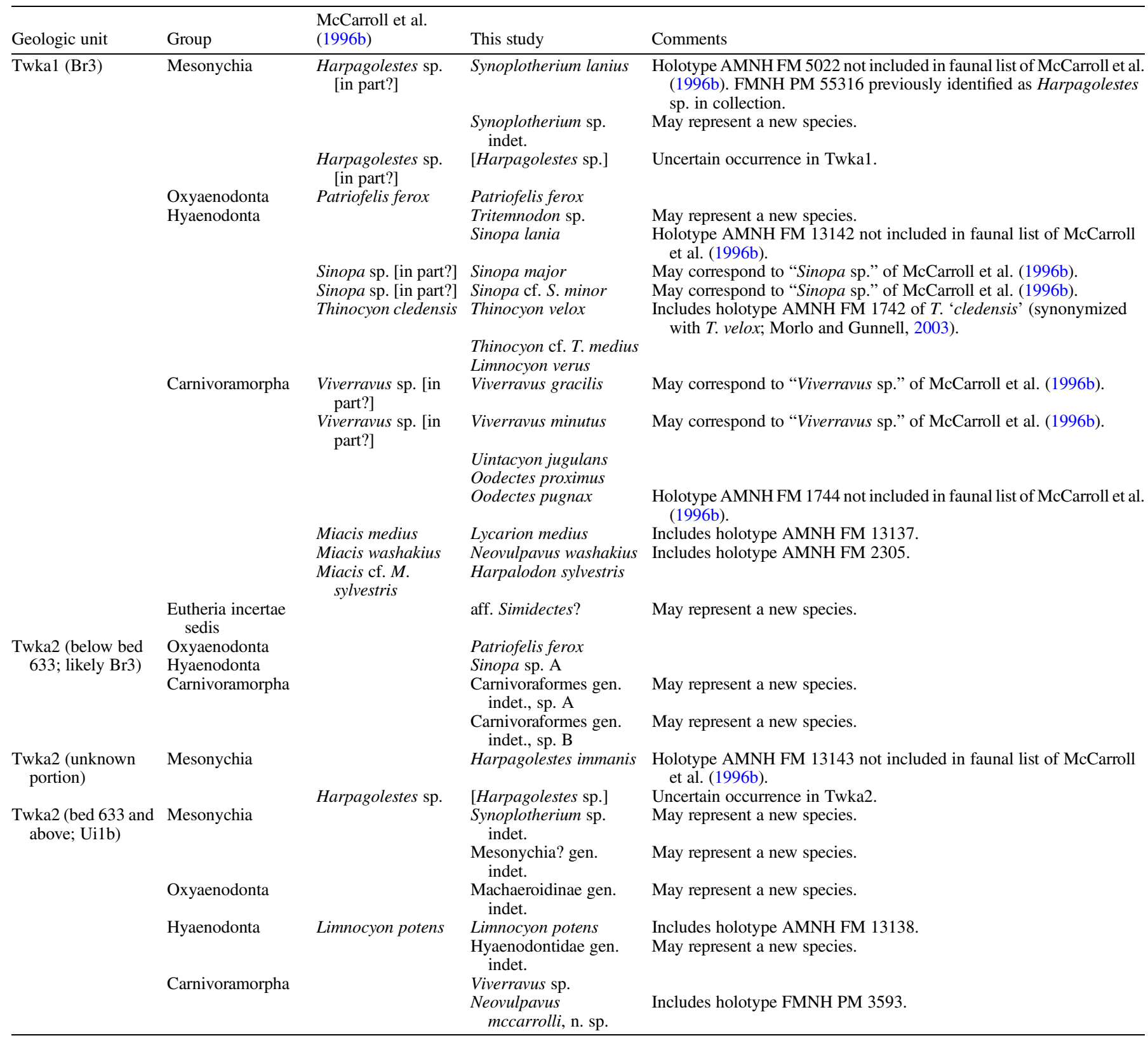

for the 'community' mean effect $\left(\overline{\beta_{\psi 1}}\right)$ and all species-specific effects $\left(\beta_{\psi 1, k}\right)$ of the occupancy covariate contained the value of zero (Fig. 45.3), but the overall pattern suggests a generally positive association of occupancy probability with locality-group area for the detected species (i.e., blue lines in Fig. 45.3 are predominantly in the positive region). With this model, estimates of community mean occupancy probabilities $(\bar{\psi})$ were poorly constrained for all locality groups, ranging from near 0 to near 1 . In comparison, the simple model without any occupancy/detection covariate (Model 1) yielded a narrower range of estimated community mean occupancy probabilities, mostly below 0.38; this pattern was reflected in the lower values of inferred species richness for Model 1 compared to Model 4 (Fig. 45.1; Table 16). Estimates of the community mean detection probability $(\bar{p})$ were consistently low for the two most probable models, rarely exceeding 0.03 .

Under the two most probable models, the estimated number of carnivorous species occupying the study system ranged from 28 to 100 in total (HPDI), and much of this uncertainty existed for each model rather than between the models. Likewise, estimates of the species richness in individual locality groups were poorly constrained, with the upper and lower bounds of 95\% HPDI differing by factors of at least 1.75 and as much as 5.8. However, the directions of shifts in species richness among locality groups were consistent across all models (Fig. 45.1, 45.2). Taking weighted (by model posterior probabilities) averages of all four models, Bayesian interpretation of the estimated species richness ratios among locality groups suggests: (1) $72 \%$ probability of increase and a median shift of 
Table 12. Summary of published occurrences of late Bridgerian to early Uintan carnivores in North America. See text for synonyms. *Includes occurrence in Washakie Basin, Wyoming. Uncertain occurrences (in terms of age, stratigraphic position, or taxonomic identity) are marked as "?". Angle brackets indicate unverifiable occurrences reported in faunal lists that cite neither specimens nor original publications describing them. ${ }^{1}$ We follow Gustafson (1986, p. 48) and consider 'Uintacyon major' Matthew, 1909, to be a junior synonym of 'Miacis' bathygnathus Scott, 1888 (= 'Uintacyon' bathygnathus of Matthew, 1909); because Bryant (1992) reassigned 'U. major' to the genus Miocyon, we accept M. bathygnathus as its valid name. ${ }^{2}$ May be based on same specimens as "cf. Tritemnodon" of Eaton (1982). ${ }^{3}$ Based on AMNH FM 12160 from Bridger C (previously identified in collection as Synoplotherium), a calcaneum that is closely comparable to that of AMNH FM 12643 (cf., Matthew, 1909) from Bridger B. ${ }^{4}$ Supposed occurrence may be in Bridgerian or Uintan portion of Washakie Formation in Sand Wash Basin, Colorado. ${ }^{5}$ We tentatively consider Localities 3 and 20 of West and Dawson (1975) to be Br3 in age based on occurrences of Hyopsodus and Orohippus (but see Murphey et al., 2018) and absence of taxa that are indicative of a Uintan age. ${ }^{6}$ Represented by SDSNH 50575. ${ }^{7}$ Reported as "Tapocyon occidentalis" based on unspecified material. ${ }^{8}$ Reported as "Tapocyon sp." and corresponds to undescribed specimen SDSNH 49600.

References: C, Campisano et al. (2014) for Whistler Squat Quarry, Devil's Graveyard Formation, Texas; DC, Dawson and Constenius (2018) for Kishenehn Formation, Montana; E1, Eaton (1982) for Blue Point marker, Wyoming; E2, Eaton (1985) for lower portion of Tepee Trail Formation, Wyoming, tentatively considered Uilb in age (see Gunnell et al., 2009); FG, Flynn and Galiano (1982) for Bone Bed A of Tepee Trail Formation, Wyoming; G1, Gazin (1946); G2, Gazin (1957); G3, Gazin (1976); GE, Gunnell et al. (2009) for North America; L, Leidy (1873) for "Henry's Fork" (presumably Twin Buttes Member of Bridger Formation); M, Matthew (1909) for "Upper Bridger" (UB = Twin Buttes Member), "Lower Washakie" (= Twka1), and "Upper Washakie" (= Twka2); ME,

McCarroll et al. (1996b) for Washakie Formation, Wyoming; MG, Morlo and Gunnell (2003); MK, Murphey and Kelly (2017) for Turtle Bluff Member (Bridger E) of Bridger Formation; S, Scott (1888); SE, Stucky et al. (1996) for Washakie Formation in Sand Wash Bain, Colorado; T, Tomiya (2013) for Friars Formation, California; TE, this study; W, Walsh (1996b); WD, West and Dawson (1975) for Washakie Formation in Sand Wash Basin, Colorado; WT, Wang and Tedford (1994); Z1, Zack (2019a; USNM PAL 173514); Z2, S.P. Zack, unpublished data on SDSNH 76932.

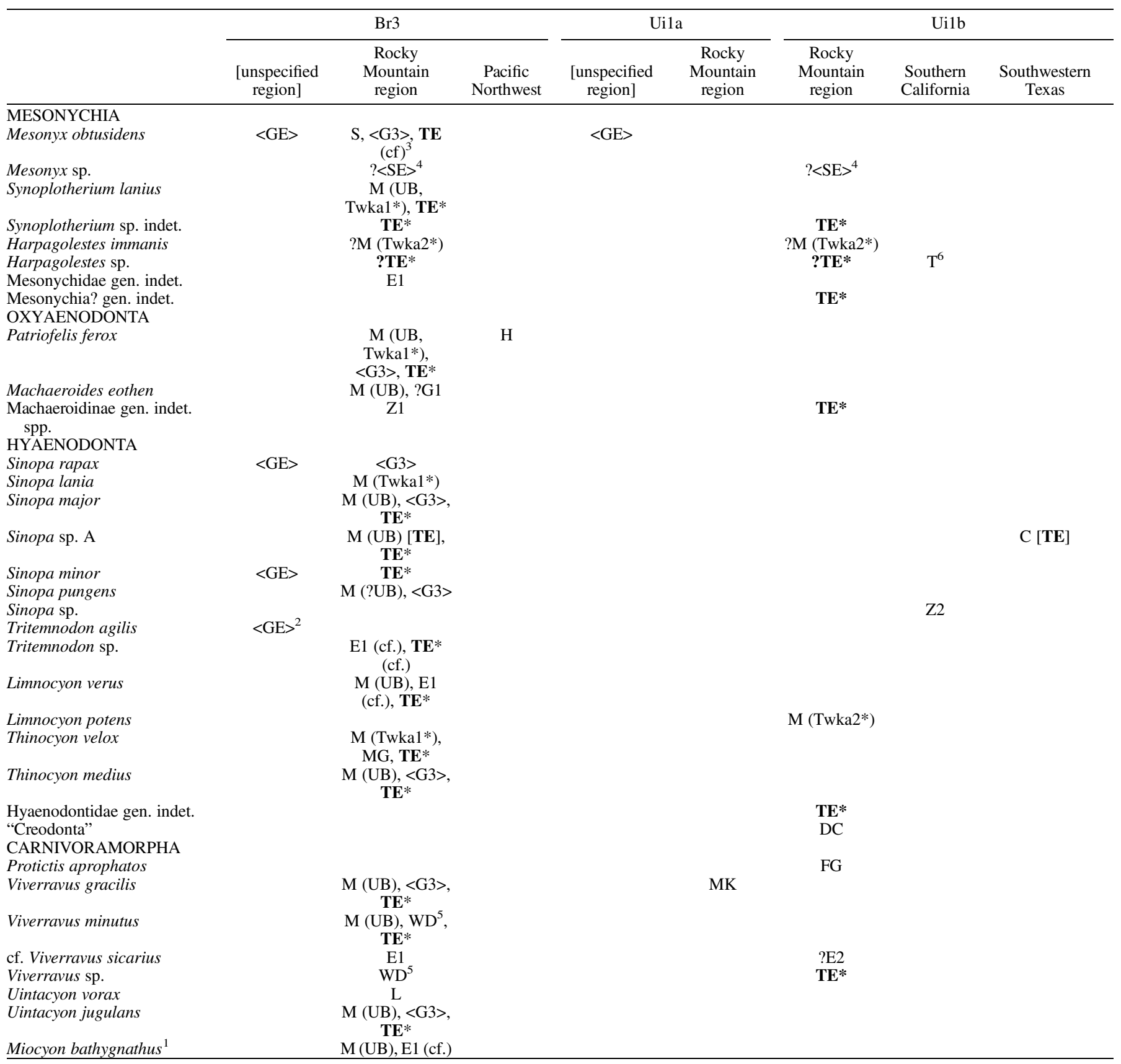


Table 12. Continued

\begin{tabular}{|c|c|c|c|c|c|c|c|c|}
\hline & \multicolumn{3}{|c|}{$\mathrm{Br} 3$} & \multicolumn{2}{|c|}{ Ui1a } & \multicolumn{3}{|c|}{ Uilb } \\
\hline & $\begin{array}{l}\text { [unspecified } \\
\text { region] }\end{array}$ & $\begin{array}{l}\text { Rocky } \\
\text { Mountain } \\
\text { region }\end{array}$ & $\begin{array}{c}\text { Pacific } \\
\text { Northwest }\end{array}$ & $\begin{array}{l}\text { [unspecified } \\
\text { region] }\end{array}$ & $\begin{array}{l}\text { Rocky } \\
\text { Mountain } \\
\text { region }\end{array}$ & $\begin{array}{l}\text { Rocky } \\
\text { Mountain } \\
\text { region }\end{array}$ & $\begin{array}{l}\text { Southern } \\
\text { California }\end{array}$ & $\begin{array}{c}\text { Southwestern } \\
\text { Texas }\end{array}$ \\
\hline Oodectes proximus & & TE* & & & & & & \\
\hline Oodectes pugnax & & M (Twka1) & & & & & & \\
\hline Oodectes sp. & $<\mathrm{GE}>$ & & & & & & & \\
\hline Neovulpavus washakius & & $\begin{array}{l}\text { M (Twka1), } \\
\text { TE* }^{*}\end{array}$ & & & & & & \\
\hline Carnivoraformes "genus A" & & & & & & & $\mathrm{T}$ & \\
\hline Walshius pacificus & & & & & & & $\mathrm{T}$ & \\
\hline Neovulpavus mccarrolli n. sp. & & & & & & TE*, ?FG & & \\
\hline $\begin{array}{l}\text { "cf. Procynodictis sp." [aff. N. } \\
\text { mccarrolli?] }\end{array}$ & & & & & & & $\mathrm{T}$ & \\
\hline $\begin{array}{l}\text { Carnivoraformes gen. indet., } \\
\text { sp. B }\end{array}$ & & $\mathbf{T E}^{*}$ & & & & & & \\
\hline "Miacidae" gen. indet. & & E1 & & & & & & $\mathrm{C}$ \\
\hline Amphicyonidae? gen. indet. & & $?<\mathrm{SE}>^{4}$ & & & & $?<\mathrm{SE}>^{4}$ & & \\
\hline $\begin{array}{l}\text { EUTHERIA INCERTAE SEDIS } \\
\text { aff. Simidectes? }\end{array}$ & & TE* & & & & & & \\
\hline
\end{tabular}

$+22 \%$ in inferred species richness (versus $+400 \%$ in detected species richness, not taking into account imperfect detection) from Locality Group 1 (Roehler's [1973] beds 569-579) to Locality Group 2 (Roehler's [1973] beds 580-632); (2) 94\% probability of decrease and a median shift of $-39 \%$ in inferred species richness (versus $-69 \%$ in detected species richness) from Locality Group 2 to Locality Group 3 (Roehler's [1973] beds 633-675); and (3) 72\% probability of decrease and a median shift of $-23 \%$ in inferred species richness (versus $+25 \%$ in detected species richness) between Locality Group 1 and Locality Group 3. Of these inferred shifts in species richness, the decline from Locality Group 2 to Locality Group 3, which corresponds to the $\mathrm{Br} 3-\mathrm{Uilb}$ transition, was most consistently estimated across all models, whereas there was much uncertainty in the magnitude of diversity shift between Locality Group 1 and either Locality Group 2 or 3 (Fig. 45.2; Table 15).

We repeated modeling with more finely divided locality groups but encountered considerable difficulty in achieving convergence of MCMC chains to their stationary distributions, presumably because of the sparseness of detection data. Consequently, we did not pursue that secondary analysis further.

Temporal dynamics of vertebrate co-detection patterns.Correlation networks depicting locality-level associations and dissociations of taxonomic groups are presented in Figure 46, along with frequencies of their observed locality occupancy. Only a few strong correlations, all positive, were detected in Locality Group 1, which contains the sparsest detection data (of the 10 observed taxonomic groups, seven were detected at five or fewer out of 29 localities). In comparison, Locality Groups 2 and 3 (with more detection data) are characterized by many strong, generally positive correlations, although the two networks differ considerably in patterns of co-detection.

Artiodactyls, primates (including plesiadapiforms), 'condylarths' (solely represented by the hyopsodontid Hyopsodus), and rodents show relatively strong positive correlations in Locality Groups 1 and 2 (Fig. 46.1, 46.2). It is worth noting that associations of these taxonomic groups were maintained while their locality occupancies increased substantially from Locality Group 1 to Locality Group 2. This subnetwork collapses in Locality Group 3, leaving only artiodactyl-rodent and artiodactyl-primate pairs in positive associations (Fig. 46.3). In all locality groups, perissodactyls represent the most common vertebrate group as measured by the locality-occupancy rates, but they do not exhibit consistent associations or dissociations with other taxa, except for the moderately positive correlation with the aquatic and semiaquatic non-mammalian vertebrates.

The positions of mammalian carnivores and their co-detection patterns with other taxa appear fluid. In Locality Group 2, hyaenodontans and carnivoramorphans are relatively common and strongly positively associated with several groups of primarily small mammals. In Locality Group 3, these two carnivore groups have lost moderately positive correlations with pantolestans, primates, and 'condylarths' (which are apparently absent). Detection of mesonychids is generally not strongly correlated with those of other taxa. Somewhat similarly, oxyaenodontans do not show strong associations with non-carnivorous mammals in Locality Group 2, in which this clade is represented only by the large oxyaenid Patriofelis. In contrast, oxyaenodontans are moderately associated with rodents, artiodactyls, and dinoceratans (uintatheres) in Locality Group 3, but it should be noted that their record in that locality group consists of a single occurrence of a small machaeroidine (FMNH PM 1506). 


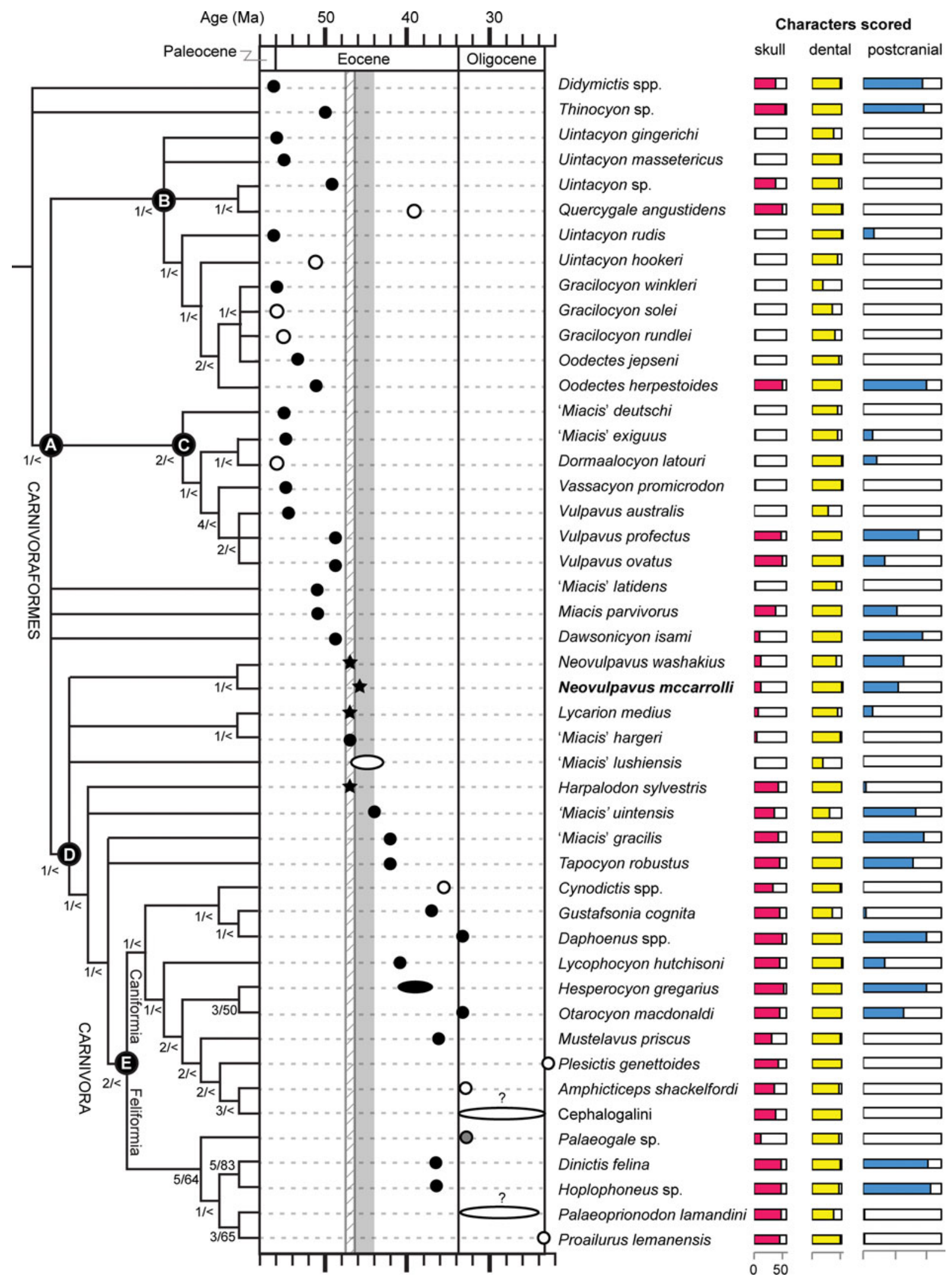


Figure 43. Cladistic analysis of early carnivoraform relationships. Bremer- and bootstrap-support values above $50 \%$ are reported for each node of strict consensus of 616 most-parsimonious trees (from analysis with Didymictis spp. as the outgroup). Labeled nodes are discussed in text and listed in Table 13. For each taxon, its first appearance date is indicated with black (North American taxa), white (Eurasian taxa), or gray (known from both North America and Eurasia); numbers of scored characters for different anatomical regions shown in columns on right. Taxa known from the Washakie Formation marked by stars, and approximate temporal ranges for Twka1 and Twka2 represented by hatched and gray band, respectively. See Table A5 for sources of approximate first appearance dates.

Bootstrap estimates of the integration metric (relative standard deviation of eigenvalues of the correlation matrix) based on resampling of 29 randomly selected localities are not tightly constrained, but a broad trend is discernible. The estimates are indistinguishable between Locality Groups 1 (median $=0.288,95 \%$ $\mathrm{CI}=[0.227,0.406])$ and $2($ median $=0.348,95 \% \mathrm{CI}=[0.275$, $0.446]$ ), but declines significantly and substantially for Locality Group 3 (median $=0.273,95 \% \mathrm{CI}=[0.218,0.415])$.

\section{Discussion}

Phylogeny of early carnivoraforms. - The cladistic relationships among early-diverging carnivoraforms are considerably better resolved in our strict consensus tree (Figs. 43, 44) than in that of Solé et al. (2016, fig. 7a), from which we modified and expanded their character matrix (and which, in turn, had been modified and expanded from matrices of Wyss and Flynn, 1993; Wesley-Hunt and Flynn, 2005; Spaulding and Flynn, 2012; and others; see Materials and Methods). Given that the strict consensus topology recovered here is broadly compatible with that of Solé et al. (2014), despite our choice of different outgroup taxa, we suspect that the addition of several poorly known ingroup taxa in the later analysis by Solé et al. (2016) led to the loss of topological resolution in their strict consensus tree. These potentially problematic taxa were excluded from our analysis because of their incompleteness, as detailed in Materials and Methods. It is also possible that: (1) inclusion of additional Paleogene carnivorans (cf., Tomiya, 2011; Tomiya and Tseng, 2016) in our expanded matrix; (2) improved sampling of morphological characters (e.g., through reidentification of FMNH PM 3869 as Neovulpavus washakius); and (3) our modifications of character-state definitions and scores-the combination of which resulted in a substantial portion $(34 \%)$ of our character matrix data being non-identical to those of Solé et al. (2016)—contributed to the greater resolution of cladistic relationships in the present study.

Resolution of the deepest nodes within Carnivoraformes and future testing of carnivoramorphan monophyly would benefit from a more extensive analysis of laurasiatherian outgroups and a comprehensive phylogenetic systematic study of Uintacyon and its close allies. At least one of the carnivoraform "synapomorphies" identified in the present analysis, namely the presence of M3 (Table 13), almost certainly will be recovered as a symplesiomorphy when more near-outgroup taxa or a broader array of laurasiatherians are considered (cf., Spaulding and Flynn, 2012; Zack, 2019a). A well-developed deltopectoral crest of the humerus, which is present in several early oxyaenodontans, also may have a phylogenetically deeper origin than Carnivoraformes, although it might instead be convergent and tied to independent locomotor specializations (Zack, 2019a).

The sequences of divergences of better-studied early carnivoraforms and crown-group Carnivora in our strict consensus tree are broadly compatible with those in the strict consensus tree of Solé et al. (2014). Specifically, both trees are consistent with the nested pattern of:

(Vulpavus spp., Miacis parvivorus, Dawsonicyon isami, (Neovulpavus washakius, (Harpalodon sylvestris, ('Miacis' gracilis, Tapocyon robustus, crown-group Carnivora))));

in the Newick tree format (note ' $M$.' gracilis here corresponds to the same OTU as "Procynodictis vulpiceps" in Solé et al., 2014; see Tomiya, 2011, 2013). Also supported by both trees are close relationships among species of Gracilocyon and Oodectes (but with the latter as paraphyletic, with O. jepseni (Guthrie, 1967a) closer to species of Gracilocyon than to the genotype species $O$. herpestoides), and early divergences within Carnivoraformes of these taxa and various species of Uintacyon. However, the grouping of Gracilocyon and Oodectes with Uintacyon and Quercygale is unique to our consensus tree. Close relationships among species in these lineages may partly explain the historically unstable generic classification of Oodectes pugnax (originally Uintacyon pugnax Wortman and Matthew, 1899).

The most notable difference between our finding and the results of other recent studies is the close affinity of the late Eocene European taxon Quercygale angustidens with the early-diverging carnivoraform Uintacyon instead of crowngroup carnivorans (cf., Wesley-Hunt and Werdelin, 2005; Tomiya, 2011; Spaulding and Flynn, 2012; Solé et al., 2016). The relationship recovered here instead supports the hypothesis of Flynn and Galiano (1982). We suspect that this marked shift in topology is largely attributable to the incorporation-for the first time in this study - of associated cranial (including basicranial) and dental character data for a species of Uintacyon ("Uintacyon sp." of Bown, 1982). One difficulty with the previously hypothesized position of Quercygale near crown-group carnivorans is that, assuming the early Eocene $Q$. smithi Solé, 2014 is indeed a species of Quercygale, it implies several long ghost lineages surrounding the origin of Carnivora (Solé et al., 2016). In contrast, the newly hypothesized position for Quercygale is more congruent temporally. Again, a comprehensive phylogenetic systematic study of Uintacyon and its possible close relatives, including middle Eocene taxa such as Q. helvetica (Rütimeyer, 1862), Miocyon, and Simamphicyon (Viret, 1942; Beaumont, 1965a; Bryant, 1992; Tomiya and Tseng, 2016), would shed much needed light on this issue.

Since both taxonomic diagnosis and cladistic analyses provide compelling evidence for elevating the subgenus Lycarion of Matthew (1909) to the generic level, we have done so for at least $L$. medius. We have not yet done so for the other species that Matthew (1909) assigned to this taxon, until its entire hypodigm can be examined in greater detail. Initial observation of the paratype YPM VP 011839 of 'Miacis' hargeri Wortman, 1901a 


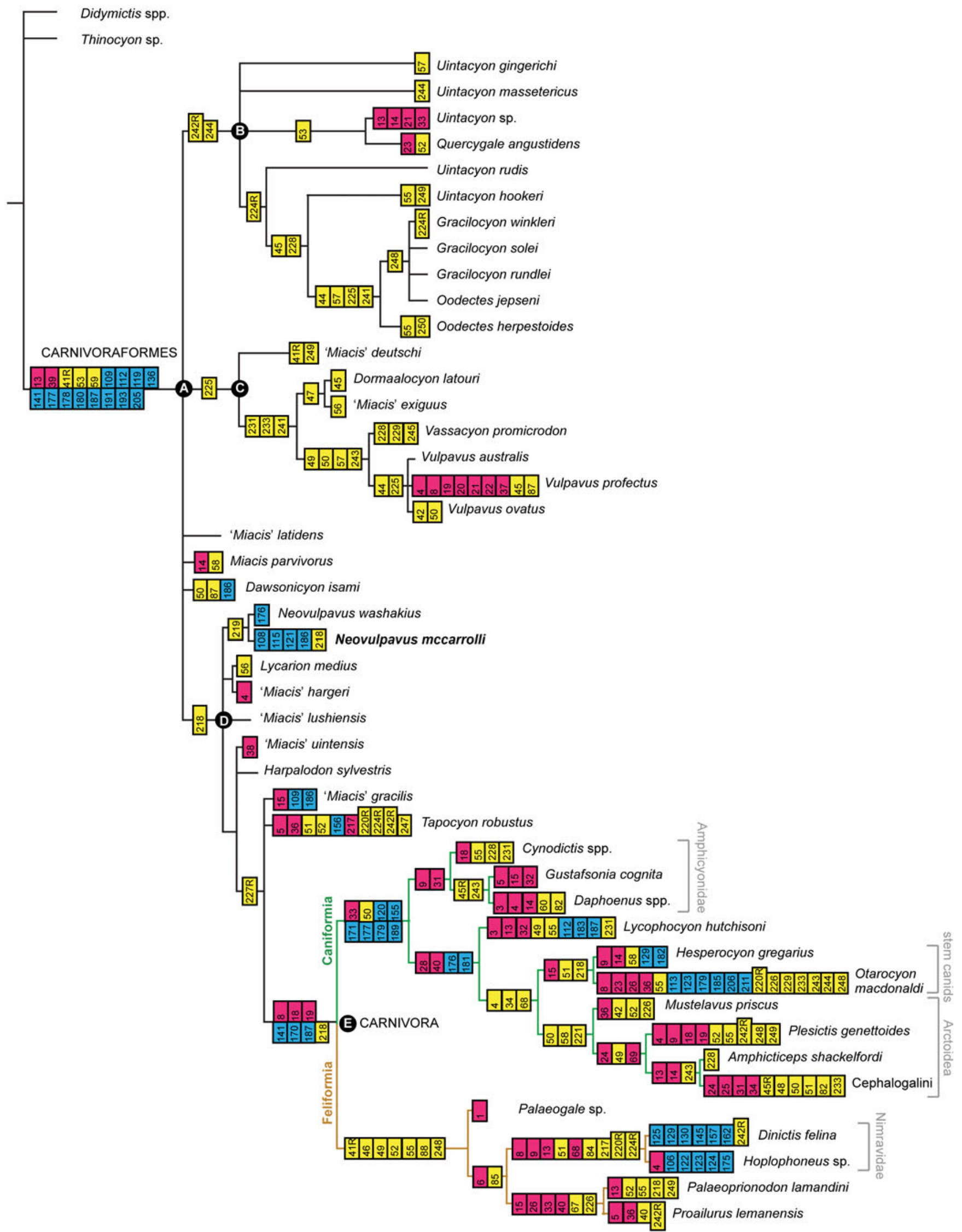

Figure 44. Apomorphies associated with early carnivoraform clades. Synapomorphies and autapomorphies common to all 616 most-parsimonious trees (with Didymictis spp. as the outgroup) are plotted on strict consensus tree. Characters pertaining to different anatomical regions are color-coded (magenta, skull; yellow, dental; light blue, postcranial). 
Table 13. Synapomorphies (for select carnivoraform clades) common to all most-parsimonious trees. *Number of operational taxonomic units (OTUs) that are: (1) in the selected clade and possess the listed synapomorphy; (2) in the selected clade and whose character states could be scored as other than "?" for the listed character; and (3) in the selected clade. For original descriptions of character states, see Supplementary Data 2.

\begin{tabular}{|c|c|c|c|c|}
\hline Clade & Synapomorphy & $\begin{array}{l}\text { Character } \\
\text { (state) }\end{array}$ & $\begin{array}{l}\text { Unique to } \\
\text { clade? }\end{array}$ & $\begin{array}{l}\text { OTUs: with trait/with data/ } \\
\text { in clade* }\end{array}$ \\
\hline Clade A & Blunt and round mastoid process & 13(1) & yes & $17 / 24 / 45$ \\
\hline \multirow[t]{16}{*}{ (Carnivoraformes) } & Clearly-defined and deep fossa for tensor tympani & 39(1) & yes & $23 / 23 / 45$ \\
\hline & M1 lingual cingulum continuous around base of protocone & $41 \mathrm{R}(1)$ & yes & $28 / 41 / 45$ \\
\hline & M3 present & $53(0)$ & yes & $22 / 36 / 45$ \\
\hline & $\mathrm{m} 2$ with low trigonid and short talonid & $59(1)$ & yes & $40 / 40 / 45$ \\
\hline & Presence of humeral deltopectoral crest & $109(0)$ & yes & $14 / 17 / 45$ \\
\hline & Comparable heights of humeral head and greater tuberosity & $112(1)$ & yes & $9 / 15 / 45$ \\
\hline & Posterior orientation of distolateral margin of humerus & $119(1)$ & yes & $10 / 15 / 45$ \\
\hline & Absence of lateral groove on ulnar shaft & $136(1)$ & yes & $14 / 14 / 45$ \\
\hline & Small radial articular surface with scaphoid & 141(1) & yes & $6 / 11 / 45$ \\
\hline & Dorsoventrally low position of astragalar head in distal view & $177(1)$ & yes & $11 / 16 / 45$ \\
\hline & Absence of astragalar fossa on lateral edge in posteroventral quadrant & $178(1)$ & yes & $13 / 15 / 45$ \\
\hline & $\begin{array}{l}\text { Astragalar head lacking proximomedial extension of articular facet onto } \\
\text { astragalar neck }\end{array}$ & $180(1)$ & yes & $16 / 16 / 45$ \\
\hline & Absence of astragalar cotylar fossa & $187(1)$ & yes & $11 / 16 / 45$ \\
\hline & Calcaneum with round cuboidal facet & 191(1) & yes & $11 / 12 / 45$ \\
\hline & Absence of fibular facet on calcaneum & 193(1) & yes & $12 / 12 / 45$ \\
\hline & Narrow ventral surface of ilium & 205(1) & yes & $7 / 7 / 45$ \\
\hline \multirow[t]{2}{*}{ Clade B } & $\begin{array}{l}\text { Approximate alignment of M1 parastylar ridge, anterior base of paracone, } \\
\text { and protocone apex }\end{array}$ & $242 \mathrm{R}(1)$ & no & $7 / 10 / 11$ \\
\hline & Fusion of M1 paracone and metacone bases & 244(0) & no & $9 / 10 / 11$ \\
\hline Clade C & Prominent p4 posterolabial cingulid & $225(1)$ & no & $4 / 7 / 7$ \\
\hline Clade D & Presence of $\mathrm{p} 3$ anterior cingular cuspulid & 218(1) & no & $10 / 22 / 24$ \\
\hline Clade E (crown & Small postorbital process & $8(1)$ & no & $9 / 12 / 15$ \\
\hline \multirow[t]{6}{*}{ Carnivora) } & Fenestra cochleae positioned posterior to mastoid tubercle & $18(0)$ & no & $11 / 13 / 15$ \\
\hline & $\begin{array}{l}\text { Foramen ovale and alisphenoid canal separated by at least diameter of } \\
\text { alisphenoid canal }\end{array}$ & $19(0)$ & no & $12 / 13 / 15$ \\
\hline & Large radial articular surface with scaphoid & $141(0)$ & no & $5 / 5 / 15$ \\
\hline & Absence of posterodistal bone spur on tibia & $170(1)$ & yes & $5 / 5 / 15$ \\
\hline & Presence of cotylar fossa on astragalus & $187(0)$ & no & $5 / 6 / 15$ \\
\hline & Absence of $\mathrm{p} 3$ anterior cingular cuspulid & $218(0)$ & no & $11 / 14 / 15$ \\
\hline
\end{tabular}

by one of us (ST) raised concern about its taxonomic identity and the association of elements cataloged under the same number (note other cases of questionable elemental associations in the YPM 'Marsh Collection' of Bridger mammals; Matthew, 1909 , p. 446, 449, 538). As discussed above, we consider one of the specimens identified by Thorpe (1923a) to represent Harpalodon sylvestris instead of ' $M$.' hargeri, and note that taxonomic identification of other fragmentary YPM specimens should be viewed with caution.

Four species of late Bridgerian to early Uintan carnivoraforms from the Rocky Mountain region (Lycarion medius, 'Miacis' hargeri, Neovulpavus washakius, and N. mccarrolli n. sp.), along with 'Miacis' lushiensis from the middle Eocene of China, were found to be early-diverging members of Clade D (Figs. 43, 44). The North American taxa appear to show differential dietary adaptations: Lycarion medius is characterized by moderately large posterior molars for enhanced grinding, whereas $N$. washakius and N. mccarrolli n. sp. exhibit progressive elongation of $\mathrm{p} 4$ with trenchant cuspulids and deep notches, likely reflecting more carnivorous diets (Friscia et al., 2007; Hartstone-Rose, 2011). Thus, intercontinental dispersal and ecological speciation may have been important drivers of evolution in the lineage leading to the origin of crown-group carnivorans.

A limitation of previous studies of carnivoramorphan phylogeny, which persists in the present analysis, is the complete lack of postcranial data for early unquestionable feliforms. This is potentially problematic for disentangling the relationships of lineages surrounding the origin of crown-group Carnivora, given the value of postcranial morphology in cladistic analysis of carnivoramorphans (Spaulding and Flynn, 2012). A detailed comparative study of postcranial specimens attributed to Eurasian Paleogene feliforms (e.g., Schlosser, 1888; Matthew and Granger, 1924; Hunt, 1998; Egi et al., 2016) may be a key to resolving several longstanding phylogenetic issues, such as the relationship of Nimravidae to crown-group carnivorans. Accurate resolution of taxa that fall within the Carnivora remains an important challenge for temporal calibration of carnivoran and mammalian phylogeny (Tomiya, 2011).

Comparison with contemporaneous carnivore assemblages. Mammalian faunal interchange between North America and other northern continents is generally thought to have been lower during the middle Eocene than in the late Paleocene to early Eocene (Woodburne, 2004; Woodburne et al., 2009). The few carnivores that are thought to have dispersed into or out of North America during the middle Eocene include the mesonychian Harpagolestes (Szalay and Gould, 1966; Jin, 2005), the hyaenodontans Propterodon and Sinopa (Morlo et al., 2014; Zack, 2019b), and the oxyaenid Apataelurus (Zack, 2019b). Late Bridgerian to early Uintan carnivore assemblages of North America in particular are distinct in retaining relictual lineages of carnivoramorphans (e.g., Viverravus, Uintacyon) that had disappeared earlier from elsewhere in the Holarctic. However, there are hints of further intercontinental ties in the carnivore assemblages of the central Rocky Mountain region. For example, the premolars of the holotype IVPP V4811 of 'Miacis' lushiensis from the middle Eocene of China (Chow, 1975) are especially similar 


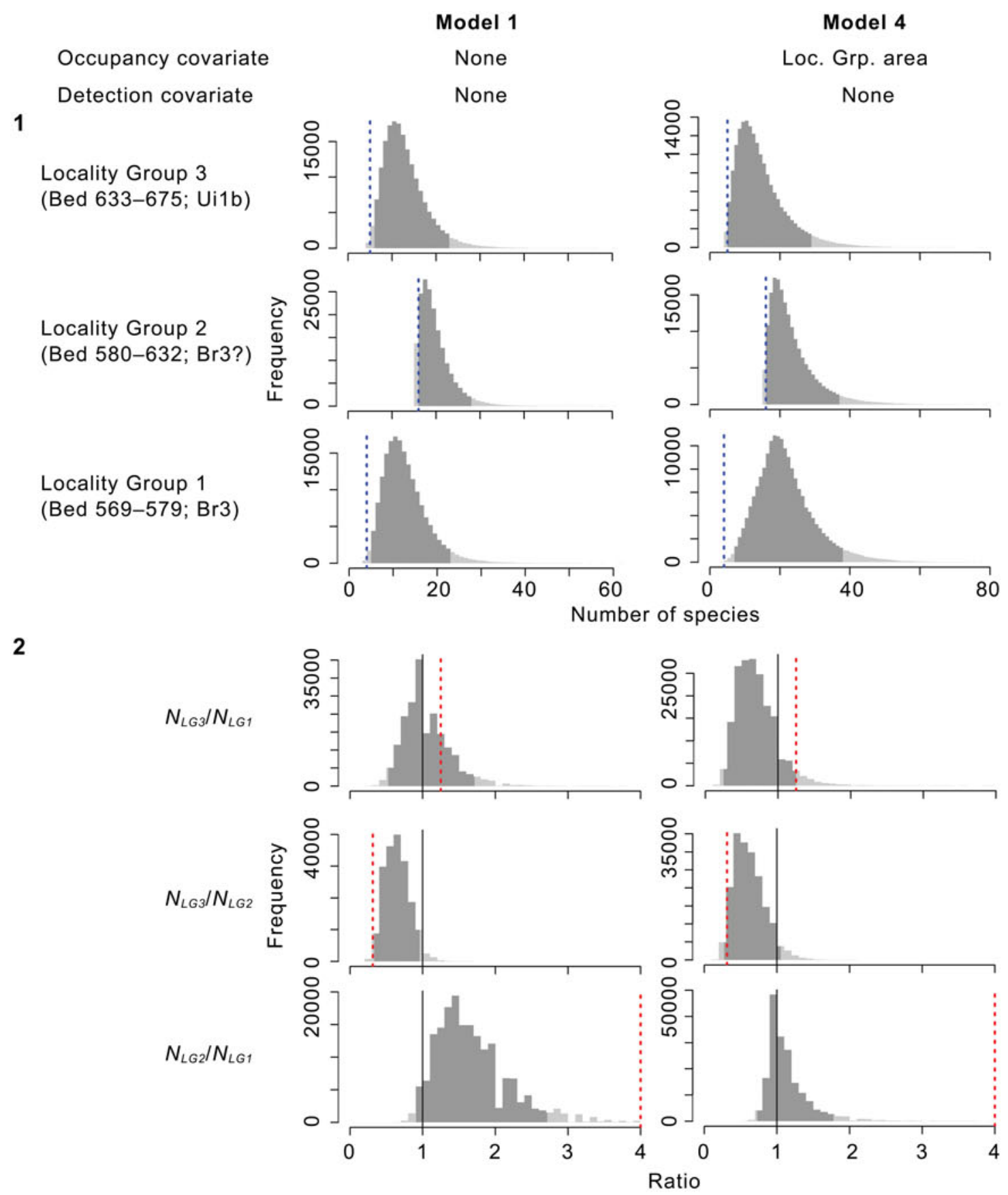

3

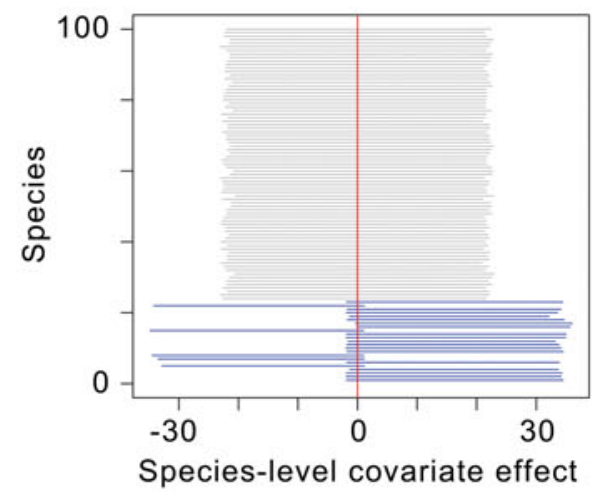


Figure 45. Carnivore diversity dynamics across three locality groups of the Washakie Formation. (1-2) Bayesian estimates (MCMC posterior samples) of species richness (1; detected and undetected species combined) and proportional shifts in richness $(\mathbf{2})$ presented for the two most probable community occupancy models. Blue- and red-dashed lines mark observed (i.e., detected) species richness and observed proportional shifts in richnesses, respectively, which do not take into account imperfect detection of species. Black vertical lines indicate ratios of 1 (i.e., no difference in inferred species richness between locality groups that are being compared). Dark-gray areas correspond to $95 \%$ highest posterior density intervals. Observed values exclude known Washakie taxa that are not represented in FMNH collection because these generally have insufficient stratigraphic resolutions for inclusion in our analysis. (3) 95\% HPDIs for effects of locality-group area on occupancy probability for detected ( $n=23$; blue) and undetected ( $n=77$; gray) species under Model 4.

Table 14. Attributes of stratigraphically delineated locality groups ('sites') in occupancy-detection modeling.

\begin{tabular}{|c|c|c|c|}
\hline & $\begin{array}{l}\text { Locality Group } 1 \text { (bed } 569- \\
579 \text {, Twka1) }\end{array}$ & $\begin{array}{l}\text { Locality Group } 2 \text { (bed 580-632, } \\
\text { Twka1 + Twka2) }\end{array}$ & $\begin{array}{l}\text { Locality Group } 3 \text { (bed } 633- \\
675 \text {, Twka2) }\end{array}$ \\
\hline Number of detected taxa of carnivorous mammals & 4 & 16 & 5 \\
\hline $\begin{array}{l}\text { Minimum-convex polygon area encompassing locality } \\
\text { centroids }\left(\mathrm{km}^{2}\right)\end{array}$ & $1.12 \times 10^{3}$ & $1.03 \times 10^{3}$ & $0.42 \times 10^{3}$ \\
\hline $\begin{array}{l}\text { Stratigraphic thickness in Roehler's (1973) measured } \\
\text { sections (m) }\end{array}$ & 28.6 & 285.8 & 290.5 \\
\hline Number of identified vertebrate specimens (NISP) & 353 & 3,976 & 877 \\
\hline Mean NISP per locality & 11.8 & 55.2 & 24.4 \\
\hline
\end{tabular}

1

Loc. Grp. 1 (Bed 569-579)

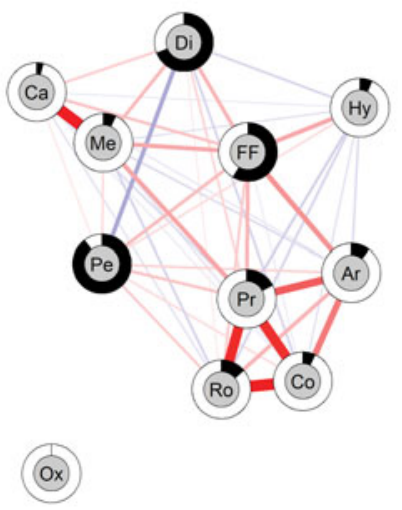

2

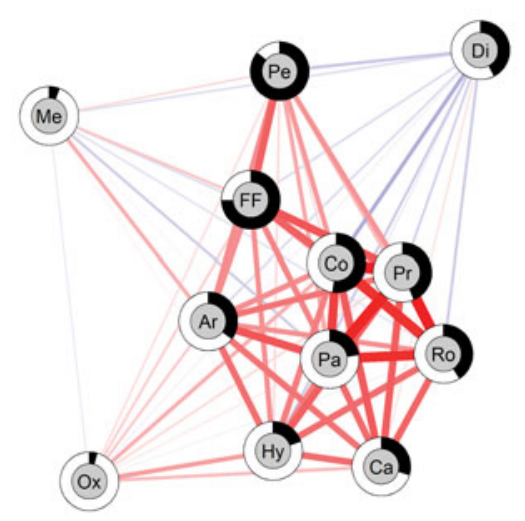

3

Loc. Grp. 3 (Bed 633-675)

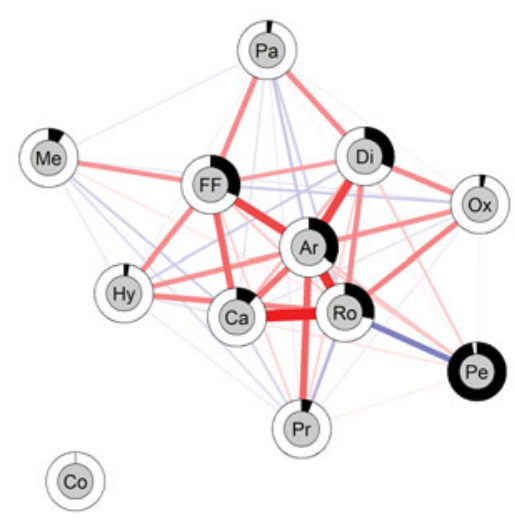

Figure 46. Correlation networks of taxic detections. (1-3) Three networks correspond to the Br3-age 'Locality Group 1' (1), Br3- (and possibly also earliest Uintan-) age 'Locality Group 2' (2), and Uilb-age 'Locality Group 3' (3) of the occupancy-detection analysis. Nodes are plotted using the Fruchterman-Reingold algorithm. Line widths and colors are proportional to correlation coefficients (blue for negative, red for positive). Black segments in pie charts indicate frequencies of observed locality occupancy (a measure of taxon abundance). Unobserved taxa shown as isolated nodes. Abbreviations: Ar, Artiodactyla; Ca, Carnivoramorpha; Co, 'Condylarthra'; Di, Dinocerata; FF, actinopterygian fishes and semiaquatic reptiles; Hy, Hyaenodonta; Me, Mesonychia; Ox, Oxyaenodonta; Pa, Pantolesta; Pe, Perissodactyla; Pr, Primates; Ro, Rodentia.

to those of 'M.' hargeri and N. washakius (cf., Tong and Lei, 1986), and M1 of 'M.' invictus from the Irdin Manha Formation of Inner Mongolia closely resembles that of Neovulpavus mccarrolli n. sp. (see Systematic Paleontology). Although 'M.' invictus is currently too poorly known to be included in our cladistic analysis, the strict consensus tree supports a trans-Pacific distribution of early members of Clade D involving at least 'M.' lushiensis (Fig. 43). This set of possible affinities adds to the growing recognition of potentially close evolutionary connections between Asia and North America during the middle Eocene (Mihlbachler, 2008; Ni et al., 2009; Bai et al., 2017; Dawson and Constenius, 2018).

In North America, late Bridgerian (Br3) mammalian carnivores are virtually unknown outside the Rocky Mountain region. A single occurrence of Patriofelis ferox in the Nut Beds section of the Clarno Formation of central Oregon shows that at least this large oxyaenid had a wide longitudinal range in western North
America (Hanson, 1996). Within the Rocky Mountain region, the Br3 mammalian fauna of the Washakie Formation is closely comparable to that of the Twin Buttes Member of the Bridger Formation (i.e., "upper Bridger" or Bridger C-D; Matthew and Granger, 1924; McCarroll et al., 1996b). Of the minimum of 21 taxa of carnivorous mammals that occur between Roehler's (1973) beds 569 and 632, almost half (10) are also known from the Twin Buttes Member, which has yielded a minimum of 15 carnivore taxa (Table 12). Fossils of the carnivore taxa that are not shared between the two basins are in general quite rare, each being known from only a few specimens. As such, it is probable that the apparent compositional difference between the two basins is exaggerated by incomplete sampling. Still, the absence in the Twin Buttes Member of the limnocyonine hyaenodontid Thinocyon velox, which is moderately common in Twka1 as well as in the Br2-age Blacks Fork Member of the Bridger Formation, is noteworthy. 
There is currently no evidence for the presence of an earliest Uintan (Ui1a)-age fauna in the Washakie Formation. An isolated molar of the viverravid Viverravus gracilis from the Turtle Bluff Member of the Bridger Formation is thus far the only carnivore material known from the Uila subage of North America (Murphey and Kelly, 2017). Comparison of the mammalian faunas from the Turtle Bluff Member and the early Uintan (Ui1b) portion of Twka2 suggests that in some respects, such as the persistence of apatemyids, the hyopsodontid Hyopsodus, the adapiform primate Notharctus, and multiple genera of omomyid primates (Murphey et al., 2018), the ecological structure of the Uila fauna was more similar to that of the preceding $\mathrm{Br} 3$ fauna than the succeeding Uilb fauna, at least in the Greater Green River Basin (see also Flynn, 1986, on mammalian faunal turnover within the Washakie Formation). If so, we expect the regional shift in carnivore composition to have been more pronounced between Uila and Ui1b, rather than precisely across the NALMA boundary between the Bridgerian and Uintan.

Early Uintan (Ui1b) mammalian assemblages are now reasonably well documented in the Rocky Mountain region, southern California, and southwestern Texas (Walsh, 1996b; Robinson et al., 2004; Gunnell et al., 2009; Tomiya, 2013; Campisano et al., 2014; Murphey et al., 2018). It is thus noteworthy that none of the carnivore species from the early Uintan portion of the Washakie Formation is definitively known from elsewhere in the continent (Table 12), although "carnivoraform Genus A" and "cf. Procynodictis sp." of Tomiya (2013) from southern California may be closely related to Neovulpavus washakius and N. mccarrolli n. sp., respectively. Together with the recently updated taxic occurrence data for Uila faunas of Wyoming and Texas (reviewed in Murphey et al., 2018), the growing data set for Uilb faunas (e.g., Kirk and Williams, 2011; Tomiya, 2011; Campisano et al., 2014; Atwater and Kirk, 2018) suggests that mammalian faunal provinciality in western North America may have started to increase earlier than it is generally recognized, that is, prior to the late Uintan NALMA (Lillegraven, 1979; Walsh, 1996b). We expect that further development of occupancy-detection modeling for paleontological applications will enable more rigorous analysis of faunal provinciality that takes into account taphonomic variations among regions and local faunas.

Carnivore diversity dynamics and its faunal context.-The present study more than doubles (from a minimum of 12 to a minimum of 27) the combined carnivore species richness for Twka1 and Twka2 reported by Matthew (1909) and McCarroll et al. (1996b). Included in the newly revised faunal list are as many as nine potentially new species in addition to Neovulpavus mccarrolli $\mathrm{n}$. sp. (Table 11). Our assessment also has resulted in temporal range extensions for two taxa (Oodectes proximus and Synoplotherium; Table 12). Yet, few carnivore species, if any, and only a small number of genera, appear to have survived from the late Bridgerian into the early Uintan in the Washakie Basin, and the faunal transition during this time continues to be marked by a large drop in taxic diversity of carnivores. Thus, much of the newly uncovered diversity accentuates the previously recognized faunal shift within the Washakie Formation, and more generally the differences between late Bridgerian and early Uintan NALMA faunas of the central Rocky Mountain region.

However, the result of occupancy-detection modeling (Fig. 45; Table 15) cautions against direct interpretation of observed data in two respects. First, observed patterns represent only a minimum bound on diversity, and it is probable that only a minority of the original diversity has so far been detected from the lower portion of Twka1 (below the Robin's-egg-blue marker bed) and the early Uintan portion of Twka2 (Fig. 45.1). Second-and more problematically for analyzing diversity dynamics - the apparent shift in species richness based only on detected taxa may grossly overestimate the true magnitude of the event (Fig. 45.2; Table 15). Thus, failure to account for imperfect detection of taxa yields distorted pictures of both absolute and relative species richness through time and space. We anticipate that flexible model-based methods to estimate scales of undetected diversity, such as those employed here, will become essential tools in studies of past as well as present biodiversity (MacKenzie et al., 2017).

Although only a simple initial implementation, our approach demonstrates the utility of model building and model-based comparison in paleo-diversity analysis, which enables evaluation of environmental and taphonomic effects on site occupancy and species detection (Table 15). The detection probability was poorly modeled by the number of identified vertebrate specimens from each locality (a proxy for combined effect of fossil productivity and sampling effort) or the individual locality area (Models 2 and 3 ). This result, together with the very low estimates for detection probabilities, seems to imply that the pattern of carnivore detections is driven more by the original preservational potentials of the taxa than the fossil recovery effort.

Two models (Models 1 and 4) stood out as the most probable (Table 15). Model 4 included the minimum convex polygon area of locality group as the covariate of occupancy probability, and the species-level effect of the covariate was generally positive for the detected species (Fig. 45.3). Thus, the statistical support for this model can be interpreted as evidence for a certain level of species-area effect, which may arise from increased types of habitats contained in larger areas. Reconstruction of paleoenvironmental variations within the basin would help test this hypothesis further. Still, it seems unlikely that a species-area effect alone can explain the median of $39 \%$ decrease in diversity between Locality Groups 2 and 3 estimated under this model: using an empirically determined scaling coefficient of 0.09 (for Malay Peninsula; Heaney, 1986) to 0.12 (for national parks in western United States; Newmark, 1986) for extant mammals on continents, a $59 \%$ decrease in area as seen between Locality Groups 2 and 3 would be expected to result in only an 8 to $10 \%$ loss of species diversity. Further, the fact that Model 1, which included no covariate of occupancy or detection, received substantial support suggests that structuring of the detection data set by a species-area relationship is moderate. It may also be a consequence of designating only three locality groups ('sites'), as well as the low detection probabilities for carnivorous taxa.

The different models consistently suggest high probabilities of an early phase of diversity gain (between Locality Groups 1 and 2) and a later phase of diversity loss (between Locality Groups 2 and 3) within the Washakie Basin. However, the magnitude of the former event is highly uncertain because it 
varies greatly depending on which model is accepted (Table 15). In addition, if the much greater stratigraphic thickness of Locality Group 2 compared to Locality Group 1 (Table 14) is indicative of a longer time span encompassed, the higher inferred diversity in Locality Group 2 may be attributable to a lesser degree of closure of its 'community' (i.e., a greater violation of the closure assumption), and consequently more inflated occupancy probability estimates (cf., Rota et al., 2009). In contrast, Locality Groups 2 and 3 have nearly equal stratigraphic thicknesses, and there is no reason to suspect that they encompass substantially different lengths of time; as such, the difference in species richness between these two locality groups cannot be easily explained as an artifact of the analytical method. Accordingly, the following discussion focuses on the more precisely inferred later event-a decline (with $94 \%$ probability) in carnivore species richness toward the early Uintan, with a median shift of $-39 \%$ (an average weighted by model posterior probabilities).

This probable drop in diversity coincides with apparent extirpation (or near extirpation) from the Washakie Basin of formerly common taxa such as the hyopsodontid Hyopsodus, plesiadapiforms, and euprimates (Fig. 2). The latter phenomenon cannot be explained by size bias in fossil recovery because similar-sized mammals belonging to other groups (primarily rodents and small ungulates) are represented by many specimens from the early Uintan portion of Twka2. This striking faunal shift - an event that has not received attention in previous studies focused on biostratigraphic rather than paleoecological transitions - seems to signal a major biomic change in the basin. In particular, the near-complete disappearance of primates suggests substantial opening of forest canopies or forest fragmentation (cf., Gregory, 1920; Hamrick, 1999; Anemone and Covert, 2000; Townsend et al., 2010; Estrada et al., 2017).

The effect of such biomic transformations is expected to propagate widely across the vertebrate fauna (Redford, 1992; Chapman and Dunham, 2018), including small to medium-sized mammalian carnivores (Michalski and Peres, 2005; Gerber et al., 2012). Indeed, the temporal dynamics of taxic codetection suggests substantial disintegration and ecological reassembly of the Washakie vertebrate fauna between the late Bridgerian and early Uintan (Fig. 46). More specifically, reductions in observed locality occupancy of primates and Hyopsodus ('condylarths') were accompanied by realignment of remaining vertebrate faunal components and a decrease in the number of strong positive associations among them. Such a pattern may reflect a transition to a less tightly structured assemblage in which: (1) habitat generalists are more prevalent than before; and (2) rare habitat specialists (e.g., primates and possibly pantolestans) have been pushed from the center to the periphery of the mammalian assemblage in terms of ecological network (Fig. 46.3). The inferred loss of carnivore diversity in the early Uintan-age Washakie assemblage can be explained as a result of environmental sorting that favored habitat generalists. Opening of forest canopies in particular is expected to reduce stratification of habitats and the range of resources that they offer-factors that likely enable niche differentiation and coexistence of potential competitors such as the extant viverrids and herpestids (Wesley-Hunt et al., 2008). Although taxic detection, in principle, is subject to taphonomic biases, observed patterns of faunal disintegration and reassembly are not readily attributable to common taphonomic processes such as size sorting; thus, we strongly suspect profound changes to the original ('live') assemblages of vertebrates in this study system.

The reason for the absence of the typically common taxon Hyopsodus in the early Uintan portion of Twka2 is unknown and merits further investigation (note there is no clear evidence that any of the UCM Sand Wash Basin localities yielding Hyopsodus is Uintan in age; see West and Dawson, 1975). Hyopsodus occurs in the approximately contemporaneous portions of the Tepee Trail Formation in the Absaroka Range (Eaton, 1985; Flynn, 1991), but it is represented there by a single, apparently ecomorphologically unique species that is unknown elsewhere (Flynn, 1991), hinting at the broad scale of environmental transitions across the central Rocky Mountain region, even beyond the Washakie Basin. As for primates in the same region, adapiforms are absent from deposits younger than the earliest Uintan (Ui1a) Turtle Bluff Member of the Bridger Formation (Kelly and Murphey, 2016; we regard the occurrence of Notharctus at UCM Locality 3 in the Sand Wash Basin to be at least older than Ui1b, based on the mammalian assemblage reported by West and Dawson, 1975), and a peculiar set of just two genera of omomyids - the diminutive Trogolemur and the dentally highly derived Tarka-are known from the early Uintan, both from Bone Bed A of the Tepee Trail Formation (McKenna, 1980, 1990; Flynn, 1983; Gunnell et al., 2008; Rose, 2008; see Ni et al., 2009, for reclassification of Tarka, and note that Ourayia occurs in Twka3 [McCarroll et al., 1996b] but not in Twka2, as erroneously listed in Gunnell et al., 2008). The precise timing of the paleoecological transition cannot yet be determined for the Washakie Basin specifically, but available data for the montane basins in the region collectively point to it occurring between the earliest Uintan and the early Uintan (ca. 47-46 Ma; Flynn, 1986; McCarroll et al., 1996b; Tsukui et al., 2011, 2013; Tsukui and Clyde, 2012; Murphey et al., 2018), rather than strictly across the Bridgerian-Uintan NALMA boundary (see also Townsend et al., 2010).

Our taxonomic reassessment and close morphological examinations of the Washakie taxa also clarify the broader evolutionary trend of increasing size and tooth sectoriality in middle Bridgerian to early Uintan carnivores in the central Rocky Mountain region (Table 17). We assessed 13 sets of closely related taxa known from the Washakie Formation, and identified nine phylogenetically independent cases (mostly within-genus comparisons) that suggest such a trend, while the remaining four taxon-sets do not show clearly directional changes, and no example of decrease in size or sectoriality was recognized. A secular trend of within-lineage body-size increase has been demonstrated for North American mammals in general over the course of the Cenozoic Era (Alroy, 1998), and for several crown carnivoran families during their evolutionary histories (Van Valkenburgh, 1999; Van Valkenburgh et al., 2004). The pattern we report here, however, differs in that it: (1) is more concentrated in time and space (over 4-6 Myr within a single physiographic province); (2) spans a phylogenetically more disparate set of lineages; and (3) includes several small- to medium-sized taxa that must have weighed $<21.5-25 \mathrm{~kg}$ (the approximate threshold for switching to large, primarily vertebrate, prey), and thus were 
Table 15. MCMC specifications and comparison of occupancy-detection models. *Bayes factor $K_{M 4}=\operatorname{Pr}\left(\operatorname{data} \mid M_{4}\right) / \operatorname{Pr}\left(\right.$ datal $\left.M_{l}\right)$, calculated for the most probable model (Model 4) relative to selected model $\left(M_{l}\right)$. ${ }^{\dagger}$ Weighted averages were calculated according to the model posterior probabilities.

\begin{tabular}{|c|c|c|c|c|c|}
\hline & Model 1 & Model 2 & Model 3 & Model 4 & Weighted average $\mathrm{e}^{\dagger}$ \\
\hline Site-level covariate of occupancy probability $\psi$ & none & none & none & locality-group area & \\
\hline MCMC burn-in & $1 \times 10^{5}$ & $1 \times 10^{5}$ & $1 \times 10^{4}$ & $1 \times 10^{5}$ & \\
\hline MCMC thinning rate & 10 & 10 & 1 & 10 & \\
\hline Prior model probability & 0.25 & 0.25 & 0.25 & 0.25 & \\
\hline Posterior model probability & 0.25 & 0.03 & 0.03 & 0.69 & \\
\hline$K_{M} 4^{*}$ & 2.8 & 21.5 & 23.5 & NA & \\
\hline $\operatorname{Pr}\left(N_{L G 3} / N_{L G 2}<1\right)$ & 0.96 & 0.99 & 0.96 & 0.93 & 0.94 \\
\hline $\operatorname{Pr}\left(N_{L G 3} / N_{L G 2}>1\right)$ & 0.02 & 0.02 & 0.02 & 0.05 & 0.04 \\
\hline Median $N_{L G 3} / N_{L G 2}$ & 0.64 & 0.63 & 0.65 & 0.59 & 0.61 \\
\hline $\operatorname{Pr}\left(N_{L G 3} / N_{L G 1}<1\right)$ & 0.42 & 0.46 & 0.42 & 0.85 & 0.72 \\
\hline $\operatorname{Pr}\left(N_{L G 3} / N_{L G 1}>1\right)$ & 0.47 & 0.43 & 0.46 & 0.12 & 0.22 \\
\hline Median $N_{L G 3} / N_{L G 1}$ & 1.00 & 1.00 & 1.00 & 0.67 & 0.77 \\
\hline
\end{tabular}

not hypercarnivorous (Carbone et al., 1999). As such, the primary driver of phenotypic shifts observed for these middle Eocene carnivores may have been different from those of the Cenozoic mammalian and crown-carnivoran cases cited above, and we suspect an environmental cause at the habitat-level. Specifically, both the reduction of carnivore species diversity - which is supported by our analysis of the Bridgerian-Uintan NALMA transition-and body-size increase in species weighing over $\sim 500 \mathrm{~g}$ (which contributes to formation of a 'mid-size gap' in mammalian body size distribution within a habitat) are concordant with opening-up of forested habitats (cf., Croft, 2001).

Increased tooth sectoriality manifested in several lineages in the form of better-developed premolar cuspules and cuspulids (which enhance the food-capturing and point-cutting functions of asymmetrical single-bladed cutting teeth; Evans and Sanson, 2003; Hartstone-Rose, 2011), more anteroposteriorly oriented shearing surfaces (e.g., prevallid, metastyle; Van Valen, 1969b), more trenchant cusps, or reduced posterior molars (Friscia et al., 2007; Table 17). These shifts, together with disappearances of likely hypocarnivorous and omnivorous taxa (e.g., Vulpavus, Palaearctonyx) before the early Uintan, may reflect a concomitant reduction in the range of non-vertebrate food sources. Interestingly, withinlineage body-size reduction in an early Eocene oxyaenid, Palaeonictis, appears to have been accompanied by reduced carnivory, as inferred from increased dental surface complexity (cf., Chester et al., 2010). Such a pattern and our new findings consistently hint at adaptive or developmental coupling of body size and dietary shifts within populations. Further studies of the Washakie fauna will help illuminate the evolutionary consequences of vertebrate faunal reassembly in the middle Eocene of North America against the backdrop of gradual global cooling.

\section{Acknowledgments}

We are grateful to staff of the Bureau of Land Management in the Rawlins and state offices for issuance of paleontological permits, assistance, and support over decades of work in the Washakie Basin. FMNH and AMNH field teams collecting in the Washakie Basin were supported by many people (see Turnbull, 1991, 2002; McCarroll et al., 1996b), and we remain especially grateful to the Eversole family for longstanding help and encouragement in our fieldwork. For assistance with curation of the Washakie fossil vertebrate collection at FMNH including digitization of locality data, we are indebted to: collections staff A. Stroup (FMNH); student interns P. Bezanis, K. Hodge, M. Juhn, D. Mitchell, A. Okamoto, and R.B. Sulser (University of Chicago), W. Buchman (University of Denver), L. Cranmer (Westtown High School, Pennsylvania), J. Driebergen (Southern Illinois

Table 16. Bayesian estimates of parameters and derived quantities for most probable occupancy-detection models. *Same for all locality groups.

\begin{tabular}{|c|c|c|c|}
\hline & Description & Model 1 & Model 4 \\
\hline$\Omega$ & super-population (zero-inflation) parameter (Kéry and Royle, 2008) & {$[0.44,1.00]$} & {$[0.29,0.97]$} \\
\hline$\overline{\beta_{\psi 0}}$ & intercept in logit function describing community mean occupancy probability $\psi$ & {$[-2.24,-0.39]$} & {$[-3.40,1.11]$} \\
\hline$\sigma_{\beta_{\psi(0)}}$ & standard deviation associated with $\overline{\beta_{\psi 0}}$ & {$[0.00,28.37]$} & {$[0.00,28.62]$} \\
\hline$\beta_{\psi 1}$ & covariate coefficient in logit function describing community mean occupancy probability $\psi$ & & {$[-1.35,4.12]$} \\
\hline$\sigma_{\beta_{\psi 1}}$ & standard deviation associated with $\overline{\beta_{\psi 1}}$ & NA & {$[0.00,25.28]$} \\
\hline$\overline{\beta_{p 0}}$ & intercept in logit function describing community mean detection probability $p$ & {$[-4.71,-3.32]$} & {$[-5.33,-3.44]$} \\
\hline$\sigma_{\beta_{00}}$ & standard deviation associated with $\overline{\beta_{p 0}}$ & {$[0.00,1.06]$} & {$[0.03,1.38]$} \\
\hline$\overline{\psi_{L G 1}}$ & community mean occupancy probability for Locality Group 1 (bed 569-579) & & {$[0.06,0.92]$} \\
\hline$\psi_{L G 2}$ & community mean occupancy probability for Locality Group 2 (bed 580-632) & {$[0.09,0.38]^{*}$} & {$[0.04,0.84]$} \\
\hline$\overline{\psi_{L G 3}}$ & community mean occupancy probability for Locality Group 3 (bed 633-675) & & {$[0.00,0.67]$} \\
\hline $\bar{p}$ & community mean detection probability & {$[0.01,0.03]$} & {$[0.00,0.03]$} \\
\hline$N_{\text {total }}$ & total number of taxa in sampled locality groups & {$[45,100]$} & {$[28,94]$} \\
\hline$N_{L G 1}$ & number of taxa (detected and undetected) occupying Locality Group 1 (bed 569-579) & {$[5,23]$} & {$[7,38]$} \\
\hline$N_{L G 2}$ & same as above for Locality Group 2 (bed 580-632) & {$[16,28]$} & {$[16,37]$} \\
\hline$N_{L G 3}$ & same as above for Locality Group 3 (bed 633-675) & {$[6,23]$} & {$[5,29]$} \\
\hline
\end{tabular}


Table 17. Morphological shifts within groups of closely related carnivores toward late Bridgerian/early Uintan of central Rocky Mountain region. Evidence for increase in body size or dental sectoriality is summarized with focus on taxa known from the Washakie Formation. Specimens of poorly known taxonomic affinities are excluded from consideration.

\begin{tabular}{|c|c|c|c|c|}
\hline Higher taxon & Focal taxon/taxa & Observations & Scope & Comments \\
\hline \multirow[t]{2}{*}{ Mesonychia } & Synoplotherium & $\begin{array}{l}\text { Larger body size in later-surviving } \\
\text { species/morphotype. }\end{array}$ & $\begin{array}{l}\text { Bridger and } \\
\text { Washakie Fm.; } \\
\text { Br3-Uilb. }\end{array}$ & Only Synoplotherium sp. indet. known from Uilb. \\
\hline & Harpagolestes & [unclear] & $\begin{array}{l}\text { Bridger and } \\
\text { Washakie Fm.; } \\
\text { Br2-Uilb. }\end{array}$ & $\begin{array}{l}\text { Additional taxonomic/phylogenetic work needed } \\
\text { before temporal pattern can be assessed. }\end{array}$ \\
\hline \multirow[t]{2}{*}{ Oxyaenodonta } & Patriofelis & $\begin{array}{l}\text { Larger body size in later-originating } \\
\text { species/morphotype. }\end{array}$ & $\begin{array}{l}\text { Bridger and } \\
\text { Washakie Fm.; } \\
\text { Br2-Br3. }\end{array}$ & $\begin{array}{l}P . \text { ferox distinguished from } P \text {. ultra primarily by } \\
\text { size (Matthew, 1909). }\end{array}$ \\
\hline & Machaeroidinae & [unclear] & $\begin{array}{l}\text { Bridger and } \\
\text { Washakie Fm.; } \\
\text { Br2-Uilb. }\end{array}$ & $\begin{array}{l}\text { Additional taxonomic/phylogenetic work needed } \\
\text { before temporal pattern can be assessed. }\end{array}$ \\
\hline \multirow[t]{4}{*}{ Hyaenodonta } & Tritemnodon & $\begin{array}{l}\text { Larger body size and greater dental } \\
\text { sectoriality in later-originating } \\
\text { species/morphotype. }\end{array}$ & $\begin{array}{l}\text { Bridger and } \\
\text { Washakie Fm.; } \\
\text { Br1b-Br3. }\end{array}$ & $\begin{array}{l}\text { Progressive reductions of metaconids and } \mathrm{m} 1 \\
\text { talonid (Fig. 9.7-9.17) interpreted as increased } \\
\text { sectoriality. }\end{array}$ \\
\hline & Sinopa & $\begin{array}{l}\text { Larger body size or greater dental } \\
\text { sectoriality in later-originating } \\
\text { species/morphotype. }\end{array}$ & $\begin{array}{l}\text { Bridger and } \\
\text { Washakie Fm.; } \\
\text { Br2-Uilb. }\end{array}$ & $\begin{array}{l}S . \text { lania marked by more trenchant cusps than } S \text {. } \\
\text { rapax. } S \text {. sp. A larger than earlier-appearing } \\
\text { species of Sinopa, and has relatively larger m3 } \\
\text { than } S . \text { major or } S \text {. rapax, which may indicate } \\
\text { increased carnivory. }\end{array}$ \\
\hline & Thinocyon & $\begin{array}{l}\text { Larger body size and possibly greater } \\
\text { dental sectoriality in later-originating } \\
\text { species/morphotype. }\end{array}$ & $\begin{array}{l}\text { Bridger and } \\
\text { Washakie Fm.; } \\
\text { Br1b-Br3. }\end{array}$ & $\begin{array}{l}\text { Mean m1L } 15 \% \text { larger in T. medius compared to } T \text {. } \\
\text { velox (data from Morlo and Gunnell, 2003). } \\
\text { More posterior orientation of M1 metastyle may } \\
\text { be interpreted as increased sectoriality (cf., Van } \\
\text { Valen, 1969b). }\end{array}$ \\
\hline & Limnocyon & $\begin{array}{l}\text { Larger body size in later-originating } \\
\text { species/morphotype. }\end{array}$ & $\begin{array}{l}\text { Bridger and } \\
\text { Washakie Fm.; } \\
\text { Br2-Ui1b. }\end{array}$ & $\begin{array}{l}\text { L. potens distinguished from L. verus primarily by } \\
\text { size (Matthew, 1909). }\end{array}$ \\
\hline \multirow[t]{5}{*}{ Carnivoramorpha } & Viverravus & $\begin{array}{l}\text { Larger body sizes in later-surviving } \\
\text { species/morphotypes; greater dental } \\
\text { sectoriality in later specimens within } \\
\text { species. }\end{array}$ & $\begin{array}{l}\text { Bridger, Washakie, } \\
\text { and Tepee Trail } \\
\text { Fm.; Br2-Ui1b. }\end{array}$ & $\begin{array}{l}\text { Moderate-sized species/morphotypes (e.g., } V \text {. } \\
\text { gracilis) occur in Ui1b, but smaller } V . \text { minutus } \\
\text { unknown after Br3. Last-surviving species ( } V . \\
\text { sicarius, occurs in Ui1b Holy City beds; Eaton, } \\
\text { 1985; Murphey et al., 2018) is also the largest. } \\
\text { Within } V . \text { gracilis, Matthew }(1909, \text { p. } 357) \text { notes } \\
\text { greater sectoriality of Br3 specimens compared } \\
\text { to Br2 specimens. }\end{array}$ \\
\hline & Uintacyon & [unclear] & $\begin{array}{l}\text { Bridger and } \\
\text { Washakie Fm.; } \\
\text { Br2-Br3. }\end{array}$ & $\begin{array}{l}\text { Additional taxonomic/phylogenetic work needed } \\
\text { before temporal pattern can be assessed. }\end{array}$ \\
\hline & Oodectes & $\begin{array}{l}\text { Larger body size in later-originating } \\
\text { species/morphotype. }\end{array}$ & $\begin{array}{l}\text { Bridger and } \\
\text { Washakie Fm.; } \\
\text { Br2-Br3. }\end{array}$ & $\begin{array}{l}\text { O. pugnax is larger than } O \text {. proximus. Neither } \\
\text { hypocarnivore known to have survived into } \\
\text { Uintan. }\end{array}$ \\
\hline & $\begin{array}{l}\text { Neovulpavus-'Miacis' } \\
\quad \text { hargeri clade }\end{array}$ & $\begin{array}{l}\text { Larger body size (in part) and greater } \\
\text { dental sectoriality in later-originating } \\
\text { species. }\end{array}$ & $\begin{array}{l}\text { Bridger and } \\
\text { Washakie Fm.; } \\
\text { Br3-Uilb. }\end{array}$ & $\begin{array}{l}\text { Early Uintan } N . \text { mccarrolli n. sp. marked by more } \\
\text { anteriorly directed paraconids (vs. 'Miacis' } \\
\text { hargeri), reduced posterior molars (vs. Lycarion } \\
\text { medius), or larger size and p4 with enlarged } \\
\text { blade-like posterior cuspulids (vs. Neovulpavus } \\
\text { washakius) compared to close relatives from Br3. }\end{array}$ \\
\hline & Harpalodon & na & $\begin{array}{l}\text { Bridger and } \\
\text { Washakie Fm.; } \\
\text { Br2-Br3. }\end{array}$ & $\begin{array}{l}\text { Monotypic genus without known close relative in } \\
\text { succeeding age (Uila/Uilb). }\end{array}$ \\
\hline
\end{tabular}

University), C. Dubois (St. John's Jesuit High School, Ohio), C. Hawley (New Trier High School, Illinois), E. Herner (Colorado State University), J. Jimenez (Loyola University Chicago), M. Karlin (Hampshire College), C. Kay (Oberlin College), M. Limbeck (Allegheny College), S. Ososky and H. Starr (Western Illinois University), F. Socki (Illinois Wesleyan University), A. Taylor (University of Birmingham); and citizen volunteers L. Coronelli, J. Gandolfi, K. Koeller, C. McGarrity, and N. Tomiya. W. Simpson, A. Stroup, and K. Angielczyk (FMNH) facilitated the present study by providing ST with curatorial advice and support, institutional knowledge, and encouragement. A. Shinya (FMNH) made a cast FMNH PM 70166 of CM 9420, with permission from A. Henrici and M. Lamanna (CM). Lori Grove (FMNH) assisted W. Turnbull in compilation of a unified map of Washakie Formation localities.
Additionally, we thank: J. Galkin, A. Gishlick, J. Meng, and R. O'Leary (AMNH), W. Simpson, A. Stroup, and K. Angielczyk (FMNH), D. Miao, D. Burnham, and K. Christopher Beard (KUVP), K. Randall and T. Deméré (SDSNH), D. Brinkman (YPM), C. Mejia and P. Holroyd (UCMP), A. Millhouse and N. Pyenson (USNM), L. Vietti (UW), and R. Eng, M. Rivin, C. Sidor, and G. Wilson (UWBM) for access to specimens under their care and assistance in collections; L. Vietti, R. Haupt, and E. Wommack (University of Wyoming) for their hospitality during ST's visit to UW Geological Museum; F. Solé (Royal Belgian Institute of Natural Sciences) for clarification on the character matrix data of Solé et al. (2014, 2016); G. Feinman and J. Seagard (FMNH) for access to document scanner used for digitization of locality map; N. Famoso (University of Oregon), 
A. Friscia (UCLA), B. Bai, C. Grohé, and Z. Tseng (AMNH), R. Dunn (Des Moines University), P.D. Polly (Indiana University), N. Egi (Kyoto University), and P. Holroyd for discussions; C. Merriman and C. Taylor (FMNH) for supporting internship and volunteer programs at FMNH; R.B. Sulser for measurements of AMNH FM 12155; B. Bai, S. Goldberg, Z. Tseng, and H. Wang (AMNH), M. Rivin and R. Eng (UWBM) and K. Angielczyk for access to microscope/macro photography equipment; and W. Simpson, N. Famoso, H. Wang, and J. Henderson (YPM) for furnishing ST and SPZ with photographs of FMNH PM 70166, UWBM 38976, AMNH FM 2305, YPM VP 011878, and YPM VP 013107. ST thanks J. Meachen (Des Moines University) for allowing him to continue this study. K.B. Townsend (Midwestern University), P. Murphey (San Diego Natural History Museum), J. Westgate (Lamar University), A. Friscia (UCLA), and L. Stroik (Grand Valley State University) organized a symposium at the 2016 annual meeting of the Society of Vertebrate Paleontology ('Advances in Middle Eocene Paleoecology: Evolutionary and Ecological Dynamics in a Post-Greenhouse World') that facilitated discussions for the present study; reviewers A. Friscia, P.D. Polly, and R. Dunn for helpful comments on an earlier version of this paper; and editors H.-D. Sues, C. Scott, C. Maples, J. Musha, B. Hunda, and J. Kastigar for editorial support.

This study was funded in part by the US National Science Foundation (NSF) grants DEB-1011474 (ST) and DEB-1655795 (MS), an American Museum of Natural History Theodore Roosevelt Memorial Grant (ST) and the AMNH Division of Paleontology Frick Fund (JF), and a Vertebrate Paleontology Collections Study Grant from the University of Washington Burke Museum (ST). NSF Collections in Support of Biological Research program (DBI-1203530 to K. Angielczyk) supported collections improvement at FMNH that laid the foundation for the present study. This is UCMP Contribution no. 3003.

\section{Accessibility of supplemental data}

Supplemental Data 1-5 are available from the Dryad Digital Repository (https://doi.org/10.5061/dryad.2jm63xsm7).

\section{References}

Adams, G.I., 1896, The extinct Felidae of North America: American Journal of Science (ser. 4), v. 1, p. 419-444.

Alroy, J., 1998, Cope's rule and the dynamics of body mass evolution in North American fossil mammals: Science, v. 280, p. 731-734.

Anemone, R.L., and Covert, H.H., 2000, New skeletal remains of Omomys (Primates, Omomyidae): functional morphology of the hindlimb and locomotor behavior of a middle Eocene primate: Journal of Human Evolution, v. 38, p. 607-633.

Archibald, J.D., 1998, Archaic ungulates ("Condylarthra"), in Janis, C.M., Scott, K.M., and Jacobs, L.L., eds., Evolution of Tertiary Mammals of North America: Vol. 1, Terrestrial Carnivores, Ungulates, and Ungulatelike Mammals: Cambridge, Cambridge University Press, p. 292-331.

Asahara, M., 2013, Unique inhibitory cascade pattern of molars in canids contributing to their potential to evolutionary plasticity of diet: Ecology and Evolution, v. 3, p. 278-285.

Asahara, M., Saito, K. Kishida, T., Takahashi, K., and Bessho, K., 2016, Unique pattern of dietary adaptation in the dentition of Carnivora: its advantage and developmental origin: Proceedings of the Royal Society B: Biological Sciences, v. 283, p. 20160375.
Atwater, A.L., and Kirk, E.C., 2018, New middle Eocene omomyines (Primates, Haplorhini) from San Diego County, California: Journal of Human Evolution, v. 124, p. 7-24.

Bai, B., Wang, Y.-Q., Mao, F.-Y., and Meng, J., 2017, New material of Eocene Helaletidae (Perissodactyla, Tapiroidea) from the Irdin Manha Formation of the Erlian Basin, Inner Mongolia, China and comments on related localities of the Huheboerhe area: American Museum Novitates, no. 2017, p. $1-45$.

Balisi, M., Casey, C., and Van Valkenburgh, B., 2018, Dietary specialization is linked to reduced species durations in North American fossil canids: Royal Society Open Science, v. 5, p. 171861. https://doi.org/10.1098/rsos. 171861.

Barker, R.J., and Link, W.A., 2013, Bayesian multimodel inference by RJMCMC: a Gibbs sampling approach: The American Statistician, v. 67, p. $150-156$.

Barrett, P.Z., 2016, Taxonomic and systematic revisions to the North American Nimravidae (Mammalia, Carnivora): PeerJ, v. 4, e1658. https://doi.org/10. $7717 /$ peerj. 1658 .

Beaumont, G. de, 1965a, Les Viverravinae (Carnivora, Miacidae) de l'éocène de la Suisse: Bulletin de la Société vaudoise des Sciences naturelles, v. 69 , p. $133-146$.

Beaumont, G. de, 1965b, Contribution à l'étude du genre Cephalogale Jourdan (Carnivora): Mémoires Suisses de Paléontologie, v. 82, p. 1-34.

Behrensmeyer, A.K., Kidwell, S.M., and Gastaldo, R.A., 2000, Taphonomy and paleobiology: Paleobiology, v. 26, p. 103-147.

Bivand, R.S., and Rundel, C., 2018, R Package 'rgeos': Interface to Geometry Engine Open Source ('GEOS'), v. 0.5-2, https://CRAN.R-project.org/ package $=$ rgeos.

Black, C.C., and Dawson, M.R., 1966, A review of late Eocene mammalian faunas from North America: American Journal of Science, v. 264, p. $321-349$.

Bohaty, S.M., and Zachos, J.C., 2003, Significant Southern Ocean warming event in the late middle Eocene: Geology, v. 31, p. 1017-1020.

Bohaty, S.M., Zachos, J.C., Florindo, F., and Delaney, M.L., 2009, Coupled greenhouse warming and deep-sea acidification in the middle Eocene: Paleoceanography, v. 24, p. PA2207. Doi:10.1029/2008PA001676.

Bonis, L. de, Peigne, S., and Hugueney, M., 1999, Carnivores feloides de l'Oligocene superieur de Coderet-Bransat (Allier, France): Bulletin de La Societe Geologique de France, v. 170, p. 939-949.

Borths, M.R., Holroyd, P.A., and Seiffert, E.R., 2016, Hyainailourine and teratodontine cranial material from the late Eocene of Egypt and the application of parsimony and Bayesian methods to the phylogeny and biogeography of Hyaenodonta (Placentalia, Mammalia): PeerJ, v. 4, p. e2639. https://doi.org/ 10.7717/peerj.2639.

Bown, T.M., 1982, Geology, paleontology, and correlation of Eocene volcaniclastic rocks, southeast Absaroka range, Hot Springs County, Wyoming: Geological Survey Professional Paper, v. 1201-A, p. A1-A75.

Broms, K.M., Hooten, M.B., and Fitzpatrick, R.M., 2016, Model selection and assessment for multi-species occupancy models: Ecology, v. 97, p. 1759-1770.

Brooks, S.P., and Gelman, A., 1998, General methods for monitoring convergence of iterative simulations: Journal of Computational and Graphical Statistics, v. 7, p. 434-455.

Bryant, H.N., 1992, The Carnivora of the Lac Pelletier Lower Fauna (Eocene: Duchesnean), Cypress Hills Formation, Saskatchewan: Journal of Paleontology, v. 66, p. 847-855.

Bryant, H.N., 1996, Explicitness, stability, and universality in the phylogenetic definition and usage of taxon names: a case study of the phylogenetic taxonomy of the Carnivora (Mammalia): Systematic Biology, v. 45, p. $174-189$.

Bryant, H.N., Russell, A.P., and Thomason, J.J., 1995, Carnassial functioning in nimravid and felid sabertooths: theoretical basis and robustness of inferences, in Thomason, J.J., ed., Functional Morphology in Vertebrate Paleontology: Cambridge, Cambridge University Press, p. 116-135.

Campisano, C.J., Kirk, E.C., Townsend, K.B., and Deino, A.L., 2014, Geochronological and taxonomic revisions of the middle Eocene Whistler Squat Quarry (Devil's Graveyard Formation, Texas) and implications for the early Uintan in Trans-Pecos Texas: PloS One, v. 9, p. e101516. https://doi.org/10.1371/journal.pone.0101516.

Carbone, C., Mace, G.M., Roberts, S.C., and Macdonald, D.W., 1999, Energetic constraints on the diet of terrestrial carnivores: Nature, v. 402, p. $286-288$.

Carroll, A.R., Doebbert, A.C., Booth, A.L., Chamberlain, C.P., Rhodes-Carson, M.K., Smith, M.E., Johnson, C.M., and Beard, B.L., 2008, Capture of highaltitude precipitation by a low-altitude Eocene lake, western US: Geology, v. 36, p. 791-794.

Cather, S.M., Chapin, C.E., and Kelley, S.A., 2012, Diachronous episodes of Cenozoic erosion in southwestern North America and their relationship to surface uplift, paleoclimate, paleodrainage, and paleoaltimetry: Geosphere, v. 8 , p. $1177-1206$. 
Chapman, C.A., and Dunham, A.E., 2018, Primate seed dispersal and forest restoration: an African perspective for a brighter future: International Journal of Primatology, v. 39, p. 427-442.

Chester, S.G., Bloch, J.I., Secord, R., and Boyer, D.M., 2010, A new smallbodied species of Palaeonictis (Creodonta, Oxyaenidae) from the Paleocene-Eocene Thermal Maximum: Journal of Mammalian Evolution, v. 17 , p. $227-243$.

Chetel, L.M., Janecke, S.U., Carroll, A.R., Beard, B.L., Johnson, C.M., and Singer, B.S., 2011, Paleogeographic reconstruction of the Eocene Idaho River, North American Cordillera: Geological Society of America Bulletin, v. 123, p. 71-88.

Chow, M.-C., 1975, Some carnivores from the Eocene of China: Vertebrata PalAsiatica, v. 13, p. 165-168.

Clark, J., 1939, Miacis gracilis, a new carnivore from the Uinta Eocene: Annals of the Carnegie Museum, v. 27, p. 349-370.

Coombs, M.C., 1971, Status of Simidectes (Insectivora, Pantolestoidea) of the late Eocene of North America: American Museum Novitates, no. 2455, p. 1-41.

Cope, E.D., 1872a, Descriptions of some new Vertebrata from the Bridger Group of the Eocene: Paleontological Bulletin, no. 1, p. 1-6.

Cope, E.D., 1872b, Third account of new Vertebrata from the Bridger Eocene of Wyoming Valley: Paleontological Bulletin, no. 3, p. 1-4.

Cope, E.D., 1872c, Notices of new Vertebrata from the Upper Waters of Bitter Creek, Wyoming Territory: Paleontological Bulletin, no. 6, p. 1-4.

Cope, E.D., 1872d, Notices of new Vertebrata from the Upper Waters of Bitter Creek, Wyoming Territory: Proceedings of the American Philosophical Society, v. 12, p. 483-486.

Cope, E.D., 1872e, Second account of new Vertebrata from the Bridger Eocene: Proceedings of the American Philosophical Society, v. 12, p. 466-468.

Cope, E.D., 1873, Third notice of extinct vertebrata from the Tertiary of the plains: Paleontological Bulletin, no. 16, p. 1-8.

Cope, E.D., 1874, Appendix FF report upon vertebrate fossils discovered in New Mexico, with description of new species, in Annual Report of the Chief of Engineers: 1874, p. 589-606. [Extract, from appendix ff of the annual report of the Chief of Engineers, 1874, separatum, 18 p.]

Cope, E.D., 1875, On the supposed Carnivora of the Eocene of the Rocky Mountains: Paleontological Bulletin, no. 20, p. 1-4.

Cope, E.D., 1877, Report upon the extinct Vertebrata obtained in New Mexico by parties of the expedition of 1874: Report upon United States Geographical Surveys West of the One Hundredth Meridian, v. 4 (pt. 2), p. $1-370$.

Cope, E.D., 1881, On the Vertebrata of the Wind River Eocene beds of Wyoming: Bulletin of the United State Geological and Geographical Survey of the Territories, v. 6, p. 183-202.

Cope, E.D., 1882, Contributions to the history of the Vertebrata of the Lower Eocene of Wyoming and New Mexico, made during 1881: Proceedings of the American Philosophical Society, v. 20, p. 138-197.

Cope, E.D., 1884, The Vertebrata of the Tertiary formations of the West: Report of the United States Geological Survey of the Territories, v. 3, p. 1-1009.

Crochet, J.Y., 1988, Le gisement du Bretou (Phosphorites du Quercy, Tarn-et-Garonne, France) et sa faune de vertébrés de l'Éocène supérieur. III. Marsupiaux, créodontes et fissipèdes: Palaeontographica Abteilung A, v. 205, p. 51-67.

Croft, D.A., 2001, Cenozoic environmental change in South America as indicated by mammalian body size distributions (cenograms): Diversity and Distributions, v. 7, p. 271-287.

Davis, S.J., Wiegand, B.A., Carroll, A.R., and Chamberlain, C.P., 2008, The effect of drainage reorganization on paleoaltimetry studies: an example from the Paleogene Laramide foreland: Earth and Planetary Science Letters, v. 275, p. 258-268.

Dawson, M.R., 1980, Paleontology and geology of the Badwater Creek area, central Wyoming: part 20, the late Eocene Creodonta and Carnivora: Annals of Carnegie Museum, v. 49, p. 79-91.

Dawson, M.R., and Constenius, K.N., 2018, Mammalian fauna of the middle Eocene Kishenehn Formation, Middle Fork of the Flathead River, Montana: Annals of Carnegie Museum, v. 85, p. 25-61.

Denison, R.H., 1938, The broad-skulled Pseudocreodi: Annals of the New York Academy of Sciences, v. 37, p. 163-257.

Denwood, M.J., 2016, 'runjags': an R package providing interface utilities, model templates, parallel computing methods and additional distributions for MCMC models in JAGS: Journal of Statistical Software, v. 71, p. 1-25.

Dubied, M., Solé, F., and Mennecart, B., 2019, The cranium of Proviverra typica (Mammalia, Hyaenodonta) and its impact on hyaenodont phylogeny and endocranial evolution: Palaeontology, v. 62, p. 983-1001.

Dunn, R.H., 2016, Revised mammalian fauna from the Sand Wash Basin and assessment of an earliest Uintan age: Program and Abstracts, Society of Vertebrate Paleontology, $76^{\text {th }}$ Annual Meeting, p. 128A.

Eaton, J.G., 1982, Paleontology and correlation of Eocene volcanic rocks in the Carter Mountain area, Park County, southeastern Absaroka Range, Wyoming: Rocky Mountain Geology, v. 21, p. 153-194.
Eaton, J.G., 1985, Paleontology and correlation of the Eocene Tepee Trail and Wiggins formations in the north fork of Owl Creek area, southeastern Absaroka Range, Hot Springs County, Wyoming: Journal of Vertebrate Paleontology, v. 5, p. 345-370.

Efron, B., 1981, Nonparametric standard errors and confidence intervals: Canadian Journal of Statistics, v. 9, p. 139-158.

Egi, N., Tsubamoto, T., Saneyoshi, M., Tsogtbaatar, K., Watabe, M., Mainbayar, B., Chinzorig, T., and Khatanbaatar, P., 2016, Taxonomic revisions on nimravids and small feliforms (Mammalia, Carnivora) from the upper Eocene of Mongolia: Historical Biology, v. 28, p. 105-119.

Eizirik, E., Murphy, W.J., Koepfli, K.-P., Johnson, W.E., Dragoo, J.W., Wayne, R.K., and O'Brien, S.J., 2010, Pattern and timing of diversification of the mammalian order Carnivora inferred from multiple nuclear gene sequences: Molecular Phylogenetics and Evolution, v. 56, p. 49-63.

Emry, R.J., 1990, Mammals of the Bridgerian (middle Eocene) Elderberry Canyon local fauna of eastern Nevada, in Bown, T.M., and Rose K.D., eds. Dawn of the Age of Mammals in the Northern Part of the Rocky Mountain Interior, North America: Geological Society of America Special Paper, v. 243 , p. $187-210$.

Epskamp, S., Cramer, A.O.J., Waldorp, L.J., Schmittmann, V.D., and Borsboom, D., 2012, qgraph: Network visualizations of relationships in psychometric data: Journal of Statistical Software, v. 48, p. 1-18.

Eronen, J.T., Janis, C.M., Chamberlain, C.P., and Mulch, A., 2015, Mountain uplift explains differences in Palaeogene patterns of mammalian evolution and extinction between North America and Europe: Proceedings of the Royal Society B: Biological Sciences, v. 282, p. 20150136. http://doi.org/ 10.1098/rspb.2015.0136.

Estrada, A., Garber, P.A., Rylands, A.B., Roos, C., Fernandez-Duque, E., et al., 2017, Impending extinction crisis of the world's primates: why primates matter: Science Advances, v. 3, p. e1600946. DOI: 10.1126/sciadv. 1600946.

Evans, A.R., and Sanson, G.D., 2003, The tooth of perfection: functional and spatial constraints on mammalian tooth shape: Biological Journal of the Linnean Society, v. 78, p. 173-191.

Erxleben, J.C.P., 1777, Systema regni animalis per classes, ordines, genera, species, varietates, cum synonymia et historia animalium, Classis I, Mammalia: Leipzig, Weygandianis, $636 \mathrm{p}$.

Fan, M., Hough, B.G., and Passey, B.H., 2014a, Middle to late Cenozoic cooling and high topography in the central Rocky Mountains: Constraints from clumped isotope geochemistry: Earth and Planetary Science Letters, v. 408, p. $35-47$.

Fan, M., Heller, P., Allen, S.D., and Hough, B.G., 2014b, Middle Cenozoic uplift and concomitant drying in the central Rocky Mountains and adjacent Great Plains: Geology, v. 42, p. 547-550.

Filhol, H., 1872, Recherches sur les mammiferes fossiles des depots de phosphate de chaux dans les departements du Lot, du Tarn et de Tarn et Garonne: Annales des sciences géologiques, v. 3, p. 1-31.

Filhol, H., 1879, Étude sur les Mammifères fossiles de Saint-Gérand le Puy (Allier): Annales des sciences géologiques, v. 19, p. 1-252.

Flynn, J., Finarelli, J., and Spaulding, M., 2010, Phylogeny of the Carnivoramorpha, and the use of the fossil record to enhance understanding of evolutionary transformations, in Goswami, A., and Friscia, A.R., eds., Carnivoran Evolution: New Views on Phylogeny, Form and Function: Cambridge, Cambridge University Press, p. 25-63.

Flynn, J.J., 1983, Correlation and geochronology of middle Eocene strata from the western United States [Ph.D. dissertation]: New York, Columbia University, $496 \mathrm{p}$.

Flynn, J.J., 1986, Correlation and geochronology of middle Eocene strata from the western United States: Palaeogeography, Palaeoclimatology, Palaeoecology, v. 55, p. 335-406.

Flynn, J.J., 1991, Hyopsodus (Mammalia) from the Tepee Trail Formation (Eocene), northwestern Wyoming: American Museum Novitates, no. 3007, p. 1-19.

Flynn, J.J., 1998, Early Cenozoic Carnivora ("Miacoidea"), in Janis, C.M., Scott, K.M., and Jacobs, L.L., eds., Evolution of Tertiary Mammals of North America: Vol. 1, Terrestrial Carnivores, Ungulates, and Ungulatelike Mammals: Cambridge, Cambridge University Press, p. 110-123.

Flynn, J.J., and Galiano, H., 1982, Phylogeny of early tertiary Carnivora with a description of a new species of Protictis from the middle Eocene of northwestern Wyoming: American Museum Novitates, no. 2725, p. 1-64.

Friscia, A., Van Valkenburgh, B., and Biknevicius, A., 2007, An ecomorphological analysis of extant small carnivorans: Journal of Zoology, v. 272, p. 82-100.

Friscia, A.R., and Rasmussen, D.T., 2010, Middle Eocene Carnivoramorpha of the Uinta Basin, Utah: Annals of Carnegie Museum, v. 79, p. 51-64.

Friscia, A.R., and Van Valkenburgh, B., 2010, Ecomorphology of North American Eocene carnivores: evidence for competition between carnivorans and creodonts, in Goswami, A., and Friscia, A.R., eds., Carnivoran Evolution: New Views on Phylogeny, Form and Function: Cambridge, Cambridge University Press, p. 311-341. 
Gazin, C.L., 1946, Machaeroides eothen Matthew, the sabertooth creodont of the Bridger Eocene: Proceedings of the United States National Museum, v. 96, p. $335-347$.

Gazin, C.L., 1957, A skull of the Bridger middle Eocene creodont, Patriofelis ulta Leidy: Smithsonian Miscellaneous Collections, v. 134, p. 1-20.

Gazin, C.L., 1962, A further study of the lower Eocene mammalian faunas of southwestern Wyoming: Smithsonian Miscellaneous Collections, v. 144, p. 1-98.

Gazin, C.L., 1976, Mammalian faunal zones of the Bridger middle Eocene: Smithsonian Contributions to Paleobiology, v. 26, p. 1-25.

Gebo, D.L., and Rose, K.D., 1993, Skeletal morphology and locomotor adaptation in Prolimnocyon atavus, an early Eocene hyaenodontid creodont: Journal of Vertebrate Paleontology, v. 13, p. 125-144.

Geisler, J.H., and McKenna, M.C., 2007, A new species of mesonychian mammal from the lower Eocene of Mongolia and its phylogenetic relationships: Acta Palaeontologica Polonica, v. 52, p. 189-212.

Gelman, A., and Rubin, D.B., 1992, Inference from iterative simulation using multiple sequences: Statistical Science, v. 7, p. 457-472.

Gerber, B.D., Karpanty, S.M., and Randrianantenaina, J., 2012, The impact of forest logging and fragmentation on carnivore species composition, density and occupancy in Madagascar's rainforests: Oryx, v. 46, p. 414-422.

Gervais, F.L.P., 1848, Zoologie et paléontologie françaises: Paris, Arthus Bertrand, $271 \mathrm{p}$.

Gingerich, P.D., 1983, Systematics of early Eocene Miacidae (Mammalia, Carnivora) in the Clark's Fork Basin, Wyoming: Contributions from the Museum of Paleontology (University of Michigan), v. 26, p. 197-225.

Gingerich, P.D., and Deutsch, H.A., 1989, Systematics and evolution of early Eocene Hyaenodontidae (Mammalia, Creodonta) in the Clark's Fork Basin, Wyoming: Contributions from the Museum of Paleontology (University of Michigan), v. 27, p. 327-391.

Gingerich, P.D., and Winkler, D.A., 1985, Systematics of Paleocene Viverravidae (Mammalia, Carnivora) in the Bighorn Basin and Clark's Fork Basin, Wyoming: Contributions from the Museum of Paleontology (University of Michigan), v. 27, p. 87-128.

Goloboff, P.A., and Catalano, S.A., 2016, TNT v. 1.5, including a full implementation of phylogenetic morphometrics: Cladistics, v. 32, p. 221-238.

Goswami, A., and Polly, P.D., 2010, Methods for studying morphological integration and modularity: Paleontological Society Papers, v. 16, p. 213-243.

Granger, W., 1909, Faunal horizons of the Washakie Formation of southern Wyoming: Bulletin of the American Museum of Natural History, v. 26, p. $13-23$.

Gray, J.E., 1830, Spicilegia zoological, or original figures and short systematic descriptions of new and unfigured animals, Part 2: London, Treüttel, Würtz \& Co. \& Wood, p. 9-12.

Green, P.J., 1995, Reversible jump Markov chain Monte Carlo computation and Bayesian model determination: Biometrika, v. 82, p. 711-732.

Gregory, W.K., 1920, On the structure and relations of Notharctus, an American Eocene primate: Memoirs of the American Museum of Natural History (New Series), v. 3, p. 51-243.

Gunnell, G., 1998a, Creodonta, in Janis, C.M., Scott, K.M., and Jacobs, L.L. eds., Evolution of Tertiary Mammals of North America: Vol. 1, Terrestria Carnivores, Ungulates, and Ungulatelike Mammals: Cambridge, Cambridge University Press, p. 91-109.

Gunnell, G.F., 1998b, Mammalian fauna from the lower Bridger Formation (Bridger A, early middle Eocene) of the southern Green River Basin, Wyoming: Contributions from the Museum of Paleontology (University of Michigan), v. 30, p. 83-130.

Gunnell, G.F., and Bartels, W.S., 1994, Early Bridgerian (middle Eocene) vertebrate paleontology and paleoecology of the southern Green River Basin, Wyoming: Rocky Mountain Geology, v. 30, p. 57-70.

Gunnell, G.F., and Bartels, W.S., 1999, Middle Eocene vertebrates from the Uinta Basin, Utah, and their relationship with faunas from the southern Green River Basin, Wyoming: Utah Geological Survey Miscellaneous Publication, v. 99, p. 429-442.

Gunnell, G.F., and Bartels, W.S., 2001, Basin margins, biodiversity, evolutionary innovation, and the origin of new taxa, in Gunnell, G.F., ed., Eocene Biodiversity: Unusual Occurrences and Rarely Sampled Habitats: New York, Springer, p. 403-432.

Gunnell, G.F., and Gingerich, P.D., 1996, New hapalodectid Hapalorestes lovei (Mammalia, Mesonychia) from the early middle Eocene of northwestern Wyoming: Contributions from the Museum of Paleontology (University of Michigan), v. 29, p. 413-418.

Gunnell, G.F., Bartels, W., Gingerich, P.D., and Torres, V., 1992, Wapiti Valley faunas: early and middle Eocene fossil vertebrates from the North Fork of the Shoshone River, Park County, Wyoming: University of Michigan Contributions from the Museum of Paleontology, v. 28, p. 279-330.

Gunnell, G.F., Rose, K.D., and Rasmussen, D.T., 2008, Euprimates, in Janis, C.M., Gunnell, G.F., and Uhen, M.D., eds., Evolution of Tertiary Mammals of North America, Vol. 2: Small Mammals, Xenarthrans, and Marine Mammals: Cambridge, Cambridge University Press, p. 239-262.

Gunnell, G.F., Murphey, P.C., Stucky, R.K., Townsend, K.B., Robinson, P., Zonneveld, J., Bartels, W., and Albright, L., 2009, Biostratigraphy and biochronology of the latest Wasatchian, Bridgerian, and Uintan North American land mammal "ages": Museum of Northern Arizona Bulletin, v. 65, p. 279-330.

Gustafson, E.P. 1986, Carnivorous mammals of the late Eocene and early Oligocene of Trans-Pecos Texas: Bulletin of the Texas Memorial Museum, v. 33 , p. $1-66$.

Guthrie, D.A., 1967a, The mammalian fauna of the Lysite Member, Wind River Formation (early Eocene) of Wyoming: Memoirs of the Southern California Academy of Sciences, v. 5, p. 1-53.

Guthrie, D., 1967b, Paeneprolimnocyon, a new genus of early Eocene limnocyonid (Mammalia, Creodonta): Journal of Paleontology, v. 41, p. 1285-1287.

Hamrick, M.W., 1999, First carpals of Eocene primate family Omomyidae: Contributions from the Museum of Paleontology (University of Michigan), v. 30, p. 191-198.

Hanson, C.B., 1996, Stratigraphy and vertebrate faunas of the BridgerianDuchesnean Clarno Formation, north-central Oregon, in Prothero, D.R. and Emry, R.J., eds., The Terrestrial Eocene-Oligocene Transition in North America: Cambridge, Cambridge University Press, p. 206-239.

Hartstone-Rose, A., 2011, Reconstructing the diets of extinct South African carnivorans from premolar 'intercuspid notch' morphology: Journal of Zoology, v. 285, p. 119-127.

Hay, O.P., 1902, Bibliography and catalogue of the fossil vertebrates of North America: Bulletin of the United States Geological Survey, v. 179, p. 1-868.

Heaney, L.R., 1986, Biogeography of mammals in SE Asia: estimates of rates of colonization, extinction and speciation: Biological Journal of the Linnean Society, v. 28, p. 127-165.

Heinrich, R.E., 1997, Referral of Miacis jepseni Guthrie to Oödectes Wortman, and an assessment of phylogenetic relationships among early Eocene Miacidae (Mammalia: Carnivora): Journal of Paleontology, v. 71, p. 1172 1178

Heinrich, R.E., and Rose, K.D., 1997, Postcranial morphology and locomotor behaviour of two early Eocene miacoid carnivorans, Vulpavus and Didymic tis: Palaeontology, v. 40, p. 279-305.

Heinrich, R.E., Strait, S.G., and Houde, P., 2008, Earliest Eocene Miacidae (Mammalia: Carnivora) from northwestern Wyoming: Journal of Paleontology, v. 82, p. 154-162.

Hijmans, R.J., 2017, R Package 'geosphere': spherical trigonometry, v. 1.5-7, https://CRAN.R-project.org/package=geosphere.

Hooker, J.J., 2010, The mammal fauna of the early Eocene Blackheath Formation of Abbey Wood, London: Monograph of the Palaeontographical Society London, v. 165, p. 1-162.

Hooten, M.B., and Hobbs, N.T., 2015, A guide to Bayesian model selection for ecologists: Ecological Monographs, v. 85, p. 3-28.

Hunt, R.M., Jr., 1977, Basicranial anatomy of Cynelos Jourdan (Mammalia: Carnivora), an Aquitanian amphicyonid from the Allier Basin, France: Journal of Paleontology, p. 826-843.

Hunt, R.M., Jr., 1996, Amphicyonidae, in Prothero, D.R., and Emry, R.J., eds., The Terrestrial Eocene-Oligocene Transition in North America: Cambridge, Cambridge University Press, p. 476-485.

Hunt, R.M., Jr., 1998, Evolution of the aeluroid Carnivora. Diversity of the earliest aeluroids from Eurasia (Quercy, Hsanda-Gol) and the origin of felids: American Museum Novitates, no. 2352, p. 1-65.

Hunt, R.M., Jr., 2001, Small Oligocene amphicyonids from North America (Paradaphoenus, Mammalia, Carnivora): American Museum Novitates, no. 331, p. 1-20.

ICZN, 1999, International Code of Zoological Nomenclature, $4^{\text {th }}$ ed.: London, International Trust for Zoological Nomenclature, $306 \mathrm{p}$.

Iknayan, K.J., and Beissinger, S.R., 2018, Collapse of a desert bird community over the past century driven by climate change: Proceedings of the National Academy of Sciences, v. 115, p. 8597-8602.

Iknayan, K.J., Tingley, M.W., Furnas, B.J., and Beissinger, S.R., 2014, Detecting diversity: emerging methods to estimate species diversity: Trends in Ecology \& Evolution, v. 29, p. 97-106.

Ivy, L.D., 1994, Systematic revision of early to middle Eocene North American Hyaenodontidae (Mammalia, Creodonta) [Ph.D. dissertation]: Boulder, University of Colorado, Boulder, $463 \mathrm{p}$.

Jeffreys, H., 1961, Theory of Probability, $3^{\text {rd }}$ ed.: Oxford, Clarendon Press, $470 \mathrm{p}$.

Jernvall, J., and Fortelius, M., 2004, Maintenance of trophic structure in fossil mammal communities: site occupancy and taxon resilience: American Naturalist, v. 164 , p. 614-624.

Jin, X., 2005, Mesonychids from Lushi Basin, Henan Province, China: Vertebrata PalAsiatica, v. 43, p. $151-164$

Kavanagh, K.D., Evans, A.R., and Jernvall, J., 2007, Predicting evolutionary patterns of mammalian teeth from development: Nature, v. 449, p. $427-$ 432. 
Kellner, K., 2017, R Package 'jagsUI': a wrapper around 'rjags' to streamline 'JAGS' Analyses, v. 1.4.9, https://CRAN.R-project.org/package=jagsUI.

Kelly, T.S., and Murphey, P.C., 2016, Mammals from the earliest Uintan (middle Eocene) Turtle Bluff Member, Bridger Formation, southwestern Wyoming, USA, Part 1: Primates and Rodentia: Palaeontologia Electronica, v. 19 , p. $1-55$. DOI: $10.26879 / 804$.

Kelly, T.S., Murphey, P.C., and Walsh, S.L., 2012, New records of small mammals from the middle Eocene Duchesne River Formation, Utah, and their implications for the Uintan-Duchesnean North American Land Mammal Age transition: Paludicola, v. 8, p. 208-251.

Kéry, M., and Royle, J.A., 2008, Hierarchical Bayes estimation of species richness and occupancy in spatially replicated surveys: Journal of Applied Ecology, v. 45, p. 589-598.

Kéry, M., and Royle, J.A., 2016, Applied Hierarchical Modeling in Ecology: Analysis of Distribution, Abundance and Species Richness in $\mathrm{R}$ and BUGS, Vol. 1, Prelude and Static Models: Amsterdam, Academic PressElsevier, $808 \mathrm{p}$.

Kirk, E.C., and Williams, B.A., 2011, New adapiform primate of Old World affinities from the Devil's Graveyard Formation of Texas: Journal of Human Evolution, v. 61, p. 156-168.

Kitts, D.B., 1957, A revision of the genus Orohippus (Perissodactyla, Equidae): American Museum Novitates, no. 1864, p. 1-40.

Kotsakis, T., 1980, Rivisione sistematica e distribuzione stratigrafica e geografica del genere Cynodictis Bravard \& Pomel (Carnivora, Mammalia): Bolletino Della Società Paleontologica Italiana, v. 19, p. 259-273.

Krishtalka, L., and Stucky, R.K., 1984, Middle Eocene marsupials (Mammalia) from northeastern Utah and the mammalian fauna from Powder Wash: Annals of the Carnegie Museum, v. 53, p. 31-45.

Leidy, J., 1869, The extinct mammalian fauna of Dakota and Nebraska including an account of some allied forms from other localities, together with a synopsis of the mammalian remains of North America: Journal of the Academy of Natural Sciences of Philadelphia (ser. 2), v. 7, p. $1-472$.

Leidy, J., 1870a, [Untitled proceedings for March 8, 1870]: Proceedings of the Academy of Natural Sciences of Philadelphia, v. 22, p. 9-11.

Leidy, J., 1870b, [Untitled proceedings for November 15, 1870]: Proceedings of the Academy of Natural Sciences of Philadelphia, v. 22, p. 125-127.

Leidy, J., 1871, [Untitled proceedings for May 16, 1871]: Proceedings of the Academy of Natural Sciences of Philadelphia, v. 23, p. 113-116.

Leidy, J., 1872, [Untitles proceedings for December 10, 1872]: Proceedings of the Academy of Natural Sciences of Philadelphia, v. 24, p. 276-278.

Leidy, J., 1873, Contributions to the extinct vertebrate fauna of the western territories: Report of the United States Geological Survey of the Territories, v. 1, p. $1-358$

Lillegraven, J.A., 1979, A biogeographical problem involving comparisons of later Eocene terrestrial vertebrate faunas of western North America, in Gray, J., and Boucot, A.J., eds., Historical Biogeography, Plate Tectonics, and the Changing Environment: Corvallis, Oregon State University Press, p. 333-347.

Liow, L.H., 2013, Simultaneous estimation of occupancy and detection probabilities: an illustration using Cincinnatian brachiopods: Paleobiology, v. 39 , p. $193-213$

MacGinitie, H.D., 1969, The Eocene Green River flora of northwestern Colorado and northeastern Utah: University of California Publications in Geological Sciences, v. 83, p. 1-140.

MacIntyre, G.T., 1966, The Miacidae (Mammalia, Carnivora). Part 1, the systematics of Ictidopappus and Protictis: Bulletin of the American Museum of Natural History, v. 131, p. 115-210.

MacIntyre, G.T., and Guthrie, D.A., 1979, Paeneprolimnocyon Guthrie, 1967, a junior synonym of Oodectes Wortman, 1901: Journal of Paleontology, v. 53, p. 1034-1036.

MacKenzie, D.I., Nichols, J.D., Royle, J.A., Pollock, K.H., Bailey, L., and Hines, J.E., 2017, Occupancy Estimation and Modeling: Inferring Patterns and Dynamics of Species Occurrence, $2^{\text {nd }}$ ed.: Amsterdam, Academic PressElsevier, 648 p.

Maddison, W.P., and Maddison, D.R., 2018, Mesquite: A Modular System for Evolutionary Analysis, v. 3.51, http://www.mesquiteproject.org

Marsh, O.C., 1871, Notice of some new fossil mammals and birds, from the Tertiary Formation of the West: American Journal of Science and Arts (ser. 3), v. 2 , p. $120-127$.

Marsh, O.C., 1872a, Preliminary description of new Tertiary mammals, Part 1: American Journal of Science and Arts (ser. 3), v. 4, p. 122-128.

Marsh, O.C., 1872b, Notes on a new genus of carnivores from the Tertiary of Wyoming: American Journal of Science and Arts (ser. 3), v. 4 , p. 406.

Marsh, O.C., 1872c, Preliminary description of new Tertiary mammals, Part 2-3: American Journal of Science and Arts (ser. 3), v. 4, p. 202-224.

Marsh, O.C., 1875, Notice of new Tertiary mammals, Part 4: American Journal of Science and Arts (ser. 3), v. 9, p. 239-250.
Marsh, O.C., 1876, Notice of new Tertiary mammals: American Journal of Science and Arts (ser. 3), v. 12, p. 401-404.

Marsh, O.C., 1877, Notice of some new vertebrate fossils: American Journal of Science (ser. 3), v. 14, p. 249-256.

Marsh, O.C., 1899, Note on a Bridger Eocene carnivore: American Journal of Science and Arts (ser. 4), v. 7, p. 397.

Martin, L.D., 1998, Nimravidae, in Janis, C.M., Scott, K.M., and Jacobs, L.L., eds., Evolution of Tertiary Mammals of North America, Vol. 1: Terrestrial Carnivores, Ungulates, and Ungulatelike mammals: Cambridge, Cambridge University Press, p. 228-235.

Matthew, W.D., 1901, Additional observations on the Creodonta: Bulletin of the American Museum of Natural History, v. 14, p. 1-37.

Matthew, W.D., 1906, The osteology of Sinopa, a creodont mammal of the middle Eocene: Proceedings of the United States National Museum, v. 30 , p. $203-233$.

Matthew, W.D., 1909, The Carnivora and Insectivora of the Bridger Basin, middle Eocene: Memoirs of the American Museum of Natural History, v. 9, p. 289-576.

Matthew, W.D., and Granger, W., 1915, A revision of the lower Eocene Wasatch and Wind River faunas: Bulletin of the American Museum of Natural History, v. 34, p. 1-103.

Matthew, W.D., and Granger, W., 1924, New Carnivora from the Tertiary of Mongolia: American Museum Novitates, no. 104, p. 1-9.

Matthew, W.D., and Granger, W., 1925, New mammals from the Irdin Manha Eocene of Mongolia: American Museum Novitates, no. 198, p. 1-10.

McCarroll, S.M., Flynn, J.J., and Turnbull, W.D., 1996a, The mammalian faunas of the Washakie Formation, Eocene age, of southern Wyoming, part III: the perissodactyls: Fieldiana Geology (New Series), v. 33 (Publ. 1474), p. $1-38$.

McCarroll, S.M., Flynn, J.J., and Turnbull, W.D., 1996b, Biostratigraphy and magnetostratigraphy of the Bridgerian-Uintan Washakie Formation, Washakie Basin, Wyoming; p. 25-39, in Prothero, D.R., and Emry, R.J., eds., The Terrestrial Eocene-Oligocene Transition in North America: Cambridge, Cambridge University Press, p. 25-39.

McGrew, P.O., Berman, J.E., Hecht, M.K., Hummel, J.M., Simpson, G.G., and Wood, A.E., 1959, The geology and paleontology of the Elk Mountain and Tabernacle Butte area, Wyoming: Bulletin of the American Museum of Natural History, v. 117, p. 117-176.

McKenna, M.C., 1980, Late Cretaceous and early Tertiary vertebrate paleontological reconnaissance, Togwotee Pass area, northwestern Wyoming, in Jacobs, L.L., ed., Aspects of Vertebrate History: Flagstaff, Arizona, Museum of Northern Arizona Press, p. 321-343.

McKenna, M.C., 1990, Plagiomenids (Mammalia: ?Dermoptera) from the Oligocene of Oregon, Montana, and South Dakota, and middle Eocene of northwestern Wyoming, in Bown, T.M., and Rose, K.D., eds., Dawn of the Age of Mammals in the Northern Part of the Rocky Mountain Interior, North America: Geological Society of America, Special Paper 243, p. 211-234.

Mellett, J.S., 1969a, A skull of Hemipsalodon (Mammalia, Deltatheridia) from the Clarno Formation of Oregon: American Museum Novitates, no. 2387, p. 1-19.

Mellett, J.S., 1969b, Carnassial rotation in a fossil carnivore: American Midland Naturalist, v. 82 , p. $287-289$.

Meredith, M., and Kruschke, J., 2018, R Package 'HDInterval': Highest (Posterior) Density Intervals, v. 0.2.0, https://CRAN.R-project.org/package= HDInterval.

Michalski, F., and Peres, C.A., 2005, Anthropogenic determinants of primate and carnivore local extinctions in a fragmented forest landscape of southern Amazonia: Biological Conservation, v. 124, p. 383-396.

Mihlbachler, M.C., 2008, Species taxonomy, phylogeny, and biogeography of the Brontotheriidae (Mammalia: Perissodactyla): Bulletin of the American Museum of Natural History, no. 311, p. 1-475.

Morlo, M., and Gunnell, G.F., 2003, Small Limnocyonines (Hyaenodontidae, Mammalia) from the Bridgerian middle Eocene of Wyoming: Thinocyon, Prolimnocyon, and Iridonon, new genus: Contributions from the Museum of Paleontology (University of Michigan), v. 31, p. 43-78.

Morlo, M., and Gunnell, G.F., 2005, New species of Limnocyon (Mammalia, Creodonta) from the Bridgerian (middle Eocene): Journal of Vertebrate Paleontology, v. 25, p. 251-255.

Morlo, M., Bastl, K., Wenhao, W., and Schaal, S.F., 2014, The first species of Sinopa (Hyaenodontida, Mammalia) from outside of North America: implications for the history of the genus in the Eocene of Asia and North America: Palaeontology, v. 57, p. 111-125.

Morris, W.J., 1954, An Eocene fauna from the Cathedral Bluffs Tongue of the Washakie Basin, Wyoming: Journal of Paleontology, p. 195-203.

Murphey, P.C., and Dunn, R.H., 2009, Hemiacodon engardae, a new species of omomyid primate from the earliest Uintan Turtle Bluff Member of the Bridger Formation, southwestern Wyoming, USA: Journal of Human Evolution, v. 57, p. 123-130. 
Murphey, P.C., and Evanoff, E., 2007, Stratigraphy, fossil distribution, and depositional environments of the Upper Bridger Formation (middle Eocene), southwestern Wyoming: Wyoming State Geological Survey Report of Investigations, v. 57, p. 1-107.

Murphey, P.C., and Evanoff, E., 2011, Paleontology and stratigraphy of the middle Eocene Bridger Formation, southern Green River Basin, Wyoming: Brigham Young University Geological Studies, v. 49, p. 83-109.

Murphey, P.C., and Kelly, T.S., 2017, Mammals from the earliest Uintan (middle Eocene) Turtle Bluff Member, Bridger Formation, southwestern Wyoming, USA, Part 2: Apatotheria, Lipotyphla, Carnivoramorpha, Condylartha, Dinocerata, Perissodactyla and Artiodactyla: Palaeontologia Electronica, v. 20, p. 1-51.

Murphey, P.C., Townsend, K.B., Friscia, A.R., Westgate, J., Evanoff, E., and Gunnell, G.F., 2017, Paleontology and stratigraphy of Middle Eocene rock units in the southern Green River and Uinta basins, Wyoming and Utah: Geology of the Intermountain West, v. 4, p. 1-53.

Murphey, P.C., Kelly, T.S., Chamberlain, K.R., Tsukui, K., and Clyde, W.C., 2018, Mammals from the earliest Uintan (middle Eocene) Turtle Bluff Member, Bridger Formation, southwestern Wyoming, USA, Part 3: Marsupialia and a reevaluation of the Bridgerian-Uintan North American Land Mammal Age transition: Palaeontologia Electronica, v. 21, p. 1-52.

Narita, Y., and Kuratani, S., 2005, Evolution of the vertebral formulae in mammals: a perspective on developmental constraints: Journal of Experimental Zoology Part B: Molecular and Developmental Evolution, v. 304 p. 91-106.

Newmark, W.D., 1986, Species-area relationship and its determinants for mammals in western North American national parks: Biological Journal of the Linnean Society, v. 28, p. 83-98.

Ni, X., Meng, J., Beard, K.C., Gebo, D.L., Wang, Y., and Li, C., 2009, A new tarkadectine primate from the Eocene of Inner Mongolia, China: phylogenetic and biogeographic implications: Proceedings of the Royal Society B: Biological Sciences, v. 277, p. 247-256.

Northrup, J.M., and Gerber, B.D., 2018, A comment on priors for Bayesian occupancy models: PloS One, v. 13, p. e0192819. https://doi.org/10.1371/ journal.pone.0192819.

Novacek, M.J., 1986, The skull of leptictid insectivorans and the higher-level classification of eutherian mammals: Bulletin of the American Museum of Natural History, v. 183, p. 1-112.

O'Leary, M.A., and Kaufman, S., 2011, MorphoBank: phylophenomics in the "cloud": Cladistics, v. 27, p. 529-537.

O'Leary, M., and Kaufman, S., 2012, MorphoBank 3.0: Web application for morphological phylogenetics and taxonomy, http://www.morphobank.org.

O'Leary, M.A., and Rose, K.D., 1995, Skeleton of the Early Eocene mesonychid Pachyaena (Mammalia: Mesonychia): Journal of Vertebrate Paleontology, v. 15 , p. 401-430.

O'Leary, M.A., Lucas, S.G., and Williamson, T.E., 2000, A new specimen of Ankalagon (Mammalia, Mesonychia) and evidence of sexual dimorphism in mesonychians: Journal of Vertebrate Paleontology, v. 20, p. 387-393.

Osborn, H.F., 1895, Fossil mammals of the Uinta Basin, expedition of 1894: Bulletin of the American Museum of Natural History, v. 12, p. 71-105.

Osborn, H.F., 1908, New or little known titanotheres from the Eocene and Oligocene: Bulletin of the American Museum of Natural History, v. 24, p. 599-617.

Osborn, H.F., and Wortman, J.L., 1892, Fossil mammals of the Wasatch and Wind River beds: collection of 1891: Bulletin of the American Museum of Natural History, v. 4, p. 81-147.

Pavlicev, M., Cheverud, J.M., and Wagner, G.P., 2009, Measuring morphological integration using eigenvalue variance: Evolutionary Biology, v. 36 , p. $157-170$.

Pebesma, E.J., and Bivand, R.S., 2005, Classes and methods for spatial data in R: R News, v. 5, p. 9-13.

Peigné, S., 2000, A new species of Eofelis (Carnivora: Nimravidae) from the Phosphorites of Quercy, France: Comptes Rendus de l'Académie des sciences, Sciences de la Terre et des planètes, v. 330, p. 653-658.

Peterson, O.A., 1919, Report upon the material discovered in the upper Eocene of the Uinta Basin by Earl Douglas in the years 1908-1909, and by O.A. Peterson in 1912: Annals of the Carnegie Museum, v. 12, p. 40-169.

Peterson, O.A., 1931, New mesonychids from the Uinta: Annals of the Carnegie Museum, p. 333-339.

Plummer, M., 2003, JAGS: a program for analysis of Bayesian graphical models using Gibbs sampling: Proceedings of the $3^{\text {rd }}$ International Workshop on Distributed Statistical Computing, v. 124, p. 20-22.

Plummer, M., Best, N., Cowles, K., and Vines, K., 2006, CODA: convergence diagnosis and output analysis for MCMC: R News, v. 6, p. 7-11.

Polly, P.D., 1996, The skeleton of Gazinocyon vulpeculus gen. et comb. Nov. and the cladistic relationships of Hyaenodontidae (Eutheria, Mammalia): Journal of Vertebrate Paleontology, v. 16, p. 303-319.

Polly, P.D., 2007, Evolutionary biology: development with a bite: Nature, v. 449 , p. 413.
Polly, P.D., Wesley-Hunt, G., Heinrich, R.E., Davis, G., and Houde, P., 2006, Earliest known carnivoran auditory bulla and support for a recent origin of crown-group Carnivora (Eutheria, Mammalia): Palaeontology, v. 49, p. $1019-1027$.

Prothero, D.R., 1996, Magnetic stratigraphy and biostratigraphy of the middle Eocene Uinta Formation, Uinta Basin, Utah, in Prothero, D.R., and Emry, R.J., eds., The Terrestrial Eocene-Oligocene transition in North America: Cambridge, Cambridge University Press, p. 3-24.

QGIS Development Team, 2014, QGIS Geographic Information System: Open Source Geospatial Foundation Project, v. 2.6.1, http://qgis.org.

Qi, T., 1991, Discovery of Lushilagus and Miacis in Jiangsu and its zoogeographical significance: Vertebrata PalAsiatica, v. 29, p. 59-63.

Quinet, G.E., 1966, Les mammifères du Landénien continental belge, second tome. Etude de la morphologie dentaire comparée des carnivores de Dormaal: Mémoires de l'Institut royal des Sciences naturelles de Belgique, v. 158, p. $1-64$.

R Development Core Team, 2018, R: A Language and Environment for Statistical Computing: R Foundation for Statistical Computing, Vienna, http:// www.R-project.org/.

Rana, R.S., Kumar, K., Zack, S.P., Solé, F., Rose, K.D., Missiaen, P., Singh, L., Sahni, A., and Smith, T., 2015, Craniodental and postcranial morphology of Indohyaenodon raoi from the early Eocene of India, and its implications for ecology, phylogeny, and biogeography of hyaenodontid mammals: Journal of Vertebrate Paleontology, v. 35, p. e965308. https://doi.org/10.1080/ 02724634.2015.965308.

Redford, K.H., 1992, The empty forest: BioScience, v. 42, p. 412-422.

Remy, R.R., 1992, Stratigraphy of the Eocene part of the Green River Formation in the south-central part of the Uinta Basin, Utah: United States Geological Survey Bulletin, v. 1787BB, p. 1-79.

Robinson, P., 1966, Fossil Mammalia of the Huerfano Formation, Eocene, of Colorado: Bulletin of the Peabody Museum of Natural History, v. 21, p. $1-95$.

Robinson, P., Gunnell, G.F., Walsh, S.L., Clyde, W.C., Storer, J.E., Stucky, R.K., Froehlich, D.J., Ferrusquia-Villafranca, I., and McKenna, M.C., 2004, Wasatchian through Duchesnean biochronology, in Woodburne, M.O., ed., Late Cretaceous and Cenozoic Mammals of North America: New York, Columbia University Press, p. 106-155.

Roehler, H.W., 1973, Stratigraphy of the Washakie Formation in the Washakie Basin, Wyoming: Geological Survey Bulletin, v. 1369, p. 1-40.

Roehler, H.W., 1992, Description and correlation of Eocene rocks in stratigraphic reference sections for the Green River and Washakie basins, southwest Wyoming: United States Geological Survey, Professional Paper, v. 1506-D, p. D1-D83.

Rohlf, F.J., 2017, Program TpsDig2: Digitize Landmarks and Outlines: Department of Ecology and Evolution, State University of New York at Stony Brook, https:/life.bio.sunysb.edu/morph/.

Rose, K.D., 1981, The Clarkforkian land-mammal age and mammalian faunal composition across the Paleocene-Eocene boundary: Papers on Paleontology (University of Michigan Museum of Paleontology), v. 26, p. 1-196.

Rose, K.D., 2008, Plagiomenidae and Mixodectidae, in Janis, C.M., Gunnell, G.F., and Uhen, M.D., eds., Evolution of Tertiary Mammals of North America, Vol. 2: Small Mammals, Xenarthrans, and Marine Mammals: Cambridge, Cambridge University Press, p. 198-206.

Rose, K.D., and Chinnery, B.J., 2004, The postcranial skeleton of early Eocene rodents: Bulletin of Carnegie Museum of Natural History, v. 2004 p. 211-245.

Rota, C.T., Fletcher Jr, R.J., Dorazio, R.M., and Betts, M.G., 2009, Occupancy estimation and the closure assumption: Journal of Applied Ecology, v. 46, p. $1173-1181$.

Rowe, T., 1988, Definition, diagnosis, and origin of Mammalia: Journal of Vertebrate Paleontology, v. 8, p. 241-264.

Rütimeyer, L., 1862, Eocaene Säugethiere aus dem Gebiet des Schweizerischen Jura: Neue Denkschriften der allgemeinen schweizerischen Gesellschaft für die gesammten Naturwissenschaften, v. 19, p. 1-98.

Sandom, C., Dalby, L., Fløjgaard, C., Kissling, W.D., Lenoir, J., Sandel, B., Trøjelsgaard, K., Ejrnæs, R., and Svenning, J.-C., 2013, Mammal predator and prey species richness are strongly linked at macroscales: Ecology, v. 94, p. 1112-1122.

Schlosser, M., 1888, Die Affen, Lemuren, Chiropteren, Insectivoren, Marsupialier, Creodonten und Carnivoren des europäischen Tertiärs und deren Beziehungen zu ihren lebenden und fossilen aussereuropäischen Verwandten, II: Carnivora: Beiträge zur Paläontologie Österreich-Ungarns und des Orients, v. 7, p. 1-162.

Schmidt-Kittler, N., 1981, Zur Stammesgeschichte der marderver-wandten Raubtiergruppen (Musteloidea, Carnivora): Eclogae Geologicae Helvetiae, v. 74, p. $753-801$.

Schreber, J.C.D., 1777, Die Säugthiere in Abbildungen nach der Natur mit Beschreibungen (1776-1778): Erlangen, W. Walther, v. 3, p. 377-440. 
Scott, W.B., 1888, On some new and little known creodonts: Journal of the Academy of Natural Sciences of Philadelphia (ser. 2), v. 9, p. 155185.

Scott, W.B., 1937, A remarkable sabertooth-like creodont from the Eocene of Utah: Science, v. 85, p. 454-455.

Scott, W.B., and Jepsen, G.L., 1936, The mammalian fauna of the White River Oligocene: part I. Insectivora and Carnivora: Transactions of the American Philosophical Society, v. 28, p. 1-153.

Shikama, T., 1943, A new Eocene creodont from the Hosan Coal Mine, Tyosen: Bulletin of the Biogeographical Society of Japan, v. 13, p. 7-11.

Silvestro, D., Antonelli, A., Salamin, N., and Quental, T.B., 2015, The role of clade competition in the diversification of North American canids: Proceedings of the National Academy of Sciences, v. 112, p. 8684-8689.

Simpson, G.G., 1944, Tempo and Mode in Evolution: New York, Columbia University Press, $237 \mathrm{p}$.

Slater, G.J., 2015, Iterative adaptive radiations of fossil canids show no evidence for diversity-dependent trait evolution: Proceedings of the National Academy of Sciences, v. 112, p. 4897-4902.

Smith, M.E., Carroll, A.R., and Singer, B.S., 2008, Synoptic reconstruction of a major ancient lake system: Eocene Green River Formation, western United States: Geological Society of America Bulletin, v. 120, p. 54-84.

Smith, M.E., Chamberlain, K., Singer, B., and Carroll, A., 2010, Eocene clocks agree: coeval 40Ar/39Ar, U-Pb, and astronomical ages from the Green River Formation: Geology, v. 38, p. 527-530.

Smith, T., and Smith, R., 2001, The creodonts (Mammalia, Ferae) from the Paleocene-Eocene transition in Belgium (Tienen Formation, MP7): Belgian Journal of Zoology, v. 131, p. 117-136.

Smith, T., and Smith, R., 2010, A new genus of "miacid" carnivoran from the earliest Eocene of Europe and North America: Acta Palaeontologica Polonica, v. 55, p. 761-765.

Solé, F., 2013, New proviverrine genus from the early Eocene of Europe and the first phylogeny of late Palaeocene-middle Eocene hyaenodontidans (Mammalia): Journal of Systematic Palaeontology, v. 11, p. 375-398.

Solé, F., 2014, New carnivoraforms from the early Eocene of Europe and their bearing on the evolution of the Carnivoraformes: Palaeontology, v. 57, p. 963-978.

Solé, F., Smith, R., Coillot, T., De Bast, E., and Smith, T., 2014, Dental and tarsal anatomy of 'Miacis' latouri and a phylogenetic analysis of the earliest carnivoraforms (Mammalia, Carnivoramorpha): Journal of Vertebrate Paleontology, v. 34, p. 1-21.

Solé, F., Smith, T., De Bast, E., Codrea, V., and Gheerbrant, E., 2016, New carnivoraforms from the latest Paleocene of Europe and their bearing on the origin and radiation of Carnivoraformes (Carnivoramorpha, Mammalia): Journal of Vertebrate Paleontology, v. 36, p. e1082480.

Spaulding, M., and Flynn, J.J., 2009, Anatomy of the postcranial skeleton of "Miacis" uintensis (Mammalia: Carnivoramorpha): Journal of Vertebrate Paleontology, v. 29, p. 1212-1223.

Spaulding, M., and Flynn, J.J., 2012, Phylogeny of the Carnivoramorpha: the impact of postcranial characters: Journal of Systematic Palaeontology, v. 10 , p. $653-677$.

Spaulding, M., Flynn, J.J., and Stucky, R.K., 2010, A new basal carnivoramorphan (Mammalia) from the 'Bridger B'(Black's Fork member, Bridger Formation, Bridgerian NALMA, middle Eocene) of Wyoming, USA: Palaeontology, v. 53, p. 815-832.

Stock, C., 1933, A miacid from the Sespe upper Eocene, California: Proceedings of the National Academy of Sciences of the United States of America, v. 19, p. 481.

Storer, J.E., 1984, Mammals of the Swift Current Creek local fauna (Eocene: Uintan), Saskatchewan: Natural History Contributions (Museum of Natural History, Regina), v. 7, p. 1-158.

Storer, J.E., 1996, Eocene-Oligocene faunas of the Cypress Hills Formation, Saskatchewan, in Prothero, D.R., and Emry, R.J., eds., The Terrestrial Eocene-Oligocene Transition in North America: Cambridge, Cambridge University Press, p. 240-261.

Stucky, R.K., 1984, Revision of the Wind River faunas, early Eocene of central Wyoming. Part 5: geology and biostratigraphy of the upper part of the Wind River Formation, northeastern Wind River Basin: Annals of Carnegie Museum, v. 53, p. 231-294.

Stucky, R.K., Prothero, D.R., Lohr, W.G., and Snyder, J.R., 1996, Magnetic stratigraphy, sedimentology, and mammalian faunas of the early Uintan Washakie Formation, Sand Wash Basin, northwestern Colorado, in Prothero, D.R., and Emry, R.J., eds., The Terrestrial Eocene-Oligocene Transition in North America: Cambridge, Cambridge University Press, p. $40-51$.

Szalay, F.S., and Gould, S.J., 1966, Asiatic Mesonychidae (Mammalia, Condylarthra): Bulletin of the American Museum of Natural History, v. 132, p. $127-174$.

Thorpe, M.R., 1923a, Notes on the Bridger (Eocene) Carnivora: American Journal of Science (ser. 5), v. 5, p. 23-39.
Thorpe, M.R., 1923b, New species of Uinta Carnivora from White River, Utah: American Journal of Science (ser. 5), v. 5, p. 218-224.

Ting, S., Wang, Y., Schiebout, J.A., Koch, P.L., Clyde, W.C., Bowen, G.J., and Wang, Y., 2004, New early Eocene mammalian fossils from the Hengyang Basin, Hunan China: Bulletin of Carnegie Museum of Natural History, v. 170, p. 291-302.

Tipper, J.C., 1979, Rarefaction and rarefiction: the use and abuse of a method in paleoecology: Paleobiology, v. 5, p. 423-434.

Tomida, Y., and Lee, Y.-N., 2004, A brief review of the Tertiary mammals from Korean Peninsula: Proceedings of the $5^{\text {th }}$ and $6^{\text {th }}$ Symposia on Collection Building and Natural History Studies in Asia and the Pacific Rim: National Science Museum Monographs, v. 24, p. 197-206.

Tomiya, S., 2011, A new basal caniform (Mammalia: Carnivora) from the middle Eocene of North America and remarks on the phylogeny of early carnivorans: PloS One, v. 6, p. e24146. https://doi.org/10.1371/journal.pone. 0024146 .

Tomiya, S., 2013, New carnivoraforms (Mammalia) from the middle Eocene of California, USA, and comments on the taxonomic status of "Miacis" gracilis: Palaeontologia Electronica, v. 16, p. 1-14.

Tomiya, S., and Tseng, Z.J., 2016, Whence the beardogs? Reappraisal of the middle to late Eocene 'Miacis' from Texas, USA, and the origin of Amphicyonidae (Mammalia, Carnivora): Royal Society Open Science, v. 3, p. 160518. http://doi.org/10.1098/rsos.160518.

Tong, Y., and Lei, Y., 1986, Fossil creodonts and carnivores (Mammalia) from the Hetaoyuan Eocene of Henan: Vertebrata PalAsiatica, v. 24, p. 210-221.

Townsend, K.B., Rasmussen, D.T., Murphey, P.C., and Evanoff, E., 2010, Middle Eocene habitat shifts in the North American western interior: a case study: Palaeogeography, Palaeoclimatology, Palaeoecology, v. 297, p. $144-158$.

Tsubamoto, T., Takai, M., and Egi, N., 2004, Quantitative analyses of biogeography and faunal evolution of middle to late Eocene mammals in East Asia: Journal of Vertebrate Paleontology, v. 24, p. 657-667.

Tsukui, K., and Clyde, W.C., 2012, Fine-tuning the calibration of the early to middle Eocene geomagnetic polarity time scale: paleomagnetism of radioisotopically dated tuffs from Laramide foreland basins: Bulletin, v. 124, p. 870-885.

Tsukui, K., Flynn, J.J., Ramezani, J., Machlus, M., Nuñez, C., Hemming, S.R., and Bowring, S.A., 2011, Magnetostratigraphy and high precision $\mathrm{U}-\mathrm{Pb}$ zircon geochronology of the Middle Eocene Bridger Formation, WY: Calibration of the Eocene GPTS: AGU Fall Meeting Abstracts, p. V44A-06.

Tsukui, K., Flynn, J.J., Ramezani, J., Machlus, M., and Bowring, S., 2013, Temporal calibration of the Bridgerian North American Land Mammal Age (NALMA): magnetostratigraphy and high precision U-Pb zircon geochronology of the middle Eocene Bridger Formation, Wyoming: Journal of Vertebrate Paleontology, Program and Abstracts, p. 228.

Turnbull, W., 1972, The Washakie Formation of Bridgerian-Uintan ages, and the related faunas, in West, R.M., ed., Guidebook, Field Conference on Tertiary Biostratigraphy of Southern and Western Wyoming: Garden City, New York, Adelphi University, p. 20-31.

Turnbull, W.D., 1978, The mammalian faunas of the Washakie Formation, Eocene age, of southern Wyoming, part I: introduction: the geology, history, and setting: Fieldiana Geology, v. 33 (publ. 1279), p. 569-601.

Turnbull, W.D., 1991, Protoptychus hatcheri Scott, 1895: the mammalian faunas of the Washakie Formation, Eocene age, of southern Wyoming, part II: the Adobetown Member, middle division (= Washakie B), Twka/2 (in part): Fieldiana Geology (New Series), v. 21 (publ. 1421), p. 1-33.

Turnbull, W.D., 2002, The mammalian faunas of the Washakie Formation, Eocene age, of Southern Wyoming, part IV: the uintatheres: Fieldiana Geology (New Series), v. 47 (publ. 1519), p. 1-189.

Turnbull, W.D., and Martill, D.M., 1988, Taphonomy and preservation of a monospecific titanothere assemblage from the Washakie Formation (late Eocene), southern Wyoming. An ecological accident in the fossil record: Palaeogeography, Palaeoclimatology, Palaeoecology, v. 63, p. 91-108.

Van Valen, L., 1965, Some European Proviverrini (Mammalia, Deltatheridia): Palaeontology, v. 8, p. 638-665.

Van Valen, L., 1969a, The multiple origins of the placental carnivores: Evolution, v. 23, p. 118-130.

Van Valen, L., 1969b, Evolution of dental growth and adaptation in mammalian carnivores: Evolution, v. 23, p. 96-117.

Van Valen, L., 1971, Adaptive zones and the orders of mammals: Evolution, v. 25 , p. $420-428$.

Van Valen, L., 1966, Deltatheridia, a new order of mammals: Bulletin of the American Museum of Natural History, v. 132, p. 1-126.

Van Valen, L., 1967, New Paleocene insectivores and insectivore classification: Bulletin of the American Museum of Natural History, v. 135, p. $217-284$. 
Van Valkenburgh, B., 1999, Major patterns in the history of carnivorous mammals: Annual Review of Earth and Planetary Sciences, v. 27, p. $463-493$.

Van Valkenburgh, B., Wang, X., and Damuth, J., 2004, Cope's rule, hypercarnivory, and extinction in North American canids: Science, v. 306, p. 101-104.

Vianey-Liaud, M., and Marivaux, L., 2017, Autopsie d'une radiation adaptative: phylogénie des Theridomorpha, rongeurs endémiques du Paléogène d'Europe-histoire, dynamique évolutive et intérêt biochronologique: Palaeovertebrata, v. 40, (3)-e1. doi: 10.18563/pv.40.3.e1.

Viret, J., 1942, Observations sur les canidés du genre Pseudamphicyon: Annales de l'Université de Lyon (Troisième Série), Section C, sciences naturelles, v. 1941-1942, p. 85-98.

Wall, W.P., 1982, The genus Amynodon and its relationship to other members of the Amynodontidae (Perissodactyla, Rhinocerotoidea): Journal of Paleontology, v. 56, p. 434-443.

Wall, W.P., 1989, The phylogenetic history and adaptive radiation of the Amynodontidae, in Prothero, D.R., and Schoch, R.M., eds., The Evolution of Perissodactyls: New York, Oxford University Press, p. 341-354.

Walsh, S.L., 1996a, Theoretical biochronology, the Bridgerian-Uintan boundary and the "Shoshonian subage" of the Uintan, in Prothero, D.R., and Emry, R.J., eds., The Terrestrial Eocene-Oligocene Transition in North America: Cambridge, Cambridge University Press, p. 52-74.

Walsh, S.L., 1996b, Middle Eocene mammal faunas of San Diego County, California, in Prothero, D.R., and Emry, R.J., eds., The Terrestrial EoceneOligocene Transition in North America: Cambridge, Cambridge University Press, p. 74-119.

Wang, J., and Zhang, Z.-Q., 2015, Phylogenetic analysis on Palaeogale (Palaeogalidae, Carnivora) based on specimens from Oligocene strata of Saint-Jacques, Nei Mongol: Vertebrata PalAsiatica, v. 53, p. 310-334.

Wang, X., 1993, Transformation from plantigrady to digitigrady: functional morphology of locomotion in Hesperocyon (Canidae, Carnivora): American Museum Novitates, no. 3069, p. 1-23.

Wang, X., and Tedford, R.H., 1994, Basicranial anatomy and phylogeny of primitive canids and closely related miacids (Carnivora, Mammalia) American Museum Novitates, no. 3092, p. 1-34.

Wang, X., Tedford, R.H., and Taylor, B.E., 1999, Phylogenetic systematics of the Borophaginae (Carnivora, Canidae): Bulletin of the American Museum of Natural History, v. 243, p. 1-391.

Wang, X., McKenna, M.C., and Dashzeveg, D., 2005, Amphicticeps and Amphicynodon (Arctoidea, Carnivora) from Hsanda Gol Formation, central Mongolia and phylogeny of basal arctoids with comments on zoogeography: American Museum Novitates, no. 3483, p. 1-60.

Wesley, G., and Flynn, J., 2003, A revision of Tapocyon (Carnivoramorpha), including analysis of the first cranial specimens and identification of a new species: Journal of Paleontology, v. 77, p. 769-783.

Wesley-Hunt, G., Dehghani, R., and Werdelin, L., 2008, Comparative ecomorphology and biogeography of Herpestidae and Viverridae (Carnivora), in Goswami, A., and Friscia, A.R., eds., Carnivoran Evolution: New Views on Phylogeny, Form and Function: Cambridge, Cambridge University Press, p. 246-268.

Wesley-Hunt, G.D., 2005, The morphological diversification of carnivores in North America: Paleobiology, v. 31, p. 35-55.

Wesley-Hunt, G.D., and Flynn, J.J., 2005, Phylogeny of the Carnivora: basal relationships among the carnivoramorphans, and assessment of the position of 'Miacoidea' relative to Carnivora: Journal of Systematic Palaeontology, v. 3, p. 1-28.

Wesley-Hunt, G.D., and Werdelin, L., 2005, Basicranial morphology and phylogenetic position of the upper Eocene carnivoramorphan Quercygale: Acta Palaeontologica Polonica, v. 50, p. 837-846.

West, R.M., 1973, Geology and mammalian paleontology of the New Fork-Big Sandy area, Sublette County, Wyoming: Fieldiana Geology, v. 29 (Publ. 1161), p. 1-193.

West, R.M., 1981, Geology and paleontology of the Bridger Formation, southern Green River Basin, southwestern Wyoming: Harpagolestes macroce phalus and comments on structure, function and diversity of middle Eocene to early Oligocene large mesonychids: Milwaukee Public Museum Contributions in Biology and Geology, v. 45, p. 1-17.

West, R.M., and Dawson, M.R., 1975, Eocene fossil Mammalia from the Sand Wash Basin, northwestern Moffat County, Colorado: Annals of the Carnegie Museum, v. 45, p. 231-253.

Wible, J.R., and Spaulding, M., 2013, On the cranial osteology of the African palm civet, Nandinia binotata (Gray, 1830) (Mammalia, Carnivora, Feliformia): Annals of Carnegie Museum, v. 82, p. 1-115.

Wilf, P., 2008, Insect-damaged fossil leaves record food web response to ancient climate change and extinction: New Phytologist, v. 178, p. 486-502.

Wilf, P., Labandeira, C.C., Johnson, K.R., Coley, P.D., and Cutter, A.D., 2001, Insect herbivory, plant defense, and early Cenozoic climate change: Proceedings of the National Academy of Sciences, v. 98 , p. 6221-6226.
Wilson, L.A., Madden, R.H., Kay, R.F., and Sánchez-Villagra, M.R., 2012, Testing a developmental model in the fossil record: molar proportions in South American ungulates: Paleobiology, v. 38, p. 308-321.

Wing, S.L., 1998, Tertiary vegetation of North America as a context for mammalian evolution, in Janis, C.M., Scott, K.M., and Jacobs, L.L. eds., Evolution of Tertiary Mammals of North America: Vol. 1, Terrestrial Carnivores, Ungulates, and Ungulatelike Mammals: Cambridge, Cambridge University Press, p. 37-65.

Wood, H.E.I., 1927, Some early Tertiary rhinoceroses and hyracodonts: Bulletins of the American Paleontologists, v. 13, p. 165-269.

Woodburne, M.O., 2004, Global events and the North American mammalian biochronology, in Woodburne, M.O., ed., Late Cretaceous and Cenozoic Mammals of North America: New York, Columbia University Press, p. 315-343.

Woodburne, M.O., Gunnell, G.F., and Stucky, R.K., 2009, Climate directly influences Eocene mammal faunal dynamics in North America: Proceedings of the National Academy of Sciences, v. 106, p. 13399-13403.

Wortman, J.L., 1901a, Studies of Eocene Mammalia in the Marsh Collection, Peabody Museum: American Journal of Science (ser. 4), v. 11, p. 333 348, 437-450.

Wortman, J.L., 1901b, Studies of Eocene Mammalia in the Marsh Collection, Peabody Museum: American Journal of Science (ser. 4), v. 12, p. 143154, 193-206, 281-296, 377-382, 421-432.

Wortman, J.L., 1902a, Studies of Eocene Mammalia in the Marsh Collection, Peabody Museum: American Journal of Science (ser. 4), v. 13, p. 39-46, 115-128, 197-206, 433-448.

Wortman, J.L., 1902b, Studies of Eocene Mammalia in the Marsh Collection, Peabody Museum: American Journal of Science (ser. 4), v. 14, p. 17-23.

Wortman, J.L., and Matthew, W.D., 1899, The ancestry of certain members of the Canidae, the Viverridae, and Procyonidae: Bulletin of the American Museum of Natural History, v. 12, p. 109-139.

Wyss, A.R., and Flynn, J.J., 1993, A phylogenetic analysis and definition of the Carnivora, in Szalay, F.S., Novacek, M.J., and McKenna, M.C., eds., Mammal Phylogeny: Placentals: New York, Springer Verlag, p. 32-52.

Zack, S.P., 2011, New species of the rare early Eocene creodont Galecyon and the radiation of early Hyaenodontidae: Journal of Paleontology, v. 85, p. 315-336.

Zack, S.P., 2012, Deciduous dentition of Didymictis (Carnivoramorpha: Viverravidae): implications for the first appearance of "Creodonta": Journal of Mammalogy, v. 93, p. 808-817.

Zack, S.P., 2019a, A skeleton of a Uintan machaeroidine 'creodont' and the phylogeny of carnivorous eutherian mammals: Journal of Systematic Palaeontology, v. 17, p. 653-689.

Zack, S.P., 2019b, The first North American Propterodon (Hyaenodonta: Hyaenodontidae), a new species from the late Uintan of Utah: PeerJ, v. 7 , p. e8136. https://doi.org/10.7717/peerj.8136.

Zack, S.P., and Rose, K.D., 2015, The postcranial skeleton of Galecyon: evidence for morphological and locomotor diversity in early Hyaenodontidae (Mammalia, Hyaenodontida): Journal of Vertebrate Paleontology, v. 35, p. e1001492.

Zack, S.P., and Tomiya, S., 2016, New postcrania clarify the affinities of the unusual Eocene mammal Simidectes: Journal of Vertebrate Paleontology, Program and Abstracts, p. 256A.

Zonneveld, J.-P., Gunnell, G.F., and Bartels, W.S., 2000, Early Eocene fossil vertebrates from the southwestern Green River Basin, Lincoln and Uinta counties, Wyoming: Journal of Vertebrate Paleontology, v. 20, p. 369-386.

Accepted: 15 August 2020

\section{Appendix}

Additional notes on character matrix data.-The morphological data set of Solé et al. (2016), which expanded upon earlier works (see Materials and Methods), was further modified for this study as summarized in Table A1 (see Table A2 for list of specimens examined and other data sources). Unless otherwise noted, character numbers followed those in Wesley-Hunt and Flynn (2005), Spaulding and Flynn (2012), and Solé et al. (2016). In addition, we introduced the following new characters:

(1) Character 247 (form of M1 protocone): 0, labial slope of protocone shallower than, or comparable to, the lingual 
slope; 1, labial slope markedly steeper than the lingual slope.

(2) Character 248 ( $\mathrm{m} 2$ postparacristid orientation): 0, parallel with postmetacristid, and directed lingually; 1, not parallel with postmetacristid, and more anteriorly directed; 2, paraconid (and postparacristid) vestigial or absent.

(3) Character 249 (form of P4 parastylar region): 0, strong anterior projection, forming deep anterior flexus with protocone region in occlusal view; 1 , weak anterior projection, with very shallow anterior flexus.

(4) Character 250 (M1 enamel crenulation along anterior border): 0 , absent; 1 , present.

The scores for Neovulpavus washakius (originally based on the holotype AMNH FM 2305) and FMNH PM 3869 (previously incorrectly cited as "PM 3868" in Spaulding and Flynn, 2012, and Solé et al., 2014, 2016) were merged to represent a single operational taxonomic unit, given close dental and postcranial similarities between the two specimens. Data from the dental elements of FMNH PM 3869 (unrecognized in previous publications) were newly incorporated into the character matrix. Scores for crown-group carnivorans not included in Solé et al.'s (2016) study were adopted from Tomiya and Tseng (2016; see also Tomiya, 2011), and those for Palaeogale sp. from Wang and Zhang (2015; their character 89 [ $\mathrm{m} 1$ metaconid presence] was not incorporated into the present analysis).

Comments on biostratigraphy.-Granger (1909) identified two distinct fossil mammal assemblages within what is today recognized as the Adobe Town Member-one with a Bridgerian and the other with a Uintan character-and designated the rocks of corresponding ages as "horizons A and B" (p. 20). He selected his "stratum No. 11" (p. 20; equivalent to bed 620 of Roehler, 1973) as the marker separating the two horizons because it was laterally extensive and easily identified within the basin. However, he also noted that the age of the overlying $\sim 16.5 \mathrm{~m}$ of sediments (his strata nos. 12 and 13) in his measured section in the northeastern part of the basin was indeterminate because they had not yielded age-diagnostic fossils.

While subsequent investigations by various workers have significantly improved the biostratigraphic interpretation of the Washakie Formation, precise position of the Bridgerian-Uintan biochronologic boundary within the sequence remains unresolved and is thought to be somewhere high in Twkal or low in Twka2, both of which represent generally fossil-poor portions of the formation (Flynn, 1986; McCarroll et al., 1996b; Gunnell et al., 2009). None of the index taxa of the earliest Uintan (Ui1a) subage is presently known from the Washakie Formation (Murphey and Dunn, 2009; Kelly and Murphey, 2016; Murphey and Kelly, 2017; Murphey et al., 2018; note Ui1a, as currently defined, differs from the original definition of the earliest Uintan "Shoshonian" interval of Flynn, 1986), although it should be noted that: (1) those taxa are known only from the Turtle Bluff Member of the Bridger Formation and may have had highly restricted distributions geographically or temporally; and (2) large mammals are poorly represented in fossil assemblages from the Turtle Bluff Member (Townsend et al., 2010;
Murphey et al., 2018). Thus, there currently is no biostratigraphic evidence supporting Roehler's (1992, p. D14) suggestion (without elaboration) that Washakie beds 629-645 are approximately coeval with the Bridger E horizon (i.e., Turtle Bluff Member).

More tractable, though still complicated, is identification of the lower boundary of early Uintan (Ui1b) horizons in the formation based on the lowest stratigraphic datum for the amynodontid rhinocerotoid Amynodon (Flynn, 1986; McCarroll et al., 1996a; Murphey et al., 2018). McCarroll et al. (1996b) reported five specimens of Amynodon advenus (Marsh, 1875) from the Twka2 interval, noting that FMNH PM 3874 from locality FM-8-57-WDT represented the stratigraphically lowest occurrence of the genus in the formation. Through extensive re-examination of Washakie perissodactyl specimens and further processing of previously uncataloged materials in the FMNH collection by one of us (ST), we recognize eight additional specimens of Amynodon from Twka2 (Appendix, Table A3); they include a second specimen from locality FM-8-57-WDT, FMNH PM 3937, which McCarroll et al. (1996b) identified as an indeterminate hyracodontid, but we regard as Amynodon based on its size and M3 with a quadratic occlusal outline (Bin Bai, personal communication with ST, 2014; see also Wall, 1989).

With the available stratigraphic resolution of locality data, FM-8-57-WDT-a fossiliferous Twka2 locality in the centralwestern part of the basin-still corresponds to the lowest stratigraphic datum for Amynodon within the Washakie Formation. However, its precise position within Twka2 is in need of clarification: Turnbull (1991, p. 2) described the lithology of locality FM-8-57-WDT - also known as the "Protoptychus locality"and considered it to be "near to the level of Roehler's bed 640," but McCarroll et al. (1996a, p. 29) stated that the lowest occurrence of Amynodon was at "approximately Bed 630" (presumably in reference to FM-8-57-WDT), without elaborating. The latter assessment was cited in subsequent studies on the Bridgerian-Uintan NALMA boundary (Walsh, 1996a; Murphey et al., 2018). The difference between beds 630 and 640 is equivalent to $\sim 112 \mathrm{~m}$ of sediments in Roehler's (1973) measured section, and is not negligible in a biostratigraphic discussion of the Washakie Formation.

Importantly, the lithology of Roehler's (1973) bed 630 itself (limy and very hard sandstone grading into oolitic limestone; Roehler, 1992) is inconsistent with that of the Protoptychus locality (dark-green and friable sandstone unit showing light induration and abundant cross-bedding, and including "thin lenticular stringers of pebbles") as described by Turnbull (1991, p. 2), and based on our observation of sedimentary matrix samples in the FMNH collection (ST). Instead, we think the combination of lithology, stratigraphic features, and occurrence of vertebrate fossils and petrified wood at locality FM-8-57-WDT better match bed 633 (cf., Roehler, 1973, 1992), which Roehler (1992) identified as Granger's (1909) stratum no. 17. Additional evidence for occurrence of Amynodon in this horizon is provided by UCMP 69378 (cf., Wall, 1982): this specimen is reportedly from Granger's stratum no. 17 on Haystack Mountain, although there is some uncertainty regarding its stratigraphic position (J. Howard Hutchison-Malcolm C. McKenna 1976-1978 correspondence on file at UCMP). 
Thus, we tentatively regard the portion of Twka 2 at and above the level of bed 633 to be Uilb in age.

Our hypothesis, which will need to be tested with additional stratigraphic work correlating horizons across the Washakie Basin, implies that there is no direct evidence for co-occurrence of the hyopsodontid Hyopsodus and primate Notharctus with Amynodon within the Washakie Formation, contrary to earlier assessments by Flynn (1986) and McCarroll et al. (1996a). This is because (1) no single locality has yielded both Amynodon and either Hyopsodus or Notharctus; (2) the highest stratigraphic occurrence of Hyopsodus is in bed 630 (FMNH PM 55694 and 55863 from locality JJF 7-25-92-1); and (3) the highest stratigraphic occurrence of Notharctus (FMNH PM 61334 from locality JJF 7-27-95-1, which represents the only occurrence of the genus in Twka2) is stratigraphically too poorly constrained to be informative (recorded as above Granger's stratum no. 11 and below the Rose Red marker bed, i.e., between bed 621 and 643). Consequently, it is possible that the lowest part of Twka2, from bed 620 to bed 630 , is $\mathrm{Br} 3$ in age (or Uila, but again, there is no evidence for it). The occurrences in that part of Twka2 of the equid Orohippus sp. (FMNH PM 61339; bed 621-643 at locality JJF 7-27-95-1), oxyaenid Patriofelis sp. (FMNH PM 70167; bed 621-625 at locality FM-6-58-WDT), hyaenodontid Sinopa sp. A (FMNH PM 62725; likely from horizon near that of FM-6-58-WDT, i.e., bed 621-625 at locality FM-4-81-WDT), carnivoraform cf. Neovulpavus washakius (FMNH PM 61576; bed 621-625 at locality FM-6-58-WDT), and brontotheriid Mesatirhinus junius (Leidy, 1872) (FMNH PM 54864; bed 625-630 at locality FM-7-83-KL/WT) - none of which is definitively known from post-Bridgerian deposits-further suggest existence of at least some Br3 horizons above Granger's (1909) stratum no. 11. Note that FMNH PM 54864 and FMNH PM 1676 were previously reported as the only early Uintan specimens of Mesatirhinus junius, a species that is otherwise confined to the late Bridgerian ( $\mathrm{Br} 3)$ subage, based on their occurrences within Twka2 (Mihlbachler, 2008, p. 33); however, as we discussed above, the lower portion of Twka2 is not necessarily Uintan in age, and the fragmentary material representing FMNH PM 1676 was considered generically indeterminate by McCarroll et al. (1996b), so neither of these specimens, in our opinion, can be regarded as a secure Uintan record of that species.

Occupancy-detection modeling procedure.-When species-specific effects are randomly drawn from common ('community') distributions, occupancy by (with probability $\psi$ ) and detection of (with probability $p$ ) species $k$ (where $k=1$, $\ldots, m$ ) at 'site' $i$ (where $i=1, \ldots, n$ ) during 'replicate' observation $j$ (where $j=1, \ldots, J_{i}$ ) can be hierarchically modeled as follows (cf., Kéry and Royle, 2016):

$$
\begin{aligned}
w_{k} & \sim \operatorname{Bernoulli}(\Omega) \\
z_{i k} \mid w_{k} & \sim \operatorname{Bernoulli}\left(w_{k} \psi_{i k}\right) \\
y_{i j k} \mid z_{i k} & \sim \operatorname{Bernoulli}\left(z_{i k} p_{i j k}\right)
\end{aligned}
$$

$$
\begin{gathered}
\operatorname{logit}\left(\psi_{i k}\right)=\beta_{\psi 0, k}+\mathbf{x}_{\mathrm{S}, i}^{\prime} \boldsymbol{\beta}_{\psi, k} \\
\operatorname{logit}\left(p_{i j k}\right)=\beta_{p 0, k}+\mathbf{x}_{\mathrm{R}, i j}^{\prime} \boldsymbol{\beta}_{p, k} \\
\Omega \sim \operatorname{Uniform}(0,1) \\
\beta_{\psi 0, k} \sim \operatorname{Normal}\left(\overline{\boldsymbol{\beta}_{\psi 0}}, \sigma_{\beta_{\psi p}}\right) \\
\boldsymbol{\beta}_{\psi, k} \sim \operatorname{Normal}\left(\overline{\boldsymbol{\beta}_{\psi}}, \boldsymbol{\sigma}_{\beta_{\psi}}\right) \\
\beta_{p 0, k} \sim \operatorname{Normal}\left(\overline{\bar{\beta}_{p 0}}, \sigma_{\beta_{p 0}}\right) \\
\boldsymbol{\beta}_{p, k} \sim \operatorname{Normal}\left(\overline{\boldsymbol{\beta}_{p}}, \quad \sigma_{\beta_{p}}\right)
\end{gathered}
$$

where $\Omega$ is the super-population parameter governing the presence of species (including those that were not detected at any site) within the spatiotemporal extent of the study system encompassed by all the sites under consideration, $z_{i k}$ and $y_{i j k}$ are binary variables for occupancy of site $i$ by species $k$ and detection of species $k$ at site $i$ during replicate observation $j$, respectively, and $\mathbf{x}_{\mathrm{S}, i}$ and $\mathbf{x}_{\mathrm{R}, i j}$ are site- and replicate-level covariates, respectively. We followed Broms et al. (2016; see also Iknayan and Beissinger, 2018; Northrup and Gerber, 2018) and specified the hyperpriors for model parameters to be weakly-informative by adopting: (1) normal distributions, each with a mean of zero and a standard deviation of 2.25 for the community-mean parameters $\left(\overline{\beta_{\psi 0}}, \overline{\beta_{\psi 1}}, \overline{\beta_{p 0}}, \overline{\beta_{p 1}}, \overline{\beta_{p 2}}\right)$; and (2) half-Cauchy distributions, each with a location-parameter value of zero and a scale-parameter value of 2.25 for the community-variance parameters $\left(\sigma_{\beta_{\psi p}}, \sigma_{\beta_{\psi 1}}, \sigma_{\beta_{p 0}}, \sigma_{\beta_{p 1}}, \sigma_{\beta_{p 2}}\right)$. All covariate values were standardized. The maximum possible number of species in the study system was set to 100 (23 detected species plus 77 undetected species); we confirmed through preliminary analyses that this amount of data augmentation sufficed to avoid artificial truncation of estimated distributions of species richnesses across locality groups.

Bayesian model selection procedure.-We assessed posterior probabilities of the occupancy-detection models by extending Hooten and Hobbs' (2015) implementation of the reversible-jump Markov chain Monte Carlo (RJMCMC) method of Barker and Link (2013) to the present case of multispecies occupancy-detection modeling. In essence, this method generates posterior model probabilities through Gibbs sampling, with the following steps: (1) select a model $M_{l}$ (a categorical variable where $l=1, \ldots, q$ ); (2) obtain parameter estimates for $M_{l}$ (select an MCMC posterior sample for $M_{l}$ produced by the modeling process); (3) calculate the full conditional probability for each model using the parameter estimates for $M_{l}$ (see below and Supplementary Data 1 for $\mathrm{R}$ script); (4) select a new model with the full conditional probability calculated in (3); (5) return to (2) and repeat for all 
available MCMC posterior samples to produce a chain of selected models; (6) compute relative frequencies of models in the chain, which represent posterior model probabilities (Barker and Link, 2013; Hooten and Hobbs, 2015). Note that the model parameters $\boldsymbol{\theta}_{l}$ are treated as random variables $\boldsymbol{\theta}_{l}$ in the Bayesian context.

The full conditional model probability for a hierarchical occupancy-detection model $M_{l}$ can be expressed as (see Barker and Link, 2013 for derivation):

$$
\operatorname{Pr}\left(M_{l} \mid \cdot\right)=\frac{\operatorname{Pr}\left(\boldsymbol{y} \mid \boldsymbol{\theta}_{l}, M_{l}\right) \operatorname{Pr}\left(\boldsymbol{\theta}_{l} \mid M_{l}\right) \operatorname{Pr}\left(\boldsymbol{u}_{l} \mid M_{l}\right)\left|\mathrm{A}_{l}\right| \operatorname{Pr}\left(M_{l}\right)}{\sum_{l=1}^{q} \operatorname{Pr}\left(\boldsymbol{y} \mid \boldsymbol{\theta}_{l}, M_{l}\right) \operatorname{Pr}\left(\boldsymbol{\theta}_{l} \mid M_{l}\right) \operatorname{Pr}\left(\boldsymbol{u}_{l} \mid M_{l}\right)\left|\mathrm{A}_{l}\right| \operatorname{Pr}\left(M_{l}\right)}
$$

where $\boldsymbol{u}_{l}$ is a set of auxiliary variables introduced to the model $M_{l}$ to maintain the same dimensionality across all models, and $\left|A_{l}\right|$ is the Jacobian determinant for mapping (i.e., bijection) of a universal parameter $\zeta$ (= "palette" of Barker and Link, 2013, which summarizes $\boldsymbol{\theta}_{l}$ and $\boldsymbol{u}_{l}$ ) onto the parameter space for the model $M_{l}$ (Barker and Link, 2013). As in the RJMCMC example of Hooten and Hobbs (2015, eq. 59), we adopted identity mapping such that each dimension of the universal parameter $\zeta$ directly corresponded to a specific model parameter $\theta_{l}$ or auxiliary variable $u_{l}$ (Table A4); thus, $\left|A_{l}\right|=1$ and the Jacobian determinant was dropped from Eq. A11.

Focusing on the numerator of Eq. A11, the likelihood term for a single-species model can be obtained as:

$$
\begin{aligned}
\operatorname{Pr}\left(\boldsymbol{y} \mid \boldsymbol{\theta}_{\boldsymbol{l}}, M_{l}\right)= & \prod_{i=1}^{n}\left[\psi_{i, l}\left(1-\prod_{j=1}^{J_{i}}\left(1-p_{i j, l}\right)\right) I \sum_{j=1}^{J_{i}} y_{i j}>0\right\} \\
& \left.+\left\{\left(1-\psi_{i, l}\right)+\psi_{i, l} \prod_{j=1}^{J_{i}}\left(1-p_{i j, l}\right)\right\} I_{\left\{\sum_{j=1}^{J_{i}} y_{i j}=0\right\}}\right]
\end{aligned}
$$

where $I$ is an indicator variable equaling 1 if the condition is satisfied and 0 otherwise (cf., Hooten and Hobbs, 2015). For our multispecies models with data augmentation, we modify Eq. A12 as:

$$
\begin{aligned}
& \operatorname{Pr}\left(\boldsymbol{y} \mid \boldsymbol{\theta}_{\boldsymbol{l}}, M_{l}\right)= \\
& \prod_{k=1}^{m} \prod_{i=1}^{n}\left[\Omega \psi_{i k, l}\left(1-\prod_{j=1}^{J_{i}}\left(1-p_{i j k, l}\right)\right) I_{\left\{\sum_{j=1}^{J_{i}} y_{j k}>0\right\}}+\{(1-\Omega)+\right. \\
& \left.\left.\quad \Omega\left(1-\psi_{i k, l}\right)+\Omega \psi_{i k, l} \prod_{j=1}^{J_{i}}\left(1-p_{i j k, l}\right)\right\} I_{\left\{\sum_{j=1}^{J_{i}} y_{i j}=0\right\}}\right]
\end{aligned}
$$

For the four models under our consideration in this study, the second and third terms in the numerator of Eq. A11-which together represent the product of the priors for the model parameters and auxiliary variables—become:

$$
\begin{gathered}
\operatorname{Pr}\left(\boldsymbol{\theta}_{l}^{(t)} \mid M_{1}\right) \operatorname{Pr}\left(\boldsymbol{u}_{l}^{(t)} \mid M_{1}\right)= \\
{\left[\operatorname{Pr}\left(\overline{\beta_{\psi 0}}=\zeta_{1}^{(t)}\right) \operatorname{Pr}\left(\sigma_{\beta_{\psi 0}}=\zeta_{2}^{(t)}\right) \operatorname{Pr}\left(\beta_{\psi 0, k}=\zeta_{3}^{(t)}\right)\right.} \\
\operatorname{Pr}\left(u_{\overline{\beta_{\psi 1}}}=\zeta_{4}^{(t)}\right) \operatorname{Pr}\left(u_{\sigma_{\beta_{\psi 1}}}=\zeta_{5}^{(t)}\right) \operatorname{Pr}\left(u_{\beta_{\psi 1}, k}=\zeta_{6}^{(t)}\right) \\
\prod_{k=1}^{m} \quad \operatorname{Pr}\left(\overline{\beta_{p 0}}=\zeta_{7}^{(t)}\right) \operatorname{Pr}\left(\sigma_{\beta_{p 0}}=\zeta_{8}^{(t)}\right) \operatorname{Pr}\left(\beta_{p 0, k}=\zeta_{9}^{(t)}\right) \\
\operatorname{Pr}\left(u \overline{\beta_{p 1}}=\zeta_{10}^{(t)}\right) \operatorname{Pr}\left(u_{\sigma_{\beta_{p 1}}}=\zeta_{11}^{(t)}\right) \operatorname{Pr}\left(u_{\beta_{p 1}, k}=\zeta_{12}^{(t)}\right) \\
\left.\operatorname{Pr}\left(u_{\overline{\beta_{p 2}}}=\zeta_{13}^{(t)}\right) \operatorname{Pr}\left(u_{\sigma_{\beta_{p 2}}}=\zeta_{14}^{(t)}\right) \operatorname{Pr}\left(u_{\beta_{p 2}, k}=\zeta_{15}^{(t)}\right)\right]
\end{gathered}
$$

$$
\begin{gathered}
\operatorname{Pr}\left(\boldsymbol{\theta}_{l}^{(t)} \mid M_{2}\right) \operatorname{Pr}\left(\boldsymbol{u}_{l}^{(t)} \mid M_{2}\right)= \\
{\left[\operatorname{Pr}\left(\overline{\beta_{\psi 0}}=\zeta_{1}^{(t)}\right) \operatorname{Pr}\left(\sigma_{\beta_{\psi 0}}=\zeta_{2}^{(t)}\right) \operatorname{Pr}\left(\beta_{\psi 0, k}=\zeta_{3}^{(t)}\right)\right.} \\
\operatorname{Pr}\left(u_{\overline{\beta_{\psi 1}}}=\zeta_{4}^{(t)}\right) \operatorname{Pr}\left(u_{\sigma_{\beta_{\psi 1}}}=\zeta_{5}^{(t)}\right) \operatorname{Pr}\left(u_{\beta_{\psi 1}, k}=\zeta_{6}^{(t)}\right) \\
\prod_{k=1}^{m} \quad \operatorname{Pr}\left(\overline{\beta_{p 0}}=\zeta_{7}^{(t)}\right) \operatorname{Pr}\left(\sigma_{\beta_{p 0}}=\zeta_{8}^{(t)}\right) \operatorname{Pr}\left(\beta_{p 0, k}=\zeta_{9}^{(t)}\right) \\
\operatorname{Pr}\left(\overline{\beta_{p 1}}=\zeta_{10}^{(t)}\right) \operatorname{Pr}\left(\sigma_{\beta_{p 1}}=\zeta_{11}^{(t)}\right) \operatorname{Pr}\left(\beta_{p 1, k}=\zeta_{12}^{(t)}\right) \\
\left.\operatorname{Pr}\left(u_{\overline{\beta_{p 2}}}=\zeta_{13}^{(t)}\right) \operatorname{Pr}\left(u_{\sigma_{\beta_{p 2}}}=\zeta_{14}^{(t)}\right) \operatorname{Pr}\left(u_{\beta_{p 2}, k}=\zeta_{15}^{(t)}\right)\right]
\end{gathered}
$$

$$
\begin{gathered}
\operatorname{Pr}\left(\boldsymbol{\theta}_{l}^{(t)} \mid M_{3}\right) \operatorname{Pr}\left(\boldsymbol{u}_{l}^{(t)} \mid M_{3}\right)= \\
{\left[\operatorname{Pr}\left(\overline{\beta_{\psi 0}}=\zeta_{1}^{(t)}\right) \operatorname{Pr}\left(\sigma_{\beta_{\psi 0}}=\zeta_{2}^{(t)}\right) \operatorname{Pr}\left(\beta_{\psi 0, k}=\zeta_{3}^{(t)}\right)\right.} \\
\operatorname{Pr}\left(u_{\overline{\beta_{\psi 1}}}=\zeta_{4}^{(t)}\right) \operatorname{Pr}\left(u_{\sigma_{\beta_{\psi 1}}}=\zeta_{5}^{(t)}\right) \operatorname{Pr}\left(u_{\beta_{\psi 1}, k}=\zeta_{6}^{(t)}\right) \\
\prod_{k=1}^{m} \quad \operatorname{Pr}\left(\overline{\beta_{p 0}}=\zeta_{7}^{(t)}\right) \operatorname{Pr}\left(\sigma_{\beta_{p 0}}=\zeta_{8}^{(t)}\right) \operatorname{Pr}\left(\beta_{p 0, k}=\zeta_{9}^{(t)}\right) \\
\operatorname{Pr}\left(u_{\overline{\beta_{p 1}}}=\zeta_{10}^{(t)}\right) \operatorname{Pr}\left(u_{\sigma_{\beta_{p 1}}}=\zeta_{11}^{(t)}\right) \operatorname{Pr}\left(u_{\beta_{p 1}, k}=\zeta_{12}^{(t)}\right) \\
\left.\operatorname{Pr}\left(\overline{\beta_{p 2}}=\zeta_{13}^{(t)}\right) \operatorname{Pr}\left(\sigma_{\beta_{p 2}}=\zeta_{14}^{(t)}\right) \operatorname{Pr}\left(\beta_{p 2, k}=\zeta_{15}^{(t)}\right)\right]
\end{gathered}
$$

$$
\begin{gathered}
\operatorname{Pr}\left(\boldsymbol{\theta}_{l}^{(t)} \mid M_{4}\right) \operatorname{Pr}\left(\boldsymbol{u}_{l}^{(t)} \mid M_{4}\right)= \\
{\left[\operatorname{Pr}\left(\overline{\beta_{\psi 0}}=\zeta_{1}^{(t)}\right) \operatorname{Pr}\left(\sigma_{\beta_{\psi 0}}=\zeta_{2}^{(t)}\right) \operatorname{Pr}\left(\beta_{\psi 0, k}=\zeta_{3}^{(t)}\right)\right.} \\
\operatorname{Pr}\left(\overline{\beta_{\psi 1}}=\zeta_{4}^{(t)}\right) \operatorname{Pr}\left(\sigma_{\beta_{\psi 1}}=\zeta_{5}^{(t)}\right) \operatorname{Pr}\left(\beta_{\psi 1, k}=\zeta_{6}^{(t)}\right) \\
\prod_{k=1}^{m} \quad \operatorname{Pr}\left(\overline{\beta_{p 0}}=\zeta_{7}^{(t)}\right) \operatorname{Pr}\left(\sigma_{\beta_{p 0}}=\zeta_{8}^{(t)}\right) \operatorname{Pr}\left(\beta_{p 0, k}=\zeta_{9}^{(t)}\right), \\
\operatorname{Pr}\left(u_{\overline{\beta_{p 1}}}=\zeta_{10}^{(t)}\right) \operatorname{Pr}\left(u_{\sigma_{\beta_{p 1}}}=\zeta_{11}^{(t)}\right) \operatorname{Pr}\left(u_{\beta_{p 1}, k}=\zeta_{12}^{(t)}\right) \\
\left.\operatorname{Pr}\left(u \overline{\beta_{p 2}}=\zeta_{13}^{(t)}\right) \operatorname{Pr}\left(u_{\sigma_{\beta_{p 2}}}=\zeta_{14}^{(t)}\right) \operatorname{Pr}\left(u_{\beta_{p 2}, k}=\zeta_{15}^{(t)}\right)\right]
\end{gathered}
$$

for $\boldsymbol{\zeta}^{(t)}$, which consists of the $t^{\text {th }}$ MCMC sample of $\boldsymbol{\theta}_{l}$ under the model $M_{l}$ and independent samples of the auxiliary variables $\boldsymbol{u}_{l}$ (see Hooten and Hobbs, 2015 for outline of the algorithm). The auxiliary variables replacing the community-mean and speciesspecific parameters $\left(u_{\overline{\beta_{\psi 1}}}, u_{\beta_{\psi 1}, k}, u_{\overline{\beta_{p 1}}}, u_{\beta_{p 1}, k}, u_{\overline{\beta_{p 2}}}, u_{\beta_{p 2}, k}\right)$ were each assigned a normal prior distribution with a mean of zero and a standard deviation of 2.25 , and those replacing the community-variance parameters $\left(u_{\sigma_{\beta_{41}}}, u_{\sigma_{\beta_{p 1}}}, u_{\sigma_{\beta_{p 2}}}\right)$ were each assigned a half-Cauchy prior distribution with a locationparameter value of zero and a scale-parameter value of 2.25 , mirroring the settings for the model parameters. Note that $\operatorname{Pr}$ 


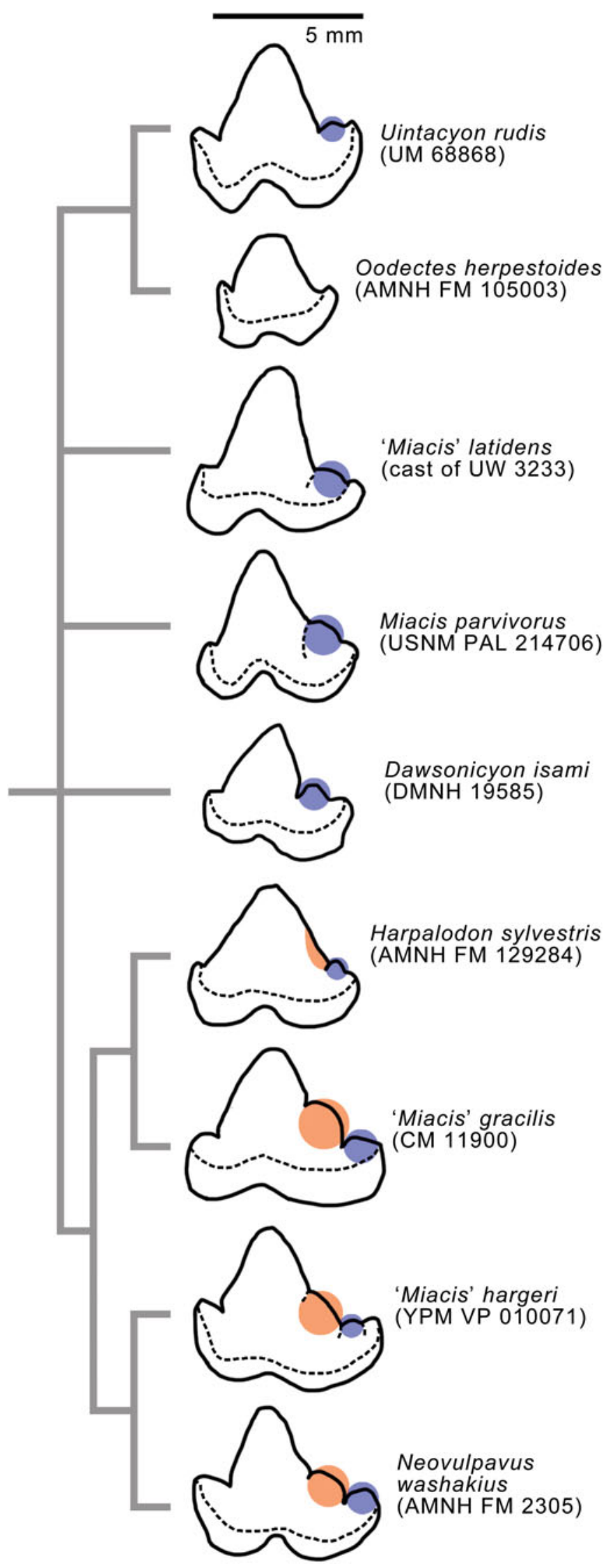

Figure A1. Interpretation of homology of $\mathrm{p} 4$ posterior cuspulids in early carnivoraforms. Posterior accessory cuspulid (orange) present in some crown-group carnivorans and derived non-carnivoran carnivoramorphans is distinguished from posterior basal cuspulid (blue) by its more dorsal position on the posterior slope of main cuspid and its tilted basal axis. Harpalodon sylvestris exhibits an intermediate condition in which a posterior basal cuspulid (reduced) is accompanied by a thinned area on the posterior slope of main cuspid (visible in lingual view), interpreted as an early stage in development of posterior accessory cuspulid. Cladogram from strict consensus of most parsimonious trees obtained in this study (see Figs. 43, 44, and Results). All outlines in labial view under the same scale.

$\left(\Omega=\Omega^{(t)}\right)$ equals 1 given the uniform hyperprior for $\Omega$ (Eq. 6), hence it is dropped from the above equations. In the present analysis, the prior model probabilities $\operatorname{Pr}\left(M_{l}\right)$ were all set to be equal.

Comments on previous identifications of Thinocyon velox and its distribution.-In reviewing published occurrences of Thinocyon velox, we noticed several misidentifications in the literature. West (1973) referred four specimens from the Bridger Formation of the Big Sandy River area in the northern Green River Basin (Br1b-Br2 in age according to Robinson et al., 2004, but earlier ages might apply to some of the localities; cf., Zonneveld et al., 2000) to T. velox. Of these, we concur with the referral of FMNH PM 15858 (right dentary with p2 and m1-2; West, 1973, pl. 3, fig. e; Fig. A2.1, A2.2) and, tentatively, FMNH PM 15859 (right $\mathrm{m} 2$ trigonid) to $T$. velox. Thus, we consider the reidentification of FMNH PM 15858 by Morlo and Gunnell (2003) as a dentary (with p3 and $\mathrm{m} 2-3$ ) of Sinopa minor to be in error.

The preserved teeth of FMNH PM 15858 are better interpreted as $\mathrm{p} 2$ and $\mathrm{m} 1-2$ of Thinocyon for the following reasons. First, the relatively low trigonid, short postparacristid, and short postmetacristid of the preserved anterior molar are inconsistent with the morphology of $\mathrm{m} 2$ in $S$. minor. Second, the preserved posterior molar is slightly, but distinctly, larger than the more anterior molar, so the two teeth are consistent with m1-2 of Thinocyon, but not with $\mathrm{m} 2-3$ of $S$. minor, in which $\mathrm{m} 3$ is typically smaller than $\mathrm{m} 2$ (Fig. 14.4). Third, the relatively tall preserved premolar matches the morphology of a hyaenodontid $\mathrm{p} 2$ better than $\mathrm{p} 3$. Finally, the position of the posterior mental foramen strongly suggests that the preserved premolar is $\mathrm{p} 2$ and not $\mathrm{p} 3$; we are not aware of any specimen of either Thinocyon or $S$. minor in which the posterior mental foramen is located so far back on the horizontal ramus to be below $\mathrm{p} 4$, as implied by Morlo and Gunnell's (2003) identification of the preserved teeth.

Of the remaining purported specimens of T. velox from the Big Sandy River area, we reidentify FMNH PM 15860 (West, 1973, p. 91; also listed as T. velox in Morlo and Gunnell [2003, p. 51]; Fig. A2.3, A2.4, A2.6) as Viverravus cf. V. gracilis based on the $\mathrm{m} 1$ morphology and relative sizes of other lower teeth as inferred from their alveoli. We regard FMNH PM 15083 (Fig. A2.5) to be an indeterminate limnocyonine that might pertain to Thinocyon, Iridodon (so far known only from a dentary), or Prolimnocyon, but not specifically referable to $T$. velox. It is notably distinct from securely identified specimens of $T$. velox in: (1) very small size-at M1L $=4.40$, it is a clear outlier when included in the sample of T. velox reported in Morlo and 


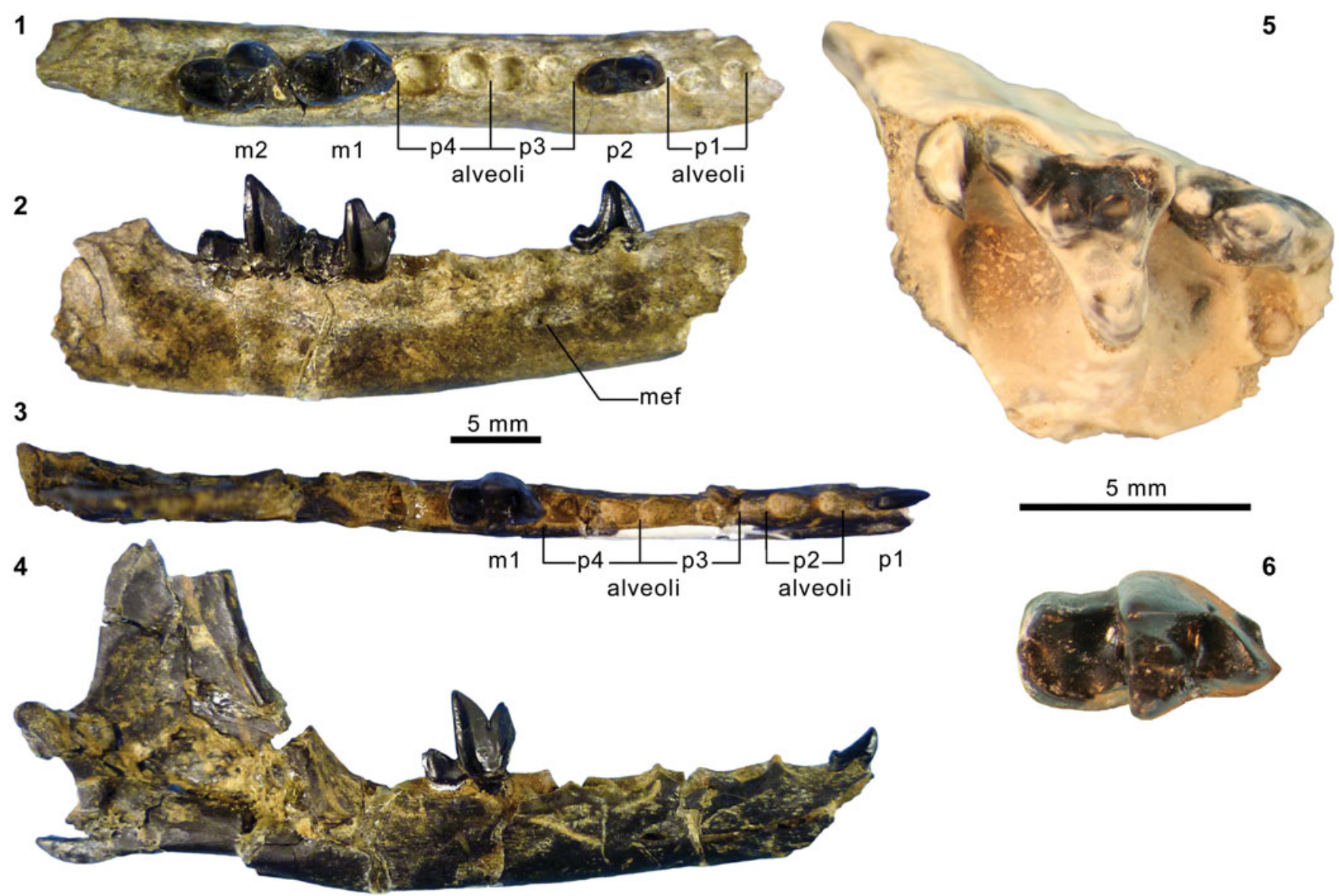

Figure A2. Reidentified carnivore fossils from the Bridger Formation, Wyoming. (1, 2) FMNH PM 15858 (Thinocyon cf. T. velox), partial right dentary with p2 and $\mathrm{m} 1-\mathrm{m} 2$, in occlusal $(\mathbf{1}$; inverted) and lateral (2) views; $(\mathbf{3 , 4}, \mathbf{6})$ FMNH PM 15860 (Viverravus $\mathrm{cf}$. V. gracilis), left dentary with p1 and $\mathrm{m} 1$ in occlusal $(\mathbf{3})$ and lateral (4; inverted) views, and closeup of left $\mathrm{m} 1$ in occlusal view (6); (5) FMNH PM 15083 (Limnocyoninae gen. indet.), right maxillary fragment with partial P4, M1, and partial M2, in occlusal view. Different scales apply to Figure A2.1-A2.4 and A2.5, A2.6. Abbreviation: mef, mental foramina.

Gunnell (2003, table 2); (2) more labially oriented M1 parastyle and metastyle (implying a considerably more closed $\mathrm{m} 2$ trigonid); (3) M1 metacone with less pronounced labiolingual compression, especially on the labial side; and (4) relatively greater lingual projection of protocone on P4 (judging from alveolus) and M1. Additionally, we reidentify FMNH PM
15085 and FMNH PM 15086 from the same area, which were previously reported as V. gracilis (West, 1973, p. 94, pl. 4, fig. b), as T. velox. Finally, FMNH PM 15849 ("?Proviverra" sp. in West [1973, p. 91]), may represent an anterolabial fragment of the left M1 of a large individual of Thinocyon (length across bases of paracone and metacone $=3.5$ ). 
Table A1. Modifications of characters and character-state scores for cladistic analysis.

\begin{tabular}{lcl}
\hline Character & Applicable taxa & Modification \\
\hline 40 & Neovulpavus washakius & Rescored as "?" because we could not infer the structure of middle lacerate foramen from the available materials. \\
All & $\begin{array}{c}\text { Modified as Character 41R to clarify the character-state definitions and eliminate the original state 2, which was } \\
\text { redundant with the state } 1 \text { of Character 47 (cf., Wesley-Hunt and Flynn, 2005). Here we define the states as: } 0 \text {, M1 } \\
\text { lingual cingulum bisected by protocone into pre- and postcingula; } 1 \text {, M1 lingual cingulum continuously defined } \\
\text { around base of protocone; 2, M1 lingual cingulum absent. }\end{array}$
\end{tabular}

Modified as Character 45R to clarify the character-state definitions as follows: 0, outline of M1 parastylar region in occlusal view shows little to no labial or anterior projection; 1, parastylar region tapers to an anteriorly-pointing end, or the long axis of parastylar region forms an acute angle of $\leq 45^{\circ}$ with the tooth row; 2, parastylar region projects predominantly in the labial direction, such that the long axis of parastylar region forms an acute angle of $>45^{\circ}$ with the tooth row.

Lycarion medius

'Miacis' gracilis

Daphoenus spp.

'Miacis' gracilis sylvestris All

Didymictis spp. 'Miacis' gracilis All gregarius All
Rescored as state 0 based on our observation of the ho

2 ), to which this character is inapplicable, as "?".

Rescored as state 0 because the linear dimensions of M2 are greater than $50 \%$ of those of M1.

Rescored as state 1 because we identified two cuspules on the left P3 of holotype-one on the posterior ridge of the main cusp, and the other formed by the posterior cingulum.

Rescored as state 0 because the holotype CM 11900 shows a more vertical medial trochlear border in posterior view than it appears in the line drawing of Clark (1939).

Rescored as state 1 based on our observation of YPM VPPU 013792.

Rescored as state 0 based on our observation of AMNH FM 2305. Although the supinator crest is damaged, its proximal and distal portions are sufficiently preserved to suggest a moderately developed crest as in Lycarion medius and Neovulpavus mccarrolli n. sp. (Figs. 26.5, 26.7, 31.12, 31.13, 37.9, 37.10).

Newly scored as state 0 (previously "?") based on our observation of the holotype AMNH FM 13137.

Rescored as polymorphically 0 and 1 (previously "1") because the referred specimen AMNH FM 129284 clearly shows a diminutive $\mathrm{p} 3$ anterior cuspulid whereas Wortman's (1901a, fig. 38) figure depicts the corresponding feature to be rather prominent in the holotype YPM VP 011808.

Rescored as all state 1 (previously all state 0 ) because we deemed the development of the p3-4 cuspulids in that taxon (based on our observation of the holotype CM 11900) to be comparable to that in Hesperocyon gregarius.

Modified as Character 220R with the following states: 0 , p4 posterior accessory cuspulid absent; $1, \mathrm{p} 4$ posterior accessory cuspulid incipient/vestigial; $2, \mathrm{p} 4$ posterior accessory cuspulid well developed and preceded by a clear notch. Based on morphology and phylogenetic distribution, we consider the $\mathrm{p} 4$ posterior accessory cuspulids in crown-group carnivorans (when present) and some derived non-carnivoran carnivoraforms to be non-homologous with posterior basal cuspulids (which are located at about the same levels as the anterior cingulids) in Thinocyon (limnocyonine hyaenodontid) and primitive carnivoraforms such as Gracilocyon, Uintacyon, 'Miacis' latidens, and Miacis parvivorus (Fig. A1). The posterior accessory cuspulid incipiently manifested as a distinct segment of the posterior ridge of main cuspid in some middle Eocene carnivoraforms such as Harpalodon sylvestris and ' $M$.' hargeri, and is distinguished from posterior basal cuspulids by the inclination of its basal axis in profile (i.e., line connecting the anterior and posterior ends of the cuspulid, which are typically marked by small notches).

Rescored as state 2 (large) and state 0 (small/vestigial), respectively.

Modified as Character 224R to better capture the development of $\mathrm{p} 4$ posterior basal cuspulid (hypoconid according to MacIntyre [1966] and non-homologous with 'posterior accessory cuspulid' in our terminology; see above) and to allow for more objective scoring (we found it difficult to consistently measure the elevation of the cuspulid as would have been necessary under the original coding). The revised character states are distinguished by an anteroposterior length of posterior basal cuspulid (measured at the level of its lowest point in profile) $\leq 33 \%$ (state 0 ) or $>33 \%$ (state 1) of the length of main cuspid (also measured at the level of its lowest point in profile).

Scored as state 1 (p4 posterolabial cingulid prominent) based on Robinson (1966, pl. 7, fig. 4) and Zack (2012, fig. 5). Rescored as state 2 (p3 and p4 equally tall) based on our observation of the holotype CM 11900.

Modified as Character $227 \mathrm{R}$ to clarify the states as: 0 , closed $\mathrm{m} 1$ trigonid, with the angle formed by lines connecting the apices of metaconid to protoconid to paraconid $<70^{\circ} ; 1$, open $\mathrm{m} 1$ trigonid, with the angle $\geq 70^{\circ}$. Consequently, Lycarion medius, 'M.' washakius, and Harpalodon sylvestris were rescored as state 0, and Daphoenus spp. and Hesperocyon gregarius were rescored as state 1.

Rescored as state 0 based on our observation of FMNH UC 496.

Rescored as state 1 because a distinct $\mathrm{m} 1$ hypoconulid was lacking in all specimens of Daphoenus that we have examined, and for nimravids as state 1 because we interpreted the single trenchant cuspid on their $\mathrm{m} 1$ to represent the hypoconid rather than hypoconulid (and considered the latter to be absent) based on the condition in Eofelis edwardsii (Peigné, 2000).

Rescored as all "'?" because we could not confidently interpret the morphology of the heavily damaged $\mathrm{m} 1$ talonid features in the holotype AMNH FM 13137.

Modified as Character 232R and a number of taxa were rescored to facilitate more consistent scoring of states, here defined as: 0 , anterior end of $\mathrm{m} 1$ cristid obliqua at same labiolingual level as notch between protoconid and metaconid regardless of the orientation of cristid obliqua; 1 , anterior end of cristid obliqua positioned further labially than notch between protoconid and metaconid.

Rescored as state 0 based on our observations.

Modified as Character $242 \mathrm{R}$ to eliminate the ambiguity in scoring of the length of parastylar area and to render the character applicable to taxa lacking M1 paraconule. The revised states are distinguished by clear non-alignment (state 0 ) or approximate alignment (state 1) of the M1 parastylar ridge, anterolingual base of paracone (immediately labial to paraconule when the latter is present), and apex of protocone.

Rescored as states 0 (M1 stylar shelf well developed) and 1 (M1 protocone anteriorly positioned), respectively, based on our observation of a cast AMNH FM 105003 of the holotype YPM VP 011861. 
Table A2. Specimens examined and other data sources for scoring character states. ${ }^{1}$ Available as MorhpoBank media (O'Leary and Kaufman, 2011, 2012).

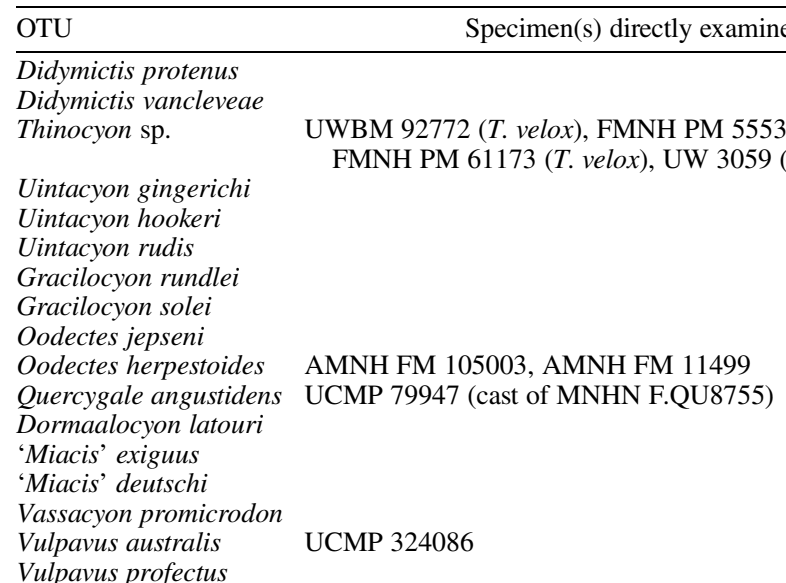

Vulpavus ovatus

$\begin{array}{ll}\text { 'Miacis' latidens } & \text { UCMP 294285 (cast of UW 3233) } \\ \text { Miacis parvivorus } & \text { AMNH FM 5019, AMNH FM 11500, USNM PAL 214706, } \\ & \text { USNM PAL 362796 } \\ \text { Dawsonicyon isami } & \end{array}$

Neovulpavus mccarrolli n. sp.

Neovulpavus washakius

Lycarion medius

'Miacis' hargeri

'Miacis' lushiensis

Harpalodon sylvestris

'Miacis' gracilis

AMNH FM 13137
FMNH PM 3593, FMNH PM 3233, UWBM 38976

AMNH FM 2305, FMNH PM 3869

YPM VP 010071

UCMP 124706 (cast of IVPP V4811)

FMNH PM 55953 (cast of AMNH FM 129284), AMNH FM Wortman (1901a)

13071

CM 12063, AMNH FM 143785 (cast of CM 11900)
Lycophocyon hutchisoni

Cynodictis spp. Gustafsonia cognita Daphoenus spp.

Hesperocyon gregarius Otarocyon macdonaldi Mustelavus priscus Plesictis genettoides Amphicticeps shackelfordi

Cephalogalini Palaeogale sp.
UCMP 85202, UCMP 170713, SDSNH 107446, SDSNH 107447

UCMP 63054, AMNH FM 10056

AMNH FM 127171 (cast of TMM 40209-200)

FMNH PM 8694, FMNH P 26243, FMNH PM 8694;

AMNH FM 12450; UCMP 28033

FMNH PM 1476, FMNH UC 496

F:AM 38986

YPM VPPU 013775

AMNH FM 11001

UCMP 100006, UCMP 100009
Literature/image source(s)

Zack (2012)

Robinson (1966)

Morlo and Gunnell (2003)

Heinrich et al. (2008, fig. 3)

Solé (2014, fig. 8)

Solé et al. (2016, fig. 4)

Hooker (2010, text-fig. 41)

Smith and Smith (2010, fig. 1)

Guthrie (1967a, fig. 21, 22); Heinrich (1997, fig. 2.3)

Solé et al. (2014)

Matthew and Granger (1915); Gingerich (1983)

Gingerich (1983); Heinrich et al. (2008)

Gingerich (1983); Solé et al. (2016)

${ }^{1}$ O'Leary and Kaufman (2012; AMNH FM 12626): https://morphobank. org/index.php/Projects/Media/id/130554/project_id/773); https://morphobank.org/index.php/Projects/Media/id/133108/ project_id/773);

https://morphobank.org/index.php/Projects/Media/id/133112/ project_id/773);

https://morphobank.org/index.php/Projects/Media/id/133116/ project_id/773)

${ }^{1}$ O'Leary and Kaufman (2012; AMNH FM 11498): https://morphobank. org/index.php/Projects/Media/id/131979/project_id/773); https://morphobank.org/index.php/Projects/Media/id/131980/ project_id/773);

https://morphobank.org/index.php/Projects/Media/id/131981/ project_id/773);

https://morphobank.org/index.php/Projects/Media/id/133062/ project_id/773);

https://morphobank.org/index.php/Projects/Media/id/133063/ project_id/773);

https://morphobank.org/index.php/Projects/Media/id/133064/ project_id/773)

Matthew and Granger (1915)

${ }^{1}$ Spaulding et al. (2010; DMNH 19585): https://morphobank.org/index. php/Projects/Media/id/86123/project_id/528); https://morphobank.org/index.php/Projects/Media/id/86124/project_id/ 528)

${ }^{1}$ O'Leary and Kaufman (2012; CM 11900): https://morphobank.org/index. php/Projects/Media/id/133848/project_id/773; https://morphobank.org/index.php/Projects/Media/id/133849/ project_id/773; https://morphobank.org/index.php/Projects/Media/id/133850/ project_id/773; https://morphobank.org/index.php/Projects/Media/id/134239/ project_id/773

Wang et al. (2005)

Wang and Zhang (2015) 
Table A2. Continued.

\begin{tabular}{lcc}
\hline OTU & Specimen(s) directly examined & Literature/image source(s) \\
\hline $\begin{array}{l}\text { Dinictis felina } \\
\begin{array}{l}\text { Hoplophoneus sp. } \\
\text { Palaeoprionodon } \\
\text { lamandini }\end{array}\end{array}$ & UCMP 10257 & Scott and Jepsen (1936); Barrett (2016) \\
Proailurus lemanensis & UCMP 63097 (P. 'mutabilis') & \\
\hline
\end{tabular}

Table A3. Specimens of rhinocerotoid Amynodon Marsh, 1877, with known stratigraphic positions within Twka2.

\begin{tabular}{|c|c|c|c|c|}
\hline $\begin{array}{l}\text { Roehler's (1973) } \\
\text { bed }\end{array}$ & Locality & $\begin{array}{l}\text { Catalog } \\
\text { number }\end{array}$ & Elements & Notes \\
\hline $661-675$ & JJF 7-19-95-1 & $\begin{array}{l}\text { FMNH PM } \\
63056\end{array}$ & weathered skull, other fragments & $\begin{array}{l}\text { Cataloged after publication of McCarroll } \\
\text { et al. (1996b). }\end{array}$ \\
\hline $650-670$ & FM-10-56-WDT & $\begin{array}{l}\text { FMNH PM } \\
1514\end{array}$ & dentary fragment, calcaneum, other fragments & Referred in McCarroll et al. (1996b). \\
\hline $650-670$ & FM-1-57-WDT & $\begin{array}{c}\text { FMNH PM } \\
3210\end{array}$ & astragalus & $\begin{array}{l}\text { Previously identified in collection as } \\
\text { brontothere. }\end{array}$ \\
\hline $644-675$ & JJF 7-21-94-1 & $\begin{array}{l}\text { FMNH PM } \\
58049\end{array}$ & fragmentary dentary + teeth + vertebrae & \\
\hline $644-675$ & JJF 7-21-94-1 & $\begin{array}{c}\text { FMNH PM } \\
59760\end{array}$ & $\begin{array}{l}\text { M1 or M2, P2, fragmentary premaxilla, distal humerus, distal } \\
\text { tibia, astragalus }\end{array}$ & \\
\hline$\sim 644$ & JJF 7-11-94-1 & $\begin{array}{c}\text { FMNH PM } \\
57090\end{array}$ & fragmentary teeth, forelimb and hind limb elements & May contain additional taxa. \\
\hline$\sim 644$ & JJF 7-11-94-1 & $\begin{array}{l}\text { FMNH PM } \\
59532\end{array}$ & fragmentary teeth + premaxilla + maxilla + femur & \\
\hline$\sim 633$ & FM-8-57-WDT & $\begin{array}{l}\text { FMNH PM } \\
3937\end{array}$ & axis, C1, partial maxilla, other fragments & $\begin{array}{l}\text { Referred in McCarroll et al. (1996b) as } \\
\text { hyracodontid. }\end{array}$ \\
\hline
\end{tabular}

Table A4. Components of universal parameter $\zeta$; and corresponding model parameters $\left(\boldsymbol{\theta}_{l}\right)$ and auxiliary variables $\left(\boldsymbol{u}_{l}\right)$ for occupancy-detection model selection using RJMCMC method.

\begin{tabular}{|c|c|c|c|c|}
\hline & Model 1 & Model 2 & Model 3 & Model 4 \\
\hline$\zeta_{1}$ & $\overline{\beta_{\psi 0}}$ & $\overline{\beta_{\psi 0}}$ & $\overline{\beta_{\psi 0}}$ & $\overline{\beta_{\psi 0}}$ \\
\hline$\zeta_{2}$ & $\sigma_{\beta_{\psi 0}}$ & $\sigma_{\beta_{\psi 0}}$ & $\sigma_{\beta_{\psi 0}}$ & $\sigma_{\beta_{\psi 0}}$ \\
\hline$\zeta_{3}$ & $\beta_{\psi 0, k}$ & $\beta_{\psi 0, k}$ & $\beta_{\psi 0, k}$ & $\frac{\beta_{\psi 0, k}}{\rho}$ \\
\hline$\zeta_{4}$ & $u_{\overline{\beta_{v 1}}}$ & $u_{\overline{\beta_{\psi 1}}}$ & $u_{\overline{\beta_{t \mid 1}}}$ & $\overline{\beta_{\psi 1}}$ \\
\hline$\zeta_{5}$ & 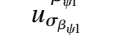 & $u_{\sigma_{\beta_{\psi 1}}}^{\beta_{4,}}$ & 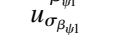 & $\sigma_{\beta_{\psi 1}}$ \\
\hline$\zeta_{6}$ & $u_{\beta_{\beta_{1-1}, k}}$ & $u_{\beta_{\psi \psi 1}, k}$ & $u_{\beta_{\beta_{11}, k}}^{p_{21}}$ & $\beta_{\psi 1, k}$ \\
\hline$\zeta_{7}$ & $\beta_{p 0}$ & $\beta_{p 0}$ & $\beta_{p 0}$ & $\beta_{p 0}$ \\
\hline$\zeta_{8}$ & $\sigma_{\beta_{p 0}}$ & $\sigma_{\beta_{p 0}}$ & $\sigma_{\beta_{p 0}}$ & $\sigma_{\beta_{p 0}}$ \\
\hline$\zeta_{9}$ & $\beta_{p 0, k}$ & $\beta_{p 0, k}$ & $\beta_{p 0, k}$ & $\beta_{p 0, k}$ \\
\hline$\zeta_{10}$ & $u_{\overline{\beta_{11}}}$ & $\beta_{p 1}$ & $u_{\overline{\beta_{10}}}$ & $u_{\overline{\beta_{01}}}$ \\
\hline$\zeta_{11}$ & $u_{\sigma_{\beta_{p 1}}}^{p_{10}}$ & $\sigma_{\beta_{p 1}}$ & $u_{\sigma_{\beta_{p 1}}}^{p 1}$ & $u_{\sigma_{\beta_{p 1}}}^{\rho_{p 1}}$ \\
\hline$\zeta_{12}$ & $u_{\beta_{p 1}, k}$ & $\beta_{p 1, k}$ & $u_{\beta_{p 1}, k}$ & $u_{\beta_{p 1}, k}$ \\
\hline$\zeta_{13}$ & $u_{\overline{\beta_{p 2}}}$ & $u_{\overline{\beta_{2 n}}}$ & $\overline{\beta_{p 2}}$ & $u \overline{\beta_{p 2}}$ \\
\hline$\zeta_{14}$ & $u_{\sigma_{\beta_{p 2}}}^{p_{21}}$ & $u_{\sigma_{\beta_{p 2}}}^{p_{12}}$ & $\sigma_{\beta_{p 2}}$ & $u_{\sigma_{\beta_{22}}}^{\tau_{p 2}}$ \\
\hline$\zeta_{15}$ & $u_{\beta_{p 2}, k}$ & $u_{\beta_{p 2}, k}$ & $\beta_{p 2, k}$ & $u_{\beta_{p 2}, k}$ \\
\hline
\end{tabular}


Table A5. Sources of approximate first appearance dates (FADs) for taxa included in cladistic analysis.

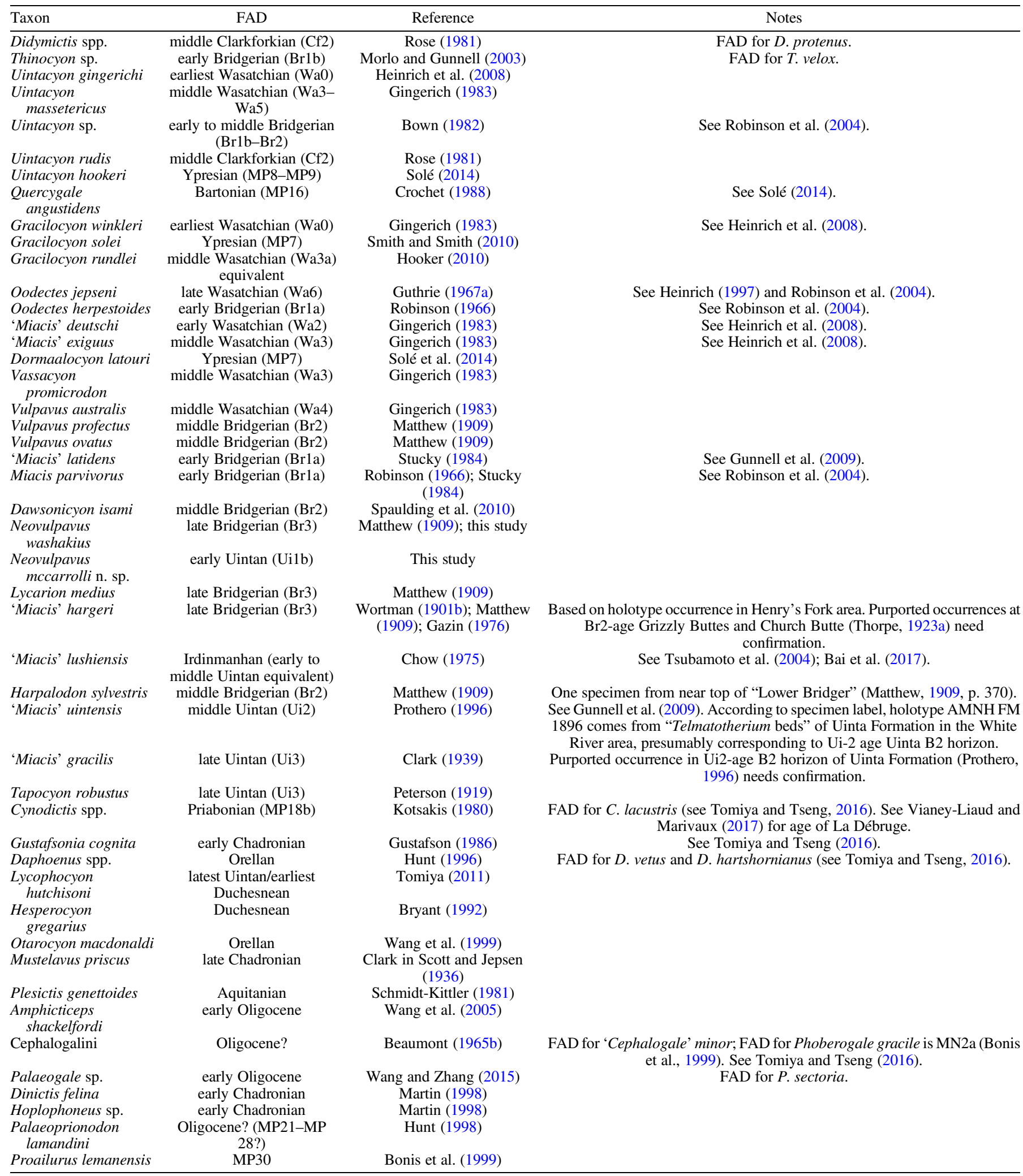

